\title{
B cell development and pneumococcal immunity in vertically acquired HIV infection
}

Sarah Eisen, February 2014

UCL

MD (Res) 
I, Sarah Eisen, confirm that the work presented in this thesis is my own. Where information has been derived from other sources, I confirm that this has been indicated in the thesis.

Signed:

Date: 28.2 .14 


\begin{abstract}
Globally, the population of vertically HIV-infected young adults is increasing. The effect of vertically acquired HIV infection on B cell development and adaptive immunity is relatively unexplored. HIV infection is known to result in perturbations in $\mathrm{B}$ cell turnover and signalling, reflecting an accelerated drive to terminal differentiation. Whilst control of HIV load with ART is generally reported to result in recovery of normal $\mathrm{B}$ cell dynamics, persistent damage to memory B cell populations is well described and generation of new memory responses may remain impaired.
\end{abstract}

This thesis explores how the development of B cell memory and the immune response to pneumococcus is altered when 'immune education' in early life occurs in the context of vertically acquired HIV infection. Young adults with vertically acquired infection were compared with those infected horizontally in early adulthood and with healthy adults.

HIV infection was associated with expanded populations of abnormally activated and immature B cells compared to healthy controls. Vertically infected patients showed decreased marginal zone and switched memory populations compared to the horizontally infected group, especially in those patients with controlled HIV viral load. HIV-infected patients showed impaired baseline anti-pneumococcal immunity and diminished humoral responses to immunisation with the pneumococcal polysaccharide vaccine, with a trend to lower antibody concentrations in the vertically compared to the horizontally infected population. There was some suggestion of benefit of early sustained viral control in the vertically infected group.

In those patients infected with HIV from early childhood, damage to B cell memory populations and impairment of generation of humoral immunity to pneumococcus is evident in early adult life. It appears likely that viral control in early childhood may help to limit this damage. 


\section{Contents}

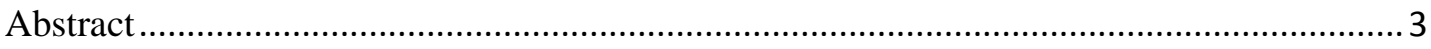

Tables

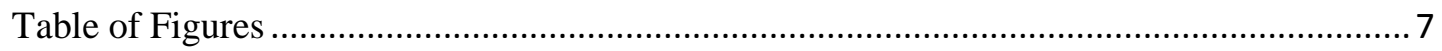

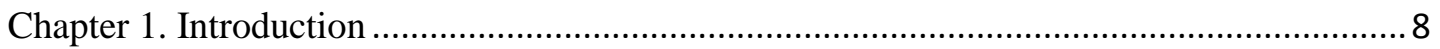

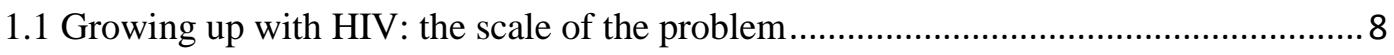

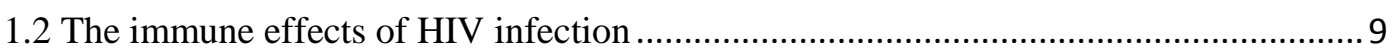

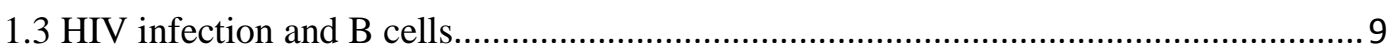

1.3.1 Direct effects of HIV on B cells.................................................................... 12

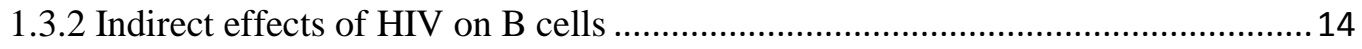

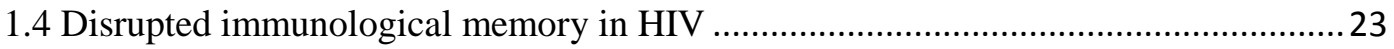

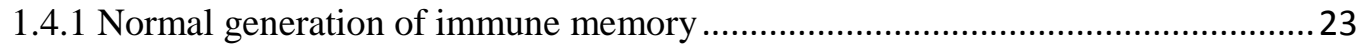

1.4.2 Immune responses to pneumococcal infection .................................................24

1.4.3 Impact of HIV infection on generation of immune memory ...............................26

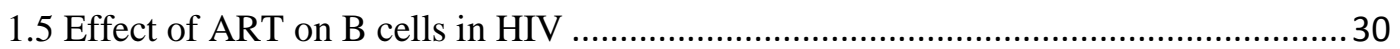

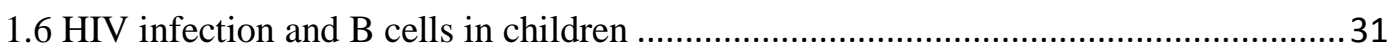

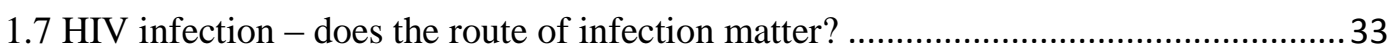

Chapter 2. Subjects, materials and methods ........................................................................ 37

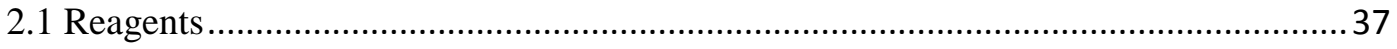

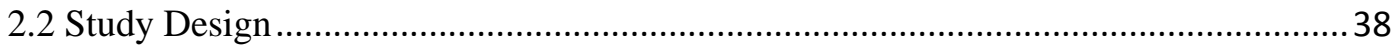

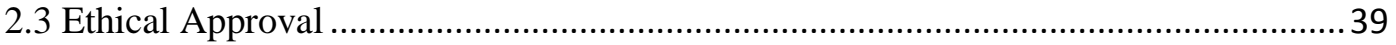

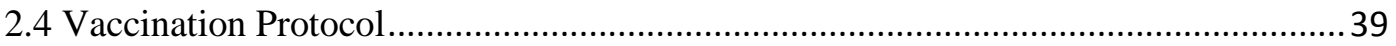

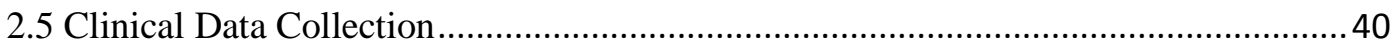

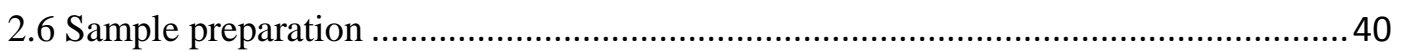

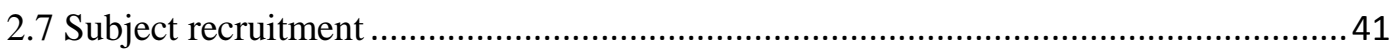

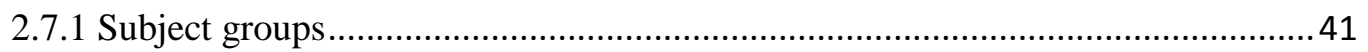

2.7.2 Subject demographics ................................................................................... 43

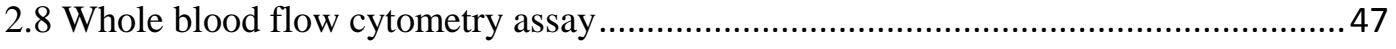

2.8.1 Definition of B cell subpopulations by surface marker expression .......................47

2.8.2 Development of the twelve colour flow cytometry assay .................................... 49

2.8.3 Flow cytometry staining protocol ………......................................................... 55

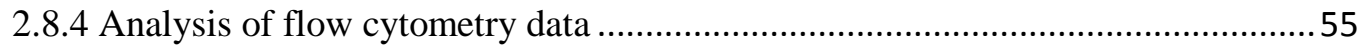

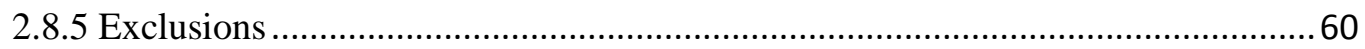

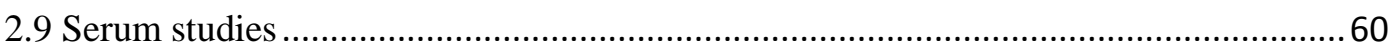


2.10 Statistics

Chapter 3. Results: flow cytometric analysis

3.1 Introduction

3.1.1 Changes in B cell subpopulations

3.1.2 Altered expression of markers of apoptosis, turnover and trafficking ..................67

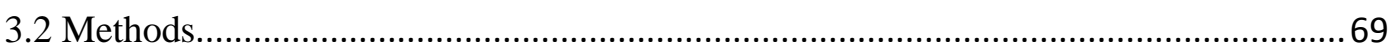

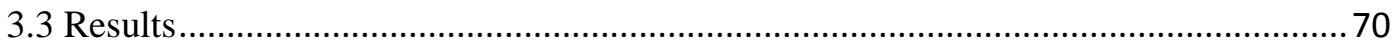

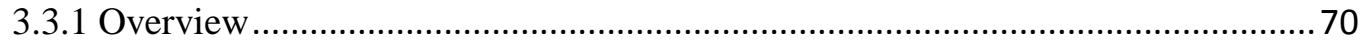

3.3.2 Changes in B cell subpopulation distribution in vertically acquired HIV infection compared to healthy controls ............................................................................. 76

3.3.3. Comparison of vertically and horizontally HIV-infected patients ....................... 80

3.3.4 Changes in expression of markers of apoptosis, turnover and trafficking .............80 80

3.3.5 Effect of $\mathrm{CD}^{+}$count and viral load on B cell subpopulations.............................. 83

3.3.6 Effect of recent HIV seroconversion in horizontally infected patients .................. 83

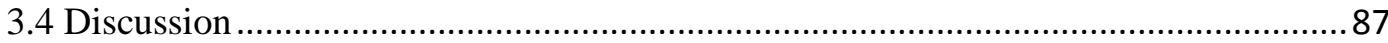

Chapter 4. Results: natural and vaccine induced response to pneumococcal polysaccharide 92

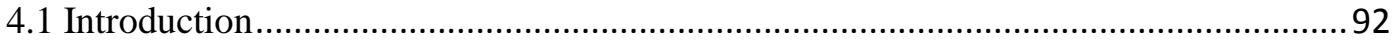

4.1.1 Pneumococcal immunity in HIV infection ...................................................... 92

4.1.2 Pneumococcal vaccine responses in HIV infection ........................................... 92

4.1.3 Evaluation of PPS-specific serum IgM and IgG concentration ...........................96

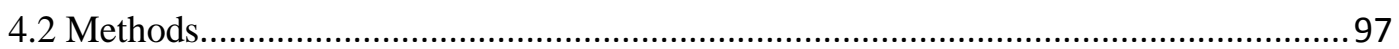

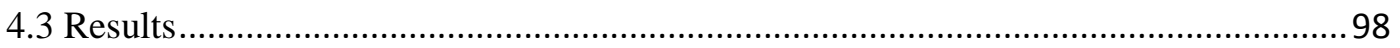

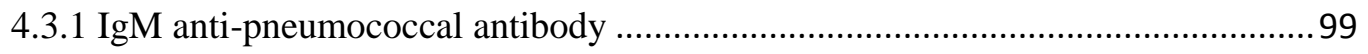

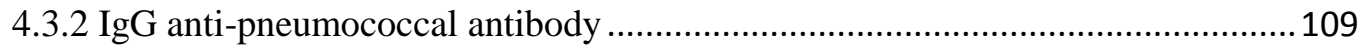

4.3.3 Correlation of $\operatorname{IgM}$ and $\operatorname{IgG}$ antibody concentration........................................ 117

4.3.4 Relationship between memory cell populations and serum antibody concentration

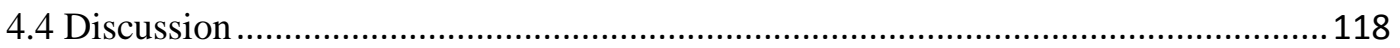

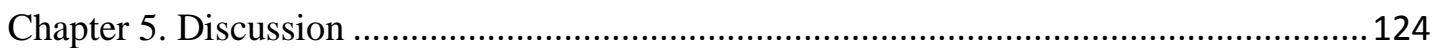

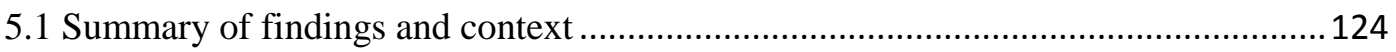

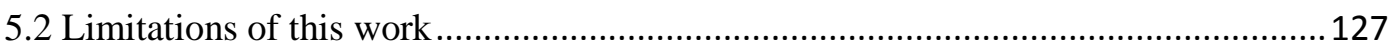

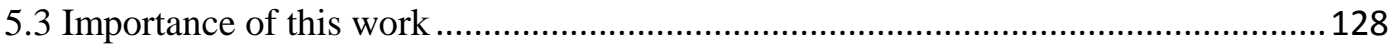

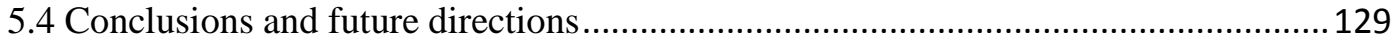

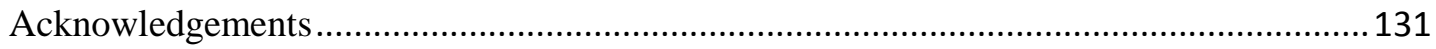

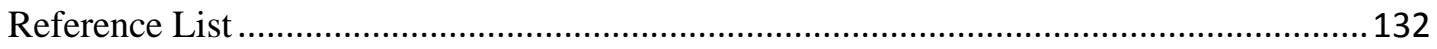




\section{Tables}

Table 1.1. Direct and indirect effects of HIV on B cells..................................................... 11

Table 1.2. Key B cell surface markers used to examine the behaviour of B cells in HIV

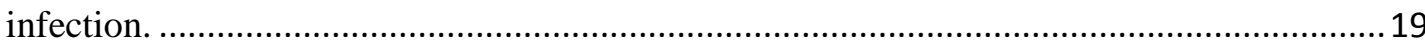

Table 1.3. Changes to B cell subpopulation distribution in adults in HIV infection. .............22

Table 1.4. Effects of ART in adults on HIV-related B cell changes.......................................30

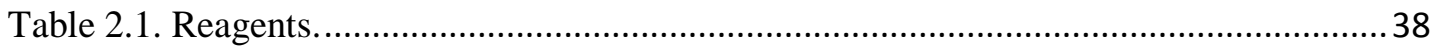

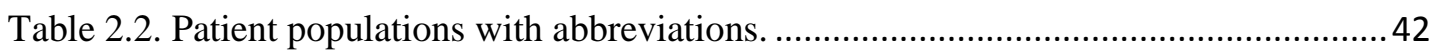

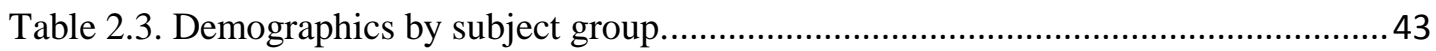

Table 2.4. Disease parameters by subject group............................................................. 45

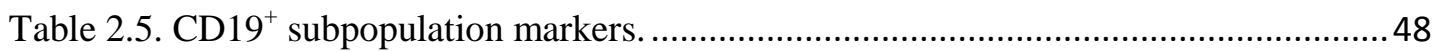

Table 2.6. Antibody conjugate concentrations used in flow cytometric assay. ......................50

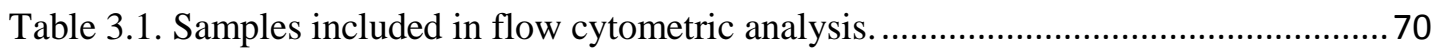

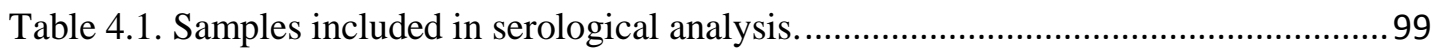

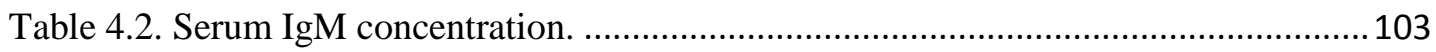

Table 4.3. Correlation analysis of IgM concentrations at various timepoints for all cohorts.

Table 4.4. Early-life viral control and serum IgM concentration .......................................108

Table 4.5. Early-life viral control and serotype coverage (IgM) ...................................... 108

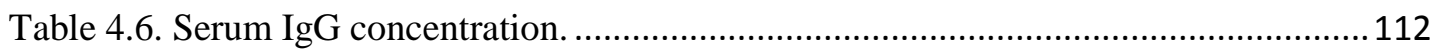

Table 4.7. Correlation analysis of $\mathrm{IgG}$ concentrations at various timepointsfor all cohorts.

Table 4.8. Early-life viral control and serum IgG concentration. ........................................ 117

Table 4.9. Early-life viral control and serotype coverage (IgG) ..................................... 117

Table 4.10. Correlation of baseline IgM and D28 and 1y IgG concentrations. ...................118 


\section{Table of Figures}

Figure 1.1. Schematic diagram showing the B cell subpopulations studied in the peripheral

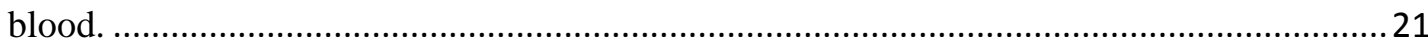

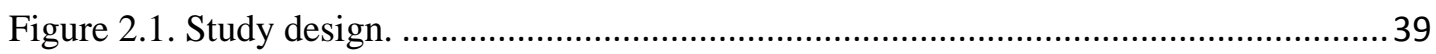

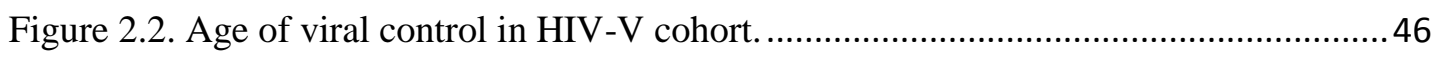

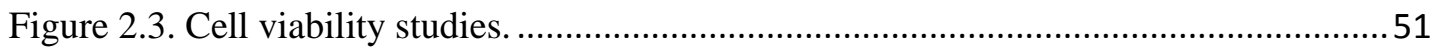

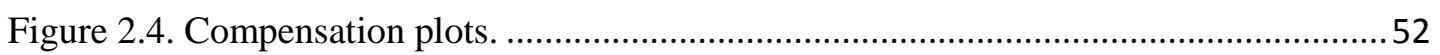

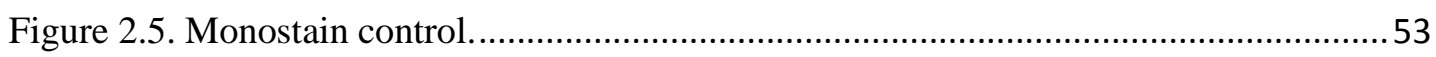

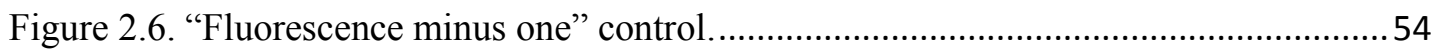

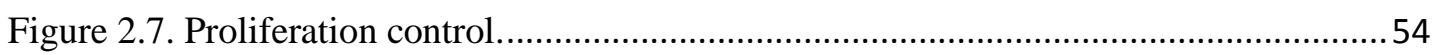

Figure 2.8. Typical flow cytometry plot showing initial gating. .........................................56

Figure 2.9. Subsequent gating to identify $\mathrm{CD} 19^{+}$subpopulations. ...................................... 58

Figure 2.10. Gating of markers of turnover, apoptosis and trafficking.................................5 59

Figure 2.11. Schematic diagram of the flow-based multiplex assay used for quantification of pneumococcal polysaccharide serotype-specific IgM and IgG. .........................................61

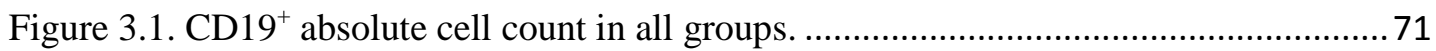

Figure 3.2. Typical flow cytometry plots showing $\mathrm{CD} 19^{+}$subpopulations in a healthy control

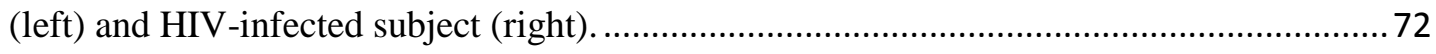

Figure 3.3. Overview of changes in $\mathrm{CD} 19^{+}$subpopulations in all groups. ........................... 73

Figure 3.4. Expression of markers of apoptosis, turnover and trafficking across CD19 ${ }^{+}$

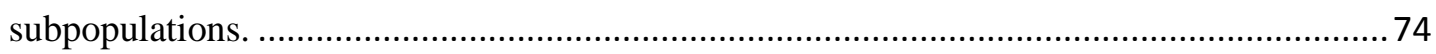

Figure 3.5. Typical flow cytometry histograms and dot plots of markers of apoptosis, turnover and trafficking in a healthy control (left) and HIV-infected subject (right),............75

Figure 3.6 a-c. B cell subpopulations in all groups.......................................................... 77

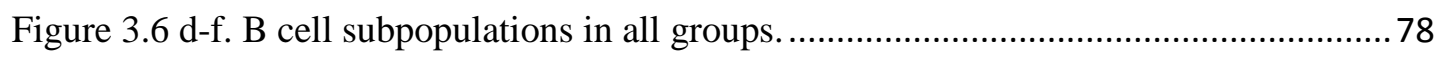

Figure 3.6 g-i. B cell subpopulations in all groups. ....................................................... 79

Figure 3.7 a-b. Expression of markers of apoptosis and trafficking on $\mathrm{CD}_{1} 9^{+}$cells, shown in

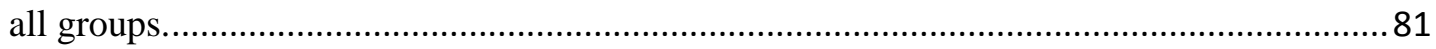

Figure $3.7 \mathrm{c}-\mathrm{d}$. Expression of markers of apoptosis and turnover on $\mathrm{CD} 19^{+}$cells, shown in all

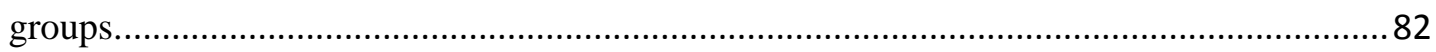

Figure 3.8. CD19 ${ }^{+}$absolute count in HIV-H and HIV-H-RS groups................................... 84

Figure 3.9: Overview of changes in $\mathrm{CD} 19^{+}$subpopulations in HIV-H and HIV-H-RS groups.

Figure 3.10: Changes in $\mathrm{CD} 19^{+}$subpopulations shown in HIV-H and HIV-H-RS groups.... 85

Figure 3.11: Changes in expression of markers of apoptosis, turnover and trafficking on

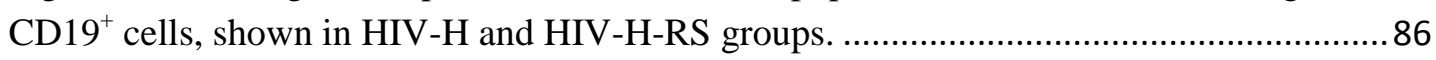

Figure 4.1: Serum IgM concentration (ug/ml, GMT with 95\% CI) in all groups................. 101

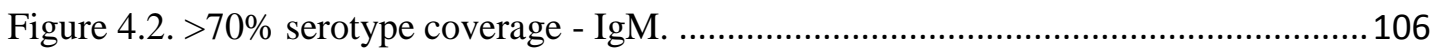

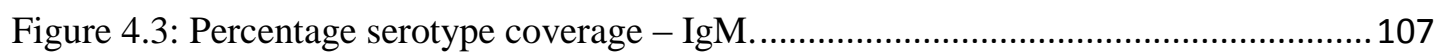

Figure 4.4: Serum IgG concentration (ug/ml, GMT with 95\% CI) in all groups................. 110

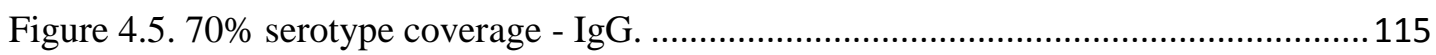

Figure 4.6: Percentage serotype coverage - IgG. ....................................................... 116 


\section{Chapter 1. Introduction}

\subsection{Growing up with HIV: the scale of the problem}

Approximately 34 million people are infected globally with the human immunodeficiency virus (HIV) and in 2012, approximately 1.6 million of these were aged 12-24 years [1]. Most of these young people live in sub-Saharan Africa, but the UK is home to nearly 1800 children with HIV [2], of whom about a third are aged 15 years or older.

Young people with HIV comprise both those infected by the horizontal route (sexual or blood product transmission) and those infected vertically from their mother in utero and/or at the time of parturition. The rate of horizontal infections in young people remains high worldwide: in 2010, young people aged 15-24 years accounted for $42 \%$ of new HIV infections in people aged 15 years and older [3]. Vertical infection remains a global concern although transmission rates are reportedly reducing; in 2011, 330,000 (280,000-390,000) children acquired HIV infection. This represents a 43\% decline since 2003 and a 24\% reduction since 2009 [4].

Mortality rates for individuals infected by HIV have reduced significantly with the advent of effective antiretroviral therapy. In 2011, about 1.7 million people died from AIDS-related causes worldwide. This represents a 24\% decline in AIDS-related mortality compared with 2005 (when about 2.3 million deaths occurred), despite increasing prevalence of the infection [4]. This improved survival, coupled with high rates of vertical transmission in the previous two decades, has resulted in increasing numbers of young adults who have been infected with HIV since birth. In the UK, the age distribution of the national cohort of paediatric HIV-infected patients has changed considerably over the years. In 1996 the median age was 5.1 years (range, 0-11 years); by 2013 it was 13.3 years (range, $0-22$ years). Similarly, the proportion of the cohort aged $\geq 15$ years increased from $<1 \%$ in 1996 to $31 \%$ in 2013 [2].

This cohort of vertically infected young adults is likely to continue to increase worldwide as effective therapy (antiretroviral therapy; ART) becomes more widely 
available and survival rates continue to increase as a result. As these children reach adulthood, their care will be transitioned from paediatric to adult services. In the UK, 382 young people left paediatric care and transitioned to adult clinics by 2011, with approximately 50 transferring each year between 2007 and 2011, at a median age of 17.6 years [2]. This population of vertically infected young adults remains poorly characterised from an immunological perspective, and there is little data to inform clinical decisions regarding such issues as drug treatment, immunisation, long term prognosis and likely medical needs. The impact of HIV infection on the developing immune system is not well understood, and it has not previously been possible to examine the long term effects due to poor survival rates. Unlike their horizontally infected counterparts, who have acquired HIV infection at a time of immunological maturity, these young adults have grown up with HIV, and the early development and education of their immune system has occurred in the context of this chronic infection. No direct comparison has been performed to date of the immunological impact of HIV infection on these two distinct patient groups.

\subsection{The immune effects of HIV infection}

The human immunodeficiency virus (HIV) is a retrovirus which infects a variety of immune cells, including $\mathrm{CD} 4^{+} \mathrm{T}$ cells, macrophages and dendritic cells. Infection of cells with HIV results in conversion of viral RNA to viral DNA, which becomes integrated into the host cell genome. Transcription of viral DNA to messenger and genomic RNA by host cell RNA polymerases results in synthesis of HIV virions, which bud out of the cell and infect other cells. Primary infection is associated with high levels of virus propagated within lymphoid organs, predominantly $\mathrm{CD}^{+} \mathrm{T}$ cells. Expansion of virus-specific cytotoxic $\mathrm{CD}^{+}$cells usually results in a degree of viral control with stabilisation of $\mathrm{CD}^{+}$cells. Ultimately, however, without treatment, destruction of $\mathrm{CD}^{+} \mathrm{T}$ cells results in immunodeficiency, susceptibility to opportunistic infections, and progression to AIDS and death [5].

\subsection{HIV infection and B cells}

HIV infection has thus traditionally been considered to be a $\mathrm{T}$ cell disease, with $\mathrm{CD}^{+}$cells the primary target [6]. Despite this focus on $\mathrm{T}$ cell involvement, HIV 
infection results in dysregulation and dysfunction of all major lymphocyte populations, in addition to myeloid cells which are involved in innate immune responses and bridging the gap between innate and adaptive immunity. Effects of HIV infection on B cells have been described even before the $\mathrm{CD} 4^{+}$cell depletion becomes evident [7,8]. Polyclonal B cell hyperactivity [7] with resulting hypergammaglobulinaemia [9], autoimmunity [10] and an increased incidence of B cell malignancy [11] were all documented early in the epidemic. Although defective $\mathrm{T}$ cell help in selection of high affinity B cells and generation of plasma cells may be implicated to some extent, the evidence for independent effects of HIV on B cell development and function has become clear.

The effects of HIV infection on B cells are thought to reflect a combination of direct interactions of the virus with B cells and indirect interactions that are associated with a wide range of systemic alterations (Table 1.1). Uncontrolled viral replication causes perturbations in B cell turnover and signalling, reflecting an accelerated drive to terminal differentiation, possibly through aberrant or poorly regulated developmental pathways [12]. 


\begin{tabular}{|c|c|c|}
\hline Mechanism & Effect & References \\
\hline \multicolumn{3}{|l|}{ Direct effects of HIV on B cells } \\
\hline $\begin{array}{l}\text { Binding of HIV envelope } \\
\text { glycoprotein gp120 to B cells } \\
\text { expressing VH3 genes } \\
\text { (superantigen-like binding) }\end{array}$ & $\begin{array}{l}\text { - Widespread functional activation of a large proportion of } \\
\text { the B cell repertoire, with consequent clonal deletion } \\
\text { - May explain increased incidence of secondary infections } \\
\text { with specific pathogens }\end{array}$ & [13-21] \\
\hline $\begin{array}{l}\text { Interaction between } \\
\text { complement receptor CD21 } \\
\text { and complement proteins } \\
\text { bound to opsonised HIV } \\
\text { virions }\end{array}$ & $\begin{array}{l}\text { - } \quad \text { Enhanced infectivity of target } \mathrm{CD} 4^{+} \mathrm{T} \text { cells as opsonised } \\
\mathrm{HIV} \text { is transferred to activated } \mathrm{T} \text { cells } \\
\text { - } \quad \text { May activate B cells directly by engagement of } \mathrm{CD} 21\end{array}$ & {$[22-25]$} \\
\hline \multicolumn{3}{|c|}{ Indirect effects of HIV on B cells } \\
\hline $\begin{array}{l}\text { Generalised activation by: } \\
\text { - } \quad \text { Increased systemic } \\
\text { cytokine concentrations } \\
\text { eg interleukins, IFNa, } \\
\text { type I IFN } \\
\text { - } \quad \text { Increased bacterial } \\
\text { translocation from the } \\
\text { gut into the blood (ie } \\
\text { chronic/intermittent } \\
\text { subclinical infection) } \\
\text { Excess immunoglobulin } \\
\text { production }\end{array}$ & $\begin{array}{l}\text { - } \text { Hypergammaglobulinaemia } \\
\text { - } \quad \text { Increased autoantibodies } \\
\text { - } \text { Increased expression of activation, proliferation, and } \\
\text { - } \quad \text { Increased turnover, reflecting increased activation and } \\
\text { drive towards terminal differentiation } \\
\text { - } \text { Appearance of apoptosis-prone subpopulations of B cells } \\
\text { with increased apoptosis contributing to depletion of } \\
\text { circulating B cell subpopulations } \\
\text { Exhaustion leading to altered migration, proliferation and } \\
\text { effector function } \\
\text { Functional implications including hyporeactivity to } \\
\text { ligation of the BCR to stimuli and impaired T cell } \\
\text { interaction by reduced co-stimulatory ability } \\
\text { Excess immunoglobulin production results in formation of } \\
\text { immune complexes with activated cells, triggering } \\
\text { secretion of inflammatory factors }\end{array}$ & $\begin{array}{l}{[7,26-} \\
29,29- \\
46,46-48] \\
{[49]} \\
{[41,50-55]} \\
\text { Reviewed } \\
\text { in }[12] \\
{[26,46]}\end{array}$ \\
\hline Altered B cell trafficking & $\begin{array}{l}\text { Impaired migration from periphery to secondary lymphoid } \\
\text { tissue (important for generation and maintenance of } \\
\text { immune memory: germinal centre reaction including class } \\
\text { switching, somatic hypermutation and affinity maturation, } \\
\text { leading to differentiation to memory and plasma cells) }\end{array}$ & {$[51,56-59]$} \\
\hline
\end{tabular}

Table 1.1. Direct and indirect effects of HIV on B cells. 


\subsubsection{Direct effects of HIV on B cells}

Direct effects of HIV on B cells were reported early in the pandemic [60] although there is little evidence that HIV can productively replicate in B cells in vivo. The low frequency of B cells directly interacting with HIV virions through the B cell receptor as compared to the degree of B cell dysregulation in HIV infection suggests that indirect effects may be more significant. There is, however, strong evidence that HIV binds to B cells in vivo.

The HIV envelope glycoprotein gp120 is known to bind B cells expressing variable region three (VH3) immunoglobulin genes. This VH3 gene family, with 22 functional genes, constitutes the largest of the seven families of functional gene segments at the human $\mathrm{VH}$ locus, and comprise about half of the expressed $\mathrm{VH}$ repertoire in adult peripheral B cells [61-65]. VH3 antibodies are crucial for defence against a variety of bacterial $[66,67]$ and viral $[68,69]$ pathogens, including bacterial polysaccharide antigens found in Streptococcus pneumoniae [70] and Haemophilus influenzae [71]. Goodglick et al. [14] determined the epitope on gp120 responsible for its binding activity, while Karray and colleagues [15] identified the sequence motifs involved in the binding process and later demonstrated that gp120 binding is restricted to immunoglobulins from the VH3 gene family [16].

Gp120 binds VH3 immunoglobulins in a non-classical, "superantigen-like" interaction outside the normal antigen-binding pocket [13]. This superantigen-like binding results in widespread functional activation of a large proportion of the B cell repertoire. As seen with other superantigens, including Staphylococcus aureus protein A (reviewed in [72]), this may result in the transient clonal expansion shown by Chong and colleagues [73] in HIV-infected patients and the development of hypergammaglobulinemia. Superantigen activation has been shown in mice [74] to result ultimately in clonal deletion leading to a long lasting clonal deficit. In 2007, using mice genetically engineered to express human antibodies, Viau [75] showed that soluble gp120 induced both depletion of B-1a cells (considered to be represented in man as innate germline IgM producing B cells) and a functional alteration of the humoral response to a protein antigen (tetanus toxoid), suggesting impact on both the innate and adaptive $\mathrm{B}$ cell response. Several reports have suggested a similar 
depletion of VH3-expressing $\mathrm{B}$ cells in humans during the late stages of HIV disease. Berberian [76] demonstrated a specific deficit of $\mathrm{VH}^{+} \mathrm{B}$ cells in 19 patients with HIV, compared to healthy controls [19,20,76]. In 1994, the same group [17] showed, in a cross-sectional clinical study, that VH3-expressing B cells were elevated in early HIV infection but depleted in those with AIDS, again consistent with a superantigen-like early activation resulting in eventual depletion of cell populations expressing these important genes. These VH3-expressing cells are preferentially expanded in memory B cell populations. Their absence in HIV infection may suggest that, in addition to depletion by superantigen activation, gp120 binding may impair B cell maturation with the failure to establish VH3-expressing memory cell populations. Scamurra et al. [21] showed in HIV patients that there was no change in VH3 expression in IgM or IgD mRNA from peripheral B cells (likely to be predominantly naïve cells), but that VH3 family expression in IgG mRNA, representing immunoglobulin secreted by memory cells, was reduced. Other studies [20], however, have showed a drastic under-representation in vivo of $\mathrm{VH}^{+}$ immunoglobulin expressed by $\operatorname{IgM}^{+}$, and naïve $\mathrm{B}$ cells, as well as by $\operatorname{IgG}^{+}$cells, in patients with HIV and low $\mathrm{CD}^{+}$counts. It has also been shown that switched memory B cells from HIV-infected patients show decreased mutation frequencies, especially in antigen-binding VH3 CDR genes [77], and that HIV infection is associated with selective defects in immunoglobulin gene utilization [78] which may have significant implications for the humoral memory response.

The advent of highly active antiretroviral therapy (HAART) has allowed changes in immune profiles to be related to HIV viraemia and disease control. Initiation of ART has been shown to result in normalisation of antibody repertoire [79] and a restored ability to produce antibody from VH3 B cells [80], which may be consistent with the findings discussed previously [21] suggesting that the naïve B cell repertoire may be relatively unaffected compared to that of memory cells. Juompan et al. [81] confirmed an inverse relationship between VH3 antibody levels and viral load. Elkins [82] also assessed the early effect of HIV infection on the integrity of the peripheral $\mathrm{B}$ cell repertoires and showed an inverse association between viraemia levels and B cell repertoire integrity. 
The presence of clonal deficits within the antibody repertoire in uncontrolled HIV is likely to have significant functional consequences. The selection of specific $\mathrm{VH}$ genes, which are subsequently linked to specific diversity (D), and joining (J) region genes, is a principle determinant of the structure of the antigen binding site [83] and thus diversity. Loss of clones, each with a specific antigen binding site, has consequences for functional immunity, as shown by previous structure-function correlations of human monoclonal antibodies specific for pneumococcal (Pnc) antigens [84]. Deletion of clones bearing specific V gene-encoded immunoglobulins, particularly the VH3 family which is important for many bacterial and viral antigens, as stated previously, will negatively impact upon the ability of the individual to recognise and control pathogens. There is evidence for a link between immunoglobulin repertoire defects and disease susceptibility: the light chain allele VkA2 encodes $\mathrm{A}^{+}$antibodies, which have high avidity to the capsular polysaccharide of Haemophilus influenzae type B, and are absent in a population that has a significantly increased incidence of infection with this pathogen [85]. VH3 is the largest family of variable genes and many of the pathogens against which an effective immune response depends on VH3 genes are commonly found in HIVinfected patients. Deletion of VH3-expressing B cells as a direct consequence of viral binding may therefore contribute to HIV-associated humoral immune dysfunction and to the increased incidence of secondary infections observed in these patients.

In addition to gp120-mediated interaction through VH3 genes, direct action of HIV on $\mathrm{B}$ cells is also thought to occur through interactions between the complement receptor $\mathrm{CD} 21$, expressed on most mature B cells, and complement proteins bound to opsonised HIV virions [22,23]. This binding may result in enhanced infectivity of target $\mathrm{CD}^{+} \mathrm{T}$ cells, as opsonised HIV has been shown to be passed to activated $\mathrm{T}$ cells [23] and may also affect B cell responses directly by engagement of CD21 [86].

\subsubsection{Indirect effects of HIV on B cells}

\section{Activation}

Non-specific immune activation is a hallmark of HIV disease and has been long recognised in B cells $[32,34,35,87]$. The direct effect of HIV binding in triggering 
superantigen-like activation has been discussed. Other HIV proteins, including the regulatory protein, Nef (Negative Regulatory Factor) [39,40], and pro-inflammatory cytokines, including interferon- $\alpha$ [30] are also known to activate B cells. Increased bacterial translocation through the gut in HIV infection may also contribute to nonspecific B cell activation [88].

The first comprehensive analysis of HIV-induced B cell hyperactivity was performed by Shirai et al. in 2001 [33]. Since then, the hyperactivation of B cells in HIV infection has been well characterised. The subpopulations of B cells responsible for increased immunoglobulin secretion have been proposed to be both hyperactivated naïve B cells [89] and an abnormally expanded B cell subpopulation expressing low levels of CD21 [45], which may be responsible for producing autoreactive antibodies $[10,33,59,90]$. Circulating B cells themselves show increased expression of activation, proliferation, and terminal differentiation markers [7,28,33,45,46,89]. This increased expression of activation markers has been shown by some studies to correlate inversely to disease control $[51,55]$ and is largely reversible by HAART [28,41,46,52,55,91], though Regidor et al. [92] showed that the reduction in serum cytokines achieved after ART was only partial, with evidence of persistent hyperactivation still evident several years after therapy initiation.

Hyperactivation has important implications for $\mathrm{B}$ cell dynamics, resulting in disturbances in B cell subpopulations (see Table 1.3) including increased turnover [41,93] apoptosis [41], and B cell dysfunction (discussed later).

Chronic B cell activation ultimately results in exhaustion, with consequent reduced function and depletion of cell populations. The "exhausted cell phenotype" has been extensively described (reviewed in [12]). Exhausted cells express high levels of inhibitory receptors [94,95], and altered expression of homing receptors resulting in abnormal migration of cells to lymph nodes [59,96]. Proliferative responses are reduced [47,97] and effector function may be impaired [59].

\section{Altered turnover and increased $B$ cell death}

Increased cell turnover in HIV infection is well established [49,93]. This tendency to increased turnover is likely to reflect the increased activation and drive towards 
terminal differentiation, and is likely to contribute to the increased emergence of B cell subpopulations prone to apoptosis $[41,52,53]$. Samuelsson [98] showed elevated levels of B cell apoptosis in all HIV-infected individuals compared with seronegative control subjects, with a tendency toward increased levels of apoptosis with progressive disease, and a positive correlation with viral load. Ultimately, this is likely to lead to depletion of B cell subpopulations [99] from peripheral blood. Equivalent change has been demonstrated in lymph node tissue [100]. Intrinsic and extrinsic pathways of apoptosis are both affected by HIV infection [53]. Activation of the intrinsic apoptosis pathway is associated with the under-expression of bcl-2, a "survival gene" which encodes an anti-apoptotic protein which blocks programmed cell death [101]. Expression of a bcl-2 transgene has been shown to rescue pre-B and immature B cells from cell death indicating that bcl-2 can inhibit the apoptotic cell death of progenitors and early B cells, and overproduction of bcl-2 protein prevents the death of B cells cultured in vitro [102,103]. In HIV infection, bcl-2 expression has been shown to be reduced on some B cell subpopulations, possibly reflecting increased susceptibility to intrinsic apoptosis [51,52]. Proneness to intrinsic apoptosis in B cells in HIV infection may also be partly due to skewing of the B cell populations as a result of hyperactivation, including an overrepresentation in HIV viraemia of immature B cells which are highly susceptible to intrinsic apoptosis [53].

The extrinsic pathway is activated by triggering of a death receptor [104], Fas, also known as CD95. In HIV infection, CD95 is the most overexpressed death receptor on the B cells of HIV-viraemic individuals, as determined by DNA microarray analysis [41]. The extrinsic pathway is often considered to be involved with removal of activated immune cells after they have performed their function or as a result of incomplete or inappropriate activation [105] and expression of CD95 seems to be increased in activated cells [41], providing further support to the hypothesis that activation contributes to the increased apoptosis seen in HIV infection. There may also be a role for the lymphopenia-induced cytokine IL-7 in the increased B cell apoptosis observed in HIV infected individuals, via an indirect mechanism involving the induction of IFN- $\Upsilon$ in T cells, which leads to consequent upregulation of CD95 on B cells [106]. The intrinsic and extrinsic pathways are not entirely distinct: the expression of bcl-2 is believed to regulate the extrinsic apoptosis pathway by 
prevention of mitochondrial disruption and subsequent caspase activation - one subtype of the Fas-mediated apoptotic pathway [107].

\section{Altered B cell trafficking}

In addition to adverse effects on B cell turnover and cell death, HIV infection has also been shown to result in derangement of lymphocyte migration and recirculation between the periphery and lymphoid tissue, which are critical for the development of effective immunity. These interactions are largely regulated by the interaction of chemokine receptors on lymphocytes with the expression of their respective ligands in different tissue compartments [108,109]. Antigen-stimulated B and T cells migrate from the periphery to secondary lymphoid tissue [110], resulting in a germinal centre (GC) reaction where class switching, somatic hypermutation and affinity maturation occur, leading to differentiation to memory and plasma cells [111].

The G-protein coupled chemokine receptor, CXCR5, is an important receptor in recruiting B cells to lymph nodes for maturation of $\mathrm{T}$ cell-dependent $\mathrm{B}$ cell responses and, with another chemokine receptor, CXCR4, is important for the organisation of the GC microarchitecture $[112,113]$. The chemokine CXCL13 is the ligand for CXCR5, and is produced by follicular dendritic and stromal cells within lymphoid tissues including the spleen, lymph nodes, gut and liver. Ligation of CXCL13 by CXCR5 is important in regulation of B cell organisation within the lymph node follicle. Upregulation of CXCR5 on B cells, therefore, promotes increased ligation by CXCL13, resulting in homing to the $\mathrm{B}$ follicle to allow a germinal reaction to take place (reviewed in [114]). Altered homing to lymphatic tissue due to changes in trafficking receptors has been long described in HIV infection [56,57]. This altered homing is thought to involve altered CXCR5 expression by B cells in HIV $[51,58,59]$, with possible negative consequences for the establishment of GC reactions. Other migration pathways, including CXCL12-CXCR4/7 mediated migration [115] may also be affected by the increased activation of B cells in HIV infection. 
The key effects of HIV on the behaviour of B cell subpopulations in terms of apoptosis, cell trafficking and cell turnover, and the markers used to examine them, are shown in Table 1.2. 


\begin{tabular}{|c|c|c|c|}
\hline $\begin{array}{c}\text { Behaviour and markers } \\
\text { used }\end{array}$ & Function & Change in HIV & References \\
\hline Intrinsic apoptosis: bcl2 & $\begin{array}{l}\text { - Anti-apoptotic protein which blocks programmed } \\
\text { cell death } \\
\text { - } \begin{array}{l}\text { Expressed differentially at different stages of B } \\
\text { cell development }\end{array} \\
\text { Used as a marker of susceptibility towards } \\
\text { intrinsic apoptosis }\end{array}$ & $\begin{array}{l}\text { Decreased in } \\
\text { some B cell } \\
\text { subpopulations }\end{array}$ & {$[51-53,55]$} \\
\hline $\begin{array}{l}\text { Extrinsic apoptosis: } \\
\text { CD95 (Fas) }\end{array}$ & $\begin{array}{l}\text { "Death receptor" triggering apoptosis via } \\
\text { extrinsic pathway } \\
\text { Used as a marker or susceptibility towards } \\
\text { extrinsic apoptosis }\end{array}$ & $\begin{array}{l}\text { Increased in } \\
\text { most B cell } \\
\text { subpopulations }\end{array}$ & $\begin{array}{l}{[41,51-} \\
55,116]\end{array}$ \\
\hline Trafficking: CXCR5 & $\begin{array}{l}\text { - } \\
\text { Impomokine receptor binding CXCL13 } \\
\text { nodes for maturation of T cell-dependent B cell } \\
\text { responses } \\
\text { - Used as a marker of B cell trafficking }\end{array}$ & $\begin{array}{l}\text { Decreased in } \\
\text { many B cell } \\
\text { subpopulations }\end{array}$ & {$[58,59]$} \\
\hline Turnover: Ki67 & $\begin{array}{l}\text { - } \quad \text { Nuclear protein } \\
\text { - } \quad \text { Used cycling marker } \\
\text { - }\end{array}$ & $\begin{array}{l}\text { Increased in } \\
\text { some B cell } \\
\text { subpopulations }\end{array}$ & {$[41,53]$} \\
\hline
\end{tabular}

Table 1.2. Key B cell surface markers used to examine the behaviour of B cells in HIV infection.

\section{Impact of HIV on peripheral B cell subpopulations}

As discussed, abnormal activation, turnover, differentiation, trafficking and apoptosis result in profound skewing of B cell populations in the peripheral blood. Although analysis of peripheral subpopulations cannot be considered necessarily to reflect exactly the status of the B cell compartments of the bone marrow and lymph tissue, the altered distribution in the blood nonetheless may give an indication of the likely degree of disruption to B cells overall. Since different immune cells have different functions and variable susceptibility to apoptosis, it is evident that 
alterations in the composition of the $\mathrm{B}$ cell population as a whole, in addition to the direct effects of HIV infection, will impact on overall B cell survival, function and repertoire.

There are numerous challenges in the evaluation of the effects of HIV infection on B cell subpopulations. Varying definitions of B cell subsets can result in confounding and contradictory results. Even in healthy HIV-negative individuals, there is a wide range of circulating B cell frequencies [117] so a large number of participants and/or longitudinal analyses are required to describe disease-related changes. There is also a high likelihood that memory B cells in tissue compartments are as important to consider as those circulating in the peripheral blood, although more difficult to study. Nonetheless, substantial evidence has accumulated during the past two decades for a significant impact on HIV infection on distribution of B cell subsets in the peripheral blood, with emergence of several abnormal B cell subpopulations and significant depletion of other normal cell populations.

The drive towards terminal differentiation is reflected in a general trend towards a reduction of effective mature populations, with an emergence of abnormally activated and exhausted populations, and a compensatory increase in immature and transitional B cells emerging from the bone marrow. These peripheral B cell subpopulation changes are described in Table 1.3 and are discussed more fully in Chapter 3. Memory populations, including both classical and marginal zone memory (discussed more fully in section 1.4.1) appear to be particularly (and possibly irreversibly) damaged in HIV infection [118,119]. Figure 1.1 shows the relationship of the various B cell subpopulations to one another. 


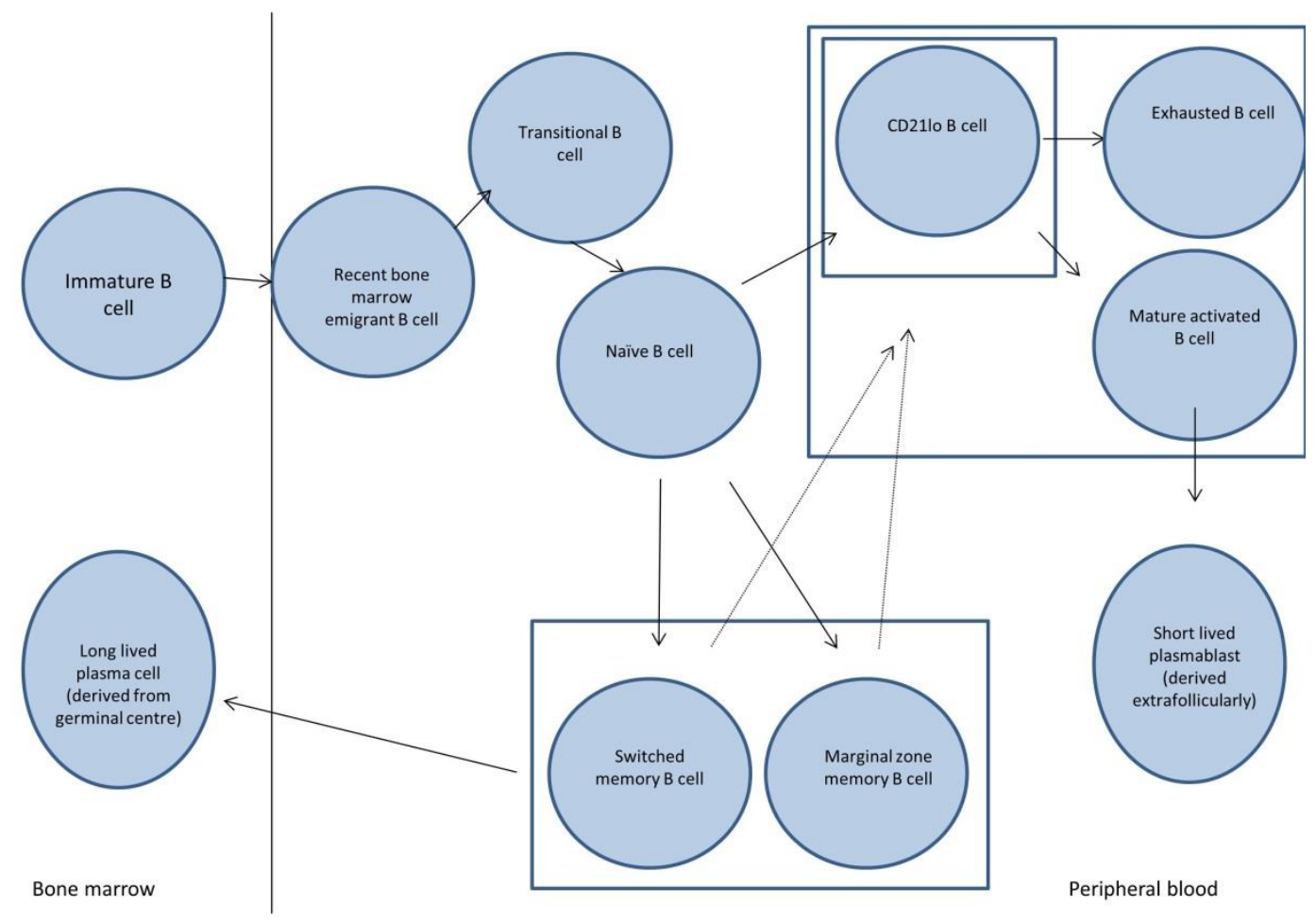

Figure 1.1. Schematic diagram showing the B cell subpopulations studied in the peripheral blood.

Markers used to identify these populations are shown in Table 2.5, Chapter 2. This figure is partially adapted from Moir et al. 2009. 


\begin{tabular}{|c|c|c|c|}
\hline Populations & Description & $\begin{array}{l}\text { Change in } \\
\text { HIV infection }\end{array}$ & References \\
\hline Naïve cells & 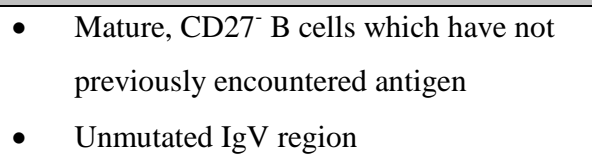 & $\begin{array}{l}\text { Decreased/ } \\
\text { increased;-- } \\
\text { effect not clear }\end{array}$ & {$[48,51,120,121]$} \\
\hline $\begin{array}{l}\text { Marginal zone } \\
\text { memory (MZM) } \\
\text { cells }\end{array}$ & $\begin{array}{l}\text { Type of memory cell expressing CD27 } \\
\text { and IgD. Predominantly secretes IgM } \\
\text { which is somatically mutated. } \\
\text { - } \quad \text { Thought to be generated in marginal } \\
\text { zone of the spleen in the absence of a } \\
\text { germinal centre reaction. } \\
\text { - Play a major role in the immediate } \\
\text { response against encapsulated bacteria } \\
\text { May be important in facilitating } \\
\text { adaptive humoral response }\end{array}$ & Decreased & {$[118,119]$} \\
\hline $\begin{array}{l}\text { Switched memory } \\
\text { cells }\end{array}$ & $\begin{array}{l}\text { Circulating } \mathrm{CD} 27^{+} \text {memory cells which } \\
\text { have undergone somatic hypermutation } \\
\text { in the germinal centre following antigen } \\
\text { exposure }\end{array}$ & Decreased & {$[55,116,118,120,122]$} \\
\hline $\begin{array}{l}\text { Recent bone } \\
\text { marrow emigrants } \\
\text { (BME) and } \\
\text { transitional cells }\end{array}$ & $\begin{array}{l}\text { - Cells thought to be at an early stage in } \\
\text { mature naïve B cell maturation } \\
\text { - Normally scarce in peripheral blood }\end{array}$ & Increased & {$[53,54,119,123-126]$} \\
\hline Plasmablasts & $\begin{array}{l}\text { - Short lived cells, believed to be } \\
\text { antibody-secreting precursors of long- } \\
\text { lived bone marrow plasma cells } \\
\text { - } \quad \text { Found with low frequency in peripheral } \\
\text { blood }\end{array}$ & Increased & {$[41,45,127]$} \\
\hline CD21 $^{10}$ cells & 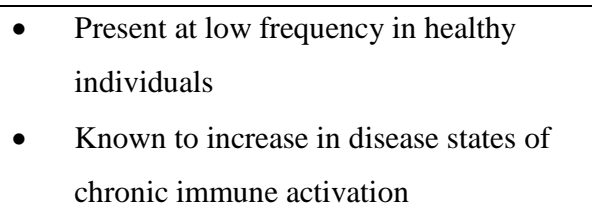 & Increased & {$[45,59]$} \\
\hline $\begin{array}{l}\text { Mature activated } \\
\text { cells }\end{array}$ & $\begin{array}{l}\text { Described in the context of HIV as } \\
\mathrm{CD} 27^{+} \mathrm{CD} 21^{\mathrm{lo}} \text {; a mature B cell showing } \\
\text { features of abnormal hyperactivation }\end{array}$ & Increased & [41] \\
\hline Exhausted cells & $\begin{array}{l}\text { Described in the context of HIV as } \\
\mathrm{CD} 27^{-} \mathrm{CD} 21^{\text {lo }} \text {, displaying features of } \\
\text { immune exhaustion, including shortened } \\
\text { replication history, reduced } \\
\text { immunoglobulin diversity and poor } \\
\text { proliferative responses }\end{array}$ & Increased & [59] \\
\hline
\end{tabular}

Table 1.3. Changes to B cell subpopulation distribution in adults in HIV infection. 


\subsection{Disrupted immunological memory in HIV}

Immunological memory is defined by the ability of the immune system to respond more effectively to pathogens previously encountered either through infection or immunisation. The damage to memory subpopulations of B cells in HIV infection, in conjunction with other mechanisms of disruption, results in profound impairment of the generation of immune responses, both to infection and immunisation.

\subsubsection{Normal generation of immune memory}

Memory cells are defined as antigen-experienced cells which have generally undergone clonal selection and a degree of affinity maturation (through somatic mutation). They are pre-primed to generate a rapid and specific response (reviewed in [128]). A classical memory B cell can be defined as a long lived, antigenexperienced, clonally selected B cell that can rapidly differentiate into a plasma cell on re-exposure to antigen [129], enabling production of high affinity, antigenspecific antibodies [130-133]. Classical memory cells have undergone $\mathrm{T}$ celldependent somatic hypermutation and some have also undergone immunoglobulin class switching $[128,134]$ in the germinal centre of the lymph node.

However, memory B cells are more heterogeneous than initially understood. In addition to the classical memory cells described above, memory responses originating through GC-independent pathways, without the cognate help of T cells, also exist. These cells are reported to have specificity for polysaccharide antigens. These B cells are found in the marginal zone (MZ) of the spleen (reviewed in [135]) and can be identified in the peripheral blood through $\operatorname{IgD}^{+}$(and generally $\operatorname{IgM}^{+}$) $\mathrm{CD} 27^{+}$expression $[136,137]$. These $\operatorname{IgM} / \mathrm{IgD}$ memory cells (hereafter referred to as marginal zone memory (MZM) cells), can be generated in the absence of GCs [138] and are thought to have undergone less proliferation than GC cells [139] with fewer somatic mutations [134] and immunoglobulin production which has, in the main, not switched to isotypes other than $\operatorname{IgM}[136]$. It is not clear whether or not somatic mutation in these cells is antigen-driven [136,140]. These cells are thought to generate a rapid, relatively high-affinity $\operatorname{IgM}$ response to encapsulated bacteria in early infection [141]. They represent a functional intermediate between innate and 
acquired immunity, and facilitate rapid bacterial clearance from the blood [142]. Human MZ B cells develop progressively over the first two years of life, and their absence in early childhood may contribute to explaining the particular unresponsiveness of infants to polysaccharide vaccines [143] as both the cells and the antibody they produce are thought to be important in facilitating the induction of adaptive humoral immunity.

\subsubsection{Immune responses to pneumococcal infection}

Streptococcus pneumoniae is a Gram-positive encapsulated diplococcus, whose polysaccharide capsule is an essential virulence factor for invasive pneumococcal (Pnc) disease (IPD). There are about 90 Pnc serotypes, based on differences in the capsule composition. Globally, about 20 serotypes are thought to cause the majority of invasive disease. The bacteria are transmitted by colonised or infected respiratory secretions. Whilst Pnc colonisation is common, most colonisation does not result in invasive disease although colonisation is considered a pre-requisite for infection. Disease occurs when the bacteria spread systemically, either by aspiration to the lungs or migration to the blood. The young and old are particularly vulnerable and Pnc disease is believed to cause about a million deaths annually worldwide [144].

The humoral immune response to $S$. pneumoniae infection is provided by pre-formed "natural" or innate IgM antibodies, the MZM B cell population and the classically generated memory B cell population. The early immune response is thought to be mediated primarily by MZM memory B cells, for which Pnc polysaccharides are dominant target antigens [145], with rapid generation of $\operatorname{IgM}$ which binds Pnc directly. In splenectomized and asplenic patients, it has been shown that the absence of MZM memory B cells is correlated with low-absent anti-polysaccharide IgM antibodies and increased susceptibility to pneumococcal infection [145]. This relationship has also been described in other unrelated immunodeficiency diseases. A loss of MZM B cells is associated with increased incidence of bacterial pneumonia in patients with common variable immune deficiency (CVID) [146] compared to patients who retain this B cell population. This MZM-mediated response is thought, in itself to result in poor generation of memory cells and minimal long lasting immune memory. However, as discussed in Section 1.4.3, MZM B cells are also thought to be important in facilitating the development of the classical $\operatorname{IgG}$ 
dominated antibody response, probably by binding of Pnc antigens to complement fragment $\mathrm{C} 3 \mathrm{~d}$ allowing immediate localisation to follicular dendritic cells in the germinal centres, where isotype switching and affinity maturation can take place (reviewed in [147]) generating lasting immune memory.

Serotype-specific antibody, mainly of IgG isotype [148,149], generated by the classical memory pathway, provides the lasting protection against Pnc disease. This antibody is both directed against the capsular polysaccharides and protein antigens located underneath the capsule, such as the bacterial-derived protein PspA, the lipoprotein PsaA, and the cell-wall component teichoic acid. Once opsonised by antibody, the bacterium is eliminated mainly by opsonophagocytosis, as the complement-resistant polysaccharide capsule protects against extracellular complement-mediated killing. Protective levels of antibody are thought to be maintained by either repeated colonisation or through bystander activation of existing memory populations [150,151]. Nasopharyngeal colonisation, and possibly invasive infection, appears to result in PPS-specific antibody production [152,153]). $60 \%$ of healthy children will have been colonised with one or more capsular serotypes of pneumococcus by 1 year of age [154], and it is unclear whether the immune response to immunisation in later life represents a primary or secondary immune response.

Other factors such as local and splenic-resident macrophages and interleukin (IL)17-producing $\mathrm{CD}^{+} \mathrm{T}$ cells in the lung and mucosal associated lymphoid tissue also play an important role in regulating protection against Pnc disease [155].

Vaccines against Pnc include both the pneumococcal polysaccharide vaccine (PPV) and the pneumococcal conjugate vaccine (PCV). PPV is a polysaccharide vaccine and is considered to induce a primarily $\mathrm{T}$ cell-independent response, mediated by naïve B cells, MZM memory population, and pre-existing switched memory to polysaccharides. PCV consists of polysaccharide conjugated to a protein carrier, and thus recruits cognate $\mathrm{T}$ cell help to induce a classical memory response, and is considered to generate lasting immune memory. 


\subsubsection{Impact of HIV infection on generation of immune memory}

\section{Increased risk of infection}

Impaired immune response with abnormal generation and maintenance of immune memory results in increased susceptibility to a variety of infections in HIV-infected patients. It has long been clear that patients with HIV infection are at higher risk of bacterial infection $[156,157]$. Early studies showed the role of B cell dysfunction in this susceptibility, with increased serum $\operatorname{IgE}$ and $\operatorname{IgA}$ levels in those patients experiencing increased frequency of opportunistic infection, even once their $\mathrm{CD}^{+}$ count had been restored by ART [158].

Streptococcus pneumoniae is a clinically important pathogen in HIV infection. Defective immunity to pneumococcal infection in HIV-infected individuals manifests clinically both in increased incidence of IPD and impaired response to immunisation with pneumococcal vaccines. The incidence of pneumococcal disease is reported to be up to one hundred times greater in HIV-infected patients than in the general population $[159,160]$ and pneumococcal infection is the commonest cause of pneumonia in HIV [161]. The effect of ART on this increased susceptibility to IPD remains controversial. Some studies have demonstrated a positive impact $[162,163]$, but this finding has not been replicated elsewhere [164,165] and any protective effect is unlikely to reduce rates in invasive disease to those seen in the HIV non-infected population [166,167]. Since the introduction of pneumococcal conjugate vaccines (PCVs) which have been associated with reduced population carriage of common disease serotypes and reduced prevalence of IPD amongst HIV-infected and noninfected adults $[168,169]$ it has been more difficult to determine the effect of ART on protection against Pnc disease.

\section{Defective generation and maintenance of immune responses in HIV infection}

The drive in HIV infection towards hyperactivation, terminal differentiation and apoptosis, combined with the consequent skewing of B cell subpopulations away from effective mature populations and towards immature and exhausted populations is likely to result in significant impairment in the ability to generate immune memory responses of both classical and MZM type and to maintain protective antibody levels to previously encountered antigens $[118,170]$. 
In order to generate an effective memory response, of either classical or marginal zone type, it is necessary for naïve cells to generate de novo immune responses to antigen [51]. This ability may be impaired in HIV infection, possibly as a consequence of hyperactivation, depletion of B cell subpopulations, and, perhaps, clonal deletion of VH3 gene families, as previously discussed. Naïve cells have been shown to proliferate poorly in response to stimuli in HIV infection [47], perhaps as a result of diminished TLR9 mRNA expression, and abnormal B cell responses to T cell-independent polyclonal B cell activators were demonstrated early in the epidemic [7,8,87], with hyperactivation of $\mathrm{B}$ cells associated with ex vivo hyporeactivity of B cells on in vitro stimulation [26].

Altered B cell function will also impact on T-dependent antibody responses and possible cell mediated immunity as B cells are very efficient cognate antigen presenting cells [114] and in HIV infection, they appear to be less able to provide stimulatory signals to $\mathrm{CD} 4^{+} \mathrm{T}$ cells following MHC-II mediated antigen presentation [46]. Additionally, T cell help normally provided to B cells is defective in HIV infection as a result of impaired interaction between CD40 and CD40 ligand, associated with impaired expression of CD25 in response to activated T cells, and consequent reduced proliferative response to IL-2. [48]. Poor T-B interaction is seen early in infection before functional and quantitative defects in T-helper activity are seen, and it is not reversed in vitro by addition of normal CD4 ${ }^{+} \mathrm{T}$ cells $([8,171]$.

The increased susceptibility to infection, including to Pnc disease, in HIV is associated with an impaired antibody response to both protein and polysaccharide antigens $[7,32,172]$. The deficit of marginal zone memory cells in adults, involved in response to polysaccharide antigens, is not reversed by ART [119]. This deficit is likely to be of considerable importance in contributing to the impaired natural immunity to S. pneumoniae seen in HIV infection [121,173] and is associated with poor immunological memory to immunisation with PPV [119], which is well documented in HIV infection (reviewed in [174]). Defects in MZM memory have also been related to susceptibility to other infections in HIV-infected patients [175].

Although depletion of classical memory populations in HIV infected individuals remains controversial $[116,118,121,122]$, the impaired generation of classical 
memory immune responses is likely to account for the poor serological response to many protein antigens, occurring both naturally and in vaccines. Reduction in pneumococcal protein antigen-specific memory B cells and in plasma anti-Pnc IgG titres has been demonstrated in HIV-infected adults [121] [173] and children [176] [177]. This is evident even during primary HIV infection, suggesting that subtle early alterations to $\mathrm{B}$ cell function may be important even prior to their depletion [52]. Reduced antibody levels to other naturally acquired bacterial $[178,179]$ and viral $[89,180]$ infections have also been shown in HIV infection; this has been shown in some studies to correlate with low memory B lymphocytes [89].

Response to immunisation with protein antigens is impaired [170,173,181-183]. PCV vaccine response is also thought to be reduced in HIV infection and most studies demonstrate impaired antibody response in HIV-infected individuals compared to healthy controls $[184,185]$. One possible explanation is the reduced capacity of memory cells to produce $\operatorname{IgG}$ and $\operatorname{IgM}$ anti-pneumococcal antibody, shown in vitro in response to B cell polyclonal stimulation [173]. Nonetheless, use of the vaccine has been associated with a reduction in vaccine-serotype IPD in HIVinfected adults even not on treatment [186].

The defects in both naturally and vaccine-induced Pnc-specific memory may be secondary to clonal deficits resulting from deletion of B cell clones expressing VH3 genes, as discussed earlier, as pneumococcal antibodies are known to use this gene family [67,187]. Reduced B cell VH3 expression correlates to reduced antipneumococcal antibody in HIV-infected adults [67]. Chang et al. [187] showed an association between the anti-PPS response and the status of the VH3 repertoire, with impaired responses associated with abnormal repertoire shift in HIV-infected individuals. These changes were later shown to be reversible by effective ART [80].

Impaired response to immunisation is, at least in part, due to a failure to maintain, as well as generate, an immune response. Malaspina [170] showed that despite similar numbers of antigen-specific antibody producing cells at one week after influenza immunisation, a significant difference in antigen-specific memory B cells was detected by day 54 between HIV-infected patients and healthy controls. This 
suggests that HIV-infected patients are able to respond to immunisation but that the maturation and maintenance of a long-lived memory response is impaired.

Furthermore, function of these antibodies, once generated, is also likely to be impaired in HIV infection, as seen by functional antibody studies performed in HIVinfected children after immunisation with PCV [188]. Pneumococcal vaccine response in HIV infection is discussed further in Chapter 4.

\section{Relationship between MZM and generation of switched memory}

There is evidence that natural $\operatorname{IgM}$ memory, MZM and switched memory may be interrelated, particularly in the context of antibody responses to polysaccharides and encapsulated bacterial antigens, where secreted $\operatorname{IgM}$ and marginal zone memory is likely to be important in promoting the subsequent adaptive immune response. It is likely that MZ memory, activated early in pneumococcal infection, plays a significant part in rapid complement-mediated localisation of antigen to the spleen [189], where antigen-specific B cells are encountered and subsequently enter the GC reaction, resulting in generation of both switched memory populations and plasmablasts. Furthermore, it has been shown [190,191] that mice genetically deficient in secreted IgM produce less (and lower affinity) antigen-specific IgG than is seen in control mice, associated with fewer and smaller germinal centres. Reduced antigen trapping is also seen on splenic follicular dendritic cells, probably because antigen trapping is partially dependent on the deposition of activated $\mathrm{C} 3$ which is induced by $\operatorname{IgM}$-antigen complexes. It is likely, therefore, that both natural and MZM-secreted IgM are important in facilitating the subsequent generation of IgG antibody from GC-derived switched memory cells for some infections. MZM depletion in HIV infection may, therefore, have implications for generation of classical memory responses, in addition to the accepted implications for marginal zone memory. 


\subsection{Effect of ART on B cells in HIV}

The effects of ART on HIV-related B cell changes in adults are summarised in Table 1.4 .

\begin{tabular}{|c|c|}
\hline Effect of ART & Key References \\
\hline \multicolumn{2}{|l|}{ Normalisation of HIV associated changes } \\
\hline Reversal of hypergammaglobulinaemia & [192] \\
\hline $\begin{array}{l}\text { Normalisation of antibody repertoire with restored ability to produce antibody from } \\
\text { VH3 B cells }\end{array}$ & {$[79-82]$} \\
\hline Partial reduction in activation markers expressed by B cells & {$[28,41,46,51,52,91,92]$} \\
\hline Possible partial reduction in extrinsic apoptosis & {$[41,51-55]$} \\
\hline Normalisation of Ki67 expression & [41] \\
\hline Normalisation of proliferation & {$[47,97]$} \\
\hline $\begin{array}{l}\text { Partial normalisation of B cell subpopulations (but probably not MZM or switched } \\
\text { memory) and reduction in terminal differentiation }\end{array}$ & {$[41,59,90,193]$} \\
\hline Controversial recovery of humoral immunity & $\begin{array}{l}{[119,170,173,194-} \\
196]\end{array}$ \\
\hline $\begin{array}{l}\text { Early ART may reverse the reduction of both MZM memory B cells and the switched } \\
\text { memory B cell compartment }\end{array}$ & {$[52,193]$} \\
\hline Early ART may result in improved memory B cell response & [193] \\
\hline \multicolumn{2}{|l|}{ Failure to normalise HIV associated changes } \\
\hline Failure to completely restore switched memory populations & {$[90,116,118,126]$} \\
\hline Failure to completely restore MZM populations & [119] \\
\hline Failure to completely restore memory responses & {$[119,170,173]$} \\
\hline
\end{tabular}

Table 1.4. Effects of ART in adults on HIV-related B cell changes.

The advent of effective ART since the mid-1990s has permitted study of the effect of slowing or reversing the HIV disease progression and isolation of the effect of HIV viraemia. Decrease in HIV viraemia with ART results in a decrease in B cell hyperactivation [28,52,197], and a normalisation of B cell dynamics including turnover [41], proliferation [47,97] and apoptosis [41,52,53]. Upregulation of genes associated with terminal differentiation have also been correlated with HIV viraemia and are thus reversible with ART [45]. It appears that these changes with ART result 
in partial normalisation of the peripheral B cell subpopulations $[59,90,193]$. However, the defect in both switched [55,59,116,118,120,126] and MZM [119] cells appears to persist despite effective treatment, with likely long term consequences for immune function. Some reports of improvement of humoral immunity against CMV and influenza in short-term treated patients [194-196] suggested that memory B cell responses may be restored by ART, but this has not been confirmed by subsequent studies $[119,170,173]$. As discussed above, the true impact of ART on susceptibility in HIV infection to IPD remains controversial.

There are few comprehensive studies examining B cell numbers and function in HIV-infected individuals who initiate ART during the acute phase of infection. However, there are indications that damage to B cell function, including generation of memory responses, may occur early in HIV infection $[52,173,192]$, which may imply benefit of early ART. Some studies have suggested that early initiation of ART does seem to restore both MZM memory B cells [52] and the switched memory B cell compartment [193].

\subsection{HIV infection and B cells in children}

The impact of HIV infection on $\mathrm{B}$ cells in the paediatric population remains relatively unexplored, and virtually no published data exists in this field regarding the growing population of adolescents with vertically-acquired HIV infection.

Hypergammaglobulinaemia has been demonstrated in children $[9,198,199]$. Reduction in B cell numbers and proportions has also been shown $[9,200,201]$. The impact of HIV infection on individual subpopulations in children has been examined in a limited number of studies. These results are somewhat contradictory and are non-longitudinal, with small cohort sizes and considerable variability in treatment status and viral control. However, work to date does suggest persistent abnormalities in B cell memory in the paediatric population, in particular, MZM populations $[199,202]$; the impact on naïve and switched memory populations is less clear $[177,199,202]$. 
Functional immune impairment, manifest as increased infection [203-205] and inadequate vaccine responses (reviewed in [203,206]), is also described in children with HIV. Impaired vaccine immunogenicity including generation and maintenance of memory has been described. Hepatitis B vaccine failure has been associated with poor virological control and CD4 lymphopenia [207]. Moss et al. 2007 demonstrated that, after primary measles immunisation in HIV-infected children, only $88 \%$ seroconverted compared to $93 \%$ of uninfected children. As with adults, the major difference was found in the maintenance of protective titres, where the HIV-infected children showed rapid decline of immunity compared to uninfected children. The same group, in 2010, identified 38 studies in which immune-specific responses were analysed in vertically-infected children on ART: in general, responses to childhood vaccines administered prior to starting ART were low, and even effective ART did not ensure sustained protective immunity, despite initially good antibody responses to those vaccines administered on therapy [208]. Reduced antibody avidity after immunisation has also been shown in children with HIV infection in the context of measles antigen [209].

Children, even without HIV infection, are at high risk of IPD, probably due, at least in part, to the delayed maturation of the marginal zone memory compartment, as discussed previously. Children with HIV infection, with their disease-associated additional deficit of marginal zone memory [202], in addition to deficits in the generation of classical immune memory, are thus exceedingly vulnerable. Von Gottberg [210] showed a 21-fold greater risk of disease in HIV-infected infants compared with healthy controls and also significantly higher rates of pneumococcal colonisation [211]. Changes to IgG VH3 repertoire in association with invasive pneumococcal disease have also been demonstrated in children which may contribute to ineffective humoral responses as discussed previously [212].

As in adults, ART does not appear to entirely restore abnormalities in memory cell populations in the paediatric population [199,202] and timing of ART is likely relevant in this context. Promising paediatric data has been presented [213], although findings are often inconsistent partly due to difficulties in study standardisation. Some studies [199] show some recovery of pre-existing immune 
memory to tetanus antigen after initiation of ART in addition to protective responses to booster vaccines, while others [214] demonstrate an ART-related improvement only in the context of revaccination.

Where ART is started early in infection, immune recovery is likely to be greatest. Memory B cells have been shown to be preserved in those children started on treatment early in the disease course but reduced in those treated later [177]. The same study showed relatively preserved responses to common vaccine antigens (measured by serum antibody and antigen-specific B cell levels) in those children starting ART before the age of one year. Further data from the same group [215] suggests reduced humoral and cellular immunity to routine childhood vaccines is seen in late ART-treated patients, and that late treatment may also be associated with higher frequencies of abnormally activated B cells.

\subsection{HIV infection - does the route of infection matter?}

It is clear that HIV infection results in complex and significant abnormalities of the B cell compartment. These abnormalities result in impaired ability to generate and maintain effective memory responses, with important clinical consequences in terms of infection and immunisation. HIV-related B cell dysfunction has been studied extensively in adults, infected by the horizontal route, and, to a more limited extent, in children, who have acquired their infection by the vertical route. Almost no data exists regarding the HIV-infected young adult population, who represent a mixture of vertically and horizontally infected patients. It is not clear whether existing findings in adults or children can be extrapolated to this age group, nor whether HIV infection affects the B cell compartment differentially in these two subgroups of patients, infected by different routes, at different ages, and with different durations of infection and history of antiretroviral exposure. An understanding of how vertically acquired HIV infection affects immune development has implications for efficacy of HIV treatment in adult life and strategies to prevent and treat common infections [216].

\section{Failure to generate effective early immune memory?}

Vertically-acquired HIV infection may result in deleterious effects on long term immunity. For these patients, infant immunisations and natural antigen exposure all 
occur in the context of chronic HIV infection and viraemia. This may lead to long term defects in natural and vaccine immunity with significant implications for later immune competence.

During childhood, antigen encounter results in establishment of memory B cell populations that provide lifelong immunity to most infections. Gradual maturation of lymphocyte populations [145,217], antibody responses [218] and increasing capacity to mount antibody responses to vaccines [219-221] are seen in early life. This is reflected in the two-fold increase of peripheral blood B cells seen in the first five months of life, with subsequent decline from the second year until adulthood [217], and in the postnatal development of lymph node microarchitecture [222-224].

Early-life antigen encounter results in the development of the immune repertoire, and shapes the specificity and diversity of the subsequent memory response. The concept of 'original antigenic sin' refers to the influence of a primary antibody response in dictating the specificity and efficacy of subsequent responses. Mouse studies [225] showed that the $\mathrm{V}$ gene repertoire induced during the initial priming stage of a T-dependent antigen-specific immune response was important in determining the later efficacy of a secondary response. Thus it is important that in the early childhood years when adaptive immunity is developing to many important pathogens, the best quality of immunity is generated. Inability to access and or generate antibodies of optimal configuration has been associated with a general phenotype of frailty [226].

This early period of life thus appears to offer the optimal opportunity for generating appropriate repertoire diversity and is therefore critical for normal immunological development. The impact of chronic HIV infection at such an important time may have particularly deleterious effects on the generation of optimal diversity of the long term immune repertoire. Early deletion of memory clones by HIV via the direct action of gp120 protein may result in a permanently damaged antibody repertoire. Increased apoptosis, a shift towards exhaustion and cell depletion, and HIV-related defects in signalling and trafficking may also contribute to the failure of these essential cell populations to develop normally, with consequent long lasting deficits in the ability to generate and maintain effective immune memory. 


\section{What is the potential for immune recovery?}

Whilst acknowledging the issue of 'original antigenic sin', it remains unclear whether the immaturity of the immune system in early childhood may paradoxically provide increased capacity for restoration and regeneration in vertically infected patients. Reconstitution of damaged cell pools has been shown in the context of $\mathrm{T}$ cell recovery in young HIV-infected children, who may compensate for HIV-related damage by increased thymic output [227-230], a process which is thought to decrease with age (reviewed in [231]). It is not yet clear whether age affects reconstitution of the $\mathrm{B}$ cell compartment, but it has been shown that even after several years of infection, the immune system may remain relatively well preserved in asymptomatic vertical HIV infection [232], and encouraging long term outcomes have been predicted [233].

Vertically-infected adolescents represent an unknown immunological population with an ever improving prognosis with effective treatment. Early immune responses form the basis of lifelong immune competence. This population have acquired their infection early in life, and, with improving drug therapy, may expect to live many years with their HIV infection. Long lasting immune competence is therefore important and preserving early immune development may be critical for later effective immune function. There is evidence that early treatment may preserve the capacity for immune reconstitution in the context of $\mathrm{T}$ cells [230] and some emerging data suggesting that early initiation of ART [177] is also needed to preserve the B cell compartment. This may have implications for timing of initiation of therapy, which is currently based on $\mathrm{CD}^{+}$counts or AIDS defining illness, and for optimisation of immunisation schedules and protocols.

There is an urgent need to develop a greater understanding of the long term implications of the early insults posed by HIV infection to the developing humoral immune system, in order to better inform use of ART in early childhood and to support effective clinical management of the expanding cohort of vertically infected young adults. Current treatment protocols vary significantly, with some advocating ART only for all children under a year of age [234], and others for all those under 5 years [235]. There is a paucity of evidence to inform these recommendations and a lack of longitudinal studies monitoring the long term impact of HIV infection in 
childhood. I hypothesise that these vertically infected young adults represent a distinct immunological group from their horizontally infected counterparts. This thesis investigates the immunological differences between these two HIV-infected cohorts, focussing on B cell phenotype and capacity to generate short and long term serological memory to pneumococcal immunisation. 


\section{Chapter 2. Subjects, materials and methods}

\subsection{Reagents}

Reagents used are listed in Table 2.1.

\begin{tabular}{|c|c|c|}
\hline Reagent & Source & Catalogue number \\
\hline Phosphate buffered saline (PBS) & Invitrogen Ltd., UK & $14190-094$ \\
\hline BD FACS lysing solution & BD Biosciences, UK & 349202 \\
\hline BD CellFIX (10x concentrate) & BD Biosciences, UK & 340181 \\
\hline Bovine serum albumin (BSA) & Sigma-Aldrich, UK & A2153 \\
\hline Saponin & Sigma-Aldrich, UK & $8047-15-2$ \\
\hline BD $^{\mathrm{TM}}$ CompBead & BD Biosciences, UK & 552843 \\
\hline CD19-PeCy ${ }^{\mathrm{TM}} 7$, clone SJ25C1 & BD Biosciences, UK & 341113 \\
\hline IgM-APC, clone G20-127 & BD Biosciences, UK & 551062 \\
\hline IgD-AlexaFluor 700, clone IA6-2 & BD Biosciences, UK & 561302 \\
\hline $\begin{array}{l}\text { PerCP-Cy5.5 anti-Human CD185 (CXCR5), clone } \\
\text { TG2/CXCR5 }\end{array}$ & $\begin{array}{l}\text { Insight Biotechnology, } \\
\text { UK }\end{array}$ & 335001 \\
\hline $\begin{array}{l}\text { CD95 Mouse Anti-Human mAb (clone DX2), } \\
\text { Pacific Blue }{ }^{\mathrm{TM}} \text { Conjugate }\end{array}$ & Invitrogen Ltd., UK & MHCD9528 \\
\hline $\begin{array}{l}\text { CD38 Mouse Anti-Human mAb (clone HIT2), } \\
\text { Qdot }{ }^{\circledR} 605 \text { Conjugate }\end{array}$ & Invitrogen Ltd., UK & Q10053 \\
\hline $\begin{array}{l}\text { CD27 Mouse Anti-Human mAb (clone CLB-27/1), } \\
\text { Qdot }{ }^{\circledR} 655 \text { Conjugate }\end{array}$ & Invitrogen Ltd., UK & Q10066 \\
\hline $\begin{array}{l}\text { CD10 Mouse Anti-Human mAb (clone MEM-78), } \\
\text { Qdot }{ }^{\circledR} 800 \text { Conjugate }\end{array}$ & Invitrogen Ltd., UK & Q10154 \\
\hline $\begin{array}{l}\text { Human CD21 Affinity Purified Polyclonal Ab, } \\
\text { Sheep IgG }\end{array}$ & R\&D Systems, UK & AF4909 \\
\hline $\begin{array}{l}\text { Bcl-2 Mouse Anti-Human mAb (clone 100), PE } \\
\text { Conjugate }\end{array}$ & Invitrogen Ltd., UK & MHBCL04 \\
\hline Ki-67 FITC (clone B56); mouse IgG1 & BD Biosciences, UK & 556026 \\
\hline Qdot ${ }^{\circledR} 705$ Antibody Conjugation Kit & Invitrogen Ltd., UK & Q22061MP \\
\hline
\end{tabular}




\begin{tabular}{|c|c|c|}
\hline $\begin{array}{l}\text { LIVE/DEAD® Fixable Violet Dead Cell Stain Kit, } \\
\text { for } 405 \mathrm{~nm} \text { excitation }\end{array}$ & Invitrogen Ltd., UK & L34957 \\
\hline Multitest 6 colour TBNK reagent & BD Biosciences, UK & 644611 \\
\hline Lymphoprep & $\begin{array}{l}\text { Axis-Shield } \\
\text { Diagnostics Ltd, UK }\end{array}$ & LYS 3773 \\
\hline Dimethyl sulfoxide (DMSO) & Sigma-Aldrich, UK & D8418-250ML \\
\hline $\begin{array}{l}\text { QuantumPlex }^{\mathrm{TM}} \text { carboxylated fluorescent beads; } \\
\mathrm{COOH} 4.4 \mu \mathrm{m} \text { and } 5.5 \mu \mathrm{m}, 10 \text { populations }\end{array}$ & $\begin{array}{ll}\text { Bangs } & \text { Laboratories } \\
\text { Inc., UK } & \end{array}$ & 239 \\
\hline $\begin{array}{l}\text { Serotype specific pneumococcal capsular } \\
\text { polysaccharide -serotypes } 1,4,5,6 \mathrm{~B}, 9 \mathrm{~V}, 14,18 \mathrm{C} \text {, } \\
22 \mathrm{~F}, 23 \mathrm{~F} \text { (PPS) }\end{array}$ & $\begin{array}{l}\text { ATCC Biologicals, } \\
\text { UK }\end{array}$ & $\begin{array}{lrr}\text { ATCC-161X, } & 173 X, & 177 X, \\
225 X, 253 X, & 197 X, & 245 X, \\
213 X, 217 X & & \end{array}$ \\
\hline $\begin{array}{l}\text { Serotype specific pneumococcal capsular } \\
\text { polysaccharide }- \text { serotypes 7F and 19F (PPS) }\end{array}$ & $\begin{array}{l}\text { Statens Serum Institut, } \\
\text { UK }\end{array}$ & 76868,76958 \\
\hline $\begin{array}{l}\text { Human antibody conjugate: whole IgG Goat Anti- } \\
\text { Human IgG, Fc } \gamma \text { fragment specific (min X Bov, } \\
\text { Hrs, Ms Sr Prot) }\end{array}$ & $\begin{array}{l}\text { Jackson } \\
\text { Immunoresearch, UK }\end{array}$ & 109-116-098 \\
\hline $\begin{array}{l}\text { R-Phycoerythrin AffiniPure F(ab')2 Frag Dnk } \\
\text { Anti-Hmn IgM, Fc(5mu) Frag Spec (min X } \\
\text { Bov,Hrs Sr Prot) }\end{array}$ & $\begin{array}{l}\text { Jackson } \\
\text { Immunoresearch, UK }\end{array}$ & $709-116-073$ \\
\hline Cell wall polysaccharide (CWPS) & $\begin{array}{l}\text { Statens Serum Institut, } \\
\text { UK }\end{array}$ & 3459 \\
\hline
\end{tabular}

Table 2.1. Reagents.

\subsection{Study Design}

The study investigated cohorts of vertically and horizontally infected young adults, and healthy control volunteers. B cell immunophenotyping was performed and subjects were immunised with pneumococcal polysaccharide vaccine and their serological response monitored over the course of one year. The study design is shown in Figure 2.1. HIV-infected individuals were recruited from paediatric and adult HIV clinics in London, as described below (Section 2.7). Following informed consent, a baseline blood sample was taken and vaccination administered. Serial blood samples were then taken at 28 days and 1 year, or at the clinic attendance most 
closely related to these timepoints, for serum studies. A single "one off" sample was taken (at any time) for B cell analysis by flow cytometry.

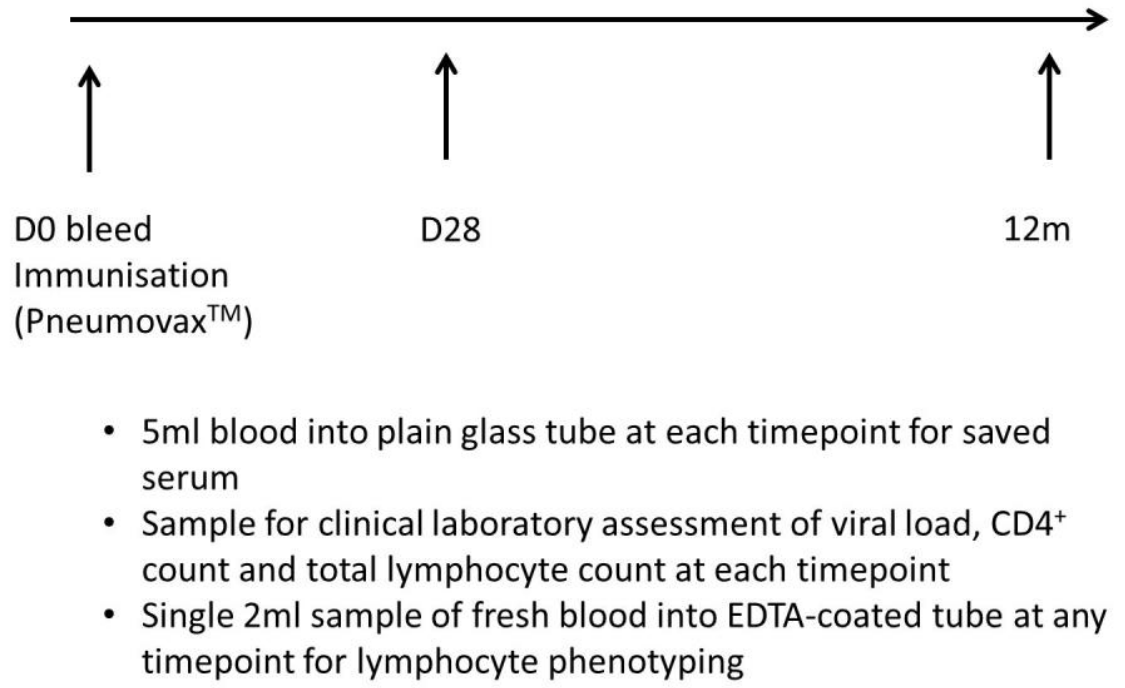

Figure 2.1. Study design.

\subsection{Ethical Approval}

Ethical approval was obtained from the London Research Ethics Committee (REC reference number 10/H0713/1; B cell development and pneumococcal immunity in paediatric HIV infection) and informed written consent was obtained from all participants.

\subsection{Vaccination Protocol}

All participants ${ }^{1}$ were immunised with Pneumovax $23^{\mathrm{TM}}$ (PPV-23) vaccine, containing pneumococcal serotypes $1,2,3,4,5,6 \mathrm{~B}, 7 \mathrm{~F}, 8,9 \mathrm{~N}, 9 \mathrm{~V}, 10 \mathrm{~A}, 11 \mathrm{~A}, 12 \mathrm{~F}$, 14, 15B, 17F, 18C, 19F, 19A, 20, 22F, 23F, and 33F (Merck \& co Inc, UK). The vaccination was administered by intramuscular injection to the non-dominant deltoid muscle.

\footnotetext{
${ }^{1}$ all participants were immunised except a group of horizontally infected patients with history of HIV seroconversion within the previous 2 years. This is further discussed in Section 2.7
} 


\subsection{Clinical Data Collection}

Data was gathered from clinical records regarding antiretroviral drug status at each blood sampling. At each bleedpoint, a blood sample was also taken concurrently with each study sample for clinical laboratory assessment of viral load. Total lymphocyte count and $\mathrm{CD}^{+}$count were analysed by the clinical laboratories at Great Ormond Street Hospital for Children NHS Foundation Trust, Great Ormond St, London WC1N 3JH. Total lymphocyte count was obtained using a Sysmex XE-5000 analyser (Sysmex, UK). $\quad \mathrm{CD}^{+}{ }^{+}$count was analysed by staining $100 \mu \mathrm{l}$ of whole blood with $5 \mu \mathrm{l}$ of Multitest 6 colour TBNK reagent. After an incubation period of 10 minutes, the sample was lysed with BD FACS lysing solution and run on a flow cytometer (BD FACSCanto II; BD Biosciences, UK). 10,000 lymphocyte events were collected; acquisition and analysis was performed using FacsDiva ${ }^{\mathrm{TM}}$ software (BD Biosciences, UK). Lymphocytes were defined by forward vs. side scatter and $\mathrm{CD} 45$ vs. side scatter, then gated $\mathrm{CD} 3$ vs. $\mathrm{CD} 19 . \mathrm{CD}^{+}$cells were gated and the $\mathrm{CD}^{+}$vs. $\mathrm{CD}^{+}$plot was used to define the $\mathrm{CD} 4^{+}$population. Absolute $\mathrm{CD} 4^{+}$count was calculated by multiplication of the $\mathrm{CD} 4^{+}$percentage by the total lymphocyte count. The HIV load was determined using the HIV-1 RNA bDNA assay (Bayer Diagnostics, UK) by the clinical laboratories at Great Ormond Street Hospital for Children NHS Foundation Trust (as above). The lower limit of detection for the assay is 50 copies $/ \mathrm{mL}$.

\subsection{Sample preparation}

Blood for serum studies $(5 \mathrm{ml})$ was taken into plain glass tubes. Serum was separated by centrifuging at $3000 \mathrm{rpm}$ for 5 minutes, aliquoted and stored at $-80{ }^{\circ} \mathrm{C}$ for subsequent analysis. Blood for immediate flow cytometric assay $(2 \mathrm{ml})$ was taken into an EDTA-coated glass tube. All blood was transported to the receiving centre within 12 hours and processed there within 24 hours. Blood for lymphocyte store (20 $\mathrm{ml}$ ) was taken into lithium heparinised glass tubes. Lymphocytes were isolated by Ficoll density centrifugation and frozen in 10\% DMSO for later analysis, outside the scope of this thesis. 


\subsection{Subject recruitment}

\subsubsection{Subject groups}

HIV-infected populations were recruited from the HIV clinics of Great Ormond Street Hospital for Children NHS Foundation Trust (Great Ormond St, London WC1N 3JH), Mortimer Market Centre, NHS Camden Provider Services (London WC1E 6JB), "56 Dean Street Clinic", Chelsea and Westminster Hospital NHS Foundation Trust (56 Dean St, London W1D 6AQ) and Royal Free London NHS Foundation Trust (Pond St, London NW3 2QG). Patients were eligible for inclusion if they were aged 12-25 years and had confirmed HIV infection. Patients with chronic co-existing non-HIV-related morbidity were excluded, as were those who were pregnant or had previously received pneumococcal immunisation with either Pneumovax $^{\mathrm{TM}}$ (Merck \& co Inc, UK) or Prevenar ${ }^{\mathrm{TM}}$ (Wyeth Vaccines, USA).

Patients were subdivided into those with infection acquired by the horizontal route (sexual or blood product transmission with documented evidence of infection more than two years previously) ( $\mathrm{HIV}-\mathrm{H} ; \mathrm{n}=29)$ and those infected by the vertical route (HIV-V; $\mathrm{n}=64$ ). All children found to be HIV positive in early childhood, where the mother is HIV positive, were regarded as vertically infected although infection may have occurred in the perinatal or postnatal period through breast feeding. A further cohort of young adults with recently acquired HIV infection (documented first positive HIV test within the previous 2 years) (HIV-H-RS; $n=9$ ) was also recruited (recent seroconverters); the HIV-RS group did not receive the pneumococcal immunisation.

The control group was composed of healthy adult volunteers, aged 18-25 years (CON; $\mathrm{n}=51$ ), recruited by approaching students of University College London (by email) and staff nurses from Great Ormond Street Hospital NHS Foundation Trust (in person). Abbreviations used to denote patient populations are shown in Table 2.2. 


\begin{tabular}{|l|l|}
\hline Patient group & Abbreviation \\
\hline Healthy control group & $\mathrm{CON}$ \\
\hline Total vertically infected patient group & $\mathrm{HIV}-\mathrm{V}$ \\
\hline Horizontally infected patient group (excluding those seroconverted in previous two years) & HIV-H \\
\hline Horizontally infected patients who have seroconverted in the previous 2 years & HIV-H-RS \\
\hline HIV viral load positive at the time of sample & ${ }^{+}\left(\mathrm{eg}: \mathrm{HIV}-\mathrm{V}^{+}\right)$ \\
\hline HIV viral load negative at the time of sample & ${ }^{-}\left(\mathrm{eg}: \mathrm{HIV}-\mathrm{V}^{-}\right)$ \\
\hline Vertically infected patient group with early and sustained viral control <10y of age & HIV-V $^{\mathrm{E}}$ \\
\hline
\end{tabular}

Table 2.2. Patient populations with abbreviations. 


\subsubsection{Subject demographics}

The demographics of study participants are shown in Table 2.3.

\begin{tabular}{|c|c|c|c|c|c|}
\hline & & & HIV infecte & jects & \\
\hline & & CON & HIV-V & HIV-H & HIV-H-RS \\
\hline $\mathbf{N}$ (total) & & 51 & 64 & 29 & 9 \\
\hline $\begin{array}{ll}\text { Age } & \text { (range) } \\
\text { (years) } & \end{array}$ & & $\begin{array}{l}22.9(19.0- \\
26.1)^{*} *\end{array}$ & $\begin{array}{l}17.4(12.4- \\
25.8) \dagger\end{array}$ & $\begin{array}{l}24.6(20.5-27.1) \\
\text { • }\end{array}$ & $\begin{array}{l}22.6(20.4- \\
25.3)\end{array}$ \\
\hline Female sex (\%) & & $80.4 *$ & 56.3 & 41.4 & 11.1 \\
\hline Ethnicity (\%) & White British & $56.9 * \%$ & $6.30 \dagger$ & 31.0 & 55.6 \\
\hline & $\begin{array}{l}\text { Black } \\
\text { African }\end{array}$ & $3.9 *$ & $75.0 \dagger$ & 31.0 & 11.1 \\
\hline & Other $^{\#}$ & $43.4 *$ & $14.1 \uparrow$ & 37.7 & 33.3 \\
\hline & Unknown & $0 *$ & $4.70 \dagger$ & 0 & 0 \\
\hline
\end{tabular}

Table 2.3. Demographics by subject group.

Data relates to the first sample collected for each patient. Data are median values (range), unless otherwise indicated. NA, not applicable. Significance is shown at $\mathrm{p}<0.05$ for the following comparisons: $* \mathrm{CON}$ and combined HIV-V and HIV-H; † HIV-V and HIV-H; † CON and HIV-V; • HIV-H and HIV-H-RS (p<0.05); \# Other: includes : other white background , Asian (Indian, Pakistani, Bangladeshi, Chinese, other Asian), Caribbean, Arab, mixed ethnicity (White and Black African, White and Asian, other).

Vertically infected (HIV-V) patients (median age 17.4 years) were younger than the horizontally infected (HIV-H) group (median age 24.6 years). The control group $(\mathrm{CON})$, had a median age of 22.9 years. CON subjects were mostly female (80.4\%), whereas HIV-V and HIV-H patients were more evenly distributed by gender $(56.3 \%$ and $41.4 \%$ female, respectively). Three quarters of the HIV-V group were of Black 
African ethnic origin, whereas the HIV-H group were evenly distributed between White British, Black African and other ethnicities.

Disease parameters in the various subject groups are shown in Table 2.4. 


\begin{tabular}{|c|c|c|c|c|}
\hline & & HIV-V & HIV-H & HIV-H-RS \\
\hline $\begin{array}{l}\text { Age at initial HIV + diagnosis, whole } \\
\text { years (range) }\end{array}$ & & $3(0-15) \dagger$ & $20(15-24)$ & $21(9-25)$ \\
\hline $\begin{array}{l}\text { Time since initial HIV + diagnosis, } \\
\text { whole years (range) }\end{array}$ & & $12.5(4-22) \dagger$ & $3(2-11) \cdot$ & $1(0-1)$ \\
\hline CD4, count, cells $/ 100 \mu \mathrm{l}$ blood (range) & & $490(10-1200)$ & $526(100-915)$ & $\begin{array}{l}489(241- \\
809)\end{array}$ \\
\hline $\begin{array}{l}\text { Viral load known to be undetectable } \\
\text { (n) }\end{array}$ & & $\begin{array}{l}34 \text { (incl. 1 off } \\
\text { ART) }\end{array}$ & $\begin{array}{l}16 \text { (incl. } 1 \text { off } \\
\text { ART) }\end{array}$ & 0 \\
\hline \multirow[t]{4}{*}{ 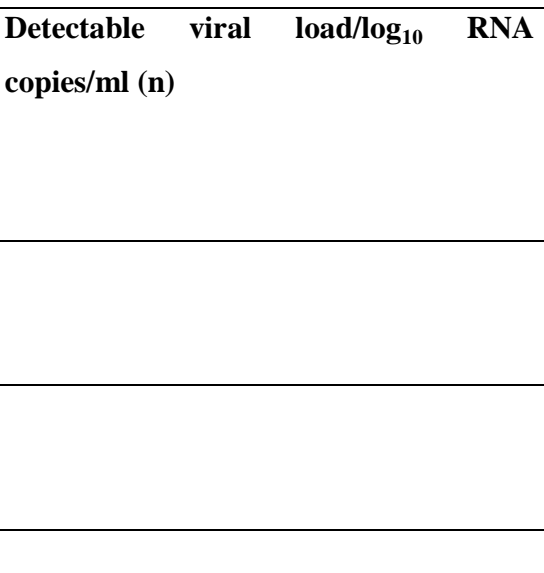 } & $50-10,000$ & $\begin{array}{l}18 \text { (incl. } 11 \text { off } \\
\text { ART) }\end{array}$ & $\begin{array}{l}9 \text { (all off } \\
\text { ART) }\end{array}$ & $\begin{array}{l}2 \text { (incl. } 1 \text { off } \\
\text { ART) }\end{array}$ \\
\hline & $\begin{array}{l}10,000- \\
100,000\end{array}$ & $\begin{array}{l}9 \text { (incl. } 5 \text { off } \\
\text { ART) }\end{array}$ & $\begin{array}{l}2 \text { (both off } \\
\text { ART) }\end{array}$ & $\begin{array}{l}4 \text { (incl. } 3 \text { off } \\
\text { ART) }\end{array}$ \\
\hline & $\begin{array}{l}100,000- \\
500,000\end{array}$ & 2 & $\begin{array}{l}2 \text { (incl. } 1 \text { off } \\
\text { ART) }\end{array}$ & $\begin{array}{l}2 \text { (both off } \\
\text { ART) }\end{array}$ \\
\hline & $>500,000$ & 0 & 0 & 0 \\
\hline Viral load unknown (n) & & 0 & 0 & 1 \\
\hline $\begin{array}{l}\text { Individuals known to be on HAART, } \\
\%\end{array}$ & & $76.6 \dagger$ & 55.2 & 33.3 \\
\hline Individuals naïve to HAART, \% & & $7.8 \dagger$ & 37.9 & 55.6 \\
\hline
\end{tabular}

Table 2.4. Disease parameters by subject group.

Data relates to the first sample collected for each patient. Data are median values (IQR), unless otherwise indicated. HAART: highly active antiretroviral therapy. NA, not applicable. Significance is shown at $\mathrm{p}<0.05$ for the comparisons:* CON and combined HIV-V and HIV-H; $\uparrow$ HIV-V and HIV-H, $₫$ CON and HIV-V; $\bullet$ HIV-H and HIV-H-RS ( $<<0.05)$. 
Median age at diagnosis was 3 years in the HIV-V group, although all patients are presumed to have been infected around the time of birth. Median age of diagnosis in the HIV-H group was 20 years. There was no difference in $\mathrm{CD}^{+}$cell count in the patient groups, nor in the number with controlled viraemia. Of those HIV-V and HIV-H infected patients with detectable viral load $\left(\mathrm{HIV}-\mathrm{V}^{+}\right.$and HIV-H $\left.{ }^{+}\right)$, only 2 patients in each group had a VL greater than 100,000 copies/ml. A greater proportion of HIV-V than HIV-H infected patients were on ART ( $\mathrm{p}=0.037)$, and a smaller proportion were naïve to therapy $(\mathrm{p}=0.003)$.

The recent seroconverter group (HIV-H-RS) was similar to the HIV-H group in terms of both demographics and disease parameters, although they were slightly younger (median age 22.6 years compared to 24.6 years in the HIV-H group) and none of the HIV-H-RS group had an undetectable viral load.

In the HIV-V patient group, viral control in childhood was examined (Figure 2.2).

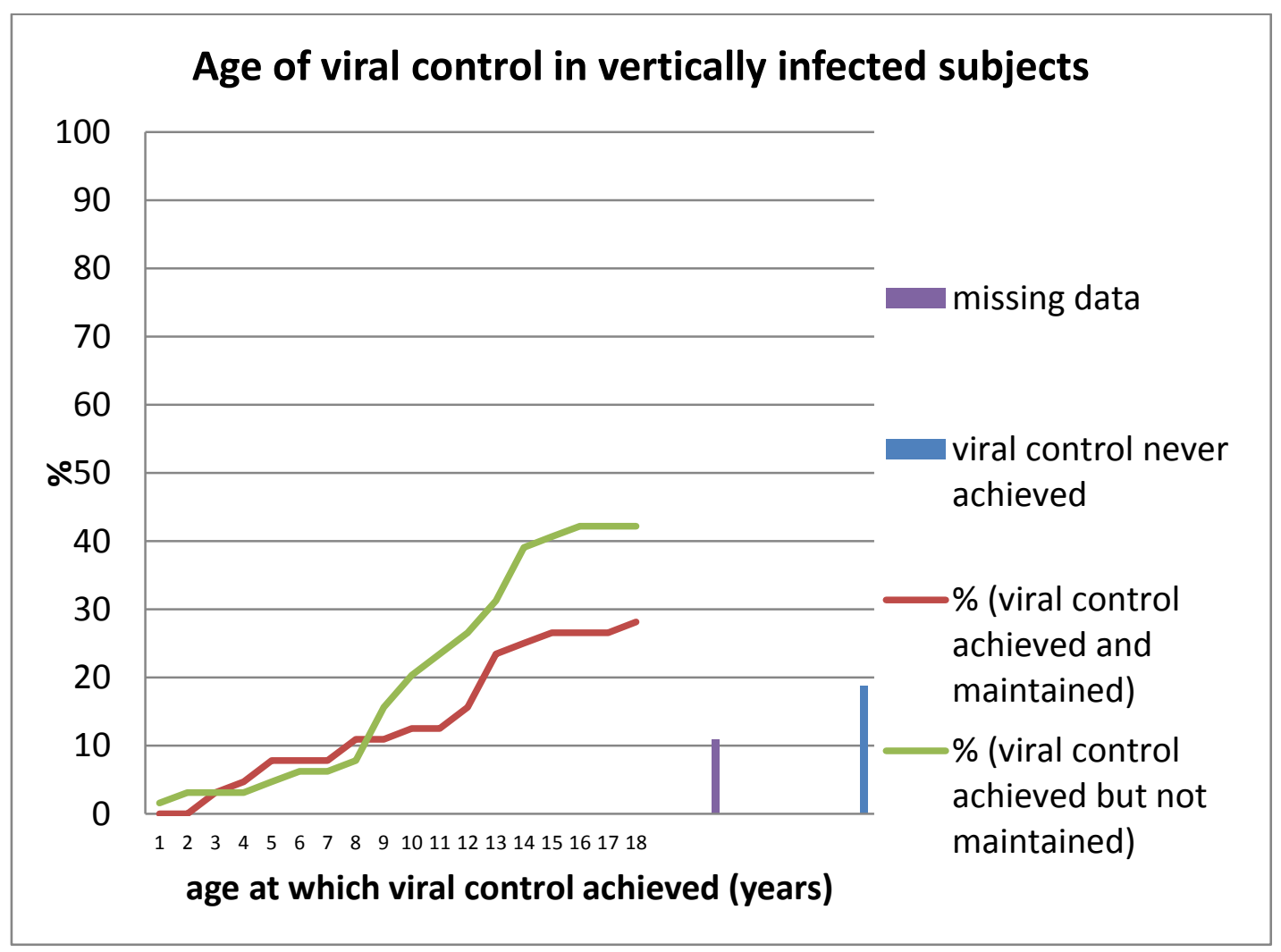

Figure 2.2. Age of viral control in HIV-V cohort.

The age at which viral control was achieved is shown. $\mathrm{n}=64$. 
Retrospective data was not available for 7 subjects because of recent arrival in the UK with incomplete documentation of medical history. 5 of these 7 subjects had documented undetectable viral load on arrival to the UK. For those patients for whom data was available, the profile was mixed. $12.5 \%$ of the cohort had achieved viral control by the age of 5 years $\left(\mathrm{HIV}-\mathrm{V}^{\mathrm{E}}\right)$ of which two thirds maintained it thereafter. $33 \%$ of the whole group had achieved viral control by the age of 10 years of which fewer than half maintained viral control subsequently and indefinitely. Approximately $28 \%$ of patients had achieved viral control and maintained this by the time of this study; $42 \%$ had documented evidence of control at a time prior to the study but failed to maintain it. $19 \%$ had never achieved viral control.

\subsection{Whole blood flow cytometry assay}

\subsubsection{Definition of B cell subpopulations by surface marker expression}

The markers used to identify $\mathrm{CD} 19^{+}$subpopulations by flow cytometry are shown in Table 2.5. 


\begin{tabular}{|c|c|c|c|}
\hline Marker & What is it? & Subpopulations & References \\
\hline CD19 & $\begin{array}{l}\text { A protein encoded by the CD19 gene, found on } \\
\text { the surface of B cells and used to identify this } \\
\text { cell population. Present from early lineage } \\
\text { development but not on mature plasma cells. } \\
\text { Acts as a B cell co-receptor in BCR-antigen } \\
\text { binding. }\end{array}$ & $\begin{array}{l}\text { Total CD19 } \\
\text { population, } \\
\text { considered to } \\
\text { identify B cells }\end{array}$ & {$[236]$} \\
\hline IgM & Membrane bound surface IgM. & \multirow{2}{*}{$\begin{array}{l}\text { Transitional cells: } \\
\mathrm{CD}^{\mathrm{hi}} \mathrm{IgM}^{\mathrm{hi}} \\
\text { Plasmablasts: } \\
\text { CD38 }{ }^{\mathrm{hi}} \mathrm{IgM}^{-}\end{array}$} & \multirow[t]{2}{*}[237,238]{} \\
\hline CD38 & $\begin{array}{l}\text { Associated with intracellular signalling. } \\
\text { Upregulated during B cell development, in B cell } \\
\text { activation and in pre-plasma cell (plasmablast) } \\
\text { differentiation. }\end{array}$ & & \\
\hline IgD & Membrane bound surface IgD. & \multirow{2}{*}{$\begin{array}{l}\text { Naïve cells: } \operatorname{IgD}^{+} \\
\mathrm{CD} 27^{-} \\
\text {Marginal zone } \\
\text { memory }(\mathrm{MZM}) \text { : } \\
\mathrm{IgD}^{+} \mathrm{CD} 27^{+} \\
\text {Switched memory } \\
\text { cells: } \mathrm{IgD}^{-} \mathrm{CD} 27^{+}\end{array}$} & \multirow[t]{2}{*}[90,118,119,202,237,238]{} \\
\hline CD27 & $\begin{array}{l}\text { Tumour necrosis factor receptor. Used to define } \\
\text { antigen-experienced B cells. Expressed on the } \\
\text { surface of classical B memory cells and MZM } \\
\text { cells and generally not on cells of naïve } \\
\text { phenotype. }\end{array}$ & & \\
\hline CD21 & $\begin{array}{l}\text { Also known as complement receptor } 2 \text { (CR2). } \\
\text { Present on mature B cells; binds complement } \\
\text { fragments enhancing B cell response to } \\
\text { complement fixed immune complexes and } \\
\text { antigens. }\end{array}$ & $\begin{array}{l}\text { CD21 }{ }^{\text {lo }} \text { cells: } \\
\text { CD } 38^{\text {lo }} \mathrm{CD} 21^{\text {lo }} \\
\text { Mature activated } \\
\text { cells: CD } 27^{+} \mathrm{CD} 21^{\text {lo }} \\
\text { Exhausted cells: } \\
\text { CD } 27^{-} \mathrm{CD} 21^{\text {lo }}\end{array}$ & $\begin{array}{l}{[237]} \\
{[90,193]} \\
{[59,193]}\end{array}$ \\
\hline CD10 & $\begin{array}{l}\text { Also known as the common acute lymphoblastic } \\
\text { leukaemia antigen (CALLA). Expressed on early } \\
\text { lymphoid precursors and recent bone marrow } \\
\text { emigrants with expression reflecting a range of } \\
\text { transitional states, and lost on maturation to naïve } \\
\text { mature B cell phenotype. Has enzymatic activity } \\
\text { over the intracellular concentration of signalling } \\
\text { peptides. }\end{array}$ & $\begin{array}{l}\text { Recent bone } \\
\text { marrow emigrants } \\
(\mathrm{BME}): \mathrm{CD} 10^{+}\end{array}$ & {$[53,90,124,125,193]$} \\
\hline
\end{tabular}

Table 2.5. CD19 ${ }^{+}$subpopulation markers. 


\subsubsection{Development of the twelve colour flow cytometry assay}

A twelve colour panel for flow cytometric assay was developed and optimised [239-241].

\section{Sourcing of antibody conjugates}

In order to examine all the subpopulations of interest, and to assess expression of markers of apoptosis, turnover and proliferation on each, it was necessary to incorporate eleven antibody conjugates and one viability dye into the flow cytometry panel. In order to achieve maximal resolution of individual markers, it was important to minimise spectral overlap of the fluorochromes used. Due to limited commercial availability of the required conventional antibody conjugates, Qdot ${ }^{\circledR}$ nanocrystal conjugates were used in some cases. These are particles with unique fluorescence properties, emitting a light colour dependent on particle size. Their emission peaks are narrow and symmetrical, and they are photostable. In the case of CD21, selfconjugation of the antibody to a $\mathrm{Qdot}{ }^{\circledR}$ was performed, as no commercial reagent was available.

\section{Antibody staining of samples}

Fluorochromes were selected for maximal sensitivity and minimal spectral overlap [242]. Appropriate antibody concentration for optimal staining was determined in each case by titration studies, as shown in Table 2.6. 


\begin{tabular}{|l|l|}
\hline Antibody & Titre in whole blood \\
\hline Extracellular staining & \\
\hline CD19-PeCy7 & $1: 33$ \\
\hline IgM-APC & $1: 10$ \\
\hline IgD-Alexa Fluor 700 & $1: 50$ \\
\hline CXCR5-PerCPCy5.5 & $1: 33$ \\
\hline CD95-Pacific Blue & $1: 20$ \\
\hline CD38-QDot $₫ 605$ & $1: 200$ \\
\hline CD27-QDot $® 655$ & $1: 100$ \\
\hline CD10-QDot $₫ 800$ & $1: 50$ \\
\hline CD21-QDot $₫ 705$ & $1: 200$ \\
\hline Intracellular staining & \\
\hline Ki67-FITC & $1: 20$ \\
\hline Bc12-PE & $1: 33$ \\
\hline
\end{tabular}

Table 2.6. Antibody conjugate concentrations used in flow cytometric assay.

\section{Controls and validation studies}

\section{Use of a viability dye to ensure exclusion of dead cells}

It is important to exclude dead cells from flow cytometric analysis, as dead cells may bind antibody non-specifically. A viability dye [243] was incubated with whole blood prior to cell staining. Studies over five days were performed to confirm that the dye identified dead cells effectively (Figure 2.3). The proportion of live lymphocytes was reduced in whole blood after 5 days of storage at room temperature, as expected. 

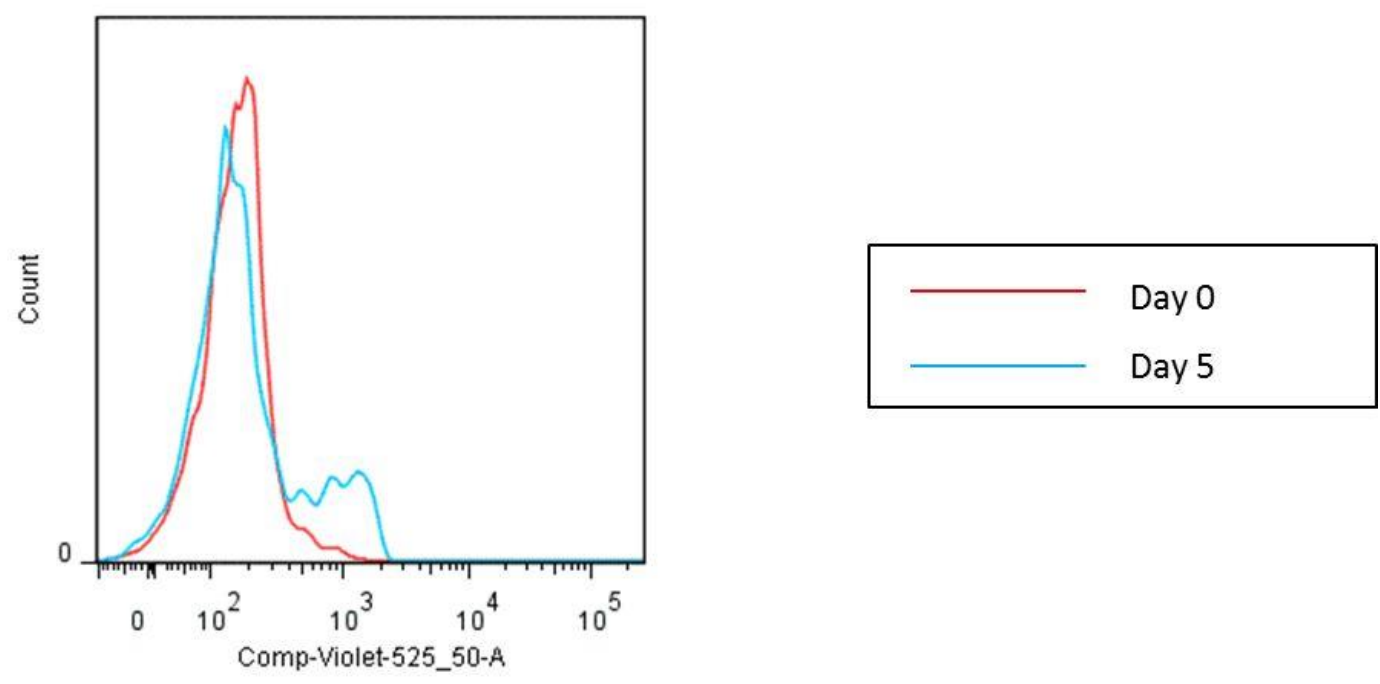

Figure 2.3. Cell viability studies.

Blood from a healthy control subject stained with amine viability dye at D0 and D5, showing a reduction in viable lymphocytes after 5 days.

\section{Use of compensation controls to reduce the impact of "fluorescence spillover"}

Compensation is the process by which the fluorescence "spillover" originating from other fluorochromes is subtracted as a percentage of the fluorescence signal from the fluorochrome of interest. Compensation was performed automatically using Flowjo software, version 7.6.4 (Treestar Inc.) [244]. Typical compensation plots for a single fluorochrome in a healthy control subject are shown in Figure 2.4. These were performed for each fluorochrome each time an assay was performed, using compensation beads (BD Biosciences, UK). Spectral overlap cannot be eliminated entirely, especially with a panel of twelve colours as used here, and does result in a reduction in sensitivity resolution, but with careful choice of fluorochromes and accurate compensation this can be minimised. 

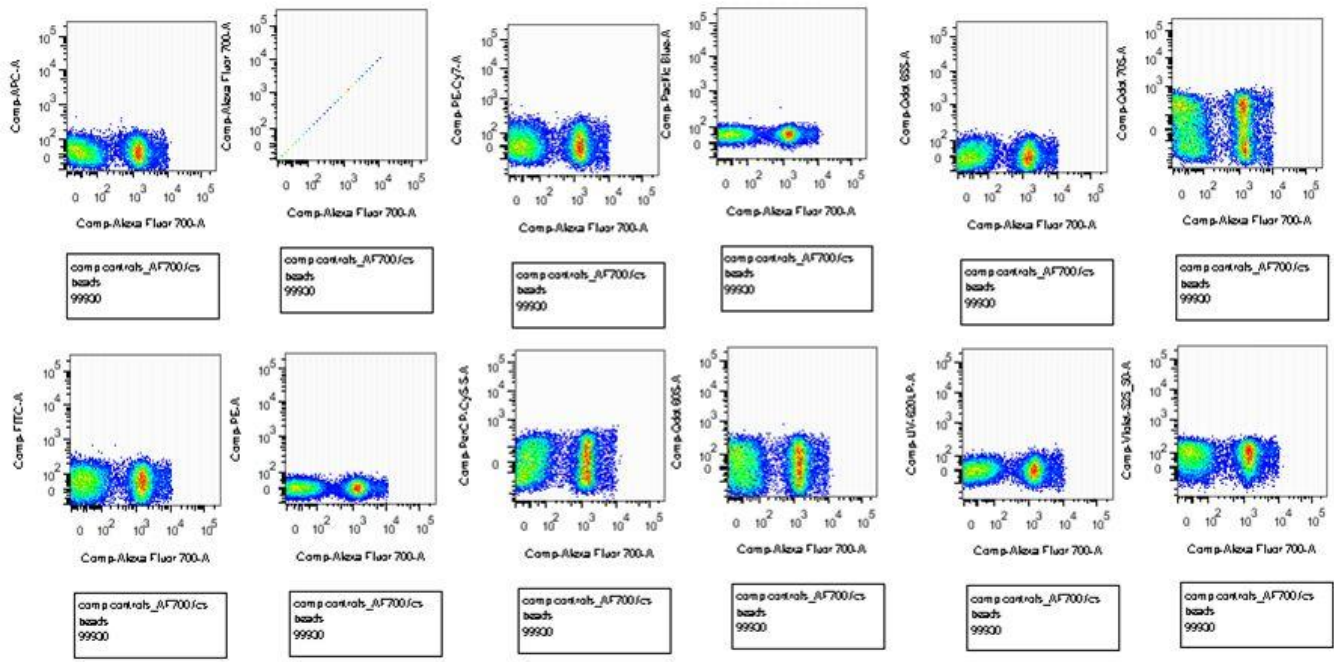

Figure 2.4. Compensation plots.

Plots are shown for a single fluorochrome (Alexa Fluor 700). Compensation was performed automatically using Flowjo software (Treestar Inc.).

DISCARD THIS PAGE 


\section{Monostain controls}

Monostain controls were used to ensure that the positive staining on a single fluorochrome was not affected by its use in combination with other stains, ie: that the multistain reflects the "true staining pattern" for individual fluorochromes. This was tested as part of validation of the assay: the staining of each fluorochrome used individually on the $\mathrm{CD} 19^{+}$population was compared to the result seen when the stain was used in conjunction with all fluorochromes in the assay. Monostain controls for a single fluorochrome are shown in Figure 2.5.
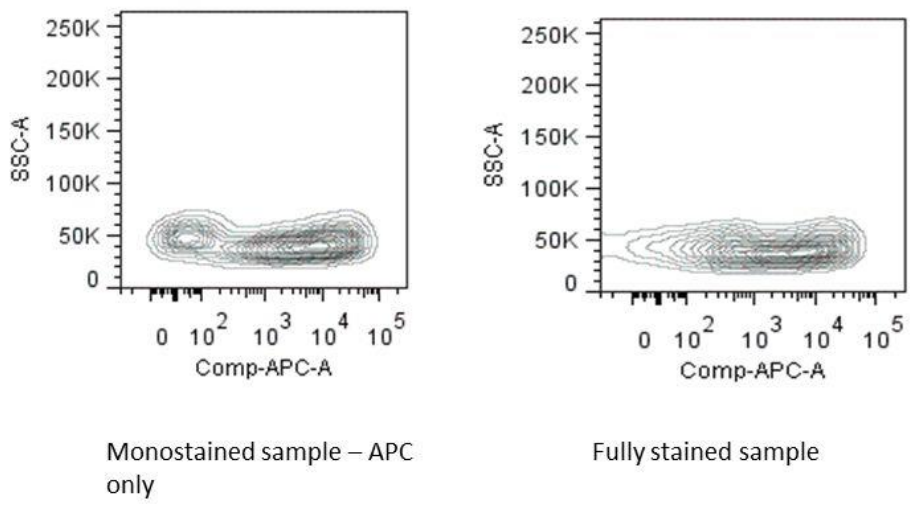

Figure 2.5. Monostain control.

Monostain controls are shown for a single fluorochrome (APC). The staining pattern of this fluorochrome on $\mathrm{CD} 19^{+}$cells was accurately represented within the multistain, when compared to the monostain.

\section{"Fluorescence minus one" controls}

"Fluorescence minus one" (FMO) controls were used to determine the threshold of positivity for each fluorochrome within the multistain [239,244]. When using a single stain, unstained cells may be used for this purpose. However, when multiple stains are used, it is important to be sure that the threshold of positivity is not affected by spectral overlap from other fluorochromes, thus a "negative control" from which to identify positive staining consists of a sample in which the appropriate cells are stained with all fluorochromes except the one of interest. In validating the assay, FMO controls were performed for all fluorochromes. It was not possible to repeat FMO controls for each fluorochrome every time an assay was performed, due to limitations of time and cost. In any case, the $\mathrm{CD} 19^{+}$subpopulations were, in the main, easily identifiable by eye. However, in the case of the $\mathrm{CD} 10^{+}$subpopulation, a distinct positive population was difficult to identify, so, in this case, an FMO control was performed with every assay (Figure 2.6). 


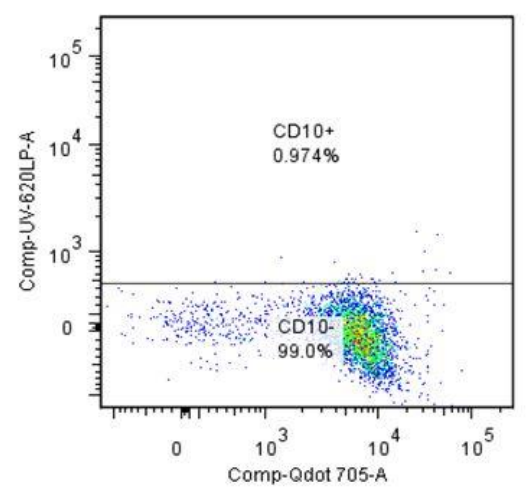

Fluorescence minus one control: sample stained with all stains apart from that used to identify $\mathrm{CD} 10^{+}$cells. This FMO control was used to set the the gate for positivity for this marker

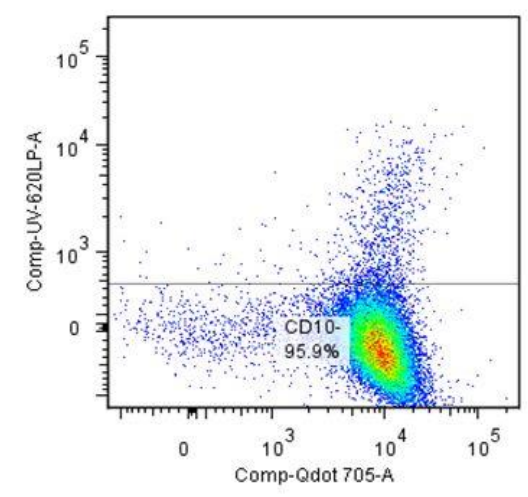

Fully stained sample, using the gate set onthe FMO control to identify CD $10^{+}$cells

Figure 2.6. "Fluorescence minus one" control.

Shown for Qdot 800, the fluorochrome used to identify CD10 ${ }^{+}$cells.

\section{Positive controls}

For those markers not expressed normally on $\mathrm{CD} 19^{+}$cells, such as Ki67, which is only minimally expressed on most healthy resting B cells, a positive control was required to ensure the fluorochrome-conjugated antibody was effective in detecting a positive population, should one be present. To check this, lymphocytes in whole blood were induced to proliferate by addition of CpG-Sac. Ki67 staining in these proliferating cells was compared to that in resting non-stimulated cells (Figure 2.7) to ensure that a population positive for Ki67 was identified.
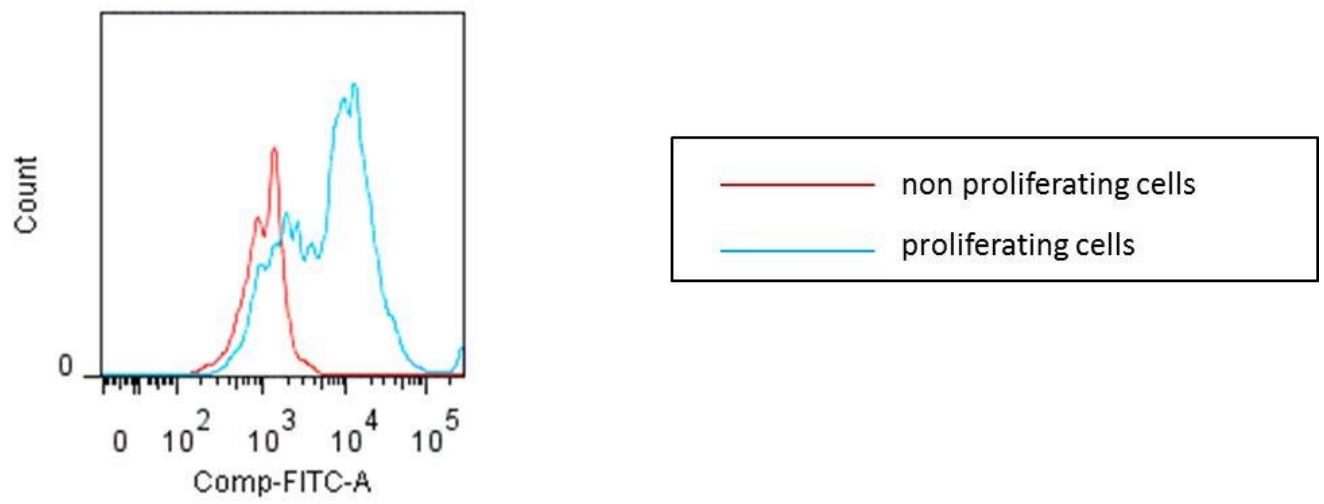

Figure 2.7. Proliferation control.

Ki67 staining is shown both on non-proliferating cells and on cells induced to proliferate by addition of CpGSAC . Ki67 expression is greater on the proliferating cells. 


\subsubsection{Flow cytometry staining protocol}

$200 \mu \mathrm{l}$ of whole blood was washed twice with $2 \mathrm{ml}$ of phosphate buffered saline by centrifuging first at $3000 \mathrm{rpm}$ for 10 minutes, followed by careful removal of supernatant and a second centrifugation at $1500 \mathrm{rpm}$ for 5 minutes. The resulting cell pellet was mixed with $2 \mu \mathrm{l}$ of a viability dye at room temperature [243], incubated in the dark at room temperature for 30 minutes, followed by washing of the cell pellet in a solution of $0.5 \%$ bovine serum albumin in PBS by centrifugation at $1500 \mathrm{rpm}$ for 5 minutes and removal of the cell pellet.

The washed cell pellet was then mixed well with a mastermix of extracellular staining antibodies and incubated for 15 minutes at room temperature in the dark. The cells were lysed by adding $2 \mathrm{ml}$ whole blood lysis buffer for 15 minutes, washed twice by centrifugation at $1500 \mathrm{rpm}$ for 5 minutes in $1 \mathrm{ml} 0.5 \%$ bovine serum albumin in PBS, fixed by addition of $150 \mu \mathrm{l}$ of cell fixing solution and left in the dark for 10 minutes. Intracellular staining was performed by permeabilising cells by centrifugation at $1800 \mathrm{rpm}$ for 5 minutes in $2 \mathrm{ml}$ of a permeabilisation buffer $(0.5 \%$ bovine serum albumin in PBS with addition of Saponin to a final concentration of $0.1 \%$ ). Supernatant was removed, and cell pellets incubated with a mastermix of intracellular antibodies for 30 minutes at $4{ }^{\circ} \mathrm{C}$ in the dark, before centrifugation at $1800 \mathrm{rpm}$ for 5 minutes in $2 \mathrm{ml}$ of $0.5 \%$ bovine serum albumin in PBS. The cells were fixed once more by addition of $50 \mu \mathrm{l}$ of cell fixing solution and kept in the dark until analysis.

Controls were also prepared. For each batch of samples stained, compensation beads were stained for all fluorochromes (including the viability dye), according to manufacturer's instructions. In addition, one unstained sample was also prepared and a single "fluorescence minus one" control was prepared, stained with all fluorochromes except CD10-QDot $® 800$.

\subsubsection{Analysis of flow cytometry data}

Analysis was performed immediately using the LSRII (BD Biosciences, UK) with FacsDiva $^{\mathrm{TM}}$ (BD Biosciences, UK) software. Dead cells, which may bind antibody 
non-specifically, were excluded by gating on the viability signal, and lymphocytes were gated on forward and side scatter. Doublet cells were excluded [245], as these "clumped" cells may bind antibody erratically; only those cells passing the laser in single file were included, ie those in which height and area are directly proportional to one another. $\mathrm{CD} 19^{+}$cells were then gated on side scatter vs CD19-PeCy7, and a minimum of 10,000 events on this $\mathrm{CD}^{+} 9^{+}$gate were collected. Initial gating strategy is shown in Figure 2.8.

i)

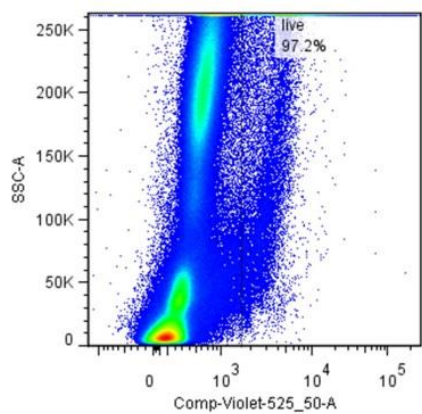

Amine viability dye

iii)

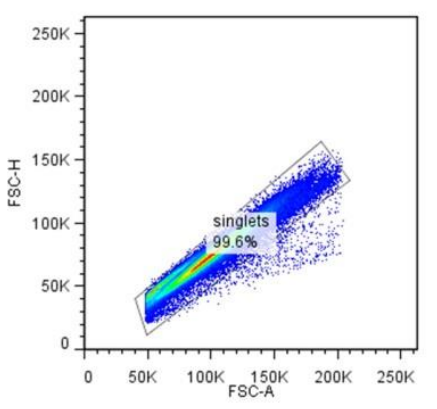

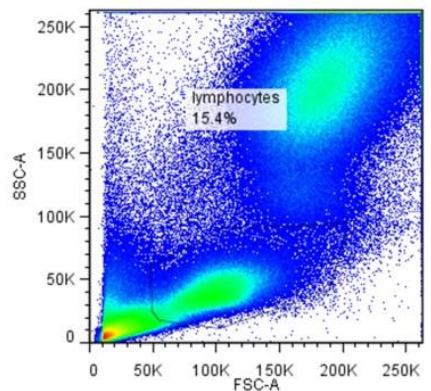

ii)

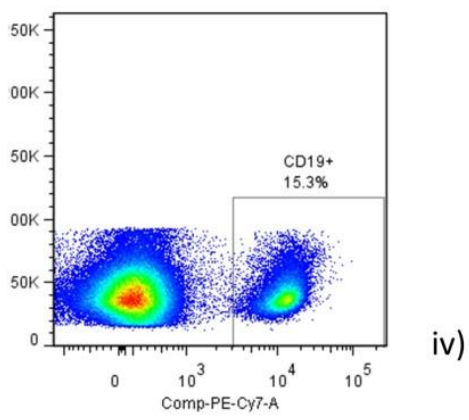

CD19

Figure 2.8. Typical flow cytometry plot showing initial gating.

Gating used to identify the $\mathrm{CD} 19^{+}$population is shown on a healthy control subject. i) exclusion of dead cells using viability dye; ii) gating on lymphocytes on forward and side scatter; iii) exclusion of doublets; iv) gating of $\mathrm{CD} 19^{+}$population.

Compensation was performed automatically using Flowjo software, version 7.6.4 (Treestar Inc.), and determined by the compensation controls [244]. Analysis of data was also performed using Flowjo software, version 7.6.4.

CD19 ${ }^{+}$cells were expressed as an absolute number of cells per microlitre of blood, which was derived from the total lymphocyte count performed in the clinical laboratory at Great Ormond Street Hospital NHS Foundation Trust and the percentage of $\mathrm{CD} 19^{+}$cells obtained by flow cytometric analysis. 
The gating strategy used for analysis is shown in Figure 2.9 (healthy control).

$\mathrm{CD} 10^{+}$cells were gated on the $\mathrm{CD} 19^{+}$population, on a plot of CD10 vs CD21 [124] (Figure 2.9, i). This gate position was set using the fluorescence minus one control (containing all stains except $\mathrm{CD} 10$ ). $\mathrm{CD} 27^{+} \mathrm{CD} 21^{\mathrm{lo}}$ and $\mathrm{CD} 27^{-} \mathrm{CD} 21^{\text {lo }}$ populations were then identified on the $\mathrm{CD}^{-} 0^{-}$population only, to ensure exclusion of $\mathrm{CD} 10^{+}$ cells, which may also be $\mathrm{CD} 27^{-} \mathrm{CD} 21^{\text {lo }}$, (reviewed in [12]) (Figure 2.9, ii). $\mathrm{CD} 38^{\mathrm{hi}} \operatorname{IgM}^{\mathrm{hi}}, \mathrm{CD} 8^{\mathrm{hi}} \operatorname{IgM}^{-}$and $\mathrm{CD} 38^{\text {lo }} \mathrm{CD} 21^{\text {lo }}$ cells were gated on the $\mathrm{CD} 19^{+}$ population (Figure 2.9, iii and iv). Finally, $\operatorname{IgD}^{+} \mathrm{CD} 27^{-}, \operatorname{IgD}^{+} \mathrm{CD} 27^{+}$and $\operatorname{IgD} \mathrm{CD}^{-} 27^{+}$ subpopulations were gated, also on the $\mathrm{CD} 19^{+}$population (Figure 2.9, v). 


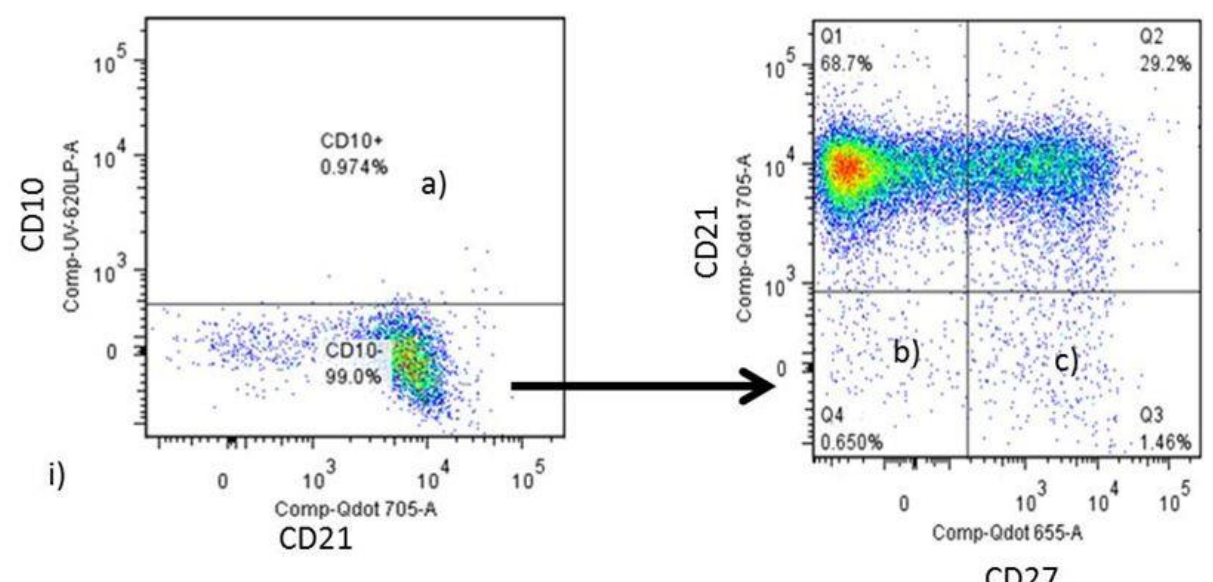

ii)
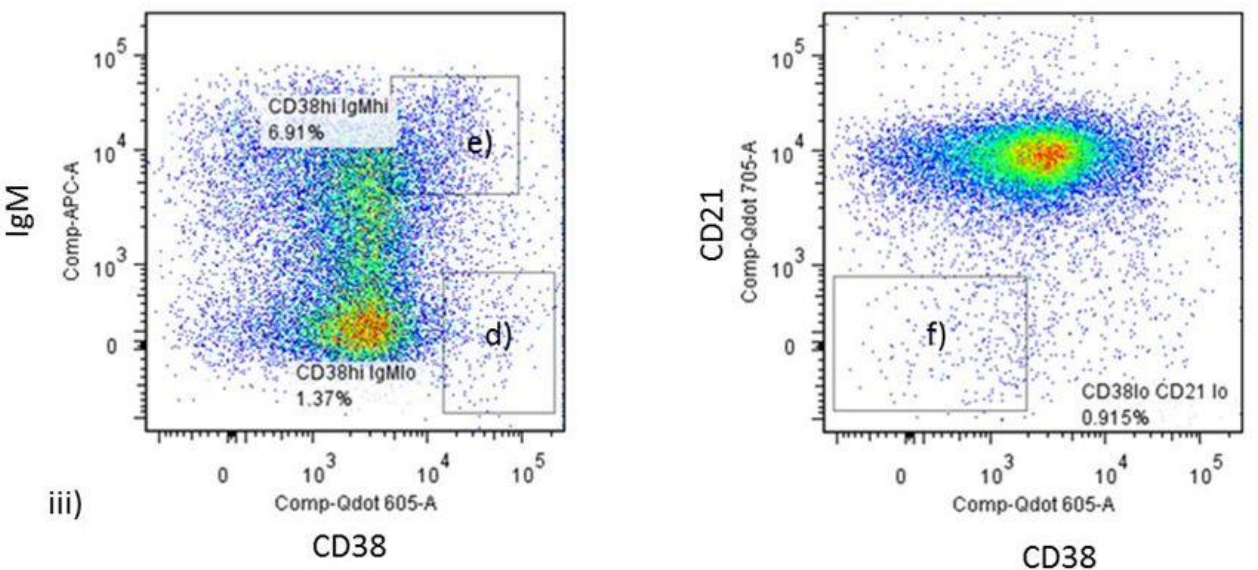

iv)

v)

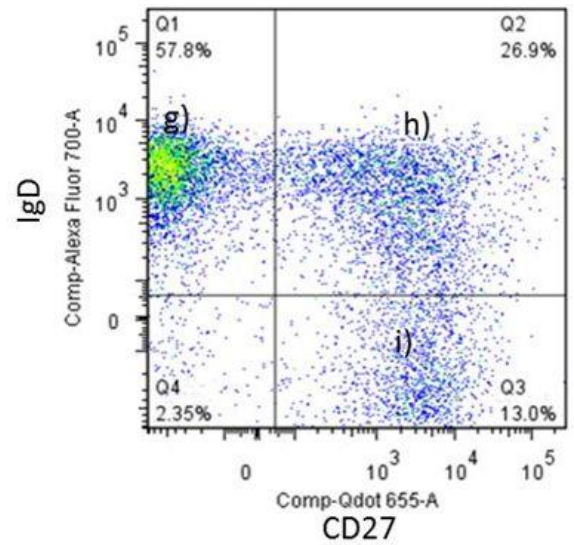

Figure 2.9. Subsequent gating to identify $\mathrm{CD} 19^{+}$subpopulations.

Gating is shown on a healthy control subject. i) $\mathrm{CD} 10^{+}$gate set on $\mathrm{CD} 19^{+}$population (based on "fluorescence minus one" control) showing immature bone marrow emigrants $\left(\mathrm{CD} 10^{+}\right.$; a); ii) gated on $\mathrm{CD}_{1} 9^{+} \mathrm{CD} 10^{-}$cells, to ensure exclusion of recent bone marrow emigrants, showing exhausted $\left(\mathrm{CD} 27^{-} \mathrm{CD} 21^{\mathrm{lo}}\right.$; b); and mature activated $\left(\mathrm{CD} 27^{+} \mathrm{CD} 21^{\text {lo }}\right.$; c) populations; iii) gated on $\mathrm{CD} 19^{+}$population, showing plasmablasts $\left(\mathrm{CD} 38^{\text {hi }} \operatorname{IgM}^{-}\right.$; d) and transitional cells $\left(\mathrm{CD} 38^{\text {hi }} \operatorname{IgM}^{\text {hi }} ;\right.$ e); iv) gated on $\mathrm{CD} 19^{+}$population, showing CD21 ${ }^{\text {lo }}$ cells $\left(\mathrm{CD} 38^{\text {lo }} \mathrm{CD} 21^{\text {lo }} ; \mathrm{f}\right)$; v) gated on $\mathrm{CD}_{1} 9^{+}$population, showing naïve $\left(\operatorname{IgD}{ }^{+} \mathrm{CD} 27^{-}\right.$; g), marginal zone memory $\left(\operatorname{IgD}^{+} \mathrm{CD} 27^{+}\right.$; h) and switched memory cells $\left(\operatorname{IgD}^{-} \mathrm{CD} 27^{+} ; \mathrm{i}\right)$. 
Expression of bcl-2, CXCR5, CD95 and Ki67 was measured in all B cell subpopulations. The gating strategy for the markers of cell behaviour in a healthy control subject is shown in Figure 2.10.

i)

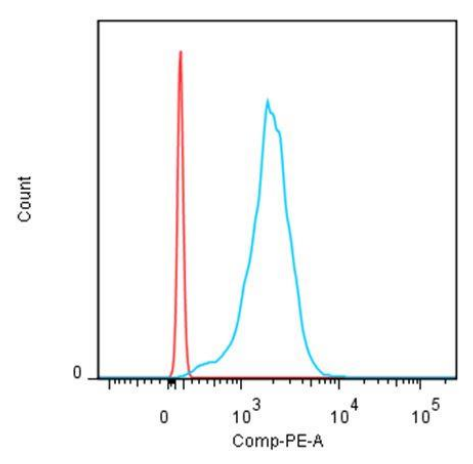

iii)

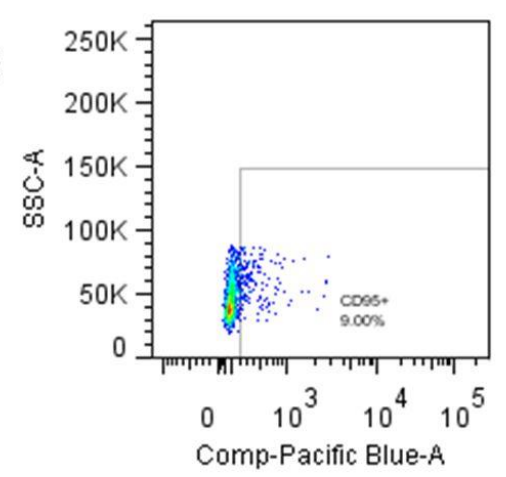

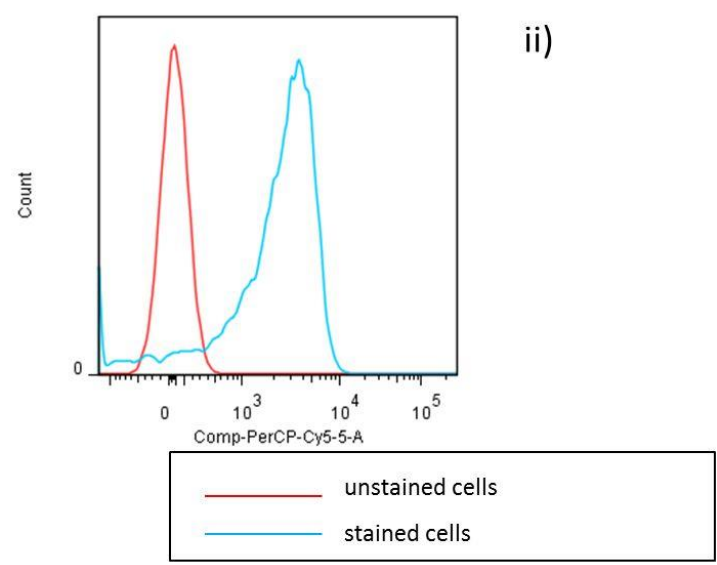

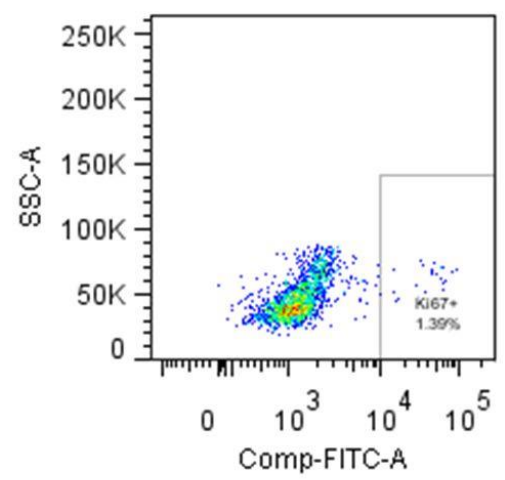

iv)

Figure 2.10. Gating of markers of turnover, apoptosis and trafficking.

Gating is shown on a healthy control subject. All markers are gated on the total $\mathrm{CD} 19^{+}$population. i) typical histogram of bcl-2 expression; expressed as median fluorescence intensity; ii) typical histogram of CXCR5 expression; expressed as median fluorescence intensity; iii) typical flow cytometry plot of CD95 expression; expressed as \% positive; iv) typical flow cytometry plot of Ki67 expression; expressed as \% positive.

Data regarding B cell subpopulations was analysed by both absolute count and percentage; the correlation was generally good thus data regarding CD19 ${ }^{+}$ subpopulations is generally expressed as percentages of the total $\mathrm{CD} 19^{+}$count. Bcl-2 and CXCR5 are expressed as median fluorescence intensity [55,58,59] (MFI), and CD95 and Ki67 as percentage of cells positive for expression of the relevant marker [53]. Comparison was performed between the CON, HIV-V and HIV-H groups. Further analysis was performed after subdivision of the patient groups based on whether HIV viraemia was detectable at the time of sampling. Vertically infected 
patients with a history of permanent viral control early in life, before the age of 10 years (early viral control; HIV $-\mathrm{V}^{\mathrm{E}}$ ) were compared to those with current, but not early-life, viraemic control $\left(\mathrm{HIV}-\mathrm{V}^{-}\right)$. Some comparisons were also performed between the HIV-H and HIV-H-RS groups.

\subsubsection{Exclusions}

Samples were excluded from analysis where the antibody staining failed ( 1 assay, all studies repeated on a subsequent sample from the same patient), or where it was not possible to obtain sufficient $\mathrm{CD} 19^{+}$cells to perform analysis (2 HIV-H subjects).

\subsection{Serum studies}

Quantification of pneumococcal polysaccharide serotype-specific $\operatorname{IgM}$ and $\operatorname{IgG}$ was performed using an established flow based multiplex assay at the Clinical Immunology laboratory, Papworth Hospital NHS Trust, Papworth Everard, Cambridge CB23 3RE. The assay, shown schematically in Figure 2.11, is based on a method described by Lal et al. in 2005 [246], in which individual carboxylated fluorescent beads were coated with serotype specific pneumococcal capsular polysaccharides (PPS) at appropriately determined concentrations (1:1.4 for serotypes $1,6 \mathrm{~B}, 9 \mathrm{~V}, 14,18 \mathrm{C}, 19 \mathrm{~F}, 23 \mathrm{~F} ; 1: 1.66$ for serotypes 4,5 and $7 \mathrm{~F}$ ) before incubation with patient serum and addition of a human antibody conjugate (at a concentration of 1:200 for $\operatorname{IgG}$ and 1:50 for $\operatorname{IgM}$ ). A pre-absorption stage with cell wall polysaccharide at a concentration of 1: 2500 [247] and serotype $22 \mathrm{~F}$ at a concentration of 1:400 [248] was also performed. Beads were then analysed by flow cytometry using a standard flow cytometer (Beckman Coulter FC500) and pneumococcal PS binding activity quantified. Data analysis, calibration, validation and report generation was performed using in-house developed software (Microsoft EXCEL). 
i)

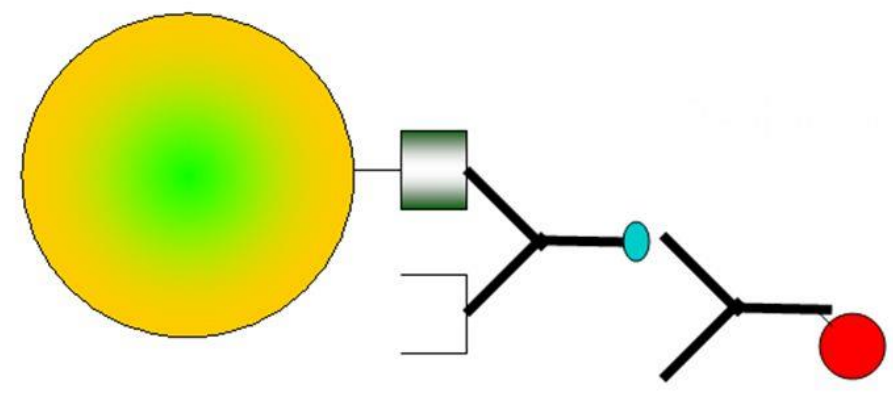

ii)

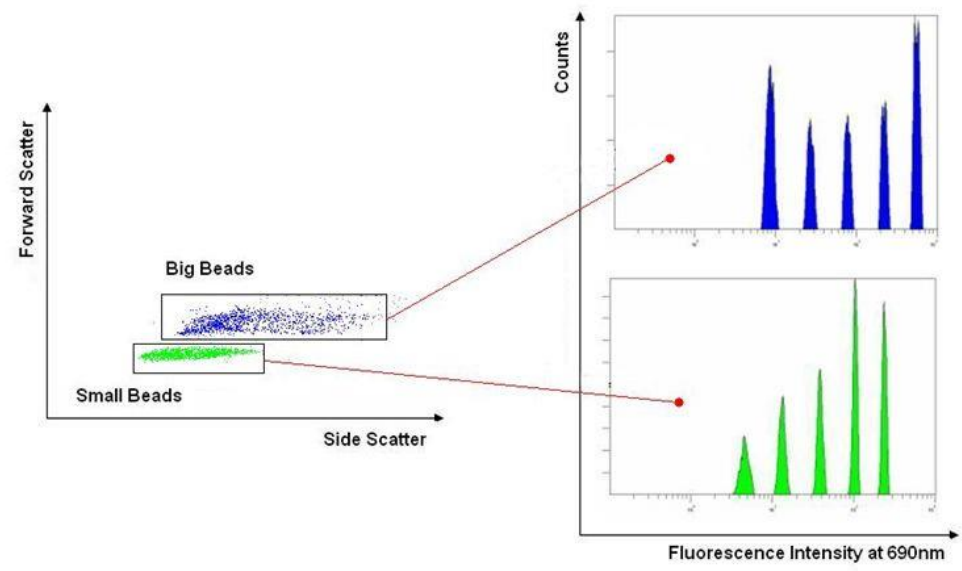

iii)

Blank beads (no antibody)

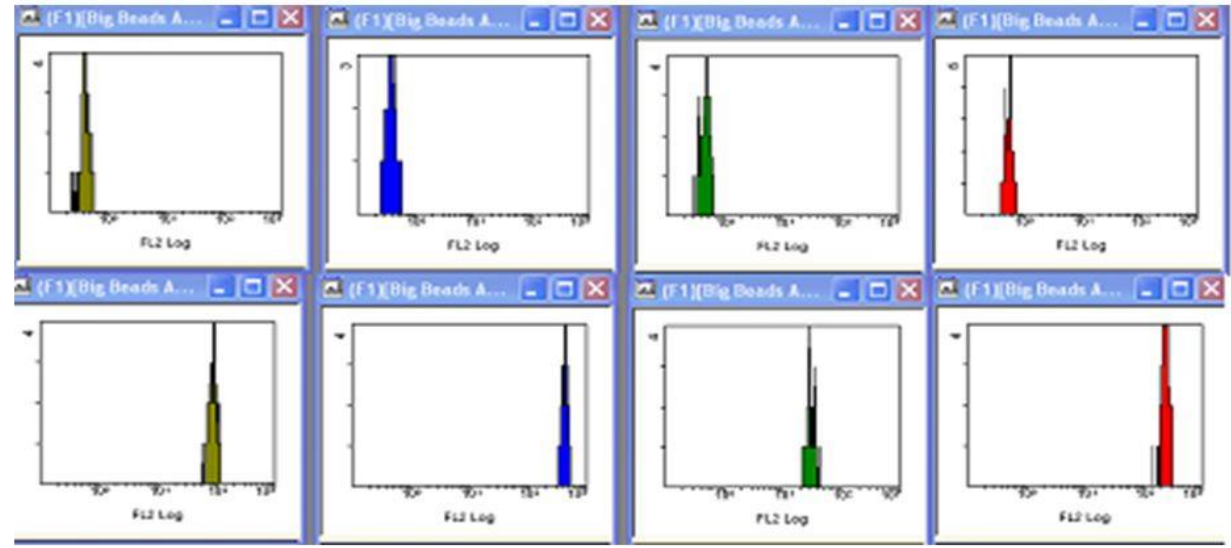

Sample positive for antibody showing fluorescence shift

Figure 2.11. Schematic diagram of the flow-based multiplex assay used for quantification of pneumococcal polysaccharide serotype-specific IgM and IgG.

i) Fluorescent beads (of two sizes and varying fluorescence intensity) coated with polysaccharide, incubated with serum and then with human antibody conjugate; ii) identification of beads by size and fluorescence intensity; iii) quantification of serotype specific anti-pneumococcal antibodies by fluorescence intensity of human antibody conjugate. 
Pnc IgM and IgG serotype-specific binding activity was assessed for 8 and 10 serotypes respectively using batched serum taken at baseline, 28 days and 1 year after immunisation with PPV, where samples were available.

Data were expressed in $\mu \mathrm{g} / \mathrm{ml}$. All values below the lower limit of detection were assigned a value of 0.01 . All values above the upper limit of detection were assigned a value of $5(\operatorname{IgM})$ and $10(\operatorname{IgG})$.

\subsection{Statistics}

Data were not normally distributed, even when log transformed, as evaluated by the Shapiro-Wilks test, and non-parametric statistical tests were used throughout. Cohort data were expressed as median values and interquartile ranges (IQR). Comparisons of continuous variables between groups were performed using the Mann Whitney U test and comparison of categorical variables was performed using the chi-squared test or Fisher's exact test (depending on sample size). Comparison of related variables in the same subject (serology data at various bleedpoints) was performed using the Wilcoxon signed rank test. Spearman's correlation coefficients were used to test correlation. Statistical analyses were performed using SPSS software, version 21 (IBM), and GraphPad Prism software (GraphPad Software Inc.), version 6. The Bonferroni correction was considered, in view of multiple comparisons performed, but was not applied. This decision was made in view of the fact that raw data is displayed, where possible, in the text and figures, with $\mathrm{p}$ values quoted. The issue of multiple comparisons is considered in the interpretation of the data and is further discussed in Chapter 5. 


\section{Chapter 3. Results: flow cytometric analysis}

\subsection{Introduction}

\subsubsection{Changes in B cell subpopulations}

Evaluation of the peripheral B cell subpopulations in vertically and horizontally HIV-infected young adults allows an assessment to be made of a possible differential immune effect on humoral immunity of HIV infection in two patient groups, those who acquired infection in early life, at the start of the process of development of adaptive immunity (HIV-V), and those acquiring infection on the background of an established mature immune system (HIV-H).

Derangement to peripheral B cell subpopulations is well documented in HIV infection. Hyperactivation, abnormal turnover, altered trafficking, disrupted apoptosis and drive towards terminal differentiation and exhaustion all contribute to changes to both the relative proportions and behaviour of various B cell types. It must be remembered that these peripheral populations offer only a "snapshot" of the overall B cell population, as the majority of B cells reside in the spleen, lymph tissue and bone marrow; nonetheless they offer a valuable insight into a range of HIVrelated immune disturbances. The changes in B cell subpopulations may be associated with reduced function, altered repertoire and overall deleterious effects on humoral immunity, as discussed in Chapter 1.

Cell surface markers used to identify subpopulations of B cells in this study are shown in Table 2.5 (Chapter 2).

\section{Depletion of mature populations}

An overall depletion of $\mathrm{B}$ cells has been reported in HIV infection in adults $[59,180,249,250]$ and in children [9,201]. Relatively few studies report on the impact on the naïve B cell population, which, in the healthy individual, comprises about 60$70 \%$ of circulating $\mathrm{B}$ cells and are required to develop de novo responses to previously unencountered antigens. Naïve cells, by definition, have an unmutated $\operatorname{IgV}$ region sequence [134], simultaneously co-express $\operatorname{IgM}$ and $\operatorname{IgD}[128,134]$ and are usually defined as $\mathrm{CD} 27^{-}$(reviewed in [251]). In adults with HIV infection, some studies have shown a relative decrease in their frequency in HIV-viraemic individuals [90] and reversal of this reduction with HAART [120]. Other studies, 
however, have shown an increase in CD27 naïve cells in drug naïve patients which normalises with viral control [51]; increased $\mathrm{CD} 27^{-}$naïve cells has also been reported in children with HIV [199] .

Depletion of existing memory populations is well established in HIV infection. As discussed in Chapter 1, B cell memory populations comprise, among others, classical memory cells and memory cells believed to represent circulating counterparts of the marginal zone memory cells of the spleen (referred to here as marginal zone memory cells). Classical memory cells are believed to comprise about $20-30 \%$ of all peripheral blood B cells in healthy individuals, but in HIV infection, several studies have shown a decrease in frequency of these switched memory B cells $[116,118,120,122,126]$, although this may only manifest in those patients with low $\mathrm{CD}^{+}$count [119]. This deficit seems not to be restored by ART [55,116,118]; indeed, effective ART may in fact reveal an underlying depletion of this cell population, not apparent in drug-naïve patients [126]. There is some evidence that early ART may prevent memory B cell loss [52,193]. The depletion of the marginal zone memory population has also been shown in peripheral blood in adults with HIV infection, although it remains controversial whether this depletion is reversed by ART $[118,119]$. This finding in peripheral blood is supported by the demonstration of selective atrophy of the marginal zone of the spleen, where MZM B cells are generated, early after infection with HIV [252].

In HIV-infected children, the impact on switched memory populations is less clear than in adults $[177,199,202]$, with some studies showing no change [202] and others showing a decrease in switched memory populations [199]. Children with HIV have reduced MZM compared to healthy controls [199], although this depletion may only be manifest with viraemic control [202]. One study [177] has shown that in children who started ART in the first year of life, memory populations were preserved; this was not seen when ART was started after the first year.

Plasmablasts have also been shown to be affected in HIV infection. Plasmablasts are short-lived cells on a differentiation route to either short or long lived plasma cells. They have high turnover and the capacity to divide and migrate. They are found with low frequency (about 1-3\%) in adult peripheral blood and have been shown to 
increase under conditions of immune activation ([253-255], including infectious diseases, autoimmune diseases and primary immunodeficiencies [237,256,257]. HIV viraemia has been shown to result in increased numbers of terminally differentiated B cells and plasmablasts [41,127] in the circulation and increased plasmacytosis in the bone marrow [122], probably as a result of the chronic immune-activating effects of HIV replication [258]. These cells show increased Ki67 and CD95 expression in HIV infection, indicative of increased turnover and susceptibility to apoptosis respectively.

\section{Changes to immature cell populations}

Along with the reduction of effective mature cell populations, there is a tendency in HIV infection towards an increase in circulating immature cell populations. This may be a compensatory mechanism by which the bone marrow production of immature B cells increases to compensate for the depletion of mature peripheral and tissue B cells, resulting in an abnormal overspill of immature cell populations into the circulation. A population known as transitional cells has been described, expressing high levels of both CD38 and IgM. In healthy individuals, their relative number decreases significantly during the first year of life and remains low thereafter [238]. These cells have been shown to be increased in HIV infection [119] and in some types of primary immune deficiency such as CVID, when they are seen to be associated with other abnormalities also described in HIV infection, such as increased plasmablasts, reduced classical memory cells, and emergence of abnormal populations [237].

A heterogeneous population of immature B cells, recently emigrated from the bone marrow to the peripheral circulation, has also been defined by varying degrees of CD10 expression [259]. These immature cells are thought to comprise about 2-4\% of all B cells in healthy individuals [260,261] and to exhibit phenotypic features of immature B cells with a lower ability to proliferate and differentiate to antibodysecreting cells after in vitro stimulation, as compared with naïve mature B cells $[260,261]$. This population of recent bone marrow emigrants has been shown to be expanded in conditions with impaired humoral immunity such as systemic lupus erythematosus (SLE) [260,261]. In HIV infection, an increase in these immature cells was described as early as 1987 [123] in AIDS patients. It has been subsequently 
shown that these cells may account for as much as $30 \%$ of peripheral blood B cells in active HIV disease in adults [124], a finding which has been confirmed by many others [53,54,126,262], and is seen in children [125,200]. It has also been described in other conditions associated with $\mathrm{CD}^{+}$depletion such as idiopathic $\mathrm{CD} 4^{+} \mathrm{T}$ lymphocytopenia [263]. The mechanistic explanation for increased immature B cell in the circulation in states of immune activation is unclear and presumably reflects altered turnover and survival in the B cell population. A putative mechanism in the context of $\mathrm{CD}^{+}$lymphopenia may involve an association between low $\mathrm{CD} 4^{+}$counts and increased serum levels of interleukin-7 (IL-7) [264]. IL-7 is known to induce the proliferation of human B cell precursors [265] and IL-7 mediated signalling is impaired in idiopathic CD4+ lymphocytopenia [266]. It has been shown that high serum levels of IL-7 directly correlate with increased frequencies of immature transitional B cells in the peripheral blood of HIV-infected individuals, which, in turn, correlate with HIV viraemia [124].

\section{Abnormal expansion of populations}

In addition to the depletion of mature $\mathrm{B}$ cell populations, and the possibly compensatory increase in immature B cell populations, there is evidence for abnormal expansion of some B cell populations in HIV infection, often characterised by low CD21 expression, which are seen only at very low frequency in healthy individuals $[267,268]$. These $\mathrm{CD} 21^{\text {lo }} \mathrm{B}$ cells have been shown to increase in various disease states including rheumatoid arthritis [269], CVID [270,271], SLE [272-274] and hepatitis C mixed cryoglobulinaemia [275] and have also been identified in HIV infection [45], considered likely to represent two abnormal subpopulations, which can be subdivided by CD27 expression (reviewed in [276] and discussed below).

$\mathrm{CD} 27^{+} \mathrm{CD} 21^{\text {lo }}$ expressing cells have been described as mature activated B cells $[53,90]$ and comprise less than $5 \%$ of circulating B cells in healthy individuals. In viraemic HIV-infected individuals they may exceed $25 \%$ of the circulating B cell compartment [59]. This expansion has been shown in a longitudinal study to be reversible with ART [59], consistent with findings that they are found at normal level in those HIV-infected patients who are aviraemic. These cells appear to have plasmacytoid features, to spontaneously secrete immunoglobulins (perhaps 
accounting for the hypergammaglobulinaemia seen in HIV infection), to be associated with HIV-induced activation, to bear elevated markers of turnover and have a high susceptibility to extrinsic apoptosis $[41,45,53]$.

In addition to these $\mathrm{CD} 27^{+}$expressing mature activated cells, a further population of cells expressing low levels of CD21 exists, which, conversely, do not express CD27. These cells have been described as an exhausted subpopulation [59] and were initially characterised by identification of a subpopulation of memory B cells in human tonsils [268] that expresses the inhibitory receptor Fc-receptor-like 4 $\left(\mathrm{FCRL} 4^{+}\right)$. Following this discovery, increased expression of $\mathrm{FCRL}^{+}$by peripheral blood-derived $\mathrm{CD} 27^{-} \mathrm{CD} 21^{\mathrm{lo}}$ mature B cells in HIV-viraemic (but not HIV-aviraemic or HIV-negative) individuals was demonstrated [59]. These cells were found to display many features of immunological exhaustion, including altered trafficking, and a stunted replication history and an increased expression of inhibitory receptors [277], which is a feature of persistent-virus-induced T cell exhaustion [96]. The expansion of this B cell population in untreated patients with preserved $\mathrm{CD} 4^{+}$counts suggests that the emergence of this population may precede the $\mathrm{CD} 4^{+}$decline [278].

\subsubsection{Altered expression of markers of apoptosis, turnover and trafficking}

HIV infection is associated with various changes in the behaviour of circulating B cells in HIV infection, as discussed in Chapter 1. Overall, there is an increased tendency towards programmed cell death, with increased turnover in some populations, and alterations in the trafficking of B cells between the periphery and the lymphoid tissues. These mechanisms may contribute to the altered subpopulation distributions discussed above.

As discussed in Chapter 1, CD95 (Fas) is a death receptor involved in the removal of activated immune cells as part of the process of extrinsic apoptosis. In healthy individuals, CD95 is weakly expressed on immature B cells and is expressed on 5$25 \%$ of mature peripheral blood B cells, with increasing positivity in more mature and activated cells (reviewed in [279]). CD95 expression has been shown to be increased on B cells of HIV-infected individuals [41], including immature, naïve, 
memory and exhausted B cells [51-53,55,116]. Effect of ART on this increase in extrinsic apoptosis is controversial: some studies show that it is not reversed by ART [54] but others suggest a direct correlation between CD95-mediated apoptosis and HIV viraemia and/or reduction with ART [41,51,53,55], though ART-mediated improvement may be only partial in the case of memory cells $[52,55]$. Only a small reduction in plasma Fas levels has been described following a year of HAART treatment in HIV adults. [116].

Bcl-2 is an anti-apoptotic protein which is, in healthy individuals, expressed differentially at different stages of B cell development; it is highly expressed in proB cells and mature B cells but downregulated at the pre-B stage of development. In HIV infection, bcl-2 protein expression has been shown to be reduced on naïve and immature cells (in HAART-naïve but not in treated patients) and correlated negatively with degree of activation as shown by CD38 expression [51,52]. No difference in bcl-2 expression was seen in $\mathrm{CD} 27^{+}$memory cells between treatmentnaïve patients, those on HAART and healthy controls, all of whom express high levels of bcl-2 suggesting resistance to apoptosis [55].

Cell turnover has been shown to be increased in HIV infection $[49,93]$. The expression of Ki67, a nuclear protein expressed in proliferating cells has been shown, ex vivo, to be a useful marker for cell turnover [93] and is increased in those cells demonstrating high levels of activation and differentiation, mature activated cells and plasmablasts [41,53], probably reflecting a drive towards terminal differentiation and exhaustion.

Abnormal B cell trafficking has been extensively discussed in Chapter 1. CXCR5 is a chemokine receptor important in recruiting $\mathrm{B}$ cells to lymph nodes to enable development of the classical memory response. It is expressed by all mature B cells [280], particularly circulating naïve cells [253,281], maintained on memory B cells $[114,282]$ and lost on plasma cells which are not thought to re-circulate through lymphoid tissue [253]. Abnormal reduction of CXCR5 expression has been demonstrated on several B cell subpopulations in HIV infection, including naïve B cells [51,58], mature, memory and pre-plasma cells [58] and exhausted cells [59] suggesting that HIV infection alters B cell trafficking. This reduction in CXCR5 expression appears to be due to internalisation of the CXCR5 receptor induced by 
upregulation of the gene encoding its ligand, CXCL13 [58]. It has been suggested that this may, in vivo, reflect abnormally high CXCL13 expression, particularly by immature dendritic cells, leading to an increase in B cell migration to areas of inflammation and immune activation, which may result in impairment of normal migration towards the germinal centre.

Some of the changes to B cell subpopulations and behavioural markers associated with HIV infection are reversible with viral control [41,59,90,193], discussed fully in Chapter 1 and shown in Table 1.4. However, changes to memory cell populations may not be fully reversed even with effective antiretroviral therapy [90,116,118,119], and there is some evidence that viral control early in life may be important in those individuals infected from childhood, in preventing damage. The impact of growing up with HIV with and without viral control on B cell lineage and behaviour is not known, and although existing studies have examined the impact of HIV on the B cell compartment in both adults (presumably mostly horizontally infected) and children (presumably infected by the vertical route), no direct comparison has been performed of these two distinct groups. This study compares the two groups both with healthy controls and with one another, in order to examine whether these two groups suffer a different impact of HIV infection in terms of their B cell phenotype and behaviour.

\subsection{Methods}

The methods are fully described in Chapter 2, section 2.8.

In brief, a single $2 \mathrm{ml}$ blood sample was taken from each study participant and analysed by flow cytometry. A twelve colour flow cytometry panel was designed to evaluate naïve and memory (marginal zone and switched) cells, plasmablasts, immature and $\mathrm{CD} 21^{\text {lo }} \mathrm{B}$ cell populations. Markers of apoptosis, turnover, and B cell trafficking were also assessed. Whole blood was stained with appropriate concentrations of fluorochrome-conjugated antibodies. Appropriate controls were included (see Appendix). Data was analysed using the LSRII (BD Biosciences, UK) with FacsDiva $^{\mathrm{TM}}$ (BD Biosciences, UK) software. Compensation was performed automatically and analysis of data was performed using Flowjo software, version 
7.6.4 (Treestar Inc.). Data was also collected regarding viral load, $\mathrm{CD}^{+}$count and total lymphocyte count from the same blood sample.

Data for B cell subpopulations is shown as a median percentage of the total population of B cells, as discussed in Chapter 2. The changes in B cell subpopulations were also measured in terms of absolute cell count; these were broadly similar to the changes in percentage.

Expression of bcl-2, CXCR5, CD95 and Ki67 were measured in all B cell subpopulations. Patterns of change were similar among all populations, and were reflected, overall, by the patterns of change found on the total $\mathrm{CD} 19^{+}$population; data is therefore reported for the total $\mathrm{CD} 19^{+}$population only. Bcl-2 and CXCR5 are expressed as median fluorescence intensity (MFI), and CD95 and Ki67 as percentage of cells positive for expression of the relevant marker, as discussed in Chapter 2.

\subsection{Results}

To evaluate whether the effect of HIV on B cell populations is similar in young adults who have grown up with HIV infection compared with those who acquired infection in adult life, flow cytometric analysis was used to examine peripheral B cell subpopulations in each of three groups. The subject groups and samples included in the flow cytometric analysis are shown in Table 3.1 .

\begin{tabular}{|l|l|l|l|l|}
\hline & \multicolumn{4}{|l|}{ HIV infected subjects } \\
\hline & CON & HIV-V & HIV-H & HIV-H-RS \\
\hline N & 47 & 53 & 27 & 9 \\
\hline Viral load undetectable at time of sample (n) & & 33 & 17 & 3 \\
\hline Viral load detectable at time of sample (n) & & 20 & 9 & 4 \\
\hline Viral load unknown (n) & & 0 & 1 & 2 \\
\hline
\end{tabular}

Table 3.1. Samples included in flow cytometric analysis.

\subsubsection{Overview}

The total B cell count was similar between healthy control and vertically infected patients and HIV-H had lower counts than both the CON and HIV-V populations; 
when analysed by VL control, in horizontal infection, there was a reduction in absolute B cell count where viral load was not controlled ( $\mathrm{p}=0.009$; Figure 3.1).

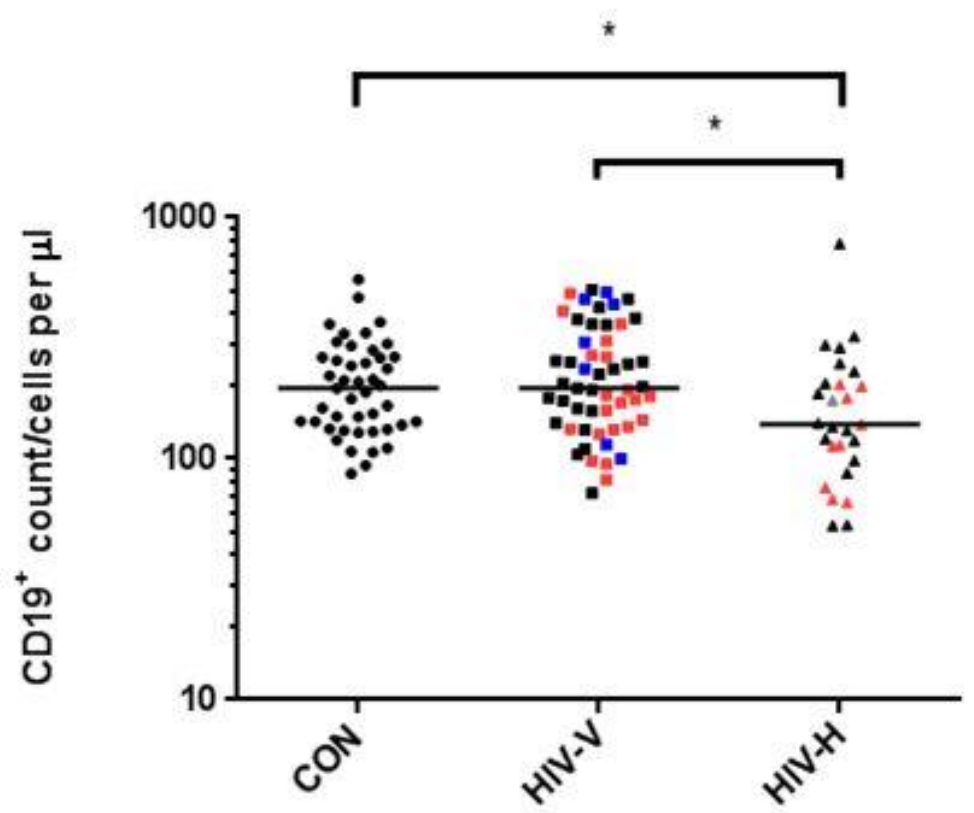

Figure 3.1. $C D 19^{+}$absolute cell count in all groups.

The median is indicated. Red indicates current detectable VL $\left(\mathrm{HIV}-\mathrm{V}^{+}\right.$and $\left.\mathrm{HIV}-\mathrm{H}^{+}\right)$; blue indicates maintained viral control $<10 \mathrm{y}$ of age in the vertically infected group $\left(\mathrm{HIV}-\mathrm{V}^{\mathrm{E}}\right)$; grey indicates VL status unknown. * $\mathrm{p} \leq$ 0.05 .

An example of flow cytometry plots from a typical control and HIV-infected patient is shown in Figure 3.2. 


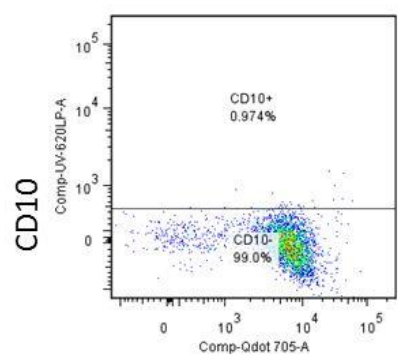

CD21
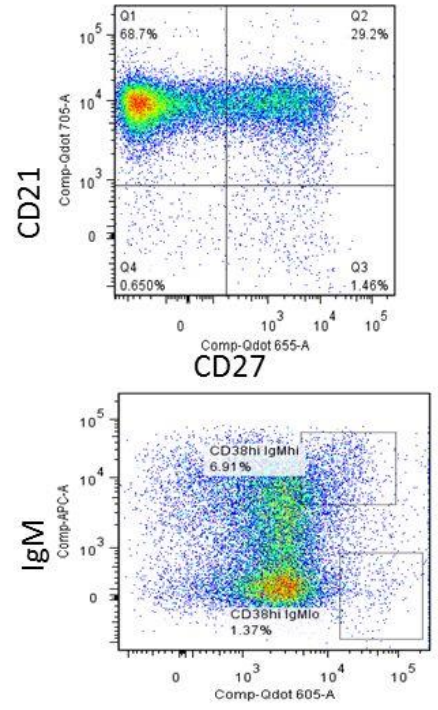

CD38

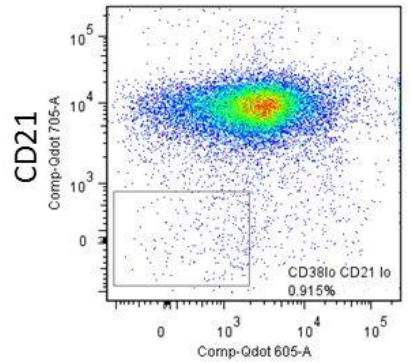

$\mathrm{CD} 38$

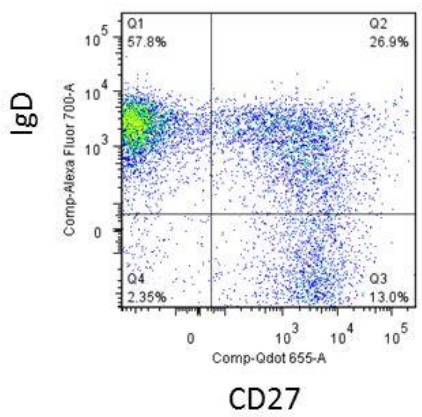

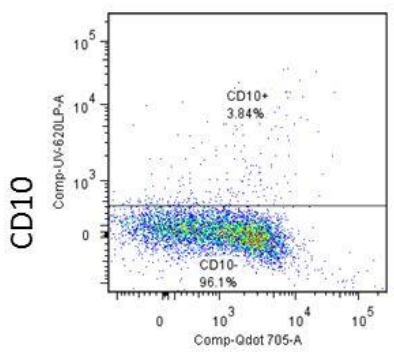

i)

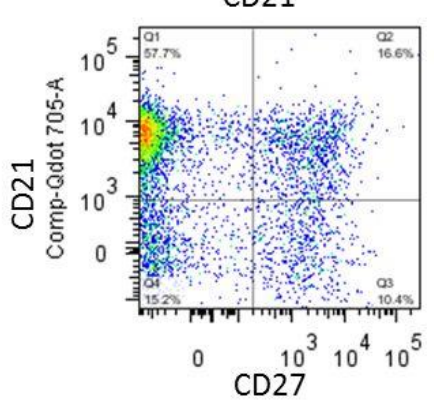

ii)

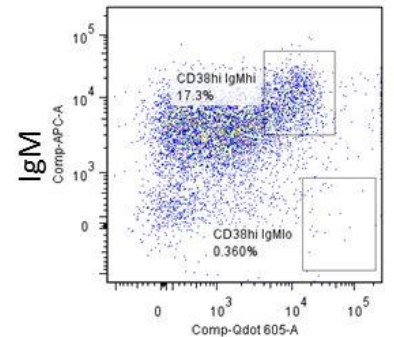

$\mathrm{CD} 38$

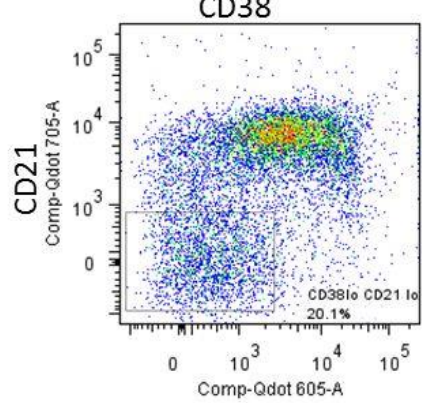

$\mathrm{CD} 38$

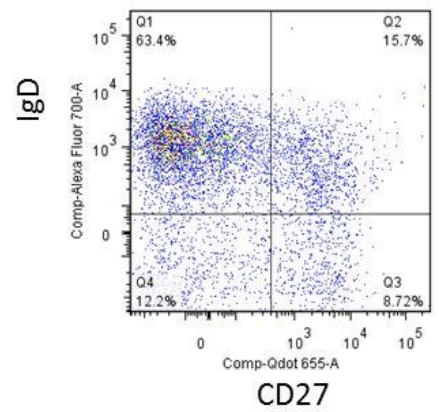

iii)

iv)

v)

Figure 3.2. Typical flow cytometry plots showing $C D 19^{+}$subpopulations in a healthy control (left) and HIV-infected subject (right).

i) $\mathrm{BME}\left(\mathrm{CD} 10^{+}\right)$; ii) mature activated $\left(\mathrm{CD} 27^{+} \mathrm{CD} 21^{\mathrm{lo}}\right)$ and exhausted $\left(\mathrm{CD} 27^{-} \mathrm{CD} 21^{\mathrm{lo}}\right) \mathrm{B}$ cells; iii) plasmablasts $\left(\mathrm{CD} 38^{\mathrm{hi}} \mathrm{IgM}^{-}\right)$and transitional cells $\left(\mathrm{CD} 38^{\mathrm{hi}} \mathrm{IgM}^{\mathrm{hi}}\right)$; iv) $\mathrm{CD} 21^{\mathrm{lo}} \mathrm{B}$ cells $\left(\mathrm{CD} 38^{\mathrm{lo}} \mathrm{CD}^{2} 1^{\mathrm{lo}}\right)$; v) naïve $\left(\operatorname{IgD}{ }^{+} \mathrm{CD}^{2} 7^{-}\right)$, marginal zone memory $\left(\operatorname{IgD}^{+} \mathrm{CD} 27^{+}\right)$, and switched memory $\left(\operatorname{IgD}^{-} \mathrm{CD} 27^{+}\right) \mathrm{B}$ cells. 


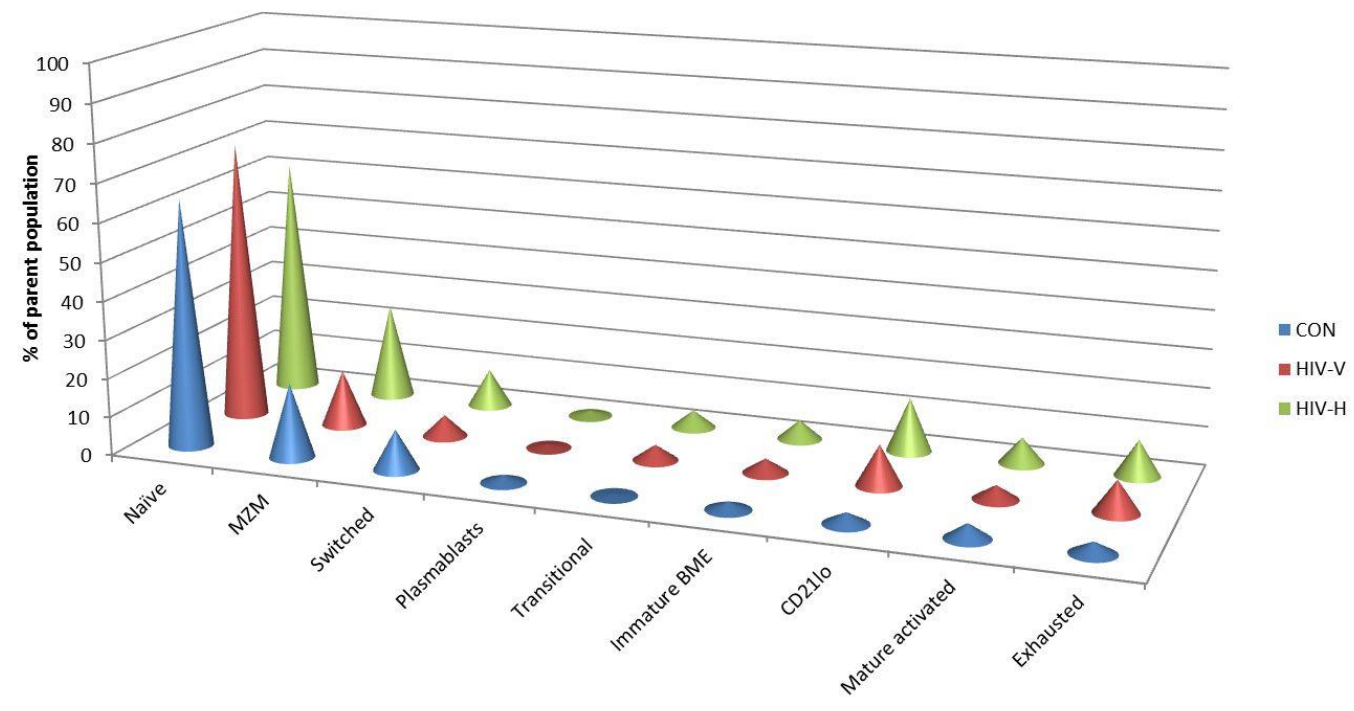

Figure 3.3. Overview of changes in $\mathrm{CD}_{19^{+}}$subpopulations in all groups.

Median values are shown for CON $(n=47)$, HIV-V $(n=53), \operatorname{HIV}-\mathrm{H}(\mathrm{n}=27)$.

Relative proportions of different B cell subpopulations were broadly similar in the three cohorts (Figure 3.3). The B cell compartment was dominated (about 2/3) by naïve B cells, with a smaller proportion of memory cells, including switched and marginal zone memory cells. Relatively low proportions of immature B cells, CD21 ${ }^{\text {lo }}$ $\mathrm{B}$ cells and plasmablasts were seen in all groups.

There was a general trend in HIV infected patients (both HIV-V and HIV-H) in the peripheral blood towards an increase in immature, and $\mathrm{CD} 21^{\text {lo }}$ cell populations. Whilst many of the changes in B cell populations were similar in both disease groups, some distinct patterns were seen; these are discussed below.

The pattern of expression of the dynamic markers on individual $B$ cell subpopulations showed considerable variation by cell phenotype (Figure 3.4). This pattern was similar between controls and both patient groups (data not shown) although intensity of expression was altered in disease. Bcl-2 was expressed on all subpopulations, particularly on MZM and switched memory cells; CD95 was also universally expressed, with highest expression on activated populations. Ki67 was expressed at low levels on all cell populations, with greatest expression on plasmablasts and mature activated cells. CXCR5 was expressed more intensely on recent $\mathrm{BME}$ and naïve $\mathrm{B}$ cells. 

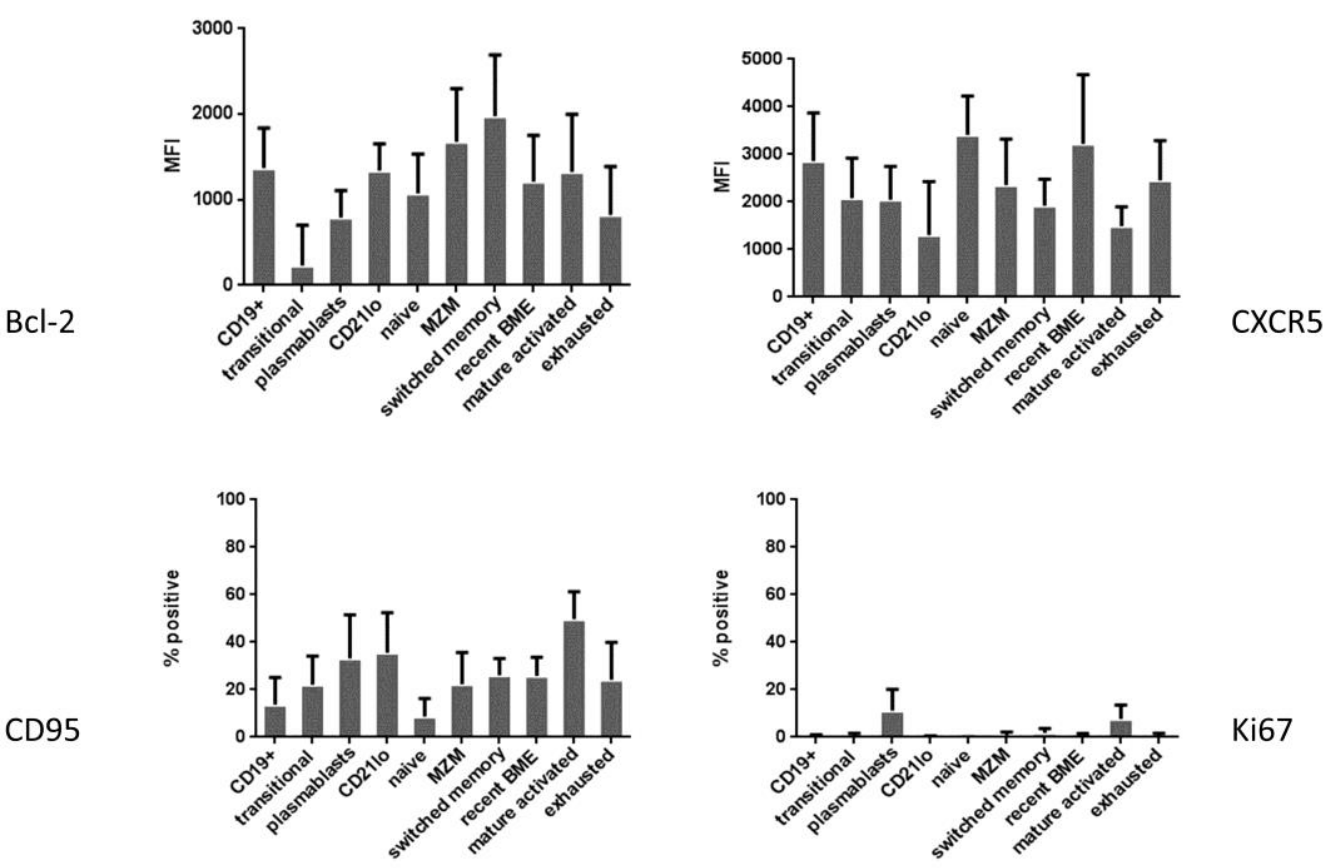

Figure 3.4. Expression of markers of apoptosis, turnover and trafficking across CD19 ${ }^{+}$ subpopulations.

All markers are gated on the total $\mathrm{CD} 19^{+}$population. Median values and IQR are shown in healthy control subjects. $n=47$.

In HIV-infected patients, both HIV-V and HIV-H, expression of markers of apoptosis, trafficking and turnover was abnormal compared to that seen in healthy controls. An example of flow cytometry plots from both a healthy subject and an HIV-infected subject is shown in Figure 3.5. 
i)

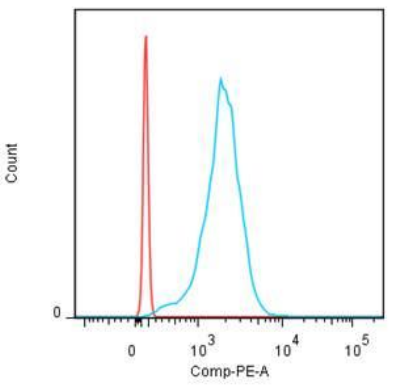

ii)
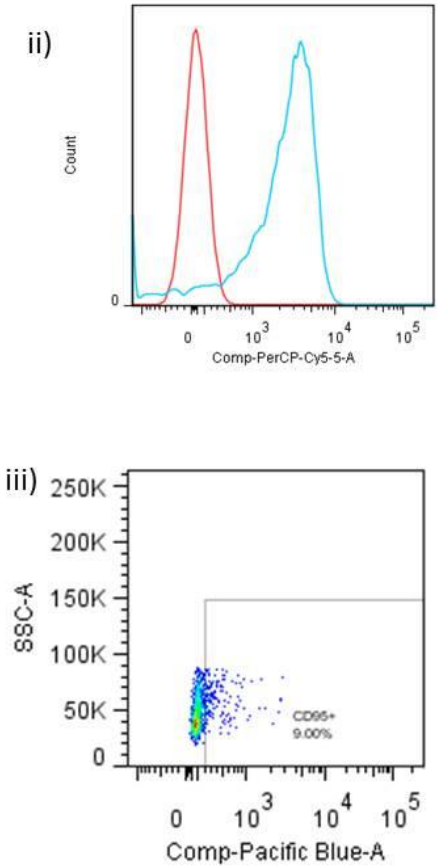

iv)

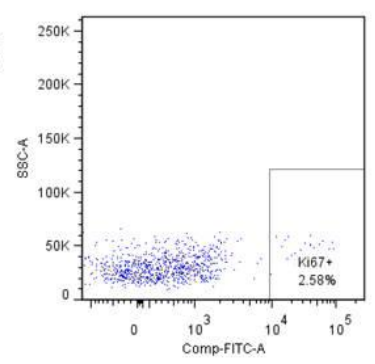

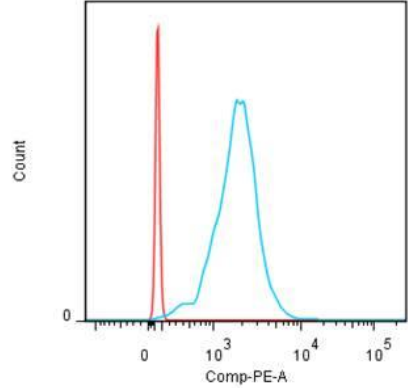
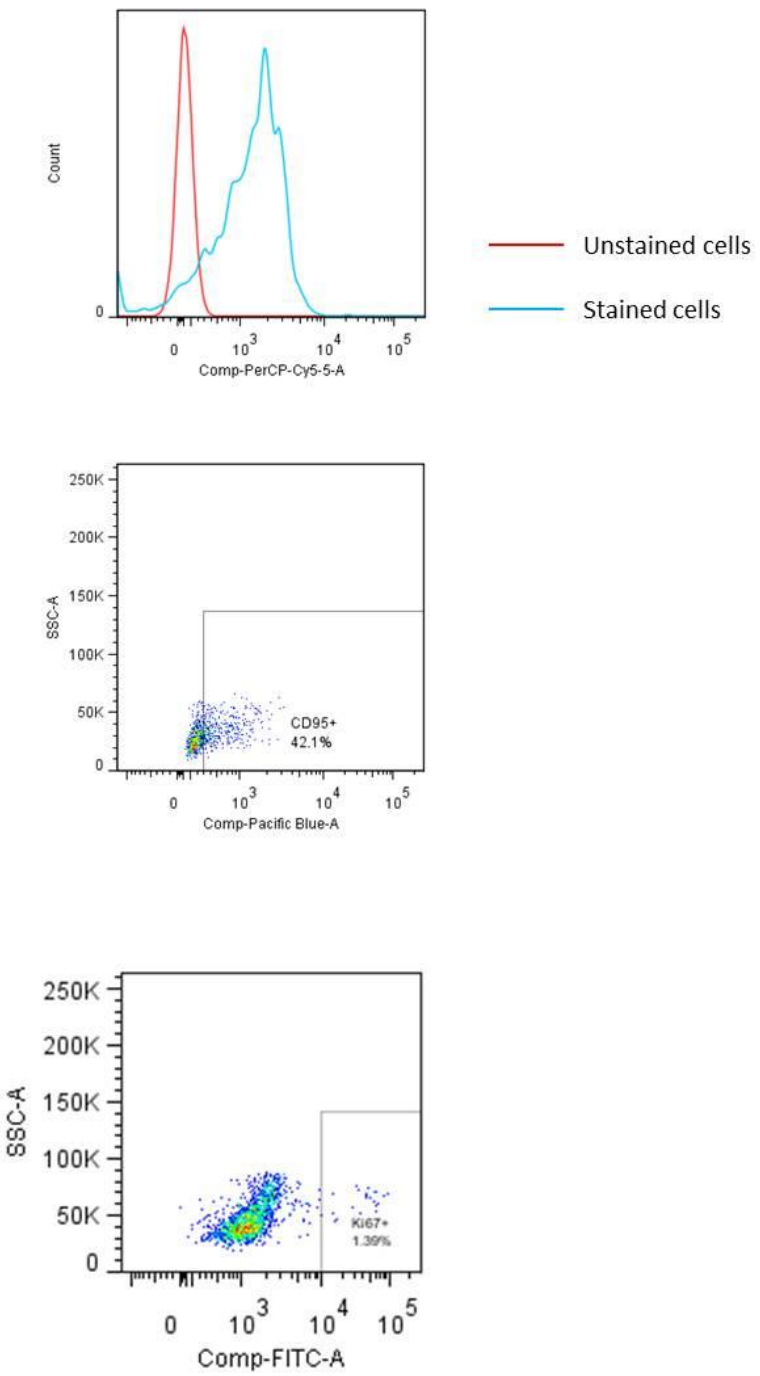

Figure 3.5. Typical flow cytometry histograms and dot plots of markers of apoptosis, turnover and trafficking in a healthy control (left) and HIV-infected subject (right).

i) Bcl-2 and ii) CXCR5; expressed as median fluorescence intensity; iii) CD95 and iv) Ki67; expressed as \% positive. All markers are gated on the total $\mathrm{CD} 19^{+}$population. 


\subsubsection{Changes in B cell subpopulation distribution in vertically acquired HIV infection compared to healthy controls}

A number of changes in circulating B cell populations were seen in patients with vertically acquired infection compared with the control group (Figure $3.6 \mathrm{a}-\mathrm{i}$ ). In the vertically infected cohort, the B cell population was more dominated by cells of naïve phenotype, including naïve cells $(\mathrm{p}=0.007), \mathrm{CD} 8^{\mathrm{hi}} \operatorname{IgM}^{\mathrm{hi}}$ transitional cells $(\mathrm{p}$ $<0.001)$ and immature BME $(\mathrm{p}=0.006)$. CD $21^{\text {lo }}$ cells $(\mathrm{p}<0.001)$ and exhausted cells ( $\mathrm{p}<0.001$ ) were also increased. These changes were not affected by control of viral load; however, the proportion of mature activated cells was increased only in those patients who remained viraemic $(\mathrm{p}<0.001)$. The increase in naïve populations was balanced by a reduction in MZM $(p=0.030)$ and switched memory $(p<0.001)$ populations. When analysed by viral control, the increase in naïve B cells and reduction in MZM was only seen in those patients with viral control ( $p=0.003$ and $p$ $=0.011$ respectively) and was not seen in patients with viraemia. Plasmablast proportion was reduced in HIV-V $(\mathrm{p}<0.001)$ compared to controls; this was not affected by viral control. 


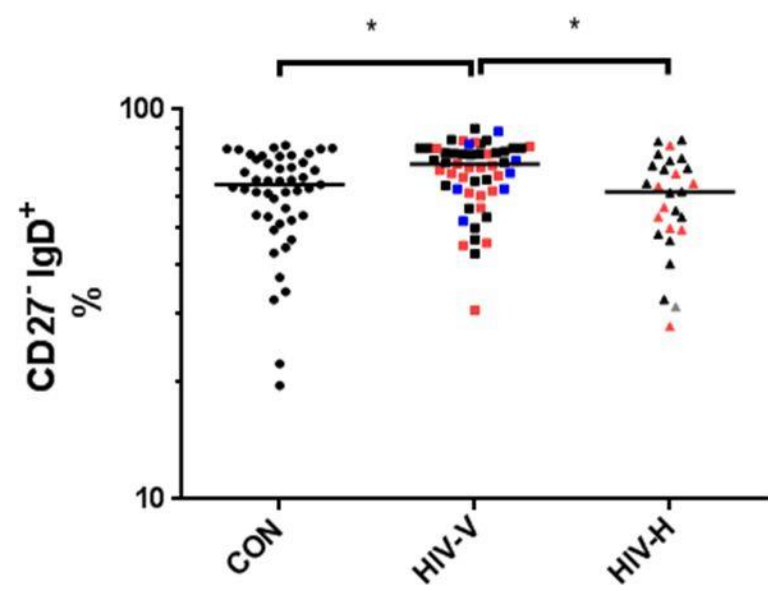

a) Naïve
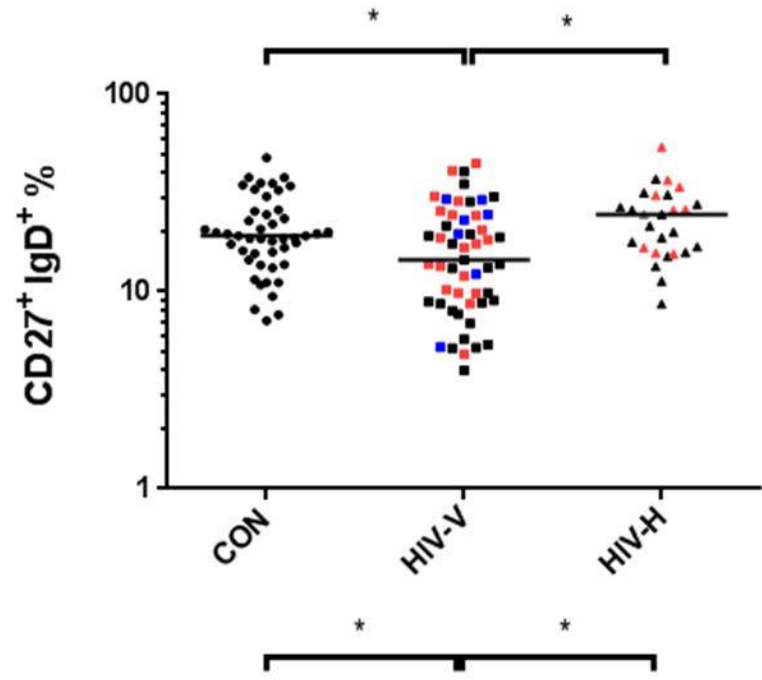

b) MZM

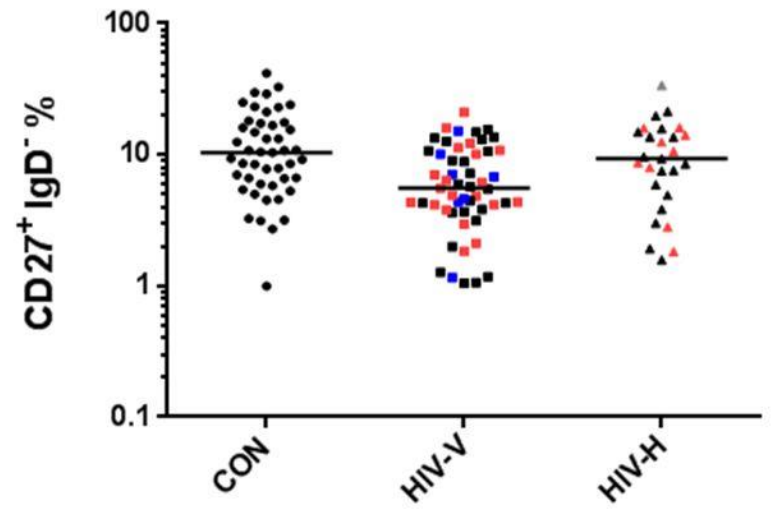

c) Switched memory

Figure 3.6 a-c. B cell subpopulations in all groups.

The percentage of total $\mathrm{CD} 19^{+}$population with median is shown. Red indicates current detectable VL (HIV-V ${ }^{+}$ and $\left.\mathrm{HIV}-\mathrm{H}^{+}\right)$; blue indicates maintained viral control $<10 \mathrm{y}$ of age in the vertically infected group $\left(\mathrm{HIV}-\mathrm{V}^{\mathrm{E}}\right)$; grey indicates VL status unknown. ${ }^{*} \mathrm{p} \leq 0.05$. 

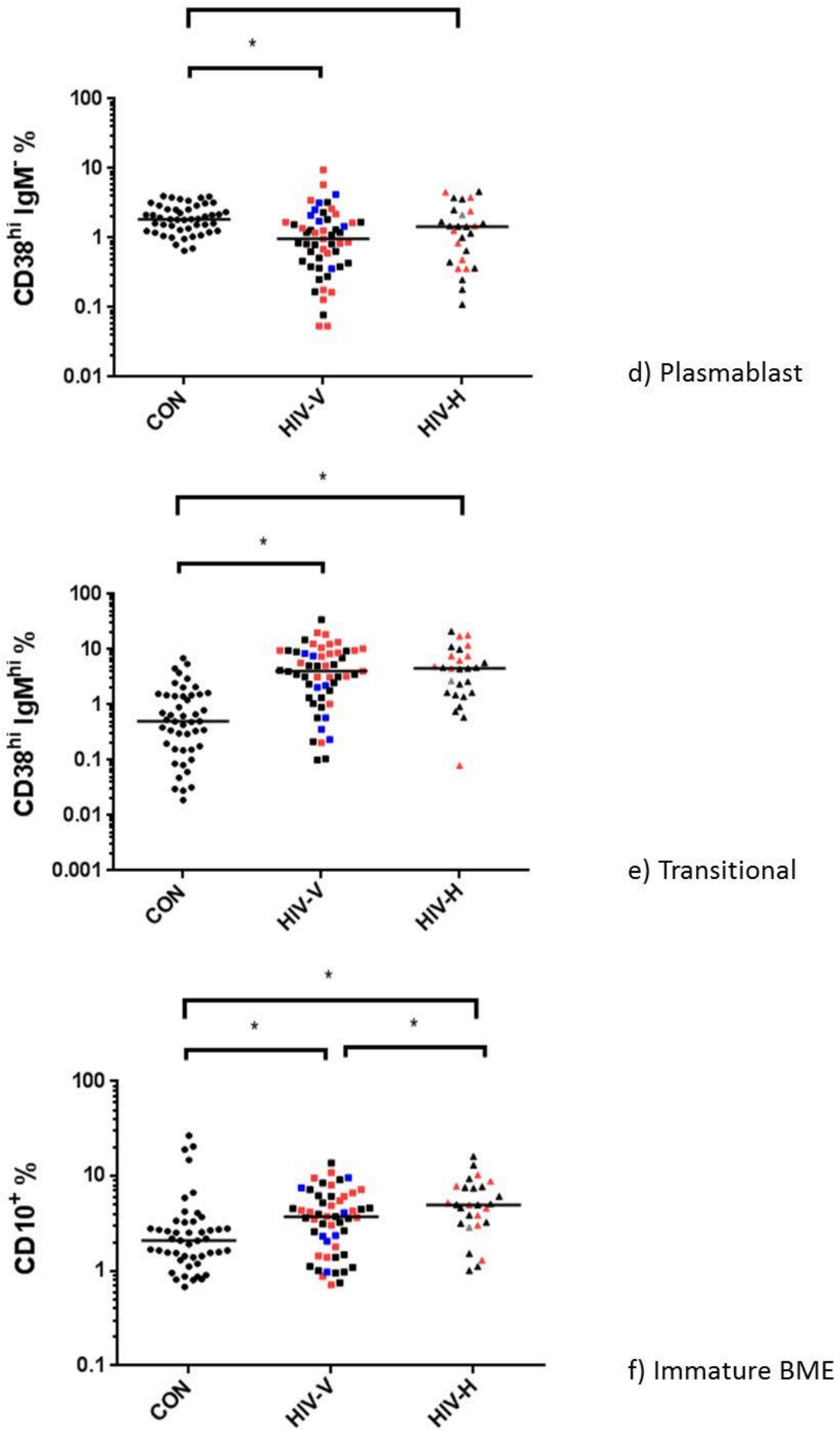

Figure 3.6 d-f. B cell subpopulations in all groups.

The percentage of total CD $19^{+}$population with median is shown. Red indicates current detectable VL (HIV-V ${ }^{+}$ and $\left.\mathrm{HIV}-\mathrm{H}^{+}\right)$; blue indicates maintained viral control $<10 \mathrm{y}$ of age in the vertically infected group $\left(\mathrm{HIV}-\mathrm{V}^{\mathrm{E}}\right)$; grey indicates VL status unknown. ${ }^{*} \mathrm{p} \leq 0.05$. 


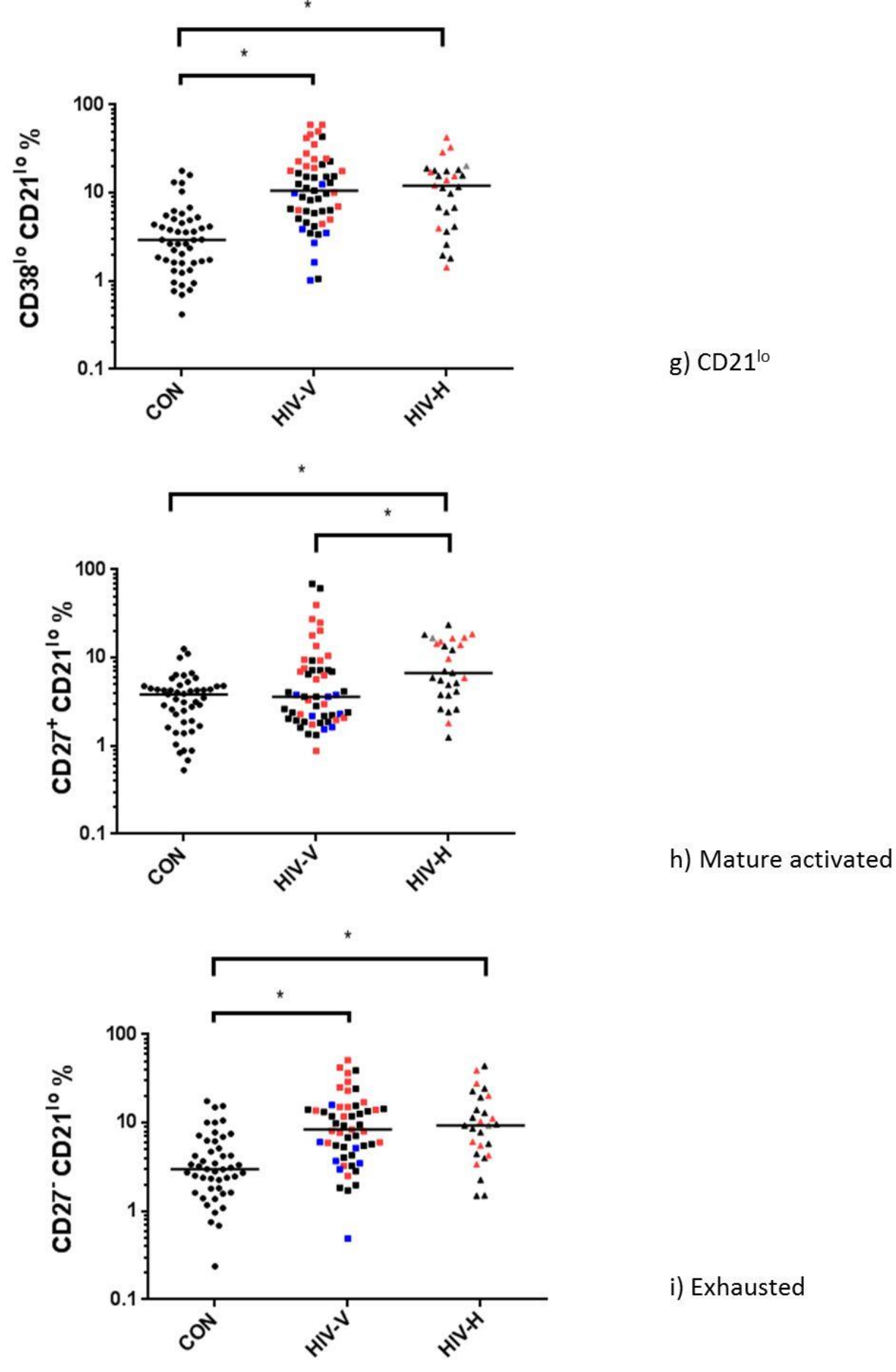

Figure 3.6 g-i. B cell subpopulations in all groups.

The percentage of total $\mathrm{CD} 19^{+}$population with median is shown. Red indicates current detectable VL (HIV-V ${ }^{+}$ and $\left.\mathrm{HIV}-\mathrm{H}^{+}\right)$; blue indicates maintained viral control $<10 \mathrm{y}$ of age in the vertically infected group $\left(\mathrm{HIV}-\mathrm{V}^{\mathrm{E}}\right.$ ); grey indicates VL status unknown. * $\mathrm{p} \leq 0.05$. 


\subsubsection{Comparison of vertically and horizontally HIV-infected patients}

In the HIV-H cohort compared to healthy controls, as with HIV-V, an increase was seen in transitional cells $(\mathrm{p}<0.001)$, immature BME $(\mathrm{p}<0.001)$, exhausted $(\mathrm{p}=$ $0.004)$ and mature activated cells $(\mathrm{p}<0.001)$; these changes were seen regardless of viral control. A decrease in plasmablasts was seen only in the aviraemic horizontally infected patients $(\mathrm{p}=0.034)$. Differences were also seen in $\mathrm{B}$ cell subpopulations between the two HIV cohorts. Immature BME and mature activated cells were increased in HIV-H compared to HIV-V ( $p=0.018$ for both populations). Naïve cell proportions were increased in HIV-V compared to HIV-H $(\mathrm{p}=0.004)$ and MZM and switched memory populations reduced ( $\mathrm{p}=0.002$ and 0.017 respectively).

\subsubsection{Changes in expression of markers of apoptosis, turnover and trafficking}

There were marked changes in expression of these markers in both HIV cohorts relative to controls and these changes were generally similar between horizontally and vertically infected individuals and were influenced by viraemia in some cases. Expression of bcl-2 was similar in all groups, although a decrease in expression compared to controls was apparent in the HIV-V $\mathrm{V}^{+}$group $(\mathrm{p}=0.001)$ (Figure 3.7a). Expression of CXCR5 was reduced in the viraemic subgroup of each cohort $(\mathrm{p}<$ 0.001 for $\mathrm{HIV}-\mathrm{V}^{+}$and 0.007 for $\mathrm{HIV}-\mathrm{H}^{+}$) (Figure 3.7b). CD95 was expressed at greater levels in both disease groups compared to controls $(\mathrm{p}=0.001$ for both groups), and was manifest regardless of viral status in HIV-V $(\mathrm{p}=0.001)$, but limited to the viraemic subgroup of the HIV-H cohort $(\mathrm{p}=0.000)$ (Figure $3.7 \mathrm{c}$ ). Ki67 expression was increased in viraemic HIV-H $(\mathrm{p}=0.005)$ and in the HIV-V cohort overall $(\mathrm{p}=0.035)$ (Figure 3.7d). 


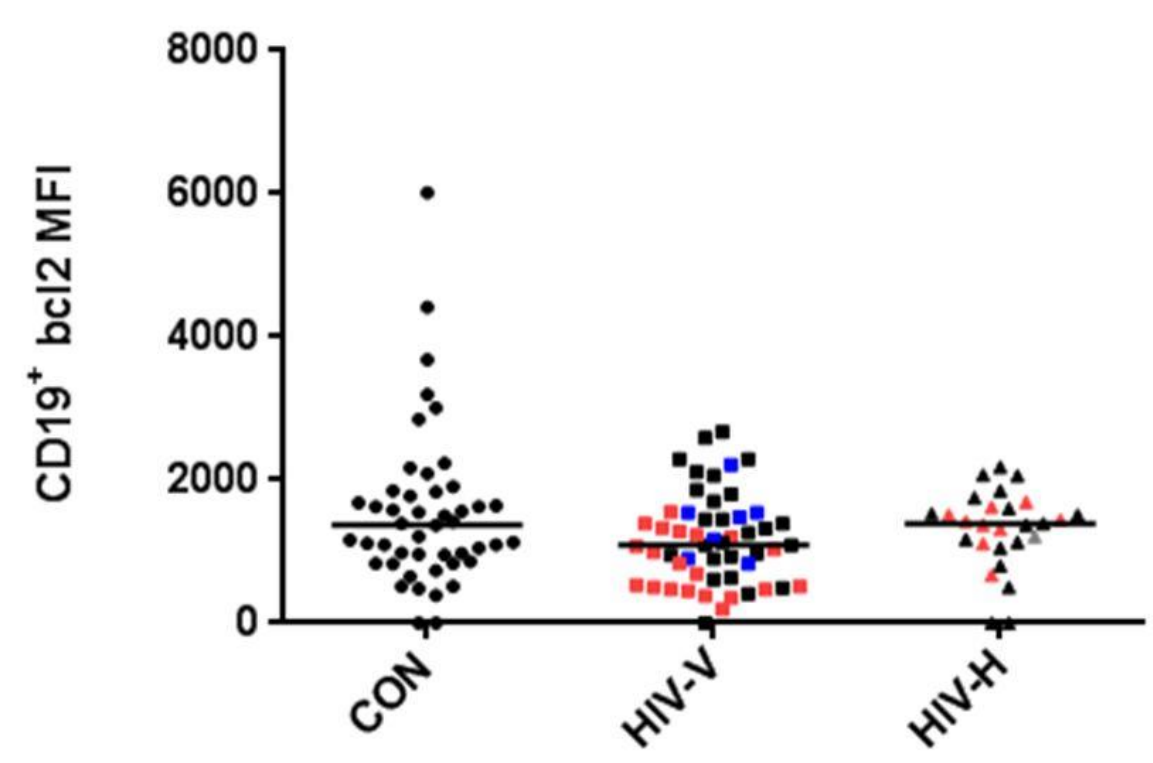

a) bcl-2 expression

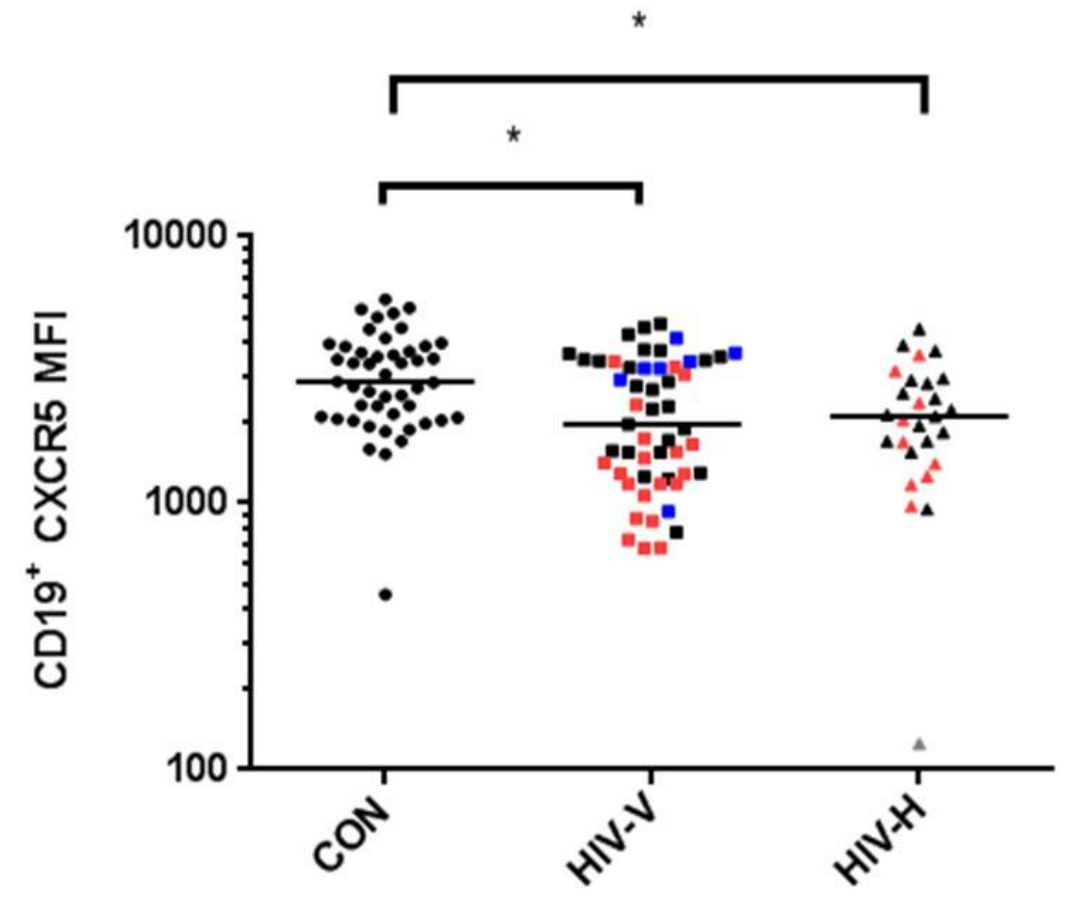

b) CXCR5 expression

Figure 3.7 a-b. Expression of markers of apoptosis and trafficking on $\mathrm{CD}_{1} 9^{+}$cells, shown in all groups.

a) bcl-2 and b) CXCR5 expression (MFI) with median is shown. All markers are gated on the total CD19 population. Red indicates current detectable VL $\left(\mathrm{HIV}-\mathrm{V}^{+}\right.$and $\left.\mathrm{HIV}-\mathrm{H}^{+}\right)$; blue indicates maintained viral control $<10 \mathrm{y}$ of age in the vertically infected group $\left(\mathrm{HIV}-\mathrm{V}^{\mathrm{E}}\right)$; grey indicates VL status unknown. * $\mathrm{p} \leq$ 0.05 . 


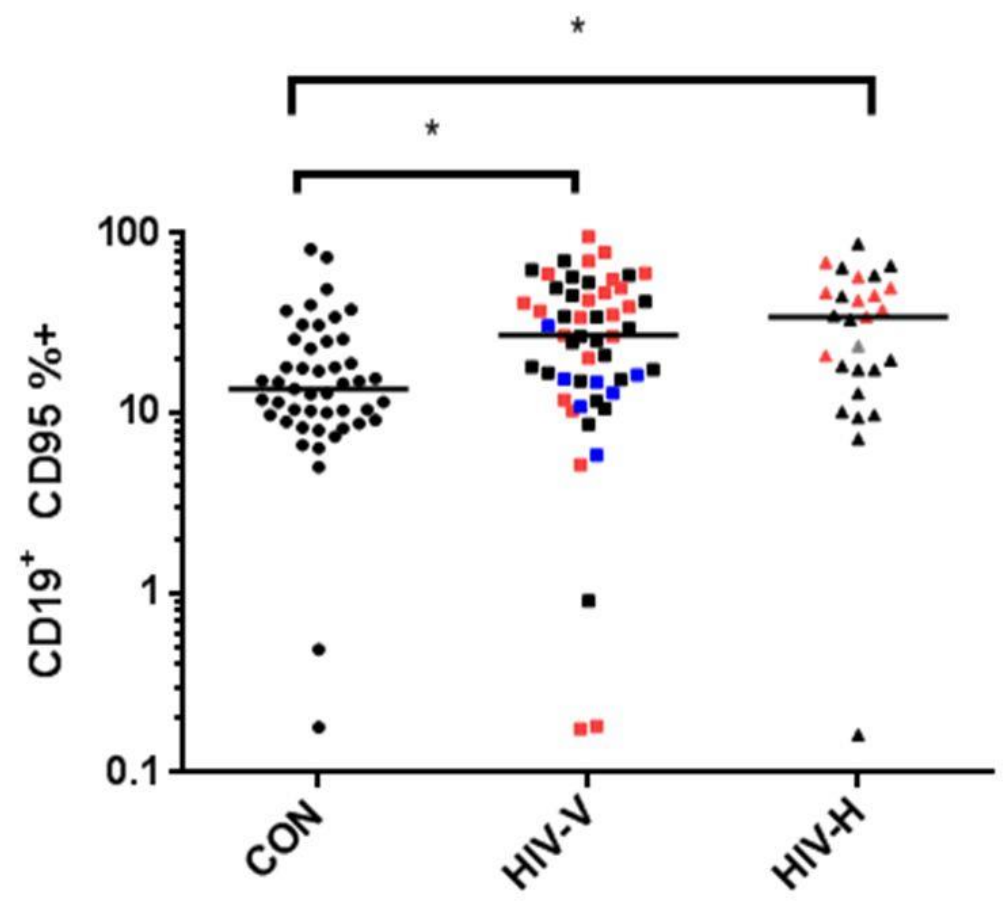

c) CD95 expression

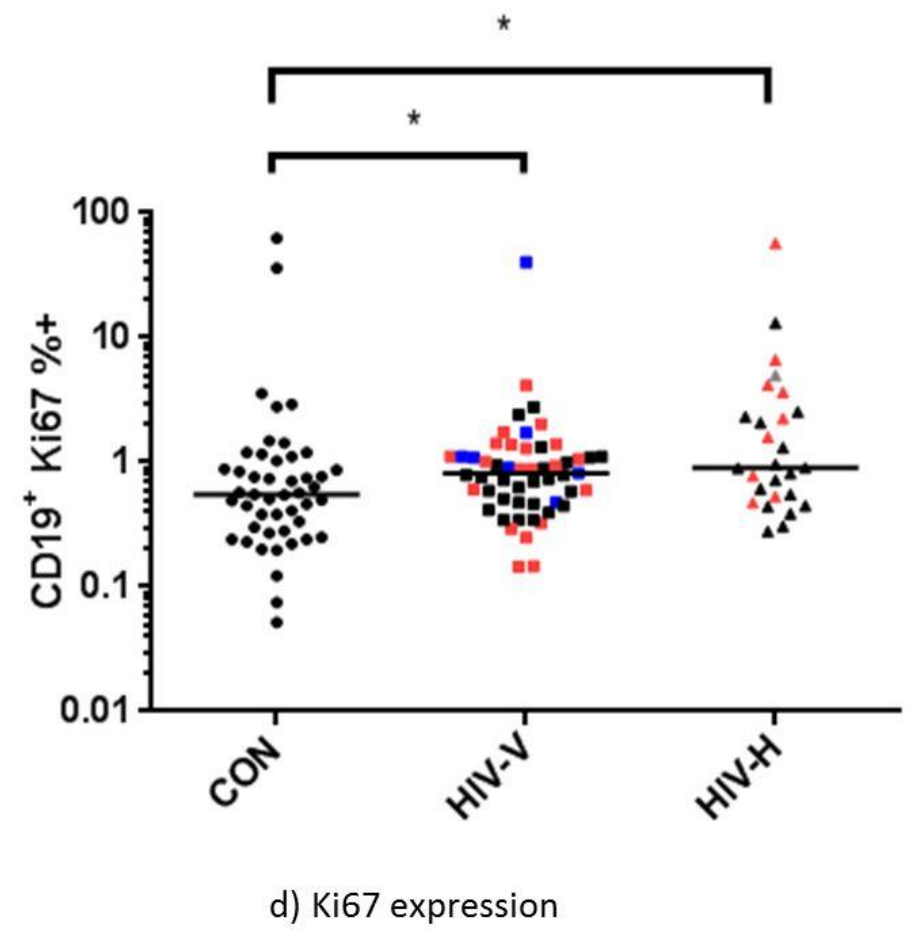

Figure 3.7 c-d. Expression of markers of apoptosis and turnover on $C D 19^{+}$cells, shown in all groups.

c) CD95 and d) Ki67 (\% positive) expression with median is shown. All markers are gated on the total CD19 ${ }^{+}$ population. Red indicates current detectable VL $\left(\mathrm{HIV}-\mathrm{V}^{+}\right.$and $\left.\mathrm{HIV}-\mathrm{H}^{+}\right)$; blue indicates maintained viral control $<10 \mathrm{y}$ of age in the vertically infected group $\left(\mathrm{HIV}-\mathrm{V}^{\mathrm{E}}\right)$; grey indicates VL status unknown. ${ }^{*} \mathrm{p} \leq 0.05$. 


\subsubsection{Effect of $\mathrm{CD}^{+}$count and viral load on B cell subpopulations}

There was no strong association between absolute $\mathrm{CD}^{+}$count and the $\mathrm{B}$ cell populations or behavioural markers analysed. Direct comparison of aviraemic and viraemic (at the time of sampling) patient subgroups, however, influenced population phenotypes and some behavioural markers, particularly in the vertically infected cohort. In the vertically infected cohort, there was an increase in transitional $(\mathrm{p}=$ $0.003)$, mature activated $(\mathrm{p}=0.019)$ and exhausted $(\mathrm{p}=0.007)$ cells in $\mathrm{HIV}-\mathrm{V}^{+}$ compared to $\mathrm{HIV}-\mathrm{V}^{-}$subjects. Bcl-2 and CXCR5 expression was also lower and CD95 higher in $\mathrm{HIV}-\mathrm{V}^{+}$compared to $\mathrm{HIV}-\mathrm{V}^{-}$subjects.

\section{Effect of early life viral control}

In the HIV-V group, patients with a history of maintained viral load control achieved before the age of 10 years $\left(\mathrm{HIV}-\mathrm{V}^{\mathrm{E}}\right)$ were compared to those HIV-V patients with current (but not early-life) viral control (HIV-V-) (Figures $3.6 \mathrm{a}-\mathrm{i})$. There was a reduction in $\mathrm{HIV}-\mathrm{V}^{\mathrm{E}}$ compared to $\mathrm{HIV}-\mathrm{V}^{-}$in the proportion of transitional cells $(\mathrm{p}=$ 0.009), CD21lo cells ( $<<0.001)$, mature activated cells $(\mathrm{p}=0.044)$ and exhausted cells $(\mathrm{p}=0.011)$, and an increase in plasmablasts. There was also a trend towards increased total $\mathrm{CD} 19^{+}$count, MZM, and switched memory populations and to a decrease in BME and naïve B cells in HIV $-\mathrm{V}^{\mathrm{E}}$, compared with HIV-V${ }^{-}$. Patients with early life viral control showed decrease in CD95 expression (Figure 3.7c) and increase in Ki67 expression (Figure 3.7d) compared with those with current but not early life control ( $\mathrm{p}=0.048$ and 0.03 respectively) and a trend towards increased bcl2 (Figure 3.7a) and CXCR5 expression (Figure 3.7b) in HIV-V ${ }^{\mathrm{E}}$ compared to HIV$\mathrm{V}^{-}$.

\subsubsection{Effect of recent HIV seroconversion in horizontally infected patients}

To evaluate whether duration of infection influenced the alterations in B cell profile seen, recent seroconverters (HIV-H-RS) were compared with patients with longer duration of infection of horizontally acquired infection (HIV-H). There was no difference between HIV-H and HIV-H-RS in total CD19 ${ }^{+}$count (Figure 3.8), nor in B cell subpopulations (Figure 3.9 and 3.10). 


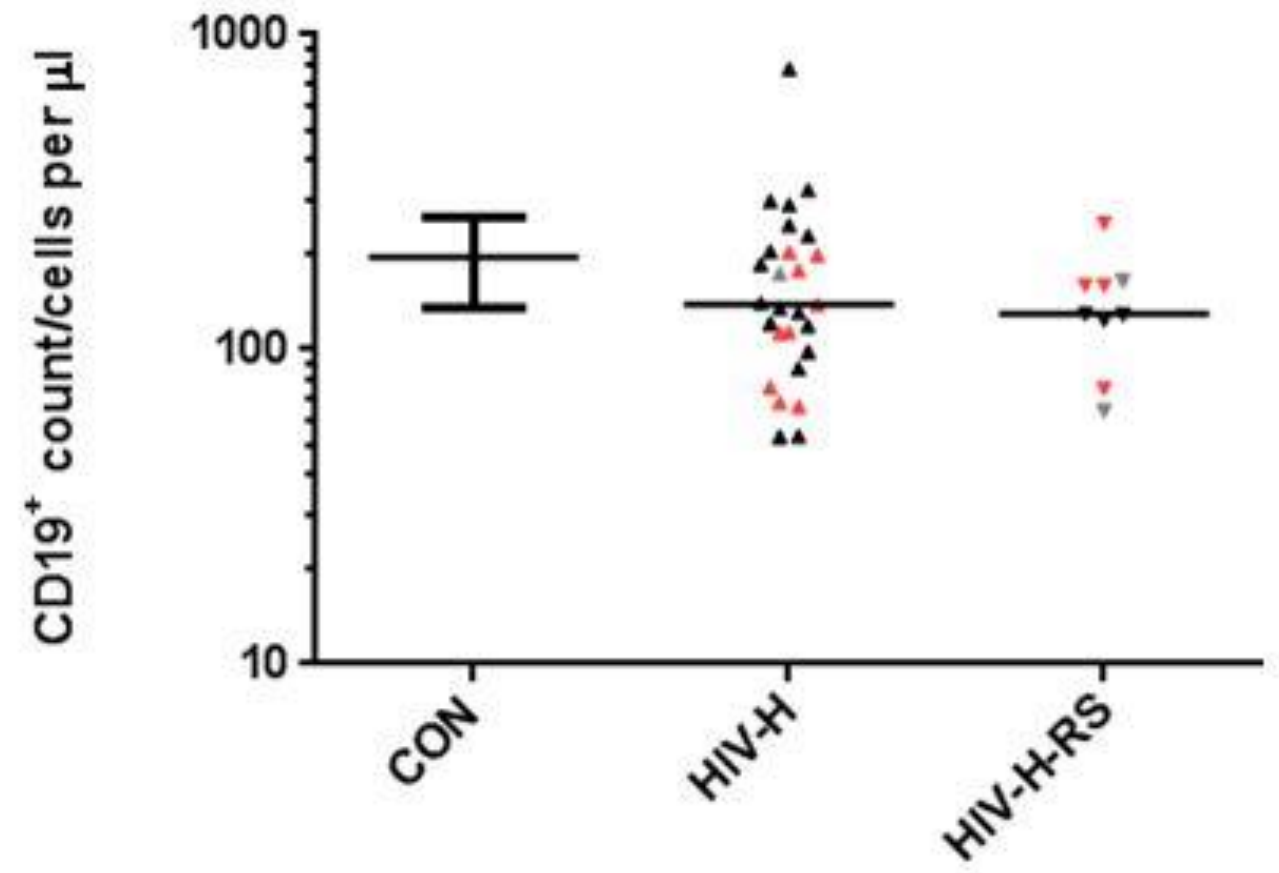

Figure 3.8. CD19+ absolute count in HIV-H and HIV-H-RS groups.

The median is indicated. The median and IQR for CON is shown for reference. Red indicates current detectable VL (HIV-H ${ }^{+}$and HIV-H-RS ${ }^{+}$; grey indicates VL status unknown.

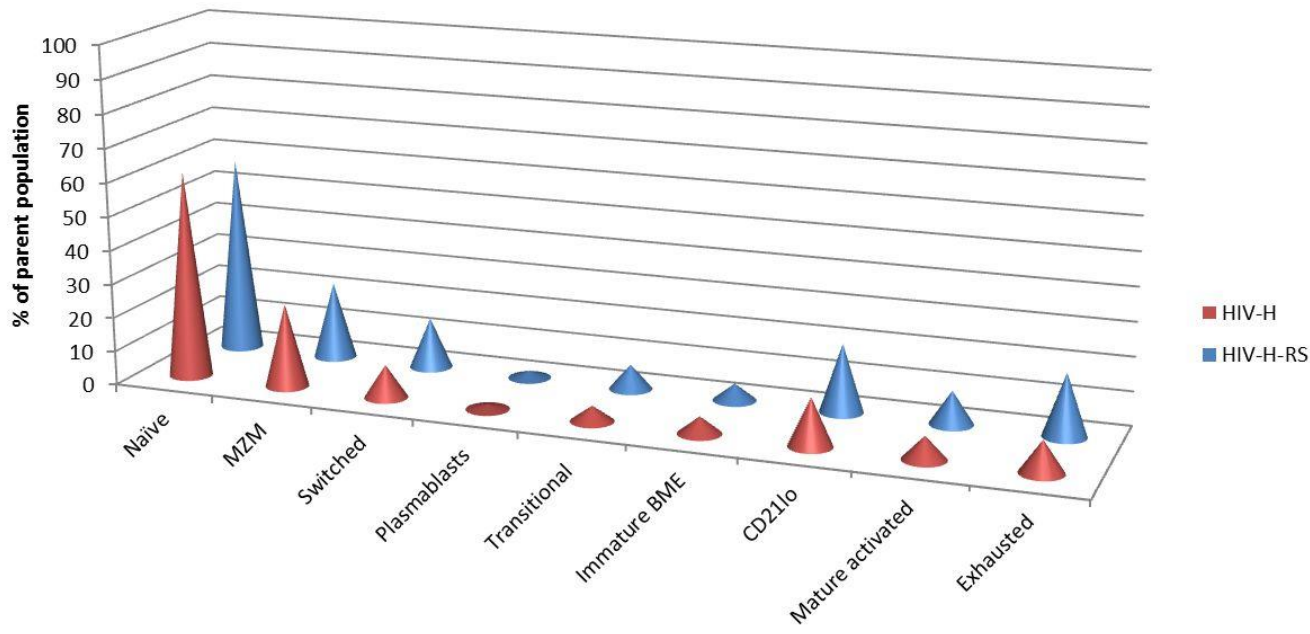

Figure 3.9: Overview of changes in $C D 19^{+}$subpopulations in HIV-H and HIV-H-RS groups. Median values are shown for HIV-H $(\mathrm{n}=27)$ and HIV-H-RS $(\mathrm{n}=9)$ 


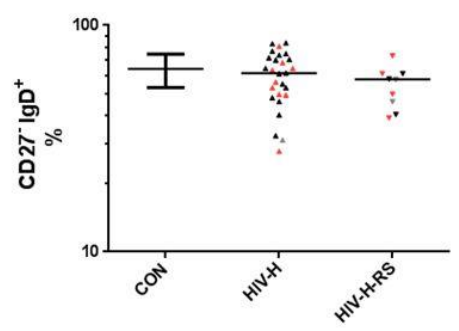

a) Naïve

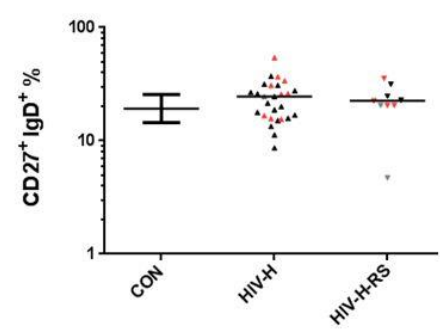

b) MZM

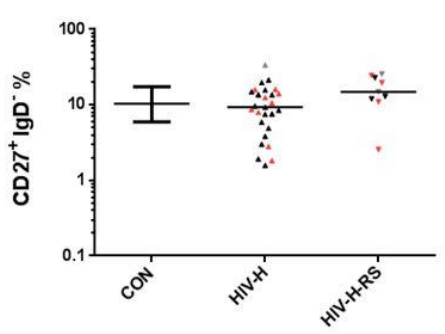

c) Switched memory

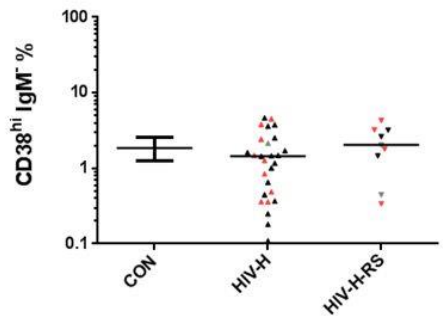

d) Plasmablast

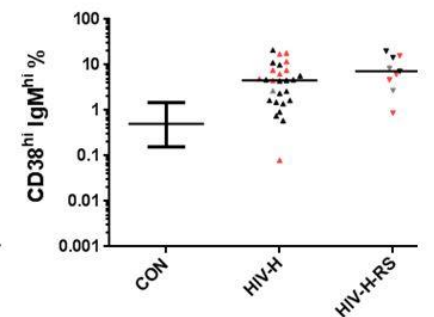

e) Transitional

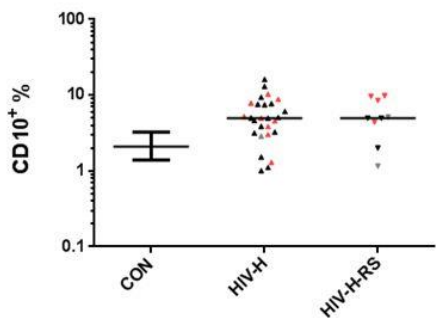

f) Immature BME

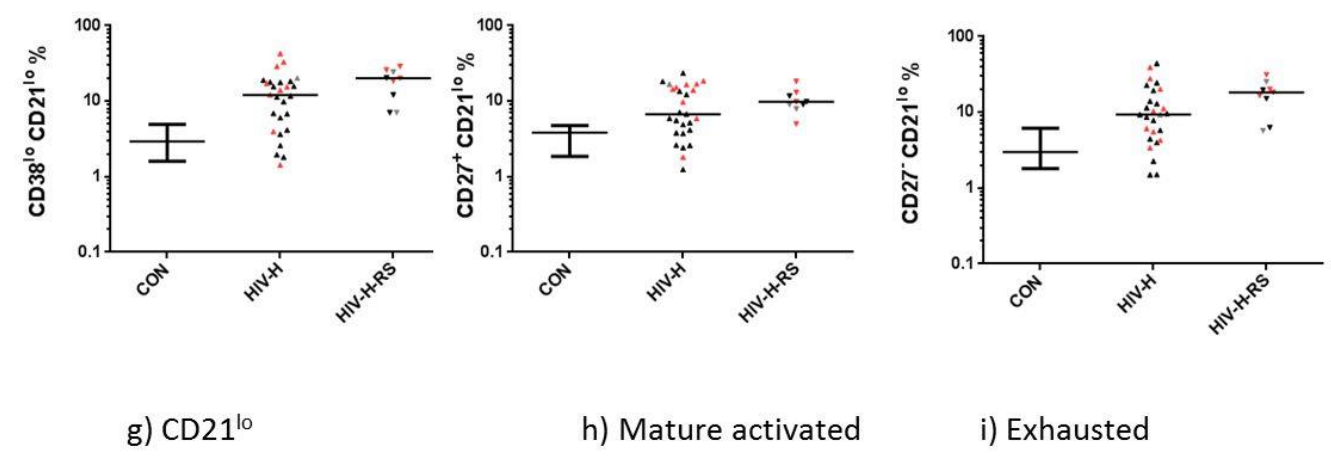

Figure 3.10: Changes in CD19+ subpopulations shown in HIV-H and HIV-H-RS groups. Percentage of total $\mathrm{CD} 19^{+}$population with median is shown. The median and IQR for CON is shown for reference. Red indicates current detectable VL $\left(\mathrm{HIV}-\mathrm{H}^{+}\right.$and $\left.\mathrm{HIV}-\mathrm{H}-\mathrm{RS}^{+}\right)$; grey indicates VL status unknown.

HIV-H-RS patients were found to have reduced CXCR5 expression on CD19 ${ }^{+}$cells, in comparison to HIV-H ( $\mathrm{p}=0.001$ ) (Figure $3.11 \mathrm{~b}$ ). 


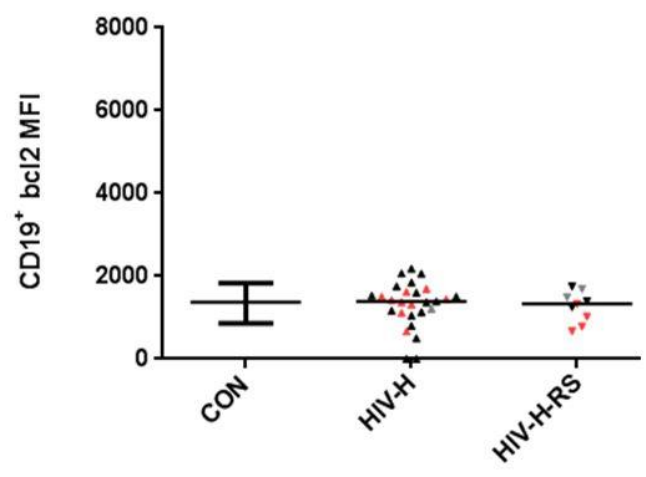

a) bcl-2 expression

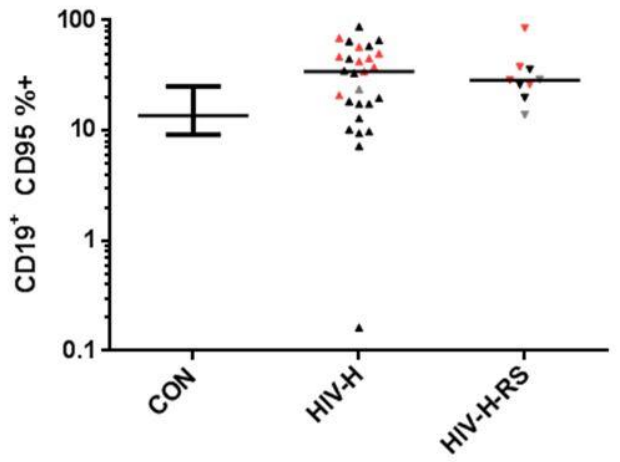

c) CD95 expression

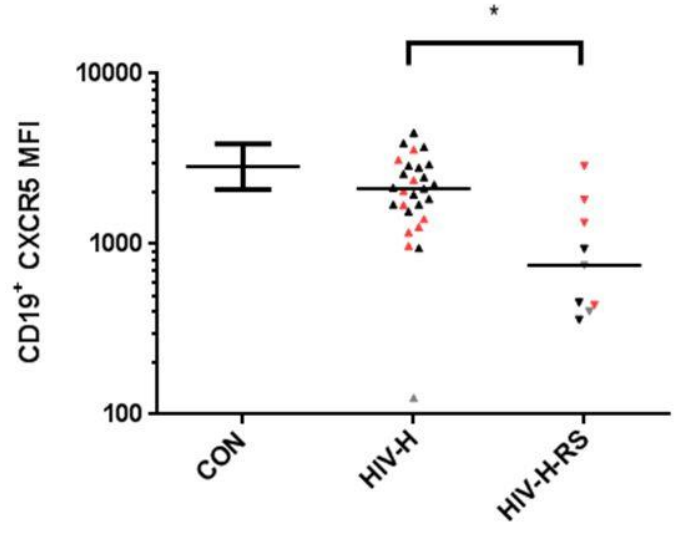

b) CXCR5 expression

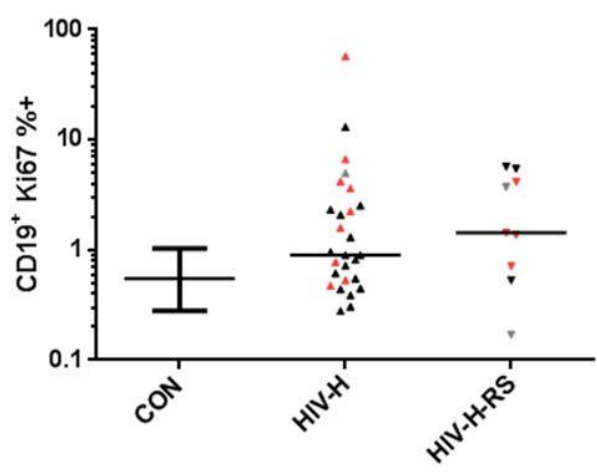

d) Ki67 expression

Figure 3.11: Changes in expression of markers of apoptosis, turnover and trafficking on CD19 ${ }^{+}$cells, shown in HIV-H and HIV-H-RS groups.

a) bcl-2 and b) CXCR5 (MFI), c) CD95 and d) Ki67 (\% positive) expression with median are shown. All markers are gated on the total $\mathrm{CD} 19^{+}$population. The median and IQR for CON is shown for reference. Red indicates current detectable VL $\left(\mathrm{HIV}-\mathrm{H}^{+}\right.$and $\left.\mathrm{HIV}-\mathrm{H}-\mathrm{RS}^{+}\right)$; grey indicates VL status unknown. ${ }^{*} \mathrm{p} \leq 0.05$. 


\subsection{Discussion}

I evaluated the impact of HIV infection on circulating B cell subpopulations in vertically and horizontally infected young adults, and healthy controls. The data presented here demonstrate that the B cell compartment is profoundly altered in vertically infected HIV patients by early adulthood, compared to uninfected young adults. There is evidence in this vertically infected cohort of ongoing immune exhaustion, altered trafficking and increased susceptibility to apoptosis, related to HIV viraemia and similar to that seen in horizontally infected patients. Depletion of memory populations, however, was demonstrated in vertically infected patients but not seen in horizontally infected young adults.

Increased immature, exhausted and abnormally activated B cells [41,53,54,59,119,123-126], with increased apoptosis [41,51-55,116], proliferation [41,53] and abnormal B cell trafficking [58,59] are well described in the B cell compartment in HIV infection. I did not, however, show a decrease in bcl-2 expression in horizontally infected patients, even in those with detectable HIV viraemia, and a decrease was only demonstrated in the viraemic subgroup of the vertically infected cohort. This is in contrast to other studies [51,53,55], and may be due to the younger age group of our cohorts compared to those examined in other studies, with consequent likely shorter duration of infection in our horizontally infected cohort at least. Interestingly, plasmablasts are shown here to decrease in both patient groups compared to healthy controls. This is the first published data regarding plasmablast populations in vertically infected individuals, but is contradictory to other studies in adults $[41,258]$, which have shown an increase in plasmablast proportion. This may be partially explained by the difference in age (and possibly duration of HIV infection and history of exposure to ART) in our patient cohort; it should also be remembered that sample sizes in this study were small.

In this study, it is noteworthy that the increase in immature and abnormally activated B cells was greater in the horizontally infected cohort compared to the vertically infected patients, despite a similar degree of viral control between the two groups. Groups were not matched for ethnicity; however limited existing data suggests that the impact of ethnicity on B cell subpopulations is minimal [283]. Recency of 
infection in the horizontal group is also unlikely to be relevant, because there was no difference between the horizontally infected cohort and a separate cohort of horizontally infected patients who had acquired their HIV infection within the previous 2 years (although this data must be interpreted with caution as the sample size of recently infected patients was small and not powered for this comparison). Indeed, duration of infection is longer in the vertically infected group, and might be expected to lead to greater changes than those seen in the horizontally infected cohort, although no studies have directly examined this. An alternative explanation is that acquisition of infection at a young age may be associated with a degree of resilience against these dynamic immunological changes of hyperactivation and exhaustion seen in those infected in adulthood. Selection bias may also play a role: those patients who have survived into adulthood despite vertical HIV transmission may represent a distinct group of vertically infected patients who are immunologically more robust and/or tolerant of their virus.

It is also possible that these changes are less obvious in vertically infected patients because of the depletion of some cell lineages, such as memory populations, in which the changes of hyperactivation and exhaustion might have been demonstrated. Changes in memory populations were demonstrated in the vertically infected cohort, who showed increased naïve B cell proportion, and reduction of MZM and switched memory populations, but not in the horizontally infected cohort.

In contrast to our findings, depletion of memory populations in horizontally infected adults $[55,116,118-122]$ has been shown by others. It is possible that the tendency, in recent years, to treat $\mathrm{HIV}$-infected individuals at higher $\mathrm{CD}^{+}$thresholds has resulted in preservation of memory B cell populations in the horizontally infected adults in our study, compared to those included in studies performed some years ago. Our cohort was considerably younger than those reported elsewhere; this may imply a shorter duration of infection, compared to the older patients included in most published studies. If duration of infection is indeed important, this may also explain the changes to memory populations shown in the vertically infected cohort, who have, by nature of their route of infection, endured lifelong HIV infection. Splenic histological analysis has indicated that disruption to splenic architecture, including to germinal centres and presumably including the marginal zone, occurs late in HIV infection [252]. It may be that our vertically infected cohort have progressed to a 
stage of infection where maintenance and generation of memory cells, of both marginal zone and switched type, is compromised, whereas the horizontally infected cohort may not yet have sustained a sufficiently long duration of HIV infection to develop these changes. This may be consistent with other studies showing that treatment early in infection may be of benefit in adults [52,193], although this remains controversial [284].

The increase in naïve B cell proportion is also reflected in the absolute naïve B cell count. This may result from increased production of this cell population, perhaps to compensate for depletion of memory populations in these vertically infected patients. It may also result from a reduced progression of naïve $B$ cells already in the circulation towards generation of memory cells, as discussed above, resulting in accumulation. The increase may be restricted to the vertically infected cohort because of the depletion of memory cell populations sustained by this group. It is also possible, however, that this cohort has a greater capacity for immune restoration via repopulation of the naïve cell pool, perhaps because of their long term exposure to HIV infection.

The increase in exhausted, activated and immature B cell subpopulations, and disturbances of B cell behaviour, were most manifest in the viraemic subgroups of each patient cohort, although most of the changes in subpopulations were still evident, albeit to a lesser extent, even in aviraemic patients, compared to healthy controls. This may suggest partial reversibility of the subpopulation disturbances with effective ART, although this is not a longitudinal study so this cannot be confirmed. The apparent reduction in subpopulation derangement with viral control is broadly consistent with reported data showing that changes to some B cell subpopulations can often be reversed with effective ART [90]. Interestingly, in the case of the naïve and MZM populations, and in contrast to most other populations studied, these changes were in fact most evident when viral load was controlled. This is consistent with data in younger children [202] and has also been shown in the context of memory populations in adult HIV subjects [126]. This may, perhaps, be explained by a role of ongoing viraemia in maintaining turnover of the MZM population, ensuring ongoing replacement of the population as depletion occurs. 
Depletion, therefore, may only become obvious once viraemia is controlled, and a new steady state achieved. This may also explain the restriction of the increase in naïve cells to those vertically infected patients with viral control, which may be partially driven itself by the depletion in the MZM population. Although the depletion of switched memory cells is apparent in both viraemic and aviraemic subgroups, there is a trend towards greater depletion in aviraemic individuals, suggesting that a similar mechanism may also underlie the dynamics of the depletion of this population.

Although viral control in later life does not seem to entirely reverse the HIVmediated derangement to B cell subpopulations, the B cell compartment seemed less affected in young HIV-V adults with early and sustained viral control, suggesting that in children, derangement in B cell development may be either avoidable and/or reversible with ART. This is consistent with published work showing that viral control in the first year of life may be important in preserving B cell memory populations and responses in children [177]. It is possible that the damage to memory populations seen in vertically infected young adults may result from HIV viraemia during the early period of critical immune development in childhood.

Interpretation of this data is subject to some limitations. It is important to remember that the subpopulations detectable in the peripheral blood are dynamic and may not accurately reflect those present in lymphoid tissue and bone marrow. Furthermore, the phenotypic definitions of cell types are complex and themselves subject to controversy. For example, CD27 expression has traditionally been considered the marker of memory B cells [134], with CD27 cells assumed to be naïve. However, CD27 memory cells have been proposed to exist in peripheral blood in both healthy patients and in disease states albeit in low numbers [285,286]. Theoretically, this may mean that $\mathrm{CD} 27^{-}$memory cell losses are incorrectly attributed to the naïve compartment. Similarly, definition of memory cells by CD27 expression is complex: CD27 is also a marker both of B cell activation and terminal differentiation [282], both of which are manifest in HIV infection; thus CD27 expression may not represent true immune memory alone [287]. Other cell subpopulations are defined by varying markers in different studies, making direct comparison with existing literature challenging. Sample sizes in this study were small, of the horizontally infected cohort in particular, and further reduced by subdivision of groups by viral 
control, meaning that interpretation must be made with caution, particularly as the variation of B cell subpopulations even in healthy individuals may be considerable. That said, other published studies report findings from patient cohorts of similar sizes, so this alone may not explain discrepancies from other published data.

These limitations notwithstanding, our study shows that vertically infected young adults show a lesser degree of dynamic immunological changes affecting their B cell compartment, but more significant damage to memory compartments, most manifest when viral load is controlled, in comparison to their horizontally infected counterparts. 


\section{Chapter 4. Results: natural and vaccine induced response to pneumococcal polysaccharide}

\subsection{Introduction}

\subsubsection{Pneumococcal immunity in HIV infection}

Pneumococcal immunity is known to be impaired in HIV infection. Rates of invasive disease are significantly elevated in both HIV-infected adults and children in the absence of ART [159,165,288-291], and it remains unclear whether the incidence of invasive pneumococcal disease has declined since the introduction of HAART.

\subsubsection{Pneumococcal vaccine responses in HIV infection}

In addition to impaired responses to natural infection, reduced response to immunisation with pneumococcal vaccines is also seen in individuals with HIV infection. There are two types of pneumococcal vaccine currently in use, the pneumococcal polysaccharide vaccine, Pneumovax ${ }^{\mathrm{TM}}$ (PPV) and the conjugate vaccine, Prevenar ${ }^{\mathrm{TM}}(\mathrm{PCV})$, which generate different kinds of immune response depending on the age of the individual and previous exposure. The response to immunisation with both vaccines is influenced by pre-existing natural immunity. Many patients have been colonised with a number of pneumococcal serotypes [154] such that immunisation may induce a mixture of primary responses in those individuals who have never been colonised and secondary immune responses in individuals who have been affected by prior colonisation [292].

\section{Pneumococcal polysaccharide vaccine (PPV)}

Nearly 100 different pneumococcal capsular serotypes exist and in general, antibody produced against one serotype is not protective against another. Pneumovax ${ }^{\mathrm{TM}}$ is a 23-valent pneumococcal polysaccharide vaccine containing a mixture of capsular polysaccharides from the most common disease-causing serotypes and has been shown to be effective in reducing the incidence of IPD, though less so in terms of protection against pneumonia [293]. As a pure polysaccharide, it acts in a T cellindependent manner, by cross-linking the $\mathrm{B}$ cell receptor and directly stimulating differentiation to plasma cells which secrete both IgM and IgG antibodies. This T cell-independent antibody response is characterised by delayed class switching, poor affinity maturation [143,294] and inability to generate an effective long lived memory response $[152,295]$ in a naive individual. In addition, Pneumovax ${ }^{\mathrm{TM}}$ is 
ineffective in children under 2 years of age [296], in whom T cell-independent responses are immature. Natural immunity may be boosted by vaccination or revaccination by this mechanism; however, there are concerns in adults that repeated use of PPV may in fact lead to subsequent attenuation of responses to Pnc exposure, a phenomenon known as immune hyporesponsiveness [295,297], which may suggest that the potential to boost memory responses through PPV may be limited. The mechanism behind this hyporesponsiveness remains unclear and has recently been attributed to depletion of long lived plasma cells [298].

Immunisation with a single dose of PPV is recommended for HIV-infected adults who have a $\mathrm{CD}^{+}$cell count greater than 200 cells/ml, in order to prevent severe pneumococcal infections [299]. However, the antibody response is impaired in the HIV-infected population. This is considered in part to be due to early damage to the marginal zone of the spleen [119] which is known to be important in supporting the development of an effective response to pneumococcal vaccines. Poor responses to PPV in HIV infection are well documented [172,181,183,300,301], with reduced duration and magnitude of serum $\operatorname{IgG}$ response compared to healthy individuals [80,302,303] and the risk for S. pneumoniae infections remains high among these individuals despite immunisation with PPV [160,164,304]. Kroon and colleagues [181] monitored specific anti-pneumococcal antibodies for 5 years after PPV administration, and showed a significantly lower mean antibody concentration in HIV patients with low $\mathrm{CD}^{+}$counts for 3 of the 8 serotypes examined. Although the rate of decline of antibody concentration showed no difference compared to healthy controls, within three years of vaccination, most HIV-infected individuals had antibody concentrations below $1.0 \mu \mathrm{g} / \mathrm{mL}$, considered in this study to be the level required for clinical protection. French et al. [305] showed that Pneumovax ${ }^{\mathrm{TM}}$ had some degree of immunogenicity in HIV-infected Ugandan adults, but the response was suboptimal, consistent with the efficacy findings of a systematic review [174] in which 11 of the 15 observational studies found various, but limited, degrees of disease protection after PPV administration. A further study by a group in Uganda [306] confirmed poor efficacy of PPV in HIV infection, and that its use was inexplicably associated with more pneumococcal disease events. Watera and colleagues [307] conducted a prolonged follow-up of these patients, and confirmed a persistent excess of all-cause pneumonia in vaccine recipients but, nonetheless, an 
unexplained survival advantage favouring vaccination. Although use of ART improves the response to pneumococcal vaccination [308], post-vaccination antibody levels are still lower among ART-treated individuals compared with HIV-uninfected people [185]. It appears, therefore, that the effectiveness of PPV in the HIV-infected population is controversial, limited and dependent upon the degree of virus-related immune deficiency $[80,173]$.

\section{Protein-polysaccharide conjugate vaccines (PCV)}

Following the success of the polysaccharide - protein conjugate vaccines in inducing protective immunity in infants to the encapsulated bacteria Haemophilus influenzae type B in the early 1990s, polyvalent pneumococcal conjugate vaccines were developed. The first vaccine, a 7 valent vaccine; Prevenar-7TM, was introduced into the infant immunisation schedule in 2006 and recently superseded by a 13-valent vaccine, Prevenar-13 $13^{\mathrm{TM}}$ in 2010 , to address the issue of serotype replacement disease.

The PCV elicits a T cell-dependent response [309], achieved by chemical conjugation of the polysaccharide to a protein carrier such as tetanus toxoid, diphtheria toxoid or cross-reactive material 197 (CRM197; a mutated diphtheria toxoid). This results in processing of the protein carrier by polysaccharide-specific B cells and MHC class II-mediated presentation of the constituent peptides to specific T cells, generating antigen-specific T cell help to PPS-binding B cells. The result is conversion of the $\mathrm{B}$ cell response from a $\mathrm{T}$-independent to a $\mathrm{T}$-dependent response with the advantage of follicular B cell activation, germinal centre formation, affinity maturation, class switching and the generation of a long lasting $\mathrm{T}$ cell-dependent memory response $[143,310]$. This bypasses some of the difficulties associated with use of the T cell-independent PPV in healthy children under 2 years of age in whom the immune system is not yet able to generate $\mathrm{T}$ cell-independent responses and results in good immunogenicity [311] and protection against invasive disease [312,313] in this population. The role of this vaccine in protection against IPD in older children and adults is currently under review.

The T cell-dependent nature of the immune response to PCV is likely to be of benefit in the immunocompromised including HIV-infected patients, who, through 
mechanisms already discussed, have impaired B cell responsiveness and limited ability to generate T-independent responses [119]. However, evidence for increased immunogenicity in this patient group remains controversial. In HIV-infected adults, study findings are largely inconsistent and comparison is challenging due to different schedules and combinations of pneumococcal immunisation. Most studies demonstrate improved antibody response in HIV-uninfected compared to infected individuals $[184,185]$. PCV has nevertheless been associated with a reduction in vaccine-serotype IPD in HIV-infected adults even not on treatment [186], though the limited serotype coverage of conjugate vaccines remains an issue of concern.

In children, analysis of the evidence is confounded by differences in vaccine formulation, dosing schedule, age, disease and treatment status at immunisation and epidemiological factors (reviewed in [165]). Data from South Africa [314,315] suggest that reduced immunogenicity in HIV-infected children is manifest only when not treated with ART. This is confirmed by a study by Nachman et al. [316] in the United States, also showing similar immunogenicity between HIV-infected but ART-treated infants and healthy control infants. Concerns regarding persistence of PCV-generated immunity exist [317,318]), however. Only one study has examined clinical efficacy. This South African randomised placebo controlled trial [319] showed that PCV was efficacious in preventing vaccine serotype-specific IPD in HIV-infected infants in all patients and showed non-significant reductions in mortality. Five year follow up of the same study [320], however, showed reduced efficacy in the HIV-infected group compared to the control group.

Little work has been done to compare directly the efficacy of PPV and PCV. Ahmed et al. [184] showed that in uninfected individuals, conjugate vaccine resulted in greater antibody concentrations than PPV, whereas in HIV-infected individuals there were no differences in immune response comparing the two vaccine types. Ho and colleagues [321], in South America, showed that both PPV23 and PCV7 were safe and immunogenic in HIV-infected adults, and that PCV7 was more immunogenic than PPV, eliciting greater and more persistent antibody concentrations for several serotypes. In a small number of HIV-infected infants and children, 5-valent PCV was more immunogenic than PPV [322]. A prime-boost strategy is also of interest, using 
PCV to prime the immune response and subsequent PPV administration to boost it and possibly recruit the additional serotypes present in PPV. Sequential vaccination with PCV and PPV led to greater antibody concentrations than reached after vaccination with PPV alone in HIV-infected adults in one study [323].

\subsubsection{Evaluation of PPS-specific serum IgM and IgG concentration}

As discussed in Chapter 1, the immune response to pneumococcal infection and immunisation is complex. $\operatorname{IgM}$ anti-pneumococcal antibody is a polymeric antibody which binds to pneumococcal capsular antigens. Unmutated IgM [324], also known as natural antibody, is thought to exist even without antigenic stimulation, and is relatively non-specific (reviewed in [325]). Mutated IgM PPS-specific antibody is believed to be produced by marginal zone memory cells (reviewed in [135]); the need for antigenic stimulation to drive this is unclear, but may result from longstanding pneumococcal nasopharyngeal colonisation or from natural infection or pneumococcal polysaccharide vaccine. Cross-linking of the B cell receptor of newly recruited short lived antigen-specific B cells by PPS is thought to drive rapid differentiation to plasma cells, which continue to secrete anti-pneumococcal $\operatorname{IgM}$ antibody (reviewed in [310]). Measurement of PPS-specific IgM concentrations, therefore, may provide an index of pre-existing natural and MZM immunity, in addition to representing an acute response to immunisation.

IgG antibody is the isotype found most frequently in the human circulation and is synthesised and secreted by plasma cells after class switching has occurred, as part of the adaptive immune response. IgG is produced mainly by T-dependent pathways. Long term production of $\mathrm{IgG}$ in response to a particular antigen relies on a combination of antibody production by long lived, terminally differentiated, plasma cells and the maintenance of a population of memory cells. These cells have undergone a germinal centre reaction with affinity maturation, and can rapidly differentiate into short lived, IgG secreting, plasma cells if the cognate antigen is reencountered (reviewed in [326]). Measurement of circulating PPS-specific IgG, therefore, may represent the generation of effective long lived memory and plasma cell populations following the GC reaction, in response to both colonisation and natural Pnc infection. Although PPV immunisation is not considered to result in significant generation of primary long lived IgG-mediated immunity, it is thought 
that PPV can boost pre-existing IgG memory [292]. In addition, there is increasing evidence that Pnc-specific IgM may have an important role in promoting the generation of long lasting, IgG-mediated, switched memory [190,191], possibly through its role in antigenic localisation to the spleen [189], promoting the GC centre reaction required to generate long-lived memory and plasma cells secreting Pncspecific $\operatorname{IgG}$.

In individuals with HIV infection, both MZM and switched memory B cell populations are known to be impaired, as discussed in Chapter 1 and shown in Chapter 3 of this thesis. Evaluation of PPS-specific IgM and IgG concentrations, pre- and post-immunisation with PPV, and comparison to healthy controls, provides some insight into the impaired immune response in HIV infection to this important pathogen.

\subsection{Methods}

The methods are fully described in Chapter 2, section 2.9. Baseline serum samples were taken pre-immunisation to evaluate for evidence of natural and pre-existing MZM immunity and PPV was then used to assess the ability of CON, HIV-V and HIV-H to generate and / or boost both short (IgM) and longer lived (IgG) serological memory responses. This was assessed by measurement of $\operatorname{IgM}$ and $\operatorname{IgG}$ antibody concentration in the blood at baseline, 28 days and one year after immunisation. Briefly, quantification of pneumococcal polysaccharide serotype-specific $\operatorname{IgM}$ and IgG was performed using an established flow based multiplex assay at the Clinical Immunology laboratory, Papworth Hospital NHS Trust. The assay is based on a method described by Lal et al. [246], in which individual carboxylated fluorescent beads were coated with serotype specific pneumococcal capsular polysaccharide. A pre-absorption stage with cell wall polysaccharide [247] and serotype 22F [248] was performed to eliminate cross-reactive binding. Beads were then analysed by flow cytometry and pneumococcal PS binding activity quantified.

The percentage of serotypes to which the subject has a putatively protective concentration of antibody is a useful index of protection. Cut-off serum 
concentration levels in this study have been defined as an antibody concentration greater than a) $0.35 \mu \mathrm{g} / \mathrm{ml}$ and b) $1.3 \mu \mathrm{g} / \mathrm{ml}$. These values are arbitrary and were selected to correspond to the titres of $\operatorname{IgG}$ antibody which are considered by the World Health Organization to be clinically protective against pneumococcal infection and/or colonisation [327] [328,329]. In the context of immunisation, the number of vaccine serotypes to which an individual responds has also been used to diagnose antibody deficiency. Depending on the number of serotypes assessed, a response to less than $50-70 \%$ of vaccine serotypes is considered to be indicative of antibody deficiency [330,331].

A possible impact of viral control in early life was also considered. A comparison was performed between those HIV-V subjects who had achieved and maintained an undetectable viral load before the age of 10 years $\left(\mathrm{HIV}-\mathrm{V}^{\mathrm{E}}\right)$, and those who were aviraemic at the time of sampling but without a history of early viral control $<10 \mathrm{y}$ of age $\left(\mathrm{HIV}-\mathrm{V}^{-}\right)$.

\subsection{Results}

Samples taken at baseline, D28 and 1 year were analysed for serotype-specific IgM and IgG in all subject groups (shown in Table 4.1). The relationship between prevaccination immunity and vaccine responsiveness was explored and compared between the cohorts. 


\begin{tabular}{|l|l|l|l|l|}
\hline & & \multicolumn{3}{|l|}{ HIV infected } \\
\hline & & \multicolumn{1}{|c|}{ CONjects } & HIV-V & HIV-H \\
\hline n (samples available for serology) & $\begin{array}{l}\text { Samples at any timepoint } \\
\text { combination }\end{array}$ & 52 & 64 & 26 \\
\hline & D0 sample & 51 & 63 & 25 \\
\hline & D28 sample & 49 & 12 & 6 \\
\hline & 1 y sample & 48 & 53 & 17 \\
\hline & Paired D0 - D28 & 49 & 12 & 6 \\
\hline Viral load undetectable at time of first & Paired D0 - 1y & 48 & 52 & 17 \\
\hline sample (n) & Paired D28-1y & 47 & 10 & 5 \\
\hline Viral load detectable at time of first & & 45 & 10 & 5 \\
\hline sample (n) & & & 34 & 14 \\
\hline Viral load unknown (n) & & & 1 & 0 \\
\hline
\end{tabular}

Table 4.1. Samples included in serological analysis.

\subsubsection{IgM anti-pneumococcal antibody}

\section{Antibody concentration at baseline, day 28 and 1 year after immunisation with PPV}

IgM antibody concentrations are shown at baseline and at 28 days and 1 year after immunisation in all subject groups (Figure 4.1). Matched pair analysis showed the same pattern as analysis of the entire cohort, thus data from all subjects regardless of matching status is shown. IgM antibody was present at baseline for all cohorts. All cohorts achieved an increase in concentration 28 days after immunisation compared to the baseline (with the exception of a single serotype, 6B, in the HIV-H cohort); however this was significant for all serotypes only in the control group ${ }^{2}$ with four and two serotype-specific IgM concentrations not rising significantly in HIV-V $\mathrm{V}^{3}$ and $\mathrm{HIV}-\mathrm{H}^{4}$ groups respectively. This pattern was maintained at one year in all groups,

\footnotetext{
${ }^{2} p<0.001$ for all serotypes except $23 F$ where $p=0.01$

${ }^{3} \mathrm{p}$ values for serotypes as follows: 0.007 (1), 0.028 (4), 0.158 (5), 0.062 (6B), 0.041 (7F), 0.504 (14),

0.272 (19F), 0.011 (23F)

${ }^{4} p$ values for all serotypes as follows: $0.043(1), 0.043(4), 0.043(5), 0.043(6 B), 0.043$ (7F), 0.144

(14), 0.043 (19F), 0.225 (23F)
} 
with a significant increase in all serotypes in the control group ${ }^{5}$ and less serotype coverage in $\mathrm{HIV}-\mathrm{V}^{6}$ and $\mathrm{HIV}-\mathrm{H}^{7}$.

${ }_{6}^{5} p<0.001$ for all serotypes except $23 F$ where $p=0.012$

${ }^{6} \mathrm{p}$ values for all serotypes as follows: $<0.001(1),<0.001(4),<0.001(5),<0.001(6 \mathrm{~B}), 0.057(7 \mathrm{~F}),<$ 0.001 (14), 0.176 (19F), < 0.001 (23F)

${ }^{7} \mathrm{p}$ values for all serotypes as follows: 0.015 (1), 0.001 (4), 0.003 (5), 0.023 (6B), 0.394 (7F), 0.023 (14), 0.018 (19F), 0.152 (23F) 


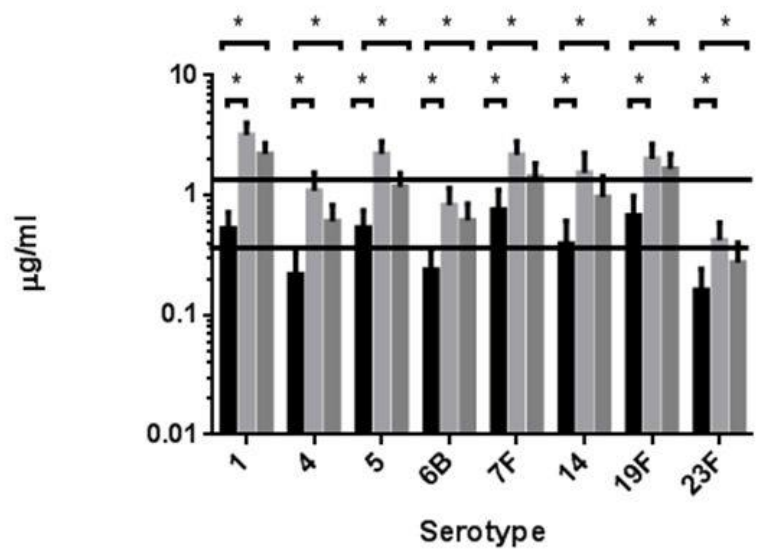

a) $\operatorname{CON} ; n=51$ (D0), 49 (D28), 48 (1y)

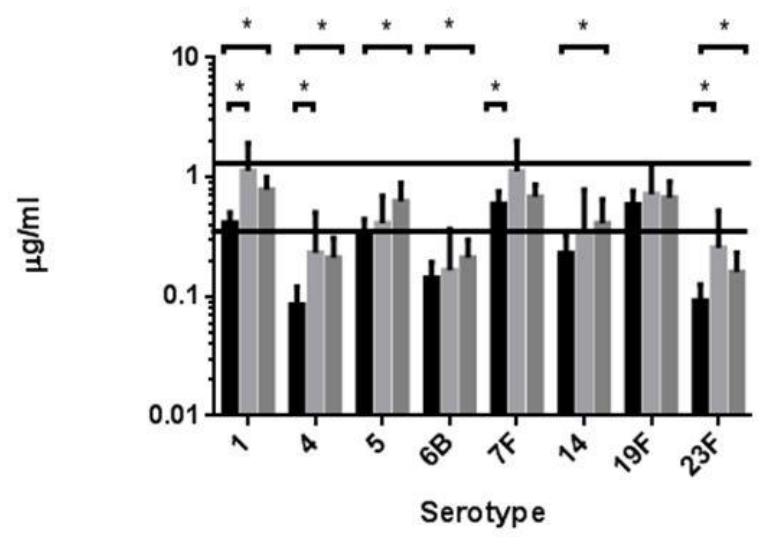

b) HIV-V: $n=63$ (D0), 12 (D28), 53(1y)

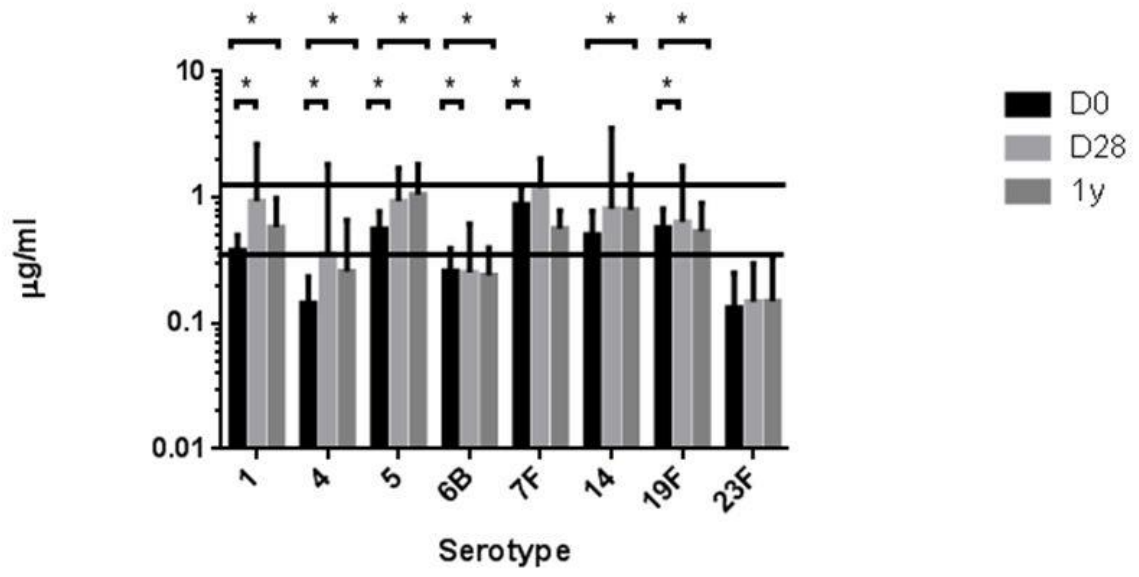

c) HIV-H: $\mathrm{n}=25$ (D0), 6 (D28), 17 (1y)

Figure 4.1: Serum IgM concentration (ug/ml, GMT with 95\% CI) in all groups.

The $0.35 \mu \mathrm{g} / \mathrm{ml}$ and $1.3 \mu \mathrm{g} / \mathrm{ml}$ IgM concentrations are shown by the solid line. *: $\mathrm{p}<0.05$ for the comparison between D0 and D28 (bottom) and D0 and 1y (top). 
Between-group comparisons (shown in Table 4.2) showed that IgM concentration was significantly greater at baseline in the control group than HIV-V in six serotypes $^{8}$, and greater than HIV-H (though not significantly so) in four serotypes ${ }^{9}$. IgM was greater in the controls than HIV-V ${ }^{10}$ and HIV-H ${ }^{11}$ in 7 and 6 serotypes respectively at a month and greater than HIV-V in all serotypes ${ }^{12}$ and HIV-H in 5 serotypes ${ }^{13}$ at a year after immunisation. The difference between healthy control and HIV-infected cohorts was most marked in the increase in antibody concentration at day 28 compared to baseline levels. There was a trend to slightly greater values in HIV-H than HIV-V at all timepoints, although this was not consistent across all serotypes and rarely reached significance ${ }^{14}$.

\footnotetext{
${ }^{8} \mathrm{p}$ values for all serotypes as follows: 0.193 (1), < 0.001 (4), 0.011 (5), 0.017 (6B), 0.028 (7F), 0.020 (14), 0.125 (19F), 0.031 (23F)

${ }^{9} \mathrm{p}$ values for all serotypes as follows: 0.188 (1), 0.125 (4), 0.691 (5), 0.930 (6B), 0.670 (7F), 0.634 (14), 0.131 (19F), 0.462 (23F)

${ }^{10} \mathrm{p}$ values for all serotypes as follows: $0.001(1),<0.001(4),<0.001(5), 0.001(6 \mathrm{~B}), 0.013$ (7F), 0.001 (14), 0.003 (19F), 0.078 (23F)

${ }^{11} \mathrm{p}$ values for all serotypes as follows: 0.004 (1), 0.068 (4), 0.015 (5), 0.020 (6B), 0.031 (7F), 0.229 (14), 0.020 (19F), 0.022 (23F)

${ }^{12} \mathrm{p}$ values for all serotypes as follows: $<0.001(1),<0.001(4), 0.007(5),<0.001(6 \mathrm{~B}),<0.001(7 F)$, 0.004 (14), < 0.001 (19F), 0.020 (23F)

${ }^{13} \mathrm{p}$ values for all serotypes as follows: $<0.001$ (1), 0.056 (4), 0.725 (5), 0.002 (6B), < 0.001 (7F), 0.511 (14), < 0.001 (19F), 0.044 (23F)

${ }^{14} \mathrm{p}$ values for all serotypes as follows:

D0: 0.617 (1), 0.133 (4), 0.047 (5), 0.028 (6B), 0.089 (7F), 0.011 (14), 0.640 (19F), 0.366 (23F)

D28 0.646 (1), 0.799 (4), 0.037 (5), 0.442 (6B), 0.721 (7F), 0.195 (14), 0.799 (19F), 0.279 (23F)

1y: 0.201 (1), 0.888 (4), 0.099 (5), 0.796 (6B), 0.225 (7F), 0.119 (14), 0.264 (19F), 0.662 (23F)
} 


\begin{tabular}{|c|c|c|c|c|c|c|c|c|c|}
\hline \multirow[t]{2}{*}{ Serotype } & \multicolumn{3}{|l|}{ D0 } & \multicolumn{3}{|l|}{ D28 } & \multicolumn{3}{|l|}{$1 y$} \\
\hline & $\mathrm{CON}$ & HIV-V & HIV-H & $\mathrm{CON}$ & HIV-V & HIV-H & $\mathrm{CON}$ & HIV-V & HIV-H \\
\hline $\mathbf{N}$ & 51 & 63 & 25 & 49 & 12 & 6 & 48 & 53 & 17 \\
\hline 1 & $\begin{array}{l}0.53 \\
(0.39- \\
0.72)\end{array}$ & $\begin{array}{l}0.42 \\
(0.34- \\
0.51)\end{array}$ & $\begin{array}{l}0.38 \\
(0.28- \\
0.50)\end{array}$ & $\begin{array}{l}3.27 \\
(2.52- \\
4.01)\end{array}$ & $\begin{array}{l}1.13^{*} \\
(0.66- \\
1.92)\end{array}$ & $\begin{array}{l}0.94 * \\
(0.33- \\
2.65)\end{array}$ & $\begin{array}{l}2.22 \\
(1.82- \\
2.71)\end{array}$ & $\begin{array}{l}0.78^{*} \\
(0.61- \\
1.00)\end{array}$ & $\begin{array}{l}0.58^{*} \\
(0.34- \\
0.99)\end{array}$ \\
\hline 4 & $\begin{array}{l}0.22 \\
(0.14- \\
0.34)\end{array}$ & $\begin{array}{l}0.09 * \\
(0.06- \\
0.12)\end{array}$ & $\begin{array}{l}0.14 \\
(0.09- \\
0.24)\end{array}$ & $\begin{array}{l}1.09 \\
(0.78- \\
1.53)\end{array}$ & $\begin{array}{l}0.23^{*} \\
(0.11- \\
0.51)\end{array}$ & $\begin{array}{l}0.36 \\
(0.07- \\
1.84)\end{array}$ & $\begin{array}{l}0.61 \\
(0.45- \\
0.83)\end{array}$ & $\begin{array}{l}0.21^{*} \\
(0.15- \\
0.31)\end{array}$ & $\begin{array}{l}0.26 \\
(0.10- \\
0.66)\end{array}$ \\
\hline 5 & $\begin{array}{l}0.54 \\
(0.39- \\
0.74)\end{array}$ & $\begin{array}{l}0.35^{*} \\
(0.27- \\
0.44)\end{array}$ & $\begin{array}{l}0.56 \dagger \\
(0.41- \\
0.77)\end{array}$ & $\begin{array}{l}2.23 \\
(1.76- \\
2.81)\end{array}$ & $\begin{array}{l}0.41 * \\
(0.24- \\
0.70)\end{array}$ & $\begin{array}{l}0.94 * \dagger \\
(0.51- \\
1.71)\end{array}$ & $\begin{array}{l}1.17 \\
(0.90- \\
1.52)\end{array}$ & $\begin{array}{l}0.63 * \\
(0.44- \\
0.89)\end{array}$ & $\begin{array}{l}1.05 \\
(0.60- \\
1.84)\end{array}$ \\
\hline 6B & $\begin{array}{l}0.24 \\
(0.061- \\
0.35)\end{array}$ & $\begin{array}{l}0.14 * \\
(0.11- \\
0.19)\end{array}$ & $\begin{array}{l}0.26 \dagger \\
(0.17- \\
0.39)\end{array}$ & $\begin{array}{l}0.82 \\
(0.59- \\
1.14)\end{array}$ & $\begin{array}{l}0.16^{*} \\
(0.07- \\
0.37)\end{array}$ & $\begin{array}{l}0.26^{*} \\
(0.10- \\
0.62)\end{array}$ & $\begin{array}{l}0.60 \\
(0.43- \\
0.84)\end{array}$ & $\begin{array}{l}0.21^{*} \\
(0.15- \\
0.30)\end{array}$ & $\begin{array}{l}0.24 * \\
(0.15- \\
0.40)\end{array}$ \\
\hline $7 F$ & $\begin{array}{l}0.76 \\
(0.51- \\
1.11)\end{array}$ & $\begin{array}{l}0.59 * \\
(0.46- \\
0.76)\end{array}$ & $\begin{array}{l}0.88 \\
(0.64- \\
1.20)\end{array}$ & $\begin{array}{l}2.17 \\
(1.67- \\
2.83)\end{array}$ & $\begin{array}{l}1.12 * \\
(0.63- \\
2.01)\end{array}$ & $\begin{array}{l}1.18^{*} \\
(0.69- \\
2.02)\end{array}$ & $\begin{array}{l}1.43 \\
(1.10- \\
1.84)\end{array}$ & $\begin{array}{l}0.69^{*} \\
(0.54- \\
0.87)\end{array}$ & $\begin{array}{l}0.56^{*} \\
(0.40- \\
0.79)\end{array}$ \\
\hline 14 & $\begin{array}{l}0.39 \\
(0.25- \\
0.61)\end{array}$ & $\begin{array}{l}0.23^{*} \\
(0.16- \\
0.33)\end{array}$ & $\begin{array}{l}0.50 \dagger \\
(0.33- \\
0.78)\end{array}$ & $\begin{array}{l}1.53 \\
(1.04- \\
2.26)\end{array}$ & $\begin{array}{l}0.34 * \\
(0.14- \\
0.79)\end{array}$ & $\begin{array}{l}0.81 \\
(0.19- \\
3.55)\end{array}$ & $\begin{array}{l}0.97 \\
(0.65- \\
1.44)\end{array}$ & $\begin{array}{l}0.41^{*} \\
(0.26- \\
0.65)\end{array}$ & $\begin{array}{l}0.80 \\
(0.42- \\
1.51)\end{array}$ \\
\hline $19 \mathrm{~F}$ & $\begin{array}{l}0.68 \\
(0.47- \\
0.98)\end{array}$ & $\begin{array}{l}0.59 \\
(0.45- \\
0.77)\end{array}$ & $\begin{array}{l}0.57 \\
(0.41- \\
0.81)\end{array}$ & $\begin{array}{l}2.01 \\
(1.51- \\
2.68)\end{array}$ & $\begin{array}{l}0.73^{*} \\
(0.40- \\
1.30)\end{array}$ & $\begin{array}{l}0.64^{*} \\
(0.23- \\
1.77)\end{array}$ & $\begin{array}{l}1.67 \\
(1.25- \\
2.23)\end{array}$ & $\begin{array}{l}0.67 * \\
(0.49- \\
0.91)\end{array}$ & $\begin{array}{l}0.54^{*} \\
(0.32- \\
0.90)\end{array}$ \\
\hline $23 F$ & $\begin{array}{l}0.16 \\
(0.11- \\
0.24)\end{array}$ & $\begin{array}{l}0.09 * \\
(0.07- \\
0.13)\end{array}$ & $\begin{array}{l}0.13 \\
(0.07- \\
0.25)\end{array}$ & $\begin{array}{l}0.42 \\
(0.30- \\
0.59)\end{array}$ & $\begin{array}{l}0.26 \\
(0.12- \\
0.52)\end{array}$ & $\begin{array}{l}0.15^{*} \\
(0.07- \\
0.30)\end{array}$ & $\begin{array}{l}0.28 \\
(1.89- \\
0.40)\end{array}$ & $\begin{array}{l}0.16^{*} \\
(0.11- \\
0.23)\end{array}$ & $\begin{array}{l}0.15^{*} \\
(0.07- \\
0.33)\end{array}$ \\
\hline
\end{tabular}

Table 4.2. Serum IgM concentration.

Serum IgM antibody concentration ( $\mu \mathrm{g} / \mathrm{ml}$, GMT, with $95 \% \mathrm{CI}$ ) by serotype at D0, D28 and 1 year is shown for each patient cohort. $\mathrm{n}=$ number of samples included in the analysis. $*$ : $\mathrm{p}<0.05$ for the comparison with CON at same timepoint $\uparrow: \mathrm{p}<0.05$ for the comparison between HIV-V and HIV-H at same timepoint.

Spread of data and serotype dominance was similar in all cohorts both pre- and postimmunisation with PPV (data not shown), with lower IgM responses to serotypes 4, $6 \mathrm{~B}$ and $23 \mathrm{~F}$ and greater responses to serotypes $1,5,7 \mathrm{~F}$ and $19 \mathrm{~F}$.

Correlation of IgM concentration at baseline, day 28 and 1 year after immunisation were assessed, to identify whether baseline concentration was predictive of subsequent short or longer term IgM response (Table 4.3). Baseline IgM concentration did not predict the IgM response at 28 days post immunisation in any 
subject group. There was, however, a positive correlation between baseline IgM concentration and $\operatorname{IgM}$ response at 1 year, in all groups, suggesting an association between the pre-immunisation concentration of $\operatorname{IgM}$ and the subsequent longer term IgM response. 


\begin{tabular}{|c|c|c|c|c|c|c|c|c|c|c|c|c|c|c|c|c|c|c|}
\hline & \multicolumn{6}{|c|}{ D0 vs D28 } & \multicolumn{6}{|c|}{ D0 vs 1y } & \multicolumn{6}{|c|}{ D28 vs $1 y$} \\
\hline & \multicolumn{2}{|c|}{$\mathrm{CON}$} & \multicolumn{2}{|c|}{ HIV-V } & \multicolumn{2}{|c|}{ HIV-H } & \multicolumn{2}{|c|}{$\mathrm{CON}$} & \multicolumn{2}{|c|}{ HIV-V } & \multicolumn{2}{|c|}{ HIV-H } & \multicolumn{2}{|c|}{$\mathrm{CON}$} & \multicolumn{2}{|c|}{ HIV-V } & \multicolumn{2}{|c|}{ HIV-H } \\
\hline & $\mathbf{r}$ & p & $\mathbf{r}$ & $\mathbf{P}$ & $\mathbf{r}$ & $\mathbf{p}$ & $\mathbf{r}$ & $\mathbf{p}$ & $\mathbf{r}$ & $\mathbf{p}$ & $\mathbf{r}$ & $\mathbf{p}$ & $\mathbf{r}$ & p & $\mathbf{r}$ & $\mathbf{p}$ & $\mathbf{R}$ & $\mathbf{p}$ \\
\hline 1 & 0.025 & 0.867 & 0.032 & 0.923 & 0.051 & 0.935 & 0.099 & 0.512 & $0.488^{*}$ & 0.000 & $0.523^{*}$ & 0.045 & 0.176 & 0.248 & -0.091 & 0.803 & 0.600 & 0.400 \\
\hline 4 & 0.095 & 0.516 & 0.360 & 0.250 & 0.359 & 0.553 & $0.457^{*}$ & 0.001 & $0.730^{*}$ & 0.000 & $0.776^{*}$ & 0.001 & $0.304 *$ & 0.042 & 0.037 & 0.920 & 0.800 & 0.200 \\
\hline 5 & 0.116 & 0.427 & 0.144 & 0.656 & 0.600 & 0.285 & 0.535 & 0.213 & $0.565^{*}$ & 0.000 & $0.864^{*}$ & 0.000 & 0.192 & 0.206 & -0.261 & 0.467 & 0.400 & 0.600 \\
\hline $6 \mathrm{~B}$ & 0.045 & 0.760 & $0.638^{*}$ & 0.025 & 0.400 & 0.505 & $0.487^{*}$ & 0.008 & $0.797 *$ & 0.000 & $0.968^{*}$ & 0.000 & $0.429^{*}$ & 0.003 & -0.134 & 0.713 & 0.400 & 0.600 \\
\hline $7 F$ & 0.253 & 0.080 & -0.410 & 0.186 & 0.300 & 0.624 & $0.385^{*}$ & 0.049 & $0.653^{*}$ & 0.000 & 0.304 & 0.271 & $0.370^{*}$ & 0.012 & -0.394 & 0.260 & 0.200 & 0.800 \\
\hline 14 & 0.094 & 0.521 & 0.357 & 0.255 & $\begin{array}{l}- \\
0.300\end{array}$ & 0.624 & 0.483 & 0.123 & 0.793* & 0.000 & $0.770^{*}$ & 0.001 & $0.366^{*}$ & 0.013 & 0.036 & 0.920 & 0.800 & 0.200 \\
\hline 19F & 0.207 & 0.153 & 0.441 & 0.152 & 0.400 & 0.505 & 0.344 & 0.162 & $0.775^{*}$ & 0.000 & $0.574^{*}$ & 0.025 & $0.395^{*}$ & 0.007 & 0.067 & 0.855 & 0.400 & 0.600 \\
\hline 23 & 0.255 & 0.076 & $0.855^{*}$ & 0.000 & 0.100 & 0.873 & $0.446^{*}$ & 0.002 & $0.878^{*}$ & 0.000 & $0.751^{*}$ & 0.001 & $0.508^{*}$ & 0.000 & $0.854^{*}$ & 0.002 & 0.800 & 0.200 \\
\hline
\end{tabular}

Table 4.3. Correlation analysis of IgM concentrations at various timepoints for all cohorts.

$\mathrm{r}$ values and $\mathrm{p}$ values are shown for each cohort for each serotype. *: $\mathrm{p}<0.05$

DISCARD THIS PAGE 


\section{Serotype coverage}

The percentage of subjects in each group responding to at least $70 \%$ of serotypes with serum $\mathrm{IgM}$ concentration of $>0.35 \mathrm{ug} / \mathrm{ml}$ and $>1.3 \mathrm{ug} / \mathrm{ml}$ was examined (Figure 4.2) and showed marked differences between patient groups ${ }^{15,16}$. At one year post immunisation, $80.4 \%$ of control subjects, $37.7 \%$ of vertically infected and $53.3 \%$ of horizontally infected patients had achieved concentrations exceeding $0.35 \mu \mathrm{g} / \mathrm{ml}$ in more than $70 \%$ of serotypes; this dropped to $15.2 \%$ in controls and $1.89 \%$ and $0.0 \%$ in vertically and horizontally infected patients respectively when the higher cut off of $1.3 \mu \mathrm{g} / \mathrm{ml}$ was examined.
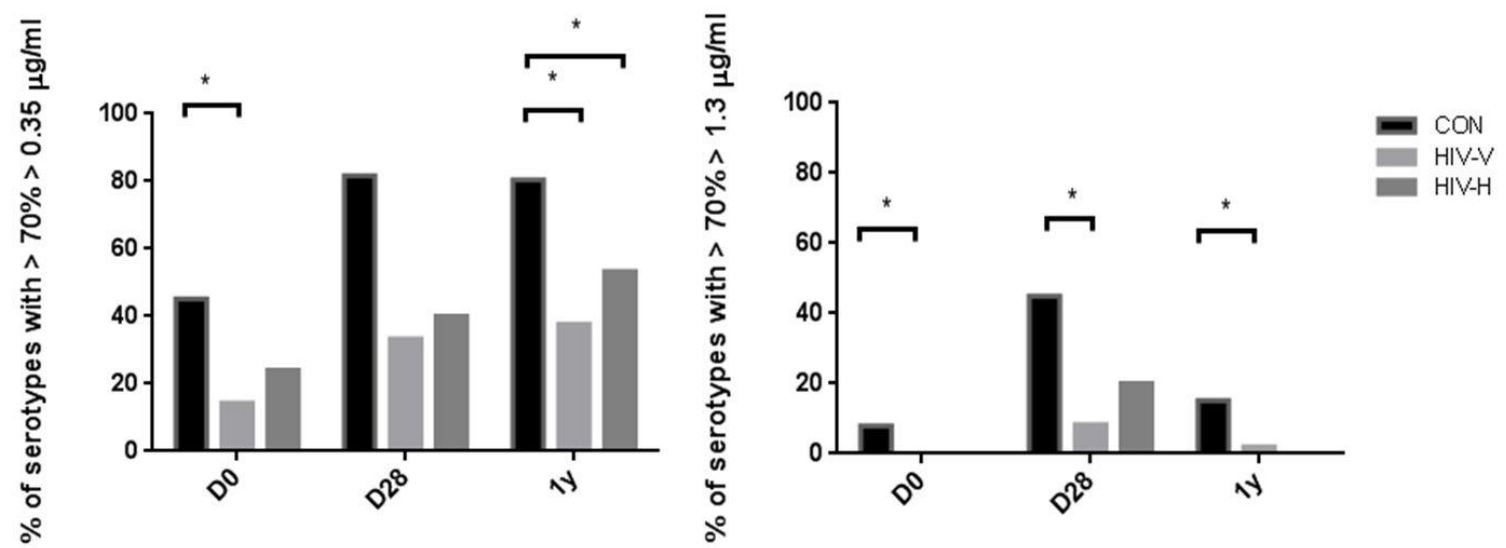

a) ) $>0.35 \mu \mathrm{g} / \mathrm{ml}$

b) $>1.3 \mu \mathrm{g} / \mathrm{ml}$

Figure 4.2. >70\% serotype coverage - IgM.

The percentage of subjects with $>70 \%$ serotypes reaching serum IgM concentration of a) $>0.35 \mu \mathrm{g} / \mathrm{ml}, \mathrm{b})>1.3$ $\mu \mathrm{g} / \mathrm{ml}$, in each group, is shown at D0, D28 and 1y. $\mathrm{n}=51,49,48(\mathrm{CON}) ; 63,12,53(\mathrm{HIV}-\mathrm{V})$, and 25, 6, 17 (HIV-H), at D0, D28 and 1y respectively. *: $\mathrm{p}<0.05$ for the comparison between groups at each timepoint.

The average percentage of serotypes with $\operatorname{IgM}$ concentration $>0.35 \mu \mathrm{g} / \mathrm{ml}$ and 1.3 $\mu \mathrm{g} / \mathrm{ml}$ was also examined in each subject group (Figure 4.3) and showed a clear trend for control subjects to achieve a greater percentage of serotype coverage at all

\footnotetext{
${ }^{15} 0.35 \mathrm{ug} / \mathrm{ml}$ cut off: $\mathrm{p}$ values for all timepoints as follows: CON cf HIV-V: $<0.001$ (D0), 0.263(D28), < 0.001 (1y)

CON cf HIV-H: 0.244 (D0), 0.266 (D28), 0.05 (1y) HIV-V cf HIV-H: 0.178 (D0), 1.00 (D28), 0.279 (1y)

${ }^{16} 1.3 \mathrm{ug} / \mathrm{ml}$ cut off: $\mathrm{p}$ values for all timepoints as follows: CON cf HIV-V: 0.037 (D0), 0.022 (D28), 0.023 (1y) CON cf HIV-H: 0.571 (D0), 0.380 (D28), 0.325 (1y) HIV-V cf HIV-H: N/A (D0), 0.515 (D28), 1.00 (1y)
} 
timepoints than HIV-infected groups. Using a cut off of $0.35 \mu \mathrm{g} / \mathrm{ml}^{17}$, at baseline, mean serotype coverage was reduced in the HIV infected cohorts compared with controls and whilst serotype coverage increased at D28 post immunisation, the increase was less in the disease groups. By 1 year, mean serotype coverage in all groups had fallen only slightly in all groups, again with lower mean serotype coverage in both disease groups. When the higher cut off of $1.3 \mu \mathrm{g} / \mathrm{ml}$ was examined $^{18}$, mean serotype coverage at baseline in CON was $18.38 \%$, HIV-V $7.54 \%$ and HIV-H $11.25 \%$. At one month, mean serotype coverage in HIV-V and HIV-H was lower than in $\mathrm{CON}$ and this pattern persisted at $1 \mathrm{y}$. When both responses to more than $70 \%$ of serotypes and percentage of serotype coverage was considered, there was a trend to a greater response of HIV-H than HIV-V subjects at both response levels but this did not reach statistical significance.

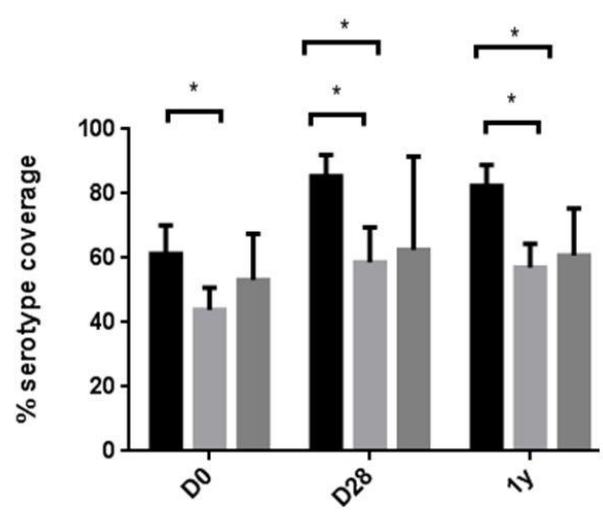

a) ) $>0.35 \mu \mathrm{g} / \mathrm{ml}$

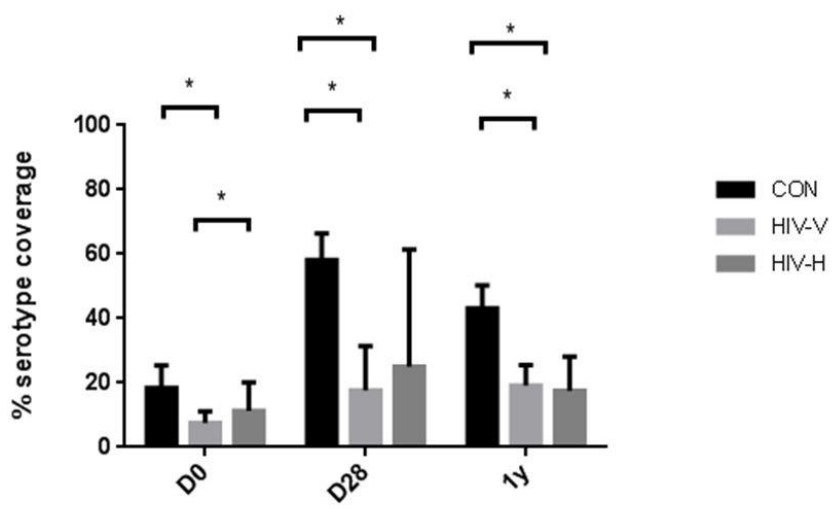

b) $>1.3 \mu \mathrm{g} / \mathrm{ml}$

Figure 4.3: Percentage serotype coverage - IgM.

The percentage of serotypes (mean with $95 \% \mathrm{CI}$ ) against which IgM concentration reaches a) $>0.35 \mu \mathrm{g} / \mathrm{ml}, \mathrm{b}$ ) $>1.3 \mu \mathrm{g} / \mathrm{ml}$ is shown at each timepoint. $\mathrm{n}=51,49,48(\mathrm{CON}) ; 63,12,53(\mathrm{HIV}-\mathrm{V})$, and 25, 6, $17(\mathrm{HIV}-\mathrm{H})$, at D0, D28 and 1y respectively. *: $\mathrm{p}<0.05$ for the comparison between groups at each timepoint.

\footnotetext{
${ }^{17} \mathrm{p}$ values for all timepoints as follows:

CON cf HIV-V: 0.016 (D0), < 0.001 (D28), < 0.001 (1y)

CON cf HIV-H: 0.253 (D0), < 0.001 (D28), 0.001 (1y)

HIV-V cf HIV-H: 0.203 (D0), 0.624 (D28), 0.565 (1y)

${ }^{18} \mathrm{p}$ values for all timepoints as follows:

CON cf HIV-V: < 0.001 (D0), < 0.001 (D28), < 0.001 (1y)

CON cf HIV-H: 0.160 (D0), < 0.001 (D28), < 0.001 (1y)

HIV-V cf HIV-H: < 0.001 (D0), 0.228 (D28), 0.829 (1y)
} 


\section{Viral control - current and in childhood}

The association between HIV viraemia (at the time of sampling) and IgM concentration was examined at all timepoints. There was no difference in $\operatorname{IgM}$ profile between those subjects with detectable viral load at the time of sampling, and those with effective viral control (data not shown), except in the case of HIV-V for selected serotypes, where IgM concentration was lower in those with detectable VL at D0 for 19F $(\mathrm{p}=0.005)$ and D28 for serotypes 4 and $5(\mathrm{p}$ value $=0.042$ and 0.012 respectively).

When patients who had achieved viral control early $\left(\mathrm{HIV}-\mathrm{V}^{\mathrm{E}}\right)$ were assessed, there was no difference in baseline $\operatorname{IgM}$ (except in serotype 19F; $\mathrm{p}=0.037$ ) and a trend towards increased IgM concentration in all serotypes at 1 year after immunisation compared to those with current but not early viral control (HIV-V $\left.{ }^{-}\right)$, shown in Table 4.4. There was also an increase in the percentage of serotypes with antibodies above the levels of $0.35 \mu \mathrm{g} / \mathrm{ml}$ and $1.3 \mu \mathrm{g} / \mathrm{ml}$ in HIV-V ${ }^{\mathrm{E}}$ compared to HIV-V ${ }^{-}$( $<<0.001$ and $\mathrm{p}=0.035$ respectively), at 1 year after immunisation (Table 4.5).

\begin{tabular}{|l|l|l|l|l|}
\hline & D0 & & $\mathbf{1 y}$ & \\
\hline & HIV-V $^{\mathrm{E}}$ & HIV-V $^{-}$ & HIV-V $^{\mathrm{E}}$ & HIV-V $^{-}$ \\
\hline $\mathbf{n}$ & $\mathbf{7}$ & $\mathbf{2 7}$ & $\mathbf{7}$ & $\mathbf{2 9}$ \\
\hline $\mathbf{1}$ & 0.41 & 0.38 & 1.52 & 0.80 \\
\hline $\mathbf{4}$ & 0.12 & 0.12 & 0.41 & 0.27 \\
\hline $\mathbf{5}$ & 0.35 & 0.45 & 1.24 & 0.79 \\
\hline $\mathbf{6 B}$ & 0.23 & 0.21 & 0.43 & 0.23 \\
\hline $\mathbf{7 F}$ & 0.74 & 0.67 & 1.17 & 0.62 \\
\hline $\mathbf{1 4}$ & 0.48 & 0.34 & $1.88^{*}$ & 0.47 \\
\hline $\mathbf{1 9 F}$ & $1.32^{*}$ & 0.75 & 1.41 & 0.68 \\
\hline $\mathbf{2 3 F}$ & 0.13 & 0.09 & 0.34 & 0.17 \\
\hline
\end{tabular}

Table 4.4. Early-life viral control and serum IgM concentration Serum IgM antibody concentration $\left(\mu \mathrm{g} / \mathrm{ml}\right.$; GMT) by serotype at D0 and 1 year is shown for HIV- $\mathrm{V}^{\mathrm{E}}$ and HIV-V $\mathrm{V}^{-}$ $. \mathrm{n}=$ number of samples included in the analysis. *: $\mathrm{p}<0.05$ for the comparison between HIV-V $\mathrm{V}^{\mathrm{E}}$ and HIV-V .

\begin{tabular}{|l|l|l|}
\hline & HIV-V $^{\mathbf{E}}$ & HIV-V $^{-}$ \\
\hline Mean \% serotypes $>\mathbf{0 . 3 5} \boldsymbol{\mu g} / \mathbf{m l}$ & & \\
\hline D0 & 42.86 & 46.76 \\
\hline 1y & $80.36^{*}$ & 54.33 \\
\hline Mean \% serotypes $>\mathbf{1 . 3} \boldsymbol{\mu g} / \mathbf{m l}$ & & \\
\hline D0 & 14.29 & 9.72 \\
\hline 1y & $32.14^{*}$ & 18.75 \\
\hline
\end{tabular}

Table 4.5. Early-life viral control and serotype coverage (IgM)

$* \mathrm{p}<0.05$ for comparison between HIV $-\mathrm{V}^{\mathrm{E}}$ and HIV-V $\mathrm{V}^{-}$

There was no correlation with $\mathrm{CD}^{+}$cell count and $\operatorname{IgM}$ concentration at any timepoint in either HIV-infected group (data not shown). 


\subsubsection{IgG anti-pneumococcal antibody}

\section{Concentrations at baseline, day 28 and 1 year after immunisation with PPV}

IgG antibody concentrations are shown at baseline and at 28 days and 1 year after immunisation in all subject groups (Figure 4.4). As with the $\operatorname{IgM}$ data, analysis including only those subjects with matched timepoint samples showed a similar pattern.

IgG was detectable prior to immunisation for all cohorts and increased 28 days after immunisation for all serotypes in the control ${ }^{19}$ and HIV-V group ${ }^{20}$, and for eight of the ten serotypes in HIV-H ${ }^{21}$. By 1 year after immunisation, $\mathrm{IgG}$ concentration was greater than at baseline against all serotypes for $\mathrm{CON}^{22}, \mathrm{HIV}-\mathrm{V}^{23}$ and all but one serotype for HIV $-\mathrm{H}^{24}$.

\footnotetext{
${ }^{19} \mathrm{p}$ values $<0.001$ for all serotypes

${ }^{20} \mathrm{p}$ values for all serotypes as follows: 0.028 (1), 0.005 (4), 0.012 (5), 0.028 (6B), 0.005 (7F), 0.005 (9V), 0.036 (14), 0.005 (18C), 0.017 (19F), 0.018 (23F)

${ }^{21} \mathrm{p}$ values for all serotypes as follows: $0.028(1), 0.028(4), 0.075(5), 0.043(6 \mathrm{~B}), 0.028$ (7F), 0.028 (9V), 0.043 (14), 0.028 (18C), 0.249 (19F), 0.043 (23F)

${ }^{22} \mathrm{p}$ values $<0.001$ for all serotypes

${ }^{23} \mathrm{p}$ values $<0.001$ for all serotypes

${ }^{24} \mathrm{p}$ values for all serotypes as follows: 0.001 (1), 0.005 (4), 0.055 (5), 0.003 (6B), 0.000 (7F), 0.001 (9V), 0.005 (14), 0.002 (18C), 0.007 (19F), 0.023(23F)
} 


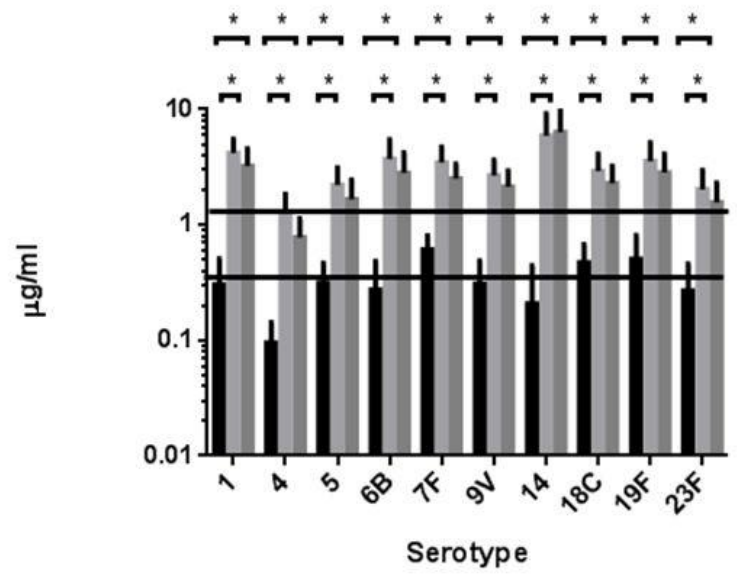

a) $\operatorname{CON} ; n=51$ (D0), 49 (D28), 48 (1y)

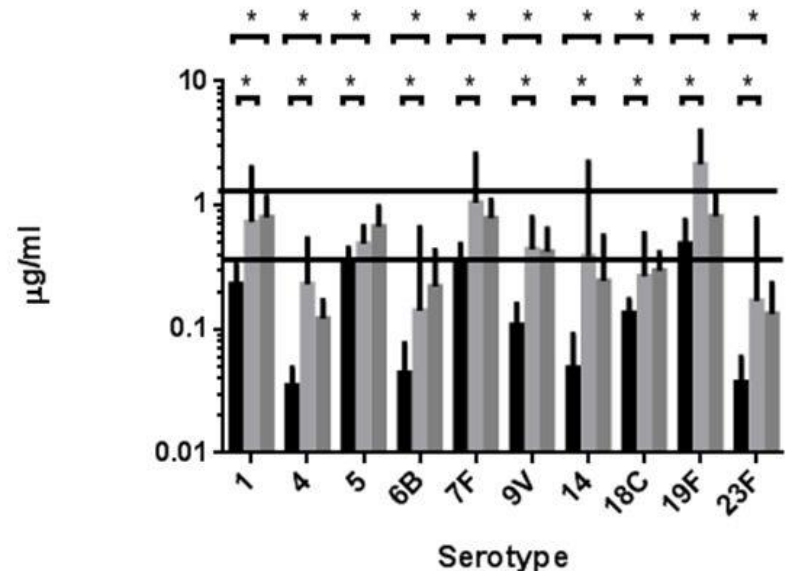

b) HIV-V: $n=63$ (D0), 12 (D28), 53(1y)

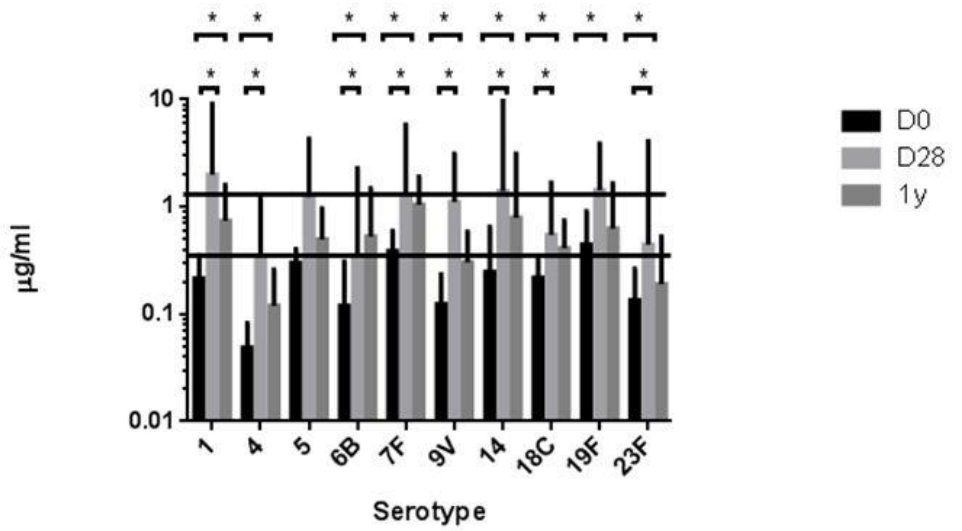

c) HIV-H: $\mathrm{n}=25$ (D0), 6 (D28), 17 (1y)

Figure 4.4: Serum IgG concentration (ug/ml, GMT with 95\% CI) in all groups.

The $0.35 \mu \mathrm{g} / \mathrm{ml}$ and $1.3 \mu \mathrm{g} / \mathrm{ml}$ IgG concentrations are shown by the solid line. *: $\mathrm{p}<0.05$ for the comparison between D0 and D28 (bottom) and D0 and 1y (top). 
IgG concentration was greater in the control group than in the HIV-infected cohorts (Table 4.6) at all bleed points for a number of serotypes and this difference increased following immunisation such that by $1 \mathrm{y}$ post immunisation, serum $\mathrm{IgG}$ concentration was greater in the control group compared with the HIV cohorts for all serotypes analysed $^{25}$. The difference between control and HIV-infected groups was greatest at day 28 for most serotypes. There was a trend to slightly greater IgG concentration in HIV-H than HIV-V disease group, particularly at D28, although this was not consistent across all serotypes and rarely reached significance ${ }^{26}$.

${ }^{25} \mathrm{p}$ values for all serotypes as follows:

DO:

CON cf HIV-V: 0.632 (1), < 0.001 (4), 0.949 (5), 0.000 (6B), 0.021 (7F), < 0.001 (9V), 0.003 (14), 0.000 (18C), $0.914(19 F),<0.001(23 F)$

CON cf HIV-H: 0.816 (1), 0.039 (4), 0.952 (5), 0.103 (6B), 0.065 (7F), 0.016 (9V), 0.914 (14), 0.006 (18C), 0.912 (19F), $0.151(23 F)$

D28:

CON cf HIV-V: $<0.001$ (1), < 0.001 (4), < 0.001 (5), 0.000 (6B), 0.004 (7F), < 0.001 (9V), $<0.001(14),<$ $0.001(18 \mathrm{C}), 0.098(19 \mathrm{~F}), 0.001(23 \mathrm{~F})$

CON cf HIV-H: $0.186(1), 0.025$ (4), 0.215 (5), 0.002 (6B), 0.052 (7F), 0.059 (9V), 0.039 (14), 0.003 (18C), 0.092(19F), $0.072(23 \mathrm{~F})$

1y:

CON cf HIV-V: $<0.001$ (1), < 0.001 (4), 0.001 (5), < 0.001 (6B), < 0.001 (7F), < 0.001 (9V), < 0.001 (14), $<0.001(18 \mathrm{C}),<0.001(19 \mathrm{~F}),<0.001(23 \mathrm{~F})$

CON cf HIV-H: 0.001 (1), < 0.001 (4), 0.002 (5), 0.001 (6B), 0.016 (7F), < 0.001 (9V), 0.002 (14), < $0.001(18 \mathrm{C}), 0.002(19 \mathrm{~F}),<0.001(23 \mathrm{~F})$

${ }^{26} \mathrm{p}$ values for all serotypes as follows:

D0: $0.771(1), 0.281(4), 0.917$ (5), 0.040 (6B), 0.683 (7F), 0.468 (9V), $0.003(14), 0.070$ (18C), 0.827 (19F),0.001 (23F)

D28: 0.256 (1), 0.404 (4), 0.048 (5), 0.462 (6B), 0.808 (7F), 0.098 (9V), $0.180(14), 0.301$ (18C), 0.350 (19F), 0.404 (23F)

1y: $0.963(1), 0.811$ (4), 0.426 (5), 0.225 (6B), 0.343 (7F), 0.564 (9V), 0.145 (14), 0.422 (18C), 0.691 (19F), 0.432 (23F) 


\begin{tabular}{|c|c|c|c|c|c|c|c|c|c|}
\hline \multirow[t]{2}{*}{ Serotype } & \multicolumn{3}{|l|}{ D0 } & \multicolumn{3}{|l|}{ D28 } & \multicolumn{3}{|l|}{$1 y$} \\
\hline & CON & HIV-V & HIV-H & $\mathrm{CON}$ & HIV-V & HIV-H & $\mathrm{CON}$ & HIV-V & HIV-H \\
\hline n & 51 & 63 & 25 & 49 & 12 & 6 & 48 & 53 & 17 \\
\hline 1 & $\begin{array}{l}0.31 \\
(0.18- \\
0.51)\end{array}$ & $\begin{array}{l}0.23 \\
(0.16- \\
0.33)\end{array}$ & $\begin{array}{l}0.21 \\
(0.13- \\
0.35)\end{array}$ & $\begin{array}{l}4.20 \\
(3.12- \\
5.54)\end{array}$ & $\begin{array}{l}0.73^{*} \\
(0.27- \\
2.01)\end{array}$ & $\begin{array}{l}1.99 \\
(0.43- \\
9.16)\end{array}$ & $\begin{array}{l}3.23 \\
(2.28- \\
4.58)\end{array}$ & $\begin{array}{l}0.80^{*} \\
(0.55- \\
1.16)\end{array}$ & $\begin{array}{l}0.74 * \\
(0.34- \\
1.59)\end{array}$ \\
\hline 4 & $\begin{array}{l}0.10 \\
(0.06- \\
0.14)\end{array}$ & $\begin{array}{l}0.03 * \\
(0.03- \\
0.05)\end{array}$ & $\begin{array}{l}0.05^{*} \\
(0.03- \\
0.08)\end{array}$ & $\begin{array}{l}1.30 \\
(0.91- \\
1.85)\end{array}$ & $\begin{array}{l}0.23^{*} \\
(0.10- \\
0.54)\end{array}$ & $\begin{array}{c}0.35^{*} \\
(0.10- \\
1.19)\end{array}$ & $\begin{array}{l}0.78 \\
(0.53- \\
1.14)\end{array}$ & $\begin{array}{l}0.12 * \\
(0.09- \\
0.17)\end{array}$ & $\begin{array}{l}0.12 * \\
(0.06- \\
0.26)\end{array}$ \\
\hline 5 & $\begin{array}{l}0.31 \\
(0.21- \\
0.47)\end{array}$ & $\begin{array}{l}0.34 \\
(0.25- \\
0.45)\end{array}$ & $\begin{array}{l}0.30 \\
(0.23- \\
0.40)\end{array}$ & $\begin{array}{l}2.21 \\
(1.56- \\
3.14)\end{array}$ & $\begin{array}{l}0.49 * \dagger \\
(0.36- \\
0.67)\end{array}$ & $\begin{array}{l}1.23 \\
(0.35- \\
4.31)\end{array}$ & $\begin{array}{l}1.66 \\
(1.13- \\
2.45)\end{array}$ & $\begin{array}{l}0.68^{*} \\
(0.47- \\
0.97)\end{array}$ & $\begin{array}{l}0.49 * \\
(0.26- \\
0.97)\end{array}$ \\
\hline 6B & $\begin{array}{l}0.28 \\
(0.16- \\
0.48)\end{array}$ & $\begin{array}{l}0.04 * \\
(0.03- \\
0.08)\end{array}$ & $\begin{array}{l}0.12 \\
(0.05- \\
0.31)\end{array}$ & $\begin{array}{l}3.73 \\
(2.54- \\
5.48)\end{array}$ & $\begin{array}{l}0.14^{*} \\
(0.03- \\
0.66)\end{array}$ & $\begin{array}{l}0.36^{*} \\
(0.05- \\
2.30)\end{array}$ & $\begin{array}{l}2.83 \\
(1.88- \\
4.24)\end{array}$ & $\begin{array}{l}0.22 * \\
(0.11- \\
0.43)\end{array}$ & $\begin{array}{l}0.53 * \\
(0.19- \\
1.48)\end{array}$ \\
\hline $7 F$ & $\begin{array}{l}0.61 \\
(0.47- \\
0.81)\end{array}$ & $\begin{array}{l}0.35^{*} \\
(0.25- \\
0.48)\end{array}$ & $\begin{array}{l}0.39 \\
(0.25- \\
0.59)\end{array}$ & $\begin{array}{l}3.47 \\
(2.55- \\
4.72)\end{array}$ & $\begin{array}{l}1.04^{*} \\
(0.42- \\
2.58)\end{array}$ & $\begin{array}{l}1.30 \\
(0.29- \\
5.84)\end{array}$ & $\begin{array}{l}2.53 \\
(1.88- \\
3.38)\end{array}$ & $\begin{array}{l}0.79 * \\
(0.57- \\
1.10)\end{array}$ & $\begin{array}{l}1.05^{*} \\
(0.57- \\
1.91)\end{array}$ \\
\hline $9 \mathrm{~V}$ & $\begin{array}{l}0.31 \\
(0.20- \\
0.49)\end{array}$ & $\begin{array}{l}0.11 * \\
(0.07- \\
0.16)\end{array}$ & $\begin{array}{l}0.12 * \dagger \\
(0.07- \\
0.23)\end{array}$ & $\begin{array}{l}2.68 \\
(1.96- \\
3.66)\end{array}$ & $\begin{array}{l}0.44^{*} \\
(0.24- \\
0.80)\end{array}$ & $\begin{array}{l}1.10 \\
(0.39- \\
3.14)\end{array}$ & $\begin{array}{l}2.13 \\
(1.55- \\
2.94)\end{array}$ & $\begin{array}{l}0.42 * \\
(0.28- \\
0.64)\end{array}$ & $\begin{array}{l}0.30^{*} \\
(0.16- \\
0.58)\end{array}$ \\
\hline 14 & $\begin{array}{l}0.21 \\
(0.10- \\
0.45)\end{array}$ & $\begin{array}{l}0.05^{*} \\
(0.03- \\
0.09)\end{array}$ & $\begin{array}{l}0.25 \dagger \\
(0.09- \\
0.65)\end{array}$ & $\begin{array}{l}5.94 \\
(3.83- \\
9.20)\end{array}$ & $\begin{array}{l}0.39 * \\
(0.07- \\
2.23)\end{array}$ & $\begin{array}{l}1.40^{*} \\
(0.10- \\
19.4)\end{array}$ & $\begin{array}{l}6.34 \\
(4.01- \\
10.04)\end{array}$ & $\begin{array}{l}0.24^{*} \\
(0.11- \\
0.56)\end{array}$ & $\begin{array}{l}0.79 * \\
(0.20- \\
3.14)\end{array}$ \\
\hline $18 \mathrm{C}$ & $\begin{array}{l}0.47 \\
(0.33- \\
0.68)\end{array}$ & $\begin{array}{l}0.13^{*} \\
(0.10- \\
0.17)\end{array}$ & $\begin{array}{l}0.22 * \\
(0.15- \\
0.33)\end{array}$ & $\begin{array}{l}2.92 \\
(2.07- \\
4.14)\end{array}$ & $\begin{array}{l}0.26^{*} \\
(0.12- \\
0.59)\end{array}$ & $\begin{array}{c}0.55^{*} \\
(0.18- \\
1.67)\end{array}$ & $\begin{array}{l}2.28 \\
(1.62- \\
2.23)\end{array}$ & $\begin{array}{l}0.30^{*} \\
(0.21- \\
0.41)\end{array}$ & $\begin{array}{l}0.41 * \\
(0.23- \\
0.75)\end{array}$ \\
\hline $19 \mathrm{~F}$ & $\begin{array}{l}0.50 \\
(0.31- \\
0.81)\end{array}$ & $\begin{array}{l}0.49 \\
(0.31- \\
0.76)\end{array}$ & $\begin{array}{l}0.45 \\
(0.22- \\
0.91)\end{array}$ & $\begin{array}{l}3.56 \\
(2.48- \\
5.13)\end{array}$ & $\begin{array}{l}2.13 \\
(1.15- \\
3.98)\end{array}$ & $\begin{array}{l}1.43 \\
(0.53- \\
3.88)\end{array}$ & $\begin{array}{l}2.84 \\
(1.96- \\
4.12)\end{array}$ & $\begin{array}{l}0.81^{*} \\
(0.52- \\
1.28)\end{array}$ & $\begin{array}{l}0.63 * \\
(0.24- \\
1.65)\end{array}$ \\
\hline 23F & $\begin{array}{l}0.27 \\
(0.16- \\
0.46)\end{array}$ & $\begin{array}{l}0.04 * \\
(0.02- \\
0.06)\end{array}$ & $\begin{array}{l}0.13 \dagger \\
(0.07- \\
0.26)\end{array}$ & $\begin{array}{l}2.03 \\
(1.39- \\
2.96)\end{array}$ & $\begin{array}{l}0.17 * \\
(0.04- \\
0.78)\end{array}$ & $\begin{array}{l}0.45 \\
(0.05- \\
4.10)\end{array}$ & $\begin{array}{l}1.57 \\
(1.07- \\
2.31)\end{array}$ & $\begin{array}{l}0.13^{*} \\
(0.07- \\
0.24)\end{array}$ & $\begin{array}{l}0.19 * \\
(0.07- \\
0.53)\end{array}$ \\
\hline
\end{tabular}

Table 4.6. Serum IgG concentration.

Serum IgG antibody concentration $(\mu \mathrm{g} / \mathrm{ml}$, GMT, with $95 \% \mathrm{CI})$ by serotype at D0, D28 and 1 year is shown for each patient cohort. $\mathrm{n}=$ number of samples included in the analysis. *: $\mathrm{p}<0-.05$ for the comparison with CON at same timepoint $\uparrow$ : significance at $\mathrm{p}<0.05$ for the comparison between HIV-V and HIV-H at same timepoint.

As with the IgM data, spread of data and serotype dominance was similar at all timepoints and across all groups (data not shown). 
To determine whether pre-existing IgG concentration predicted response to the vaccines, the correlation between baseline and subsequent IgG concentration, and responses at day 28 and 1 year after immunisation was made (Table 4.7). This showed that pre-immunisation concentration correlated with response at 28 days post-immunisation more strongly than seen with $\operatorname{IgM}$ concentration in all cohorts and a positive correlation between baseline $\operatorname{IgG}$ and $\mathrm{IgG}$ response at 1 year was also seen. As with the IgM data, there was also some correlation between IgG concentration at day 28 and 1 year post-immunisation. 


\begin{tabular}{|c|c|c|c|c|c|c|c|c|c|c|c|c|c|c|c|c|c|c|}
\hline & \multicolumn{6}{|c|}{ D0 vs D28 } & \multicolumn{6}{|c|}{ D0 vs 1y } & \multicolumn{6}{|c|}{ D28 vs $1 y$} \\
\hline & \multicolumn{2}{|c|}{ CON } & \multicolumn{2}{|c|}{ HIV-V } & \multicolumn{2}{|c|}{ HIV-H } & \multicolumn{2}{|c|}{$\mathrm{CON}$} & \multicolumn{2}{|c|}{ HIV-V } & \multicolumn{2}{|c|}{ HIV-H } & \multicolumn{2}{|c|}{ CON } & \multicolumn{2}{|c|}{ HIV-V } & \multicolumn{2}{|c|}{ HIV-H } \\
\hline & $\mathbf{r}$ & p & $\mathbf{r}$ & p & $\mathbf{r}$ & $\mathbf{p}$ & $\mathbf{r}$ & p & $\mathbf{r}$ & p & $\mathbf{r}$ & p & $\mathbf{r}$ & p & $\mathbf{r}$ & $\mathbf{p}$ & $\mathbf{r}$ & $\mathbf{p}$ \\
\hline 1 & $\begin{array}{l}0.369 \\
*\end{array}$ & $\begin{array}{l}0.00 \\
9\end{array}$ & $\begin{array}{l}0.673 \\
*\end{array}$ & $\begin{array}{l}0.03 \\
3\end{array}$ & $\begin{array}{l}0.812 \\
*\end{array}$ & $\begin{array}{l}0.05 \\
0\end{array}$ & $\begin{array}{l}0.792 \\
*\end{array}$ & $\begin{array}{l}0.00 \\
0\end{array}$ & $0.386^{*}$ & 0.05 & 0.471 & $\begin{array}{l}0.05 \\
7\end{array}$ & $\begin{array}{l}0.418 \\
*\end{array}$ & $\begin{array}{l}0.00 \\
3\end{array}$ & $\begin{array}{l}0.667 \\
*\end{array}$ & $\begin{array}{l}0.05 \\
0\end{array}$ & $\begin{array}{l}0.900 \\
*\end{array}$ & $\begin{array}{l}0.03 \\
7\end{array}$ \\
\hline 4 & $\begin{array}{l}0.329 \\
*\end{array}$ & $\begin{array}{l}0.02 \\
1\end{array}$ & 0.355 & $\begin{array}{l}0.31 \\
4\end{array}$ & 0.463 & $\begin{array}{l}0.35 \\
5\end{array}$ & $\begin{array}{l}0.628 \\
*\end{array}$ & $\begin{array}{l}0.00 \\
0\end{array}$ & $0.424^{*}$ & 0.02 & $\begin{array}{l}0.701 \\
*\end{array}$ & $\begin{array}{l}0.00 \\
2\end{array}$ & $\begin{array}{l}0.504 \\
*\end{array}$ & $\begin{array}{l}0.00 \\
0\end{array}$ & 0.469 & $\begin{array}{l}0.20 \\
3\end{array}$ & $\begin{array}{l}0.900 \\
*\end{array}$ & $\begin{array}{l}0.03 \\
7\end{array}$ \\
\hline 5 & $\begin{array}{l}0.386 \\
*\end{array}$ & $\begin{array}{l}0.00 \\
6\end{array}$ & 0.199 & $\begin{array}{l}0.58 \\
2\end{array}$ & 0.429 & $\begin{array}{l}0.39 \\
7\end{array}$ & $\begin{array}{l}0.589 \\
*\end{array}$ & $\begin{array}{l}0.00 \\
0\end{array}$ & $0.620^{*}$ & $\begin{array}{l}0.00 \\
0\end{array}$ & $\begin{array}{l}0.677 \\
*\end{array}$ & $\begin{array}{l}0.00 \\
3\end{array}$ & $\begin{array}{l}0.524 \\
*\end{array}$ & $\begin{array}{l}0.00 \\
0\end{array}$ & 0.008 & $\begin{array}{l}0.98 \\
3\end{array}$ & $\begin{array}{l}0.900 \\
*\end{array}$ & $\begin{array}{l}0.03 \\
7\end{array}$ \\
\hline 6B & $\begin{array}{l}0.321 \\
*\end{array}$ & $\begin{array}{l}0.02 \\
5\end{array}$ & $\begin{array}{l}0.643 \\
*\end{array}$ & $\begin{array}{l}0.04 \\
5\end{array}$ & 0.655 & $\begin{array}{l}0.15 \\
8\end{array}$ & $\begin{array}{l}0.733 \\
*\end{array}$ & $\begin{array}{l}0.00 \\
0\end{array}$ & $0.743^{*}$ & $\begin{array}{l}0.00 \\
0\end{array}$ & 0.381 & $\begin{array}{l}0.13 \\
1\end{array}$ & $\begin{array}{l}0.377 \\
*\end{array}$ & $\begin{array}{l}0.00 \\
9\end{array}$ & 0.648 & $\begin{array}{l}0.05 \\
9\end{array}$ & $\begin{array}{l}0.900 \\
*\end{array}$ & $\begin{array}{l}0.03 \\
7\end{array}$ \\
\hline $7 F$ & $\begin{array}{l}0.644 \\
*\end{array}$ & $\begin{array}{l}0.00 \\
0\end{array}$ & $\begin{array}{l}0.742 \\
*\end{array}$ & $\begin{array}{l}0.01 \\
4\end{array}$ & 0.714 & $\begin{array}{l}0.11 \\
1\end{array}$ & $\begin{array}{l}0.620 \\
*\end{array}$ & $\begin{array}{l}0.00 \\
0\end{array}$ & $0.660^{*}$ & $\begin{array}{l}0.00 \\
0\end{array}$ & $\begin{array}{l}0.656 \\
*\end{array}$ & $\begin{array}{l}0.00 \\
4\end{array}$ & $\begin{array}{l}0.625 \\
*\end{array}$ & $\begin{array}{l}0.00 \\
0\end{array}$ & $\begin{array}{l}0.962 \\
*\end{array}$ & $\begin{array}{l}0.00 \\
0\end{array}$ & 0.70 & $\begin{array}{l}0.08 \\
8\end{array}$ \\
\hline $9 \mathrm{~V}$ & 0.072 & $\begin{array}{l}0.63 \\
5\end{array}$ & $\begin{array}{l}0.818 \\
*\end{array}$ & $\begin{array}{l}0.00 \\
4\end{array}$ & 0.771 & $\begin{array}{l}0.07 \\
2\end{array}$ & $\begin{array}{l}0.596 \\
*\end{array}$ & $\begin{array}{l}0.00 \\
0\end{array}$ & $\begin{array}{l}0.0588 \\
*\end{array}$ & $\begin{array}{l}0.00 \\
0\end{array}$ & $\begin{array}{l}0.745 \\
*\end{array}$ & $\begin{array}{l}0.00 \\
1\end{array}$ & 0.247 & $\begin{array}{l}0.09 \\
4\end{array}$ & $\begin{array}{l}0.711 \\
*\end{array}$ & $\begin{array}{l}0.03 \\
2\end{array}$ & $\begin{array}{l}1.000 \\
*\end{array}$ & $\begin{array}{l}0.00 \\
0\end{array}$ \\
\hline 14 & 0.141 & $\begin{array}{l}0.33 \\
3\end{array}$ & 0.180 & $\begin{array}{l}0.61 \\
9\end{array}$ & 0.334 & $\begin{array}{l}0.51 \\
8\end{array}$ & $\begin{array}{l}0.634 \\
*\end{array}$ & $\begin{array}{l}0.00 \\
0\end{array}$ & $0.705^{*}$ & $\begin{array}{l}0.00 \\
0\end{array}$ & 0.419 & $\begin{array}{l}0.09 \\
4\end{array}$ & $\begin{array}{l}0.321 \\
*\end{array}$ & $\begin{array}{l}0.02 \\
8\end{array}$ & 0.426 & $\begin{array}{l}0.25 \\
3\end{array}$ & $\begin{array}{l}0.900 \\
*\end{array}$ & $\begin{array}{l}0.03 \\
7\end{array}$ \\
\hline $\begin{array}{l}18 \\
\mathrm{C}\end{array}$ & $\begin{array}{l}0.400 \\
*\end{array}$ & $\begin{array}{l}0.00 \\
4\end{array}$ & $\begin{array}{l}0.857 \\
*\end{array}$ & $\begin{array}{l}0.00 \\
2\end{array}$ & 0.314 & & $\begin{array}{l}0.793 \\
*\end{array}$ & $\begin{array}{l}0.00 \\
0\end{array}$ & $0.482^{*}$ & $\begin{array}{l}0.00 \\
0\end{array}$ & & $\begin{array}{l}0.01 \\
8\end{array}$ & $\begin{array}{l}0.566 \\
*\end{array}$ & $\begin{array}{l}0.00 \\
0\end{array}$ & $\begin{array}{l}0.946 \\
*\end{array}$ & $\begin{array}{l}0.00 \\
0\end{array}$ & $\begin{array}{l}0.066 \\
7\end{array}$ & $\begin{array}{l}0.21 \\
9\end{array}$ \\
\hline $\begin{array}{l}19 \\
F\end{array}$ & 0.184 & $\begin{array}{l}0.20 \\
6\end{array}$ & $\begin{array}{l}0.875 \\
*\end{array}$ & $\begin{array}{l}0.00 \\
1\end{array}$ & $\begin{array}{l}- \\
0.143\end{array}$ & $\begin{array}{l}0.78 \\
7\end{array}$ & $\begin{array}{l}0.655 \\
*\end{array}$ & $\begin{array}{l}0.00 \\
0\end{array}$ & $0.785^{*}$ & $\begin{array}{l}0 . * 0 \\
0\end{array}$ & $\begin{array}{l}0.814 \\
*\end{array}$ & $\begin{array}{l}0.00 \\
0\end{array}$ & $\begin{array}{l}0.390 \\
*\end{array}$ & $\begin{array}{l}0.00 \\
7\end{array}$ & $\begin{array}{l}0.833 \\
*\end{array}$ & 0005 & 0.300 & $\begin{array}{l}0.62 \\
4\end{array}$ \\
\hline 23 & $\begin{array}{l}0.317 \\
*\end{array}$ & $\begin{array}{l}0.02 \\
7\end{array}$ & 0.609 & $\begin{array}{l}0.06 \\
2\end{array}$ & $\begin{array}{l}0.986 \\
*\end{array}$ & $\begin{array}{l}0.00 \\
0\end{array}$ & $\begin{array}{l}0.758 \\
*\end{array}$ & $\begin{array}{l}0.00 \\
0\end{array}$ & $0.717^{*}$ & $\begin{array}{l}0.00 \\
0\end{array}$ & & $\begin{array}{l}0.00 \\
1\end{array}$ & & $\begin{array}{l}0.00 \\
0\end{array}$ & $\begin{array}{l}0.894 \\
*\end{array}$ & $\begin{array}{l}0.00 \\
1\end{array}$ & $\begin{array}{l}0.900 \\
*\end{array}$ & $\begin{array}{l}0.03 \\
7\end{array}$ \\
\hline
\end{tabular}

Table 4.7. Correlation analysis of $\operatorname{IgG}$ concentrations at various timepointsfor all cohorts.

$\mathrm{r}$ values and $\mathrm{p}$ values are shown for each cohort for each serotype. *: $\mathrm{p}<0.05$

DISCARD THIS PAGE 


\section{Serotype coverage}

The percentage of subjects in each group with more than $70 \%$ of serotypes greater than the putative protective levels of a) $0.35 \mu \mathrm{g} / \mathrm{ml}$ and b) $1.3 \mu \mathrm{g} / \mathrm{ml}$ was examined. Serotype coverage was considerably greater in control subjects compared with HIV infected individuals (Figure 4.5). At one year post immunisation, 93.8\% of control subjects, and $34.5 \%$ and $47.1 \%$ of vertically and horizontally infected patients respectively, had achieved PPS IgG concentrations exceeding $0.35 \mu \mathrm{g} / \mathrm{ml}$ in more than $70 \%$ of serotypes ${ }^{27}$; this dropped to $58.3 \%$ in controls and only $1.82 \%$ and $11.8 \%$ in vertically and horizontally infected patients respectively when the higher cut off of $1.3 \mu \mathrm{g} / \mathrm{ml}$ was used ${ }^{28}$ (Figure 4.5 ).

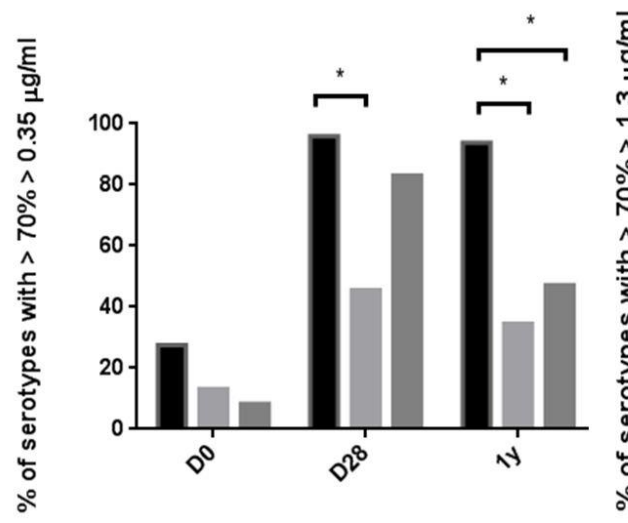

a) ) $>0.35 \mu \mathrm{g} / \mathrm{ml}$

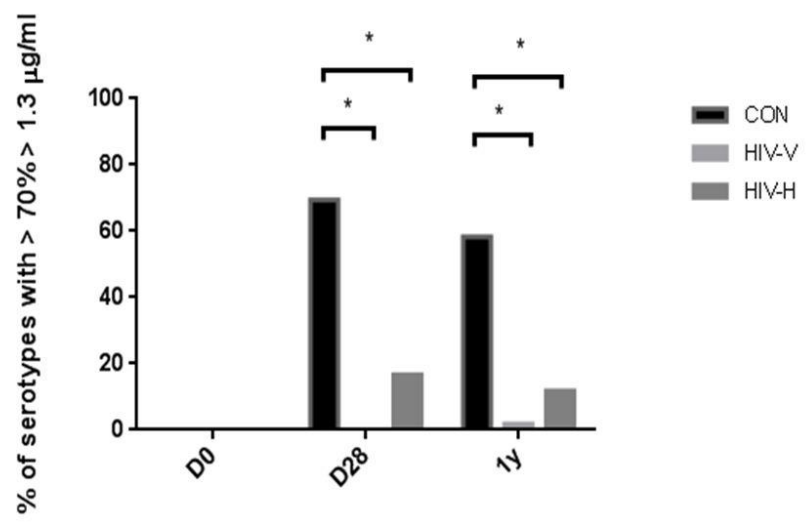

b) $>1.3 \mu \mathrm{g} / \mathrm{ml}$

Figure 4.5. $70 \%$ serotype coverage - $\operatorname{Ig} G$.

The percentage of subjects with $>70 \%$ serotypes reaching serum $\operatorname{IgG}$ concentration of a) $>0.35 \mu \mathrm{g} / \mathrm{ml}, \mathrm{b})>1.3$ $\mu \mathrm{g} / \mathrm{ml}$, in each group at D0, D28 and 1y is shown. $\mathrm{n}=51,49,48(\mathrm{CON}) ; 63,12,53$ (HIV-V), and 25, 6, 17 (HIVH), at D0, D28 and 1y respectively. *: p $<0.05$ for the comparison between groups at each timepoint.

\footnotetext{
${ }^{27} \mathrm{p}$ values for all timepoints as follows:

CON cf HIV-V: 0.057 (D0), < 0.001 (D28), < 0.001 (1y)

CON cf HIV-H: 0.270 (D0), 0.298 (D28), < 0.001 (1y)

HIV-V cf HIV-H: 0.739 (D0), 0.304 (D28), 0.326 (1y)

${ }^{28} \mathrm{p}$ values for all timepoints as follows:

CON cf HIV-V: N/A (D0), < 0.001 (D28), < 0.001 (1y)

CON cf HIV-H: N/A (D0), 0.002 (D28), 0.001 (1y)

HIV-V cf HIV-H: N/A (D0), 0.353 (D28), 0.133 (1y)
} 
As with IgM, the greater serotype coverage in the control group compared to HIVinfected groups was seen both pre- and post-immunisation (Figure 4.6) using both the $0.35 \mu \mathrm{g} / \mathrm{ml}^{29}$ and $1.3 \mu \mathrm{g} / \mathrm{ml}^{30}$ cut offs.

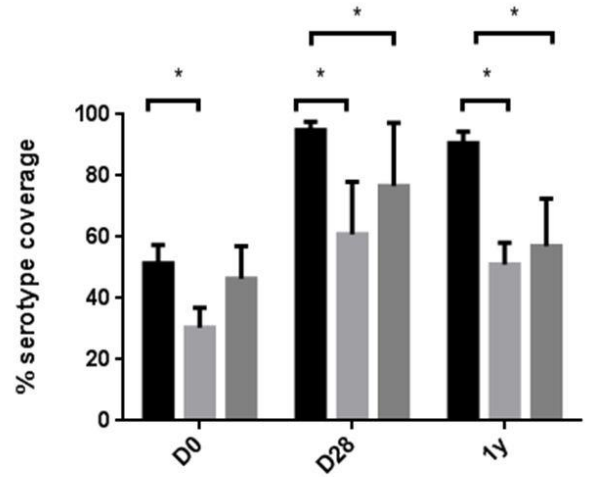

a) ) $>0.35 \mu \mathrm{g} / \mathrm{ml}$

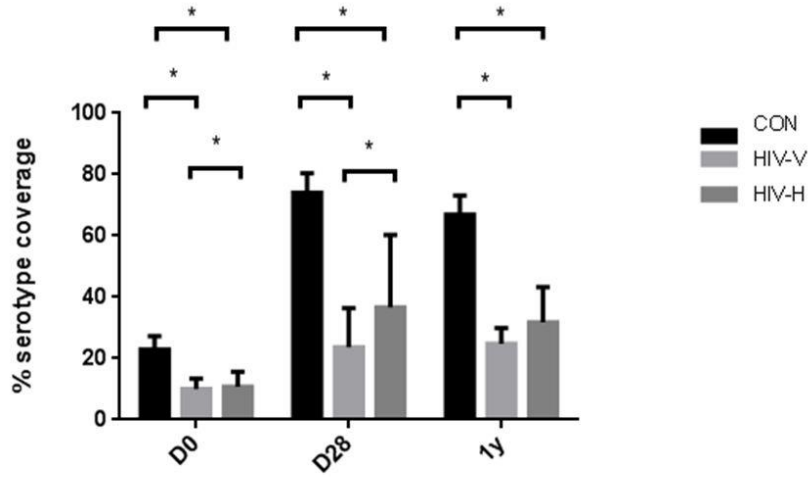

b) $>1.3 \mu \mathrm{g} / \mathrm{ml}$

Figure 4.6: Percentage serotype coverage - IgG.

Percentage of serotypes (mean with $95 \% \mathrm{CI}$ ) against which IgG concentration reaches a) $>0.35 \mu \mathrm{g} / \mathrm{ml}, \mathrm{b}$ ) $>1.3$ $\mu \mathrm{g} / \mathrm{ml}$ at each timepoint. $\mathrm{n}=51,49,48(\mathrm{CON}) ; 63,12,53(\mathrm{HIV}-\mathrm{V})$, and 25, 6, 17 (HIV-H), at D0, D28 and 1y respectively. $*$ : $<0.05$ for the comparison between groups at each timepoint.

The HIV-H cohort showed a trend towards greater serotype coverage than HIV-V but this did not reach significance ${ }^{31}$.

\section{Viral control - current and in childhood}

There was no difference in serotype-specific IgG concentration between those subjects with detectable viral load at the time of sampling, and those with viral control (data not shown), except in HIV-V, where concentration of serotype $1 \mathrm{IgG}$ was greater at baseline in those with detectable VL $(p=0.028)$ and concentration of $4,6 \mathrm{~B}, 9 \mathrm{~V}$ and 14 were lower in those with detectable VL $(\mathrm{p}=0.024,0.039,0.017$

\footnotetext{
${ }^{29} \mathrm{p}$ values for all timepoints as follows:

CON cf HIV-V: 0.002 (D0), < 0.001 (D28), < 0.001 (1y)

CON cf HIV-H: 0.088 (D0), < 0.001 (D28), < 0.001 (1y)

${ }^{30} \mathrm{p}$ values for all timepoints as follows:

CON cf HIV-V: 0.008 (D0), < 0.001 (D28), < 0.001 (1y)

CON cf HIV-H:0.034 (D0), < 0.001 (D28), < 0.001 (1y)

${ }^{31} \mathrm{p}$ values for all timepoints as follows:

$0.35 \mu \mathrm{g} / \mathrm{ml}$ cut off: HIV-V cf HIV-H: 0.181 (D0), 0.027 (D28), 0.395 (1y)

$1.3 \mu \mathrm{g} / \mathrm{ml}$ cut off: HIV-V cf HIV-H: 0.645 (D0), 0.046 (D28), 0.273 (1y)
} 
and 0.025 respectively) and in $\mathrm{HIV}-\mathrm{H}$ where concentration of serotype $18 \mathrm{C}$ was lower in those with detectable VL at both baseline $(\mathrm{p}=0.025)$ and $1 \mathrm{y}(\mathrm{p}=0.023)$.

When the HIV-V infected group was examined according to viral control in childhood, there was no difference in baseline IgG but a trend towards increased IgG concentration in all serotypes at 1 year after immunisation with PPV in HIV-V ${ }^{\mathrm{E}}$ compared to HIV-V' (Table 4.8). There was also an increase in the percentage of serotypes with antibodies above the putative protective levels of $0.35 \mu \mathrm{g} / \mathrm{ml}$ and 1.3 $\mu \mathrm{g} / \mathrm{ml}$ in HIV-V $\mathrm{V}^{\mathrm{E}}$ compared to $\mathrm{HIV}_{-} \mathrm{V}^{-}$( $\mathrm{p}<0.001$ and 0.004 respectively) at 1 year after immunisation (Table 4.9).

\begin{tabular}{|l|l|l|l|l|}
\hline & D0 & & $\mathbf{1 y}$ & \\
\hline & HIV-V $^{\text {E }}$ & HIV-V $^{-}$ & HIV-V $^{\text {E }}$ & HIV-V $^{-}$ \\
\hline $\mathbf{n}$ & $\mathbf{7}$ & $\mathbf{2 7}$ & $\mathbf{7}$ & $\mathbf{2 9}$ \\
\hline $\mathbf{1}$ & 0.20 & 0.17 & 1.24 & 0.90 \\
\hline $\mathbf{4}$ & 0.06 & 0.04 & 0.27 & 0.16 \\
\hline $\mathbf{5}$ & 0.32 & 0.32 & 1.76 & 0.69 \\
\hline $\mathbf{6 B}$ & 0.50 & 0.10 & $1.73^{*}$ & 0.39 \\
\hline $\mathbf{7 F}$ & 0.24 & 0.36 & 1.28 & 0.85 \\
\hline $\mathbf{9 V}$ & 0.19 & 0.14 & $1.31^{*}$ & 0.54 \\
\hline $\mathbf{1 4}$ & 0.05 & 0.11 & 3.42 & 0.65 \\
\hline $\mathbf{1 8 C}$ & 0.14 & 0.18 & 0.64 & 0.40 \\
\hline $\mathbf{1 9 F}$ & 0.95 & 0.42 & 1.79 & 0.78 \\
\hline $\mathbf{2 3 F}$ & 0.06 & 0.07 & 0.61 & 0.21 \\
\hline
\end{tabular}

Table 4.8. Early-life viral control and serum IgG concentration.

Serum IgG antibody concentration $\left(\mu \mathrm{g} / \mathrm{ml}\right.$; GMT) by serotype at D0 and 1 year is shown for HIV-V $\mathrm{V}^{\mathrm{E}}$ and HIV-V $\mathrm{V}^{-}$ $. \mathrm{n}=$ number of samples included in the analysis. $*: \mathrm{p}<0.05$ for the comparison between HIV $-\mathrm{V}^{\mathrm{E}}$ and HIV-V .

\begin{tabular}{|l|l|l|}
\hline & HIV-V $^{\mathbf{E}}$ & HIV-V $^{-}$ \\
\hline Mean \% serotypes $>\mathbf{0 . 3 5} \boldsymbol{\mu g} / \mathbf{m l}$ & & \\
\hline D0 & 34.29 & 32.00 \\
\hline 1y & $77.14^{*}$ & 52.59 \\
\hline Mean \% serotypes $>\mathbf{1 . 3} \mathbf{\mu g} / \mathbf{m l}$ & & \\
\hline D0 & 11.43 & 11.60 \\
\hline 1y & $42.86^{*}$ & 24.44 \\
\hline
\end{tabular}

Table 4.9. Early-life viral control and serotype coverage (IgG).

$* \mathrm{p}<0.05$ for comparison between HIV $-\mathrm{V}^{\mathrm{E}}$ and HIV $-\mathrm{V}^{-}$

There was no correlation with $\mathrm{CD}^{+}$cell count and $\mathrm{IgG}$ concentration at any timepoint in either HIV-infected cohort (data not shown).

\subsubsection{Correlation of IgM and IgG antibody concentration}

To explore the relationship between serotype specific $\operatorname{IgM}$ and $\operatorname{IgG}$, the correlation between the pre-immunisation $\operatorname{IgM}$ concentration and post-immunisation $\operatorname{IgG}$ concentration (at 28 days and 1 year) was examined (Table 4.10). There was a 
positive correlation between pre-immunisation $\operatorname{IgM}$ titre and $\mathrm{IgG}$ concentration at 1 year post immunisation in HIV-V individuals. This was not seen in healthy controls or HIV-H subjects.

\begin{tabular}{|c|c|c|c|c|c|c|c|c|c|c|c|c|}
\hline & \multicolumn{6}{|c|}{ IgM D0 vs IgG D28 } & \multicolumn{6}{|c|}{ IgM D0 vs IgG 1y } \\
\hline & \multicolumn{2}{|l|}{ CON } & \multicolumn{2}{|c|}{ HIV-V } & \multicolumn{2}{|c|}{ HIV-H } & \multicolumn{2}{|l|}{ CON } & \multicolumn{2}{|l|}{ HIV-V } & \multicolumn{2}{|l|}{ HIV-H } \\
\hline & $\mathbf{r}$ & $\mathbf{p}$ & $\mathbf{r}$ & $\mathbf{p}$ & $\mathbf{r}$ & $\mathbf{p}$ & $\mathbf{r}$ & $\mathbf{p}$ & $\mathbf{r}$ & $\mathbf{p}$ & $\mathbf{r}$ & $\mathbf{P}$ \\
\hline 1 & -0.112 & 0.442 & $0.692^{*}$ & 0.018 & 0.116 & 0.827 & 0.167 & 0.256 & $0.272 *$ & 0.045 & 0.052 & 0.844 \\
\hline 4 & 0.140 & 0.338 & -0.160 & 0.639 & -0.058 & 0.913 & 0.282 & 0.052 & $0.353^{*}$ & 0.009 & $0.510^{*}$ & 0.037 \\
\hline 5 & 0.170 & 0.243 & -0.048 & 0.888 & 0.086 & 0.872 & 0.259 & 0.076 & $0.353^{*}$ & 0.009 & 0.263 & 0.309 \\
\hline 6B & -0.058 & 0.692 & -0.085 & 0.805 & -0.600 & 0.208 & -0.082 & 0.581 & $0.295^{*}$ & 0.030 & 0.207 & 0.424 \\
\hline $7 F$ & 0.203 & 0.162 & 0.169 & 0.620 & -0.771 & 0.072 & 0.219 & 0.136 & $0.373 *$ & 0.005 & -0.032 & 0.903 \\
\hline 14 & 0.148 & 0.311 & -0.477 & 0.138 & -0.086 & 0.872 & $0.325^{*}$ & 0.024 & $0.338^{*}$ & 0.012 & -0.183 & 0.482 \\
\hline 19F & 0.001 & 0.993 & 0.592 & 0.056 & 0.486 & 0.329 & 0.036 & 0.806 & $0.389 *$ & 0.004 & 0.139 & 0.596 \\
\hline 23 & 0.026 & 0.861 & 0.324 & 0.331 & -0.486 & 0.329 & 0.174 & 0.236 & $0.382 *$ & 0.004 & 0.044 & 0.865 \\
\hline
\end{tabular}

Table 4.10. Correlation of baseline IgM and D28 and 1y IgG concentrations.

$\mathrm{r}$ values and $\mathrm{p}$ values are shown for each cohort for each serotype. *. $\mathrm{p}<0.05$.

\subsubsection{Relationship between memory cell populations and serum antibody concentration}

To clarify whether the serum response to immunisation was related to abundance of memory B cell populations, the relationship between MZM and switched memory B cell percentage and $\operatorname{IgM}$ and $\operatorname{IgG}$ and was examined in all cohorts both pre and one year after immunisation with PPV. Subjects were divided into good and poor responders, based on achieving $>70 \%$ serotype coverage with a cut off of either 0.35 $\mu \mathrm{g} / \mathrm{ml}$ or $1.3 \mu \mathrm{g} / \mathrm{ml}$. A reduced proportion of MZM B cells was seen in those HIV-V patients defined as poor IgM responders at baseline, using a cut off of $0.35 \mu \mathrm{g} / \mathrm{ml}$ (p $=0.032$ ), compared to those with higher baseline responses; this relationship was not seen in healthy controls or HIV-H subjects, or at 1 year after immunisation.

\subsection{Discussion}

I investigated the impact of vertically and horizontally acquired HIV infection on pre-existing immunity to PPS and the short and long term humoral immune response 
to PPV. I found that both pre-existing and post-immunisation IgM and IgG responses were significantly impaired in both HIV cohorts, with some trend to lower antibody concentrations in the vertically infected cohort compared with their horizontally infected counterparts. Pre-existing $\operatorname{IgM}$ and $\operatorname{IgG}$ concentration predicted the longer term $\operatorname{IgM}$ and $\operatorname{IgG}$ responses respectively at one year, and in the case of the vertically infected cohort, pre-immunisation IgM predicted the concentration of $\operatorname{IgG}$ at 1 year after immunisation. Early sustained viral control was associated with greater serum antibody titres in the vertically infected cohort.

I have shown that $\operatorname{IgM}$ and $\operatorname{IgG}$ antibodies to pneumococcal capsule serotypes were present at baseline in both healthy control and HIV infected patients. IgM at baseline, in this previously unimmunised population, is likely to represent both natural, non-mutated antibody [324] and, probably, IgM secreted by marginal zone cells. IgG present at baseline is likely be produced by mutated memory cells [292] produced as a result of both prior colonisation and non-invasive infection with Streptococcus pneumoniae [152,153]. Increases in anti-Pnc antibodies were manifest at both one month and one year after immunisation with PPV in both healthy controls and HIV infected patients.

Serum antibody concentrations were, in general, lower at all timepoints in both HIVinfected cohorts than in controls. Lower baseline levels of IgM may represent defects in natural $\operatorname{IgM}$ immunity to Pnc, in addition to the documented effects on the marginal zone compartment $[118,119]$; previous studies have not directly examined the impact of HIV infection on natural IgM-mediated immunity to Pnc. Lower baseline levels of PPS-specific IgG have been shown in other studies [173] and may represent a failure in HIV to develop and/or maintain serological memory to previous infection and/or colonisation. At both 28 days and one year postimmunisation, the response to PPV vaccine was also of lower magnitude in HIVinfected patients for both IgM and IgG isotypes than that seen in healthy controls. This is consistent with most existing data showing that, after immunisation with PPV, both adults [302] and children [332] with HIV infection mount a poorer response than healthy controls. Overall, this relatively poor IgM and $\operatorname{IgG}$ response to PPV may suggest impairment of both marginal zone and switched memory responses in $\mathrm{HIV}$-infected patients. Impaired generation and boosting of memory responses may also result from poor generation of de novo responses by naïve cells, 
due to hyperactivation [51], hyporeactivity to proliferation stimuli [26] and abnormal B cell trafficking [58].

The poorer antibody response to PPV in our HIV-infected cohorts resulted in a very low proportion of both vertically and horizontally HIV-infected individuals reaching the putatively protective level of antibody concentration greater than $1.3 \mu \mathrm{g} / \mathrm{ml}$ in least $70 \%$ of serotypes tested at one year after immunisation. Whilst this study describes the concentration of antibody produced in response to PPV immunisation, there is also evidence for qualitative, as well as quantitative, defects in HIV infection, although this has mainly been examined in the context of the conjugate vaccine $[314,315]$. These qualitative defects are likely to further compound the compromised protection against pneumococcal infection in HIV-infected patients who have undergone immunisation and will be explored using serum from the cohorts described, in future studies.

The role of viral control in protecting vaccine responses is unclear. There was no difference in the response of HIV-infected individuals by viraemic control at time of blood sampling. This is difficult to interpret in the context of existing literature. Few studies report the impact of viral load directly on the serological response to PPV. Of those that do, an independent association between high HIV viral load and low vaccine effectiveness has been reported [333]. However, other studies, looking at the impact of ART on vaccine response show that the vaccine has only a modest effect even with therapy (and thus (presumably) control of viral load) [302]. Other studies have been performed on patients not on ART, likely with uncontrolled viral load, preventing comparison of response according to viraemic status [307,334]. ART is known to reverse, at least partially, several of the immunological effects of HIV believed to underlie poor PPV efficacy, including VH3 repertoire disruption [79-82], apoptosis [41,51-55], and proliferation [47,97], so control of viral load might plausibly be expected to be associated with improved responses to PPV. However, it is not clear that depletion in switched and MZM memory populations is restored by ART (and thus effective viral control) [90,116,118,119], which may be consistent with our findings, albeit in relatively small cohorts, that viraemia at the time of sampling does not appear to impact on the immune response to PPS in HIV infected individuals. 
There was some suggestion in my data of poorer immune response in the vertically infected cohort, compared to the horizontally HIV-infected individuals. This may be related to the deficiency of both marginal zone and switched memory populations demonstrated in the vertically, but not horizontally infected, population (discussed in Chapter 3), and may be related to HIV infection during a period of critical immune development in early childhood, when primary exposure to $S$. pneumoniae is likely to have taken place. HIV viraemia at this time may have resulted in early damage to the immune repertoire, including VH3 gene bearing lineages [212], resulting in generation of poor quality clones responding to pneumococcal antigens following early exposure or colonisation. If the responding cells to PPV are predominantly those induced through natural infection, it would be unsurprising that neonatal infection has a greater impact on response to PPV in adulthood compared to in adultacquired infection. This hypothesis may be consistent with the finding that early control of viraemia in the vertically infected cohort seemed, in this work, to be associated with an improved and potentially clinically relevant serological response to the PPV vaccine at 1 year, for both IgM and IgG. This is consistent with data from Pensieroso et al. [177], which showed relatively preserved anti-pneumococcal titres in those children started on ART before one year of age.

The slightly older age of the horizontally infected cohort, compared to the vertically infected participants, may also be relevant to the apparent slight difference in antibody concentrations demonstrated. One study [150] has shown that for many serotypes of pneumococcal polysaccharide capsule, there is a marked increase in baseline antibody concentration in those aged older than 20 years, compared to younger individuals. In addition, the vertically infected group were primarily of Black African ethnicity, and the horizontally infected group of mixed ethnicity. Some studies have shown increased rates of pneumococcal disease in those of African-American race [304]. It has been postulated that this may be due to limited IgG antibody response to pneumococcal capsular polysaccharides in these populations [306,334]. One recent study, however, found no significant difference in antibody responses to pneumococcal challenge, in the context of revaccination, between those of African American and Caucasian ethnicity [335].

No data was collected regarding prior exposure to Pnc, either by swabbing to assess colonisation, or by assessment of household controls to attempt to control for this 
variable. Childhood environment may impact on exposure (by colonisation or noninvasive infection, such as otitis media); although data was not examined regarding childhood environment, a proportion of both groups were born outside the UK, and are thus likely to have Pnc exposure histories which are difficult to compare. Exposure history would have been useful, as prior exposure is likely to be important in determining baseline immunity, which in turn, is likely to play a role in determining subsequent immune responses to PPS. Samples at 28 days after immunisation were few in the HIV-infected cohorts (this did not coincide with a routine clinic visit for most patients and was thus poorly attended), meaning that limited conclusions could be drawn regarding the relationship of baseline and short term immune responses. However, my data show that in the case of both $\operatorname{IgM}$ and IgG anti-pneumococcal antibody, in controls and patients, baseline antibody concentrations may predict, to some extent, the subsequent long term response to PPV, suggesting that there may be an element of secondary "boosting" in both the IgM and IgG memory response. Existing data confirm that the longer term $\operatorname{IgG}$ response to PPV immunisation is predicted by pre-immunisation serotype specific serum $\operatorname{IgG}$ concentration [336] and suggests that the IgG response to PPV may be secondary in nature [292].

In addition, the role of baseline $\operatorname{IgM}$ in facilitating the subsequent adaptive responses was explored by comparing pre-immunisation $\operatorname{IgM}$ with post-immunisation $\operatorname{IgG}$ responses. My data suggests that baseline IgM concentration predicted not only the subsequent IgM response, but also the serotype-specific anti-pneumococcal IgG concentration a year after administration of PPV vaccine in the vertically infected cohort. This suggests that the pre-existing presence of IgM memory, generated by the marginal zone compartment, may be relevant in promoting subsequent production of high affinity IgG [189,190,337]. Interestingly, this relationship between baseline IgM and later IgG production was only manifest in the vertically infected cohort in this study. This does not seem to be related to the low pre-existing IgM levels in this cohort per se, as healthy control subjects with low baseline IgM concentrations showed no correlation with post-immunisation IgG concentrations. The correlation seen in the vertically infected patients may be related to the marginal zone deficit seen only in this cohort (discussed in Chapter 3), as the marginal zone B 
cells are believed to account for production of least part of the pre-existing IgM. Those vertically infected patients with baseline IgM concentrations below $0.35 \mu \mathrm{g} / \mathrm{ml}$ were indeed shown to have lower percentages of MZM B cells than those with higher IgM concentrations.

In conclusion, this work shows that HIV-infected young adults have both impaired natural immunity and diminished serological response to PPV vaccine compared to healthy controls. Vertically infected individuals may fare worse, perhaps because of duration of infection or depletion of MZM during critical stages of immune development. Early ART may limit the impaired responses observed in this study. 


\section{Chapter 5. Discussion}

\subsection{Summary of findings and context}

This study is, to my knowledge, the first direct comparison of a cohort of vertically HIV-infected individuals with a cohort of similarly aged horizontally infected patients. It is also the first study to focus specifically on disturbance of peripheral blood B cell subpopulations and humoral immunity to pneumococcal polysaccharides in vertically infected HIV-infected individuals older than 12 years. I have showed that HIV infection was associated with derangement of B cell subpopulations, with expansion of abnormally activated and exhausted populations, and evidence of an increase in B cell apoptosis and altered B cell trafficking. Memory B cell populations were reduced in the vertically infected population and, as previously reported in paediatric cohorts [202], this was most apparent when viral load was controlled. HIV infection was also associated with impaired humoral immunity to PPS affecting both natural and vaccine induced immunity.

Although these findings are broadly consistent with existing literature, showing increased immature, activated and exhausted cell populations in both adults $[53,54,59,90,119,124,126,262]$ and children $[125,200]$ and impaired natural and vaccine-induced immunity to Pnc $[80,119,172-174,181,183,300-303,305]$, it is challenging to compare our findings directly with those reported elsewhere. Previous studies have included either adults, presumably infected by the horizontal route and considerably older than the cohort investigated here, or children, presumably infected by the vertically infected route, but of a younger age group than those considered here (usually aged younger than 12-15 years).

In this study, the vertically infected cohort showed a reduction in both marginal zone and switched B cell memory, which was not seen in those who acquired their HIV infection in adulthood. This, taken with the trend towards poorer generation of serological memory, may suggest that the vertically infected cohort suffers greater reduction in the ability to generate and sustain immunological memory than their horizontally infected counterparts. Depletion of marginal zone memory may be particularly important: there is evidence from our data (in the vertically infected 
cohort) and from others [336] that baseline IgM immunity, which is likely to be partly of marginal zone type, may also predict the ability to recruit an effective switched memory response.

The deficit of marginal zone and switched memory cells in vertically infected young adults compared to those infected by the horizontal route may be a result of any or all of several differences between the two groups. The vertically and horizontally infected groups have not only a different route, but also a different duration, of infection. There is no existing data examining the impact of route of infection per se on immunity and it is impossible to examine this factor in isolation. Duration of infection may be important: existing literature [52,193] suggests that treatment early in the infection may be beneficial, perhaps suggesting that longer standing, untreated HIV disease has more significant deleterious effects. Certainly, damage to lymphoid tissue in long standing infection has been shown [252], and might, plausibly, be more extensive in those patients who have been infected since birth than in those recently infected, resulting in impairment of function required for generation and maintenance of effective B cell memory.

Perhaps most importantly, the timing of HIV infection, in relation to immune development, is drastically different in vertically and horizontally infected patients. Those young adults infected by the horizontal route have acquired their HIV infection in the context of a mature and presumably normal immune system, whereas those vertically infected have endured HIV viraemia during a critical window of early immunological development, which may have had significant impact on their ability to generate healthy and normal immunological repertoire and function. Early childhood is the time when many important pathogens are encountered for the first time, and the quality of the immune responses generated are likely to be important for lifelong immune function [225]; impairment of generation of normal early-life immune responses, as may occur in childhood HIV infection, may thus have long lasting impact on immune competence.

In addition to these differences which are inherent to the two cohorts, it is important to acknowledge demographic differences between the two HIV-infected groups, which were not perfectly matched in terms of either age (horizontally infected patients were slightly older), nor ethnicity. However, as discussed previously, there 
is little data to support a significant role for these factors in determining the status of the B cell compartment either in healthy or HIV-infected individuals, and it is unlikely that these factors explain the differences seen.

Despite the potentially deleterious timing and significantly longer duration of infection in the vertically infected cohort, there are some encouraging findings in this group. The increased naïve B cell population in the vertically infected patients, compared to those infected in adulthood, may, perhaps, represent an increased capacity for restoration and regeneration, perhaps as a result of slightly younger age, or perhaps resulting from achievement of a new immunological "steady state" due to long standing infection. Reconstitution of damaged cell pools has been shown in the context of T cell recovery in young HIV-infected children, as discussed in Chapter 1. Vertically infected patients also showed a smaller increase in immature and abnormally activated B cell populations than did their horizontally infected counterparts, which may further suggest resilience to the dynamic changes of HIV infection, consistent with data showing that the immune system may remain relatively well preserved in even longstanding asymptomatic HIV infection [232], and encouraging long term outcomes have been predicted [233]. Lastly, although natural and vaccine-induced immunity was reduced in both patient groups compared to healthy controls, it is perhaps reassuring that the difference between the vertically and horizontally infected groups was slight, possibly indicating relatively little impact of their long duration of infection on their capacity to generate and maintain humoral immunity, at least in the context of pneumococcal infection.

My data suggests that early and sustained control of HIV viraemia may protect against both HIV-related derangement to B cell subpopulations and impairment of the serological response to PPV immunisation. This is consistent with other data, in younger children, showing benefit of early initiation of ART [177], and might perhaps have been more pronounced in our study had it been possible to examine the impact of viral control in the first year of life, a distinction prevented by the small sample size in this study. Currently, ART in vertically infected infants in Europe is initiated at birth, but in children presenting after the first year of life, initiation of 
treatment is guided by clinical progression or $\mathrm{CD}^{+}$depletion [234]. Globally, World Health Organisation guidelines recommend treatment of all children under 5 years of age [235] and the guidelines in Europe are currently being revised and may suggest treatment for all children under 3 years old (personal communication with Nigel Klein). This work may be of importance in contributing to an understanding of the importance of ART in early life in vertically infected children, in order to preserve the B cell compartment of the immune system for the future.

\subsection{Limitations of this work}

Variation in immunological parameters, even amongst healthy individuals, means that large study populations are required to robustly demonstrate disease-related differences. This work was limited by small patient numbers, inevitable due to the relative paucity of young adults aged 12-25 years in the UK infected with HIV by either the vertical or horizontal route. The sample sizes in this study, however, are not dissimilar from that studied in other published work. Recent local endeavours to ensure patient immunisations were up to date, including with PPV/PCV, as a result of the recent H1N1 influenza epidemic in 2009, reduced patients eligible for recruitment still further, as only those with no history of prior PPV/PCV were eligible for inclusion in the study. Poor clinic attendance (with "did not attend" rates for follow up appointments above $80 \%$ for some patient groups; personal communication) resulted in limited sample size for follow-up data. Due to limited numbers of patients suitable for recruitment, it was not possible to ensure homogeneity of patient cohorts in terms of antiretroviral status and history, clinical status and viral load. Potentially confounding differences between groups in terms of ethnicity and age were also unavoidable due to the epidemiological patterns seen in these patient groups in the UK. Historical data regarding viral control was difficult to obtain and was not available for all patients, particularly those who had recently arrived in the UK.

Clinical protection against pneumococcal disease is a function of both antibody concentration and function. Analysis in this study of generation of serological memory was quantitative only; there is significant evidence in the literature for 
impact of HIV infection on function of antibodies [314,315] in addition to the reduction in serum concentrations and this will be explored in future work.

The statistical analysis of data presented in this thesis is comprehensively described. However it is acknowledged that multiple comparisons were performed on the data set. Whilst a Bonferroni correction was not applied, individual $\mathrm{p}$ values are given where relevant, to enable the reader to evaluate the likely probability of significance.

This was a cross-sectional study, with follow up limited to one year after immunisation. Further longitudinal data regarding this vertically infected cohort of young adults will be important in determining their long term prognosis and requirements for clinical care.

\subsection{Importance of this work}

This study is the first to interrogate the B cell immunity of this growing group of vertically HIV-infected young adults and to perform a direct comparison with young adults infected in adulthood by the horizontal route.

While it may be relatively reassuring that the vertically infected cohort, despite their longer duration of infection, show B cell phenotype and function broadly similar to the horizontally infected group (perhaps as a result of good clinical care and access to ART), the deficits seen in the memory compartment are concerning. Currently, once transitioned from paediatric care, these young adults are treated alongside other young adults infected by the horizontal route, according to the same clinical guidelines. These data, however, suggests that the vertically infected young adults are, in fact, a distinct immunological group from their horizontally infected counterparts and may exhibit a different profile of clinical risk, particularly to encapsulated organisms such as $S$. pneumoniae. This patient group may benefit particularly from appropriate immunisation and surveillance, as they age and as their HIV infection progresses.

The trend towards relative sparing of B cell subpopulations and vaccine-induced Pnc immunity in those with early-life viral control in this study also suggests the importance of early effective ART in mitigating against HIV-related B cell derangements. While early ART is already part of existing guidelines for those 
infants diagnosed at birth [234], it is not currently recommended for those children diagnosed after the first year of life in all guidelines, who may, in fact, benefit from early viral control.

\subsection{Conclusions and future directions}

These data suggest that vertically and horizontally infected young adults appear to be immunologically distinct populations in the context of humoral immunity and specifically pneumococcal immunity.

Studies are already underway within our own group to analyse B cell immunoglobulin repertoire by CDR spectratyping to establish whether defects seen in the vertically infected population may result from a failure to establish good quality immune repertoire, perhaps due to viraemia at a critical window of immune development. Future work in this area should aim to examine larger patient cohorts, with greater homogeneity in terms of viral control and previous antiretroviral exposure and improved matching for ethnicity, to reduce the potentially confounding effects of these variables. As the cohort of vertically infected patients grows older, better intergroup matching for age with horizontally infected patients may also be possible. Further studies should also address deficits in functional, as well as quantitative, serological memory. It would also be of interest to examine specific memory B cell responses, which are suggested by some data in HIV-infected children, in the context of influenza vaccination, to be a better correlate of vaccineinduced protection that antibody concentration [338].

Although it is not possible to control for duration of infection, which is an inherent difference between the patient cohorts, it may be possible to further elucidate the mechanism(s) underlying differences in the cohorts. Biopsy of lymphoid tissue, although not feasible for ethical reasons, would also be useful to identify contribution of fibrosis secondary to disease duration to the impaired B cell compartment in vertically infected patients.

Further work of this kind will be important in determining the nature and extent of immunological differences between these two cohorts of vertically and horizontally 
infected young adults and in elucidating their underlying mechanisms. This may be ultimately relevant in optimising clinical management. 


\section{Acknowledgements}

\section{With the greatest of thanks to:}

Helen Baxendale and Nigel Klein for their supervision and support

All in the Department of Infectious Diseases and Microbiology, Institute of Child Health, UCL, particularly Robin Callard, Hannah Poulsom, Marianne Jacobsen, Hannah Jones and Vania de Toledo

All at the HIV Family Clinic, Great Ormond Street Hospital NHS Foundation Trust, in particular Margaret Clapson and Jacquie Flynn

All at The TEAM Clinic and Adult HIV Clinics, Mortimer Market Centre, Camden Provider Services, in particular Carmel Young, Karen Gurney, Dr Richard Gilson and Dr Eva Jungmann

Dr Nneka Nwokolo at the 56 Dean Street Clinic, Chelsea and Westminster Hospital NHS Foundation Trust)

All at the The Royal Free Hospital HIV Clinic

The Clinical Research Facility, Great Ormond Street Hospital Foundation Trust, in particular Lincy Koshy

Ayad Eddaoudi, Flow Cytometry Facility, Institute of Child Health, UCL

David Goldblatt and all in the Immunobiology Group, Institute of Child Health, UCL

Kimberly Gilmour, Clinical Scientist, Department of Immunology, Great Ormond Street Hospital NHS Foundation Trust

Alasdair Bamford, Imperial College London

Claire Hayden, Papworth Hospital NHS Foundation Trust

Ali Judd at the Collaborative HIV Paediatric Study

All patients and their families, and all healthy control subject volunteers

My husband, Alistair, my daughter, Beth, my parents and friends, for all their support and love 


\section{Reference List}

1 United Nations Economic and Social Council, Commission on Population and Development. Adolescents and Young People, Report of the Secretary General; http://daccess-ddsny.un.org/doc/UNDOC/GEN/N12/220/30/PDF/N1222030.pdf?OpenElement. 2013. 25-90013.

2 CHIPS Cohort Summary Data; http://www.chipscohort.ac.uk/summary_data.asp. 2013. 259-0013.

3 UNAIDS Factsheet: Adolescents, young people and HIV; http://www.unaids.org/en/media/unaids/contentassets/documents/factsheet/2012/20120417 FS adolescentsyoungpeoplehiv en.pdf. 2013. 25-9-0013.

4 UNAIDS Report on the Global AIDS Epidemic; http://www.unaids.org/en/media/unaids/contentassets/documents/epidemiology/2012/gr2012 /20121120_UNAIDS_Global_Report_2012_en.pdf. 2013. 25-9-0013.

5 Greene WC, Peterlin BM. Charting HIV's remarkable voyage through the cell: Basic science as a passport to future therapy. Nat Med 2002;8(7):673-80.

6 Klatzmann D, Barre-Sinoussi F, Nugeyre MT et al. Selective tropism of lymphadenopathy associated virus (LAV) for helper-inducer T lymphocytes. Science 1984;225(4657):59-63.

7 Lane HC, Masur H, Edgar LC et al. Abnormalities of B-cell activation and immunoregulation in patients with the acquired immunodeficiency syndrome. $N$ Engl J Med 1983;309(8):453-8.

8 Terpstra FG, Al BJ, Roos MT et al. Longitudinal study of leukocyte functions in homosexual men seroconverted for HIV: rapid and persistent loss of B cell function after HIV infection. Eur J Immunol 1989;19(4):667-73.

9 Shearer WT, Easley KA, Goldfarb J et al. Prospective 5-year study of peripheral blood CD4, CD8, and CD19/CD20 lymphocytes and serum Igs in children born to HIV-1 women. The P(2)C(2) HIV Study Group. J Allergy Clin Immunol 2000;106(3):559-66.

$10 \mathrm{Ng}$ VL. B-lymphocytes and autoantibody profiles in HIV disease. Clin Rev Allergy Immunol 1996;14(4):367-84.

11 Martinez-Maza O, Breen EC. B-cell activation and lymphoma in patients with HIV. Curr Opin Oncol 2002;14(5):528-32.

12 Moir S, Fauci AS. B cells in HIV infection and disease. Nat Rev Immunol 2009;9(4):235-45.

13 Berberian L, Goodglick L, Kipps TJ et al. Immunoglobulin VH3 gene products: natural ligands for HIV gp120. Science 1993;261(5128):1588-91.

14 Goodglick L, Zevit N, Neshat MS et al. Mapping the Ig superantigen-binding site of HIV-1 gp120. J Immunol 1995;155(11):5151-9.

15 Karray S, Zouali M. Identification of the B cell superantigen-binding site of HIV-1 gp120. Proc Natl Acad Sci U S A 1997;94(4):1356-60.

16 Karray S, Juompan L, Maroun RC et al. Structural basis of the gp120 superantigen-binding site on human immunoglobulins. J Immunol 1998;161(12):6681-8. 
17 Berberian L, Shukla J, Jefferis R et al. Effects of HIV infection on VH3 (D12 idiotope) B cells in vivo. J Acquir Immune Defic Syndr 1994;7(7):641-6.

18 Berberian L, Valles-Ayoub Y, Sun N et al. A VH clonal deficit in human immunodeficiency virus-positive individuals reflects a B-cell maturational arrest. Blood 1991;78(1):175-9.

19 Muller S, Wang H, Silverman GJ et al. B-cell abnormalities in AIDS: stable and clonallyrestricted antibody response in HIV-1 infection. Scand J Immunol 1993;38(4):327-34.

20 David D, Demaison C, Bani L et al. Selective variations in vivo of VH3 and VH1 gene family expression in peripheral B cell IgM, IgD and IgG during HIV infection. Eur J Immunol 1995;25(6):1524-8.

21 Scamurra RW, Miller DJ, Dahl L et al. Impact of HIV-1 infection on V(H)3 gene repertoire of naive human B cells. Journal of Immunology 2000;164(10):5482-91.

22 Kacani L, Prodinger WM, Sprinzl GM et al. Detachment of human immunodeficiency virus type 1 from germinal centers by blocking complement receptor type 2. J Virol 2000;74(17):7997-8002.

23 Moir S, Malaspina A, Li Y et al. B cells of HIV-1-infected patients bind virions through CD21-complement interactions and transmit infectious virus to activated T cells. J Exp Med 2000;192(5):637-46.

24 Malaspina A, Moir S, Nickle DC et al. Human immunodeficiency virus type 1 bound to B cells: relationship to virus replicating in CD4+ T cells and circulating in plasma. $J$ Virol 2002;76(17):8855-63.

25 Rickert RC. Regulation of B lymphocyte activation by complement C3 and the B cell coreceptor complex. Curr Opin Immunol 2005;17(3):237-43.

26 Conge AM, Tarte K, Reynes J et al. Impairment of B-lymphocyte differentiation induced by dual triggering of the B-cell antigen receptor and CD40 in advanced HIV-1-disease. Aids 1998;12(12):1437-49.

27 De Milito A. B lymphocyte dysfunctions in HIV infection. Curr HIV Res 2004;2(1):11-21.

28 Fournier AM, Fondere JM, ix-Panabieres C et al. Spontaneous secretion of immunoglobulins and anti-HIV-1 antibodies by in vivo activated B lymphocytes from HIV-1-infected subjects: monocyte and natural killer cell requirement for in vitro terminal differentiation into plasma cells. Clin Immunol 2002;103(1):98-109.

29 Mir KD, Mavigner M, Silvestri G. The myeloid cytokine network in AIDS pathogenesis. Cytokine Growth Factor Rev 2012;23(4-5):223-31.

30 Mandl JN, Barry AP, Vanderford TH et al. Divergent TLR7 and TLR9 signaling and type I interferon production distinguish pathogenic and nonpathogenic AIDS virus infections. Nat Med 2008;14(10):1077-87.

31 Muller F, Aukrust P, Nordoy I et al. Possible role of interleukin-10 (IL-10) and CD40 ligand expression in the pathogenesis of hypergammaglobulinemia in human immunodeficiency virus infection: modulation of IL-10 and Ig production after intravenous Ig infusion. Blood 1998;92(10):3721-9.

32 Ammann AJ, Schiffman G, Abrams D et al. B-cell immunodeficiency in acquired immune deficiency syndrome. JAMA 1984;251(11):1447-9. 
33 Shirai A, Cosentino M, Leitman-Klinman SF et al. Human immunodeficiency virus infection induces both polyclonal and virus-specific B cell activation. J Clin Invest 1992;89(2):561-6.

34 Pahwa S, Fikrig S, Menez R et al. Pediatric Acquired-Immunodeficiency-Syndrome Demonstration of Lymphocyte-B Defects Invitro. Diagnostic Immunology 1986;4(1):24-30.

35 Mizuma H, Zolla-Pazner S, Litwin S et al. Serum IgD elevation is an early marker of B cell activation during infection with the human immunodeficiency viruses. Clin Exp Immunol 1987;68(1):5-14.

36 Bernasconi NL, Traggiai E, Lanzavecchia A. Maintenance of serological memory by polyclonal activation of human memory B cells. Science 2002;298(5601):2199-202.

37 Perrier C, Arijs I, Staelens D et al. Interleukin-15 receptor alpha expression in inflammatory bowel disease patients before and after normalization of inflammation with infliximab. Immunology 2013;138(1):47-56.

38 Cerutti A, Puga I, Cols M. Innate control of B cell responses. Trends Immunol 2011;32(5):202-11.

39 Swingler S, Brichacek B, Jacque JM et al. HIV-1 Nef intersects the macrophage CD40L signalling pathway to promote resting-cell infection. Nature 2003;424(6945):213-9.

40 Swingler S, Zhou J, Swingler C et al. Evidence for a pathogenic determinant in HIV-1 Nef involved in B cell dysfunction in HIV/AIDS. Cell Host Microbe 2008;4(1):63-76.

41 Moir S, Malaspina A, Pickeral OK et al. Decreased survival of B cells of HIV-viremic patients mediated by altered expression of receptors of the TNF superfamily. J Exp Med 2004;200(7):587-99.

42 Brenchley JM, Price DA, Douek DC. HIV disease: fallout from a mucosal catastrophe? Nat Immunol 2006;7(3):235-9.

43 Brenchley JM, Price DA, Schacker TW et al. Microbial translocation is a cause of systemic immune activation in chronic HIV infection. Nat Med 2006;12(12):1365-71.

44 Nixon DE, Landay AL. Biomarkers of immune dysfunction in HIV. Curr Opin HIV AIDS 2010;5(6):498-503.

45 Moir S, Malaspina A, Ogwaro KM et al. HIV-1 induces phenotypic and functional perturbations of B cells in chronically infected individuals. Proc Natl Acad Sci U S A 2001;98(18):10362-7.

46 Malaspina A, Moir S, Kottilil S et al. Deleterious effect of HIV-1 plasma viremia on B cell costimulatory function. J Immunol 2003;170(12):5965-72.

47 Jiang W, Lederman MM, Mohner RJ et al. Impaired naive and memory B cell responsiveness to TLR9 stimulation in HIV-infection. J Virol 2008.

48 Moir S, Ogwaro KM, Malaspina A et al. Perturbations in B cell responsiveness to CD4+ T cell help in HIV-infected individuals. Proc Natl Acad Sci U S A 2003;100(10):6057-62.

49 De Boer RJ, Mohri H, Ho DD et al. Turnover rates of B cells, T cells, and NK cells in simian immunodeficiency virus-infected and uninfected rhesus macaques. $J$ Immunol 2003;170(5):2479-87. 
50 Samuelsson A, Sonnerborg A, Heuts N et al. Progressive B cell apoptosis and expression of Fas ligand during human immunodeficiency virus type 1 infection. AIDS Res Hum Retroviruses 1997;13(12):1031-8.

51 Chong Y, Ikematsu H, Yamamoto $M$ et al. Increased frequency of CD27(-) (naive) B cells and their phenotypic alteration in HIV type 1-infected patients. Aids Research and Human Retroviruses 2004;20(6):621-9.

52 Titanji K, Chiodi F, Bellocco R et al. Primary HIV-1 infection sets the stage for important B lymphocyte dysfunctions. Aids 2005;19(17):1947-55.

53 Ho J, Moir S, Malaspina A et al. Two overrepresented B cell populations in HIV-infected individuals undergo apoptosis by different mechanisms. Proceedings of the National Academy of Sciences of the United States of America 2006;103(51):19436-41.

54 Rethi B, Sammicheli S, Amu S et al. Concerted effect of lymphopenia, viraemia and T-cell activation on Fas expression of peripheral B cells in HIV-1-infected patients. Aids 2013;27(2):155-62.

55 Chong Y, Ikematsu H, Kikuchi K et al. Selective ${ }_{\mathrm{CD} 27_{+}}$(memory) B cell reduction and characteristic B cell alteration in drug-naive and HAART-treated HIV type 1-infected patients. AIDS Res Hum Retroviruses 2004;20(2):219-26.

56 Forster R, Schweigard G, Johann S et al. Abnormal expression of the B-cell homing chemokine receptor BLR1 during the progression of acquired immunodeficiency syndrome. Blood 1997;90(2):520-5.

57 Jinquan T, Moller B, Storgaard M et al. Chemotaxis and IL-8 receptor expression in B cells from normal and HIV-infected subjects. J Immunol 1997;158(1):475-84.

58 Cagigi A, Mowafi F, Phuong Dang LV et al. Altered expression of the receptor-ligand pair CXCR5/CXCL13 in B cells during chronic HIV-1 infection. Blood 2008;112(12):4401-10.

59 Moir S, Ho J, Malaspina A et al. Evidence for HIV-associated B cell exhaustion in a dysfunctional memory B cell compartment in HIV-infected viremic individuals. J Exp Med 2008;205(8):1797-805.

60 Schnittman SM, Lane HC, Higgins SE et al. Direct polyclonal activation of human B lymphocytes by the acquired immune deficiency syndrome virus. Science 1986;233(4768):1084-6.

61 Demaison C, David D, Letourneur F et al. Analysis of human VH gene repertoire expression in peripheral CD19+ B cells. Immunogenetics 1995;42(5):342-52.

62 Huang C, Stewart AK, Schwartz RS et al. Immunoglobulin heavy chain gene expression in peripheral blood B lymphocytes. J Clin Invest 1992;89(4):1331-43.

63 Zouali M, Theze J. Probing VH gene-family utilization in human peripheral B cells by in situ hybridization. J Immunol 1991;146(8):2855-64.

64 Logtenberg T, Schutte ME, Inghirami G et al. Immunoglobulin VH gene expression in human B cell lines and tumors: biased VH gene expression in chronic lymphocytic leukemia. Int Immunol 1989;1(4):362-6.

65 Matsuda F, Ishii K, Bourvagnet $\mathrm{P}$ et al. The complete nucleotide sequence of the human immunoglobulin heavy chain variable region locus. J Exp Med 1998;188(11):2151-62. 
66 Silverman GJ, Lucas AH. Variable region diversity in human circulating antibodies specific for the capsular polysaccharide of Haemophilus influenzae type b. Preferential usage of two types of VH3 heavy chains. J Clin Invest 1991;88(3):911-20.

67 Abadi J, Friedman J, Mageed RA et al. Human antibodies elicited by a pneumococcal vaccine express idiotypic determinants indicative of $\mathrm{V}(\mathrm{H}) 3$ gene segment usage. $J$ Infect Dis 1998;178(3):707-16.

68 Andris JS, Ehrlich PH, Ostberg L et al. Probing the human antibody repertoire to exogenous antigens. Characterization of the $\mathrm{H}$ and $\mathrm{L}$ chain $\mathrm{V}$ region gene segments from anti-hepatitis B virus antibodies. J Immunol 1992;149(12):4053-9.

69 Ikematsu W, Kobarg J, Ikematsu $\mathrm{H}$ et al. Clonal analysis of a human antibody response. III. Nucleotide sequences of monoclonal IgM, IgG, and IgA to rabies virus reveal restricted $\mathrm{V}$ kappa gene utilization, junctional $\mathrm{V}$ kappa $\mathrm{J}$ kappa and $\mathrm{V}$ lambda $\mathrm{J}$ lambda diversity, and somatic hypermutation. J Immunol 1998;161(6):2895-905.

70 Janoff EN, Breiman RF, Daley CL et al. Pneumococcal disease during HIV infection. Epidemiologic, clinical, and immunologic perspectives. Ann Intern Med 1992;117(4):31424.

71 Adderson EE, Shackelford PG, Quinn A et al. Diversity of immunoglobulin light chain usage in the human immune response to Haemophilus influenzae type $\mathrm{b}$ capsular polysaccharide. Pediatr Res 1993;33(3):307-11.

72 Zouali M. B-cell superantigens: implications for selection of the human antibody repertoire. Immunol Today 1995;16(8):399-405.

73 Chong Y, Ikematsu H, Ariyama I et al. Evidence of B cell clonal expansion in HIV type 1infected patients. AIDS Res Hum Retroviruses 2001;17(16):1507-15.

74 Silverman GJ, Cary SP, Dwyer DC et al. A B cell superantigen-induced persistent "Hole" in the B-1 repertoire. J Exp Med 2000;192(1):87-98.

75 Viau M, Veas F, Zouali M. Direct impact of inactivated HIV-1 virions on B lymphocyte subsets. Mol Immunol 2007;44(8):2134-44.

76 Berberian L, Valles-Ayoub Y, Sun N et al. A VH clonal deficit in human immunodeficiency virus-positive individuals reflects a B-cell maturational arrest. Blood 1991;78(1):175-9.

77 Bowers E, Scamurra RW, Asrani A et al. Decreased Mutation Frequencies among Immunoglobulin G Variable Region Genes during Viremic HIV-1 Infection. PLoS ONE 2014;9(1):e81913.

78 Xiao M, Prabakaran P, Chen W et al. Deep sequencing and Circos analyses of antibody libraries reveal antigen-driven selection of Ig VH genes during HIV-1 infection. Exp Mol Pathol 2013;95(3):357-63.

79 Quan CP, Watanabe S, Pamonsinlapatham P et al. Different dysregulations of the natural antibody repertoire in treated and untreated HIV-1 patients. J Autoimmun 2001;17(1):81-7.

80 Subramaniam KS, Segal R, Lyles RH et al. Qualitative change in antibody responses of human immunodeficiency virus-infected individuals to pneumococcal capsular polysaccharide vaccination associated with highly active antiretroviral therapy. $J$ Infect Dis 2003;187(5):758-68.

81 Juompan L, Lambin P, Zouali M. Selective deficit in antibodies specific for the superantigen binding site of gp120 in HIV infection. FASEB J 1998;12(14):1473-80. 
82 Elkins MK, Vittinghoff E, Baranzini SE et al. Longitudinal analysis of B cell repertoire and antibody gene rearrangements during early HIV infection. Genes Immun 2005;6(1):66-9.

83 Tonegawa S. Somatic generation of antibody diversity. Nature 1983;302(5909):575-81.

84 Baxendale HE, Goldblatt D. Correlation of molecular characteristics, isotype, and in vitro functional activity of human antipneumococcal monoclonal antibodies. Infect Immun 2006;74(2):1025-31.

85 Feeney AJ, Atkinson MJ, Cowan MJ et al. A defective Vkappa A2 allele in Navajos which may play a role in increased susceptibility to haemophilus influenzae type b disease. J Clin Invest 1996;97(10):2277-82.

86 Rickert RC. Regulation of B lymphocyte activation by complement C3 and the B cell coreceptor complex. Curr Opin Immunol 2005;17(3):237-43.

87 Kekow J, Kern P, Schmitz H et al. Abnormal B-cell response to T-cell-independent polyclonal B-cell activators in homosexuals presenting persistent generalized lymph node enlargement and HTLV-III antibodies. Diagn Immunol 1986;4(2):107-11.

88 Brenchley JM, Price DA, Schacker TW et al. Microbial translocation is a cause of systemic immune activation in chronic HIV infection. Nat Med 2006;12(12):1365-71.

89 De Milito A, Nilsson A, Titanji K et al. Mechanisms of hypergammaglobulinemia and impaired antigen-specific humoral immunity in HIV-1 infection. Blood 2004;103(6):2180-6.

90 Moir S, Malaspina A, Ho J et al. Normalization of B cell counts and subpopulations after antiretroviral therapy in chronic HIV disease. Journal of Infectious Diseases 2008;197(4):572-9.

91 Notermans DW, de Jong JJ, Goudsmit J et al. Potent antiretroviral therapy initiates normalization of hypergammaglobulinemia and a decline in HIV type 1-specific antibody responses. AIDS Res Hum Retroviruses 2001;17(11):1003-8.

92 Regidor DL, Detels R, Breen EC et al. Effect of highly active antiretroviral therapy on biomarkers of B-lymphocyte activation and inflammation. Aids 2011;25(3):303-14.

93 Kovacs JA, Lempicki RA, Sidorov IA et al. Identification of dynamically distinct subpopulations of T lymphocytes that are differentially affected by HIV. J Exp Med 2001;194(12):1731-41.

94 Day CL, Kaufmann DE, Kiepiela P et al. PD-1 expression on HIV-specific T cells is associated with T-cell exhaustion and disease progression. Nature 2006;443(7109):350-4.

95 Trautmann L, Janbazian L, Chomont $\mathrm{N}$ et al. Upregulation of PD-1 expression on HIVspecific CD8+ T cells leads to reversible immune dysfunction. Nat Med 2006;12(10):1198202.

96 Wherry EJ, Ha SJ, Kaech SM et al. Molecular signature of CD8+ T cell exhaustion during chronic viral infection. Immunity 2007;27(4):670-84.

97 Malaspina A, Moir S, Dipoto AC et al. CpG oligonucleotides enhance proliferative and effector responses of B Cells in HIV-infected individuals. J Immunol 2008;181(2):1199-206.

98 Samuelsson A, Brostrom C, van Dijk N et al. Apoptosis of CD4+ and CD19+ cells during human immunodeficiency virus type 1 infection--correlation with clinical progression, viral load, and loss of humoral immunity. Virology 1997;238(2):180-8. 
99 McCune JM. The dynamics of CD4+ T-cell depletion in HIV disease. Nature 2001;410(6831):974-9.

100 Muro-Cacho CA, Pantaleo G, Fauci AS. Analysis of apoptosis in lymph nodes of HIVinfected persons. Intensity of apoptosis correlates with the general state of activation of the lymphoid tissue and not with stage of disease or viral burden. J Immunol 1995;154(10):555566.

101 Merino R, Ding L, Veis DJ et al. Developmental regulation of the Bcl-2 protein and susceptibility to cell death in B lymphocytes. EMBO J 1994;13(3):683-91.

102 Nunez G, London L, Hockenbery D et al. Deregulated Bcl-2 gene expression selectively prolongs survival of growth factor-deprived hemopoietic cell lines. J Immunol 1990;144(9):3602-10.

103 Strasser A, Whittingham S, Vaux DL et al. Enforced BCL2 expression in B-lymphoid cells prolongs antibody responses and elicits autoimmune disease. Proc Natl Acad Sci U S A 1991;88(19):8661-5.

104 Siegel RM. Caspases at the crossroads of immune-cell life and death. Nat Rev Immunol 2006;6(4):308-17.

105 Defrance T. Mature B cells: apoptosis checkpoints. Transplantation 2005;79(3 Suppl):S4S7.

106 Sammicheli S, Dang VP, Ruffin N et al. IL-7 promotes CD95-induced apoptosis in B cells via the IFN-gamma/STAT1 pathway. PLoS ONE 2011;6(12):e28629.

107 Hua F, Cornejo MG, Cardone MH et al. Effects of Bcl-2 levels on Fas signaling-induced caspase-3 activation: molecular genetic tests of computational model predictions. J Immunol 2005;175(2):985-95

108 Okada T, Cyster JG. B cell migration and interactions in the early phase of antibody responses. Curr Opin Immunol 2006;18(3):278-85.

109 Rojo D, Suetomi K, Navarro J. Structural biology of chemokine receptors. Biol Res 1999;32(4):263-72.

110 Cyster JG. Chemokines, sphingosine-1-phosphate, and cell migration in secondary lymphoid organs. Annu Rev Immunol 2005;23:127-59.

111 McHeyzer-Williams LJ, McHeyzer-Williams MG. Antigen-specific memory B cell development. Annu Rev Immunol 2005;23:487-513.

112 Allen CD, Okada T, Tang HL et al. Imaging of germinal center selection events during affinity maturation. Science 2007;315(5811):528-31.

113 Allen CD, Ansel KM, Low C et al. Germinal center dark and light zone organization is mediated by CXCR4 and CXCR5. Nat Immunol 2004;5(9):943-52.

114 Sagaert X, Sprangers B, De Wolf-Peeters C. The dynamics of the B follicle: understanding the normal counterpart of B-cell-derived malignancies. Leukemia 2007;21(7):1378-86.

115 Brandes M, Legler DF, Spoerri B et al. Activation-dependent modulation of B lymphocyte migration to chemokines. Int Immunol 2000;12(9):1285-92.

116 De Milito A, Morch C, Sonnerborg AS et al. Loss of memory (CD27) B lymphocytes in HIV-1 infection. Aids 2001;15(8):957-64. 
117 Morbach H, Eichhorn EM, Liese JG et al. Reference values for B cell subpopulations from infancy to adulthood. Clin Exp Immunol 2010;162(2):271-9.

118 D'Orsogna LJ, Krueger RG, McKinnon EJ et al. Circulating memory B-cell subpopulations are affected differently by HIV infection and antiretroviral therapy. Aids 2007;21(13):174752.

119 Hart M, Steel A, Clark SA et al. Loss of discrete memory B cell subsets is associated with impaired immunization responses in HIV-1 infection and may be a risk factor for invasive pneumococcal disease. Journal of Immunology 2007;178(12):8212-20.

120 Longwe H, Gordon S, Malamba R et al. Characterising B cell numbers and memory B cells in HIV infected and uninfected Malawian adults. BMC Infect Dis 2010;10:280.

121 Iwajomo OH, Finn A, Ogunniyi AD et al. Impairment of Pneumococcal Antigen Specific Isotype-Switched Igg Memory B-Cell Immunity in HIV Infected Malawian Adults. PLoS ONE 2013;8(11):e78592.

122 Nagase H, Agematsu K, Kitano K et al. Mechanism of hypergammaglobulinemia by HIV infection: circulating memory B-cell reduction with plasmacytosis. Clin Immunol 2001;100(2):250-9.

123 Martinez-Maza O, Crabb E, Mitsuyasu RT et al. Infection with the human immunodeficiency virus (HIV) is associated with an in vivo increase in B lymphocyte activation and immaturity. J Immunol 1987;138(11):3720-4.

124 Malaspina A, Moir S, Ho J et al. Appearance of immature/transitional B cells in HIVinfected individuals with advanced disease: correlation with increased IL-7. Proc Natl Acad Sci U S A 2006;103(7):2262-7.

125 Cagigi A, Palma P, Nilsson A et al. The impact of active HIV-1 replication on the physiological age-related decline of immature-transitional B-cells in HIV-1 infected children. Aids 2010.

126 Pensieroso S, Galli L, Nozza S et al. B-cell subset alterations and correlated factors in HIV-1 infection. Aids 2013;27(8):1209-17.

127 Doria-Rose NA, Connors M. Antibody-secreting B cells in HIV infection. Curr Opin HIV AIDS 2009;4(5):426-30.

128 Tangye SG, Good KL. Human IgM+CD27+ B cells: memory B cells or "memory" B cells? J Immunol 2007;179(1):13-9.

129 Tarlinton D. B-cell memory: are subsets necessary? Nat Rev Immunol 2006;6(10):785-90.

130 Slifka MK, Matloubian M, Ahmed R. Bone marrow is a major site of long-term antibody production after acute viral infection. $J$ Virol 1995;69(3):1895-902.

131 Slifka MK, Ahmed R. B cell responses and immune memory. Dev Biol Stand 1998;95:10515.

132 Slifka MK, Ahmed R. Long-lived plasma cells: a mechanism for maintaining persistent antibody production. Curr Opin Immunol 1998;10(3):252-8.

133 Gatto D, Martin SW, Bessa J et al. Regulation of memory antibody levels: the role of persisting antigen versus plasma cell life span. J Immunol 2007;178(1):67-76. 
134 Klein U, Rajewsky K, Kuppers R. Human immunoglobulin (Ig)M+IgD+ peripheral blood B cells expressing the CD27 cell surface antigen carry somatically mutated variable region genes: CD27 as a general marker for somatically mutated (memory) B cells. J Exp Med 1998;188(9):1679-89.

135 Cerutti A, Cols M, Puga I. Marginal zone B cells: virtues of innate-like antibody-producing lymphocytes. Nat Rev Immunol 2013;13(2):118-32.

136 Weller S, Braun MC, Tan BK et al. Human blood IgM "memory" B cells are circulating splenic marginal zone B cells harboring a prediversified immunoglobulin repertoire. Blood 2004;104(12):3647-54.

137 Wardemann H, Boehm T, Dear N et al. B-1a B cells that link the innate and adaptive immune responses are lacking in the absence of the spleen. J Exp Med 2002;195(6):771-80.

138 Weller S, Faili A, Garcia C et al. CD40-CD40L independent Ig gene hypermutation suggests a second B cell diversification pathway in humans. Proc Natl Acad Sci U S A 2001;98(3):1166-70.

139 van Zelm MC, van der Burg M, van Dongen JJ. Homeostatic and maturation-associated proliferation in the peripheral B-cell compartment. Cell Cycle 2007;6(23):2890-5.

140 Berkowska MA, Driessen GJ, Bikos V et al. Human memory B cells originate from three distinct germinal center-dependent and -independent maturation pathways. Blood 2011;118(8):2150-8.

141 Shi Y, Agematsu K, Ochs HD et al. Functional analysis of human memory B-cell subpopulations: IgD+CD27+ B cells are crucial in secondary immune response by producing high affinity IgM. Clin Immunol 2003;108(2):128-37.

142 Casali P, Schettino EW. Structure and function of natural antibodies. Curr Top Microbiol Immunol 1996;210:167-79.

143 Kelly DF, Snape MD, Clutterbuck EA et al. CRM197-conjugated serogroup C meningococcal capsular polysaccharide, but not the native polysaccharide, induces persistent antigen-specific memory B cells. Blood 2006;108(8):2642-7.

144 Fedson DS, Scott JA. The burden of pneumococcal disease among adults in developed and developing countries: what is and is not known. Vaccine 1999;17 Suppl 1:S11-S18.

145 Kruetzmann S, Rosado MM, Weber H et al. Human immunoglobulin M memory B cells controlling Streptococcus pneumoniae infections are generated in the spleen. J Exp Med 2003;197(7):939-45.

146 Carsetti R, Rosado MM, Donnanno S et al. The loss of IgM memory B cells correlates with clinical disease in common variable immunodeficiency. Journal of Allergy and Clinical Immunology 2005;115(2):412-7.

147 Zandvoort A, Timens W. The dual function of the splenic marginal zone: essential for initiation of anti-TI-2 responses but also vital in the general first-line defense against bloodborne antigens. Clin Exp Immunol 2002;130(1):4-11.

148 Colino J, Shen Y, Snapper CM. Dendritic cells pulsed with intact Streptococcus pneumoniae elicit both protein- and polysaccharide-specific immunoglobulin isotype responses in vivo through distinct mechanisms. J Exp Med 2002;195(1):1-13. 
149 Wu ZQ, Shen Y, Khan AQ et al. The mechanism underlying T cell help for induction of an antigen-specific in vivo humoral immune response to intact Streptococcus pneumoniae is dependent on the type of antigen. J Immunol 2002;168(11):5551-7.

150 Balmer P, Borrow R, Findlow J et al. Age-stratified prevalences of pneurnococcal-serotypespecific immunoglobulin $\mathrm{G}$ in England and their relationship to the serotype-specific incidence of invasive pneumococcal disease prior to the introduction of the pneumococcal 7 valent conjugate vaccine. Clinical and Vaccine Immunology 2007;14(11):1442-50.

151 Virolainen A, Jero J, Kayhty H et al. Nasopharyngeal antibodies to pneumococcal capsular polysaccharides in children with acute otitis media. J Infect Dis 1995;172(4):1115-8.

152 Musher DM, Groover JE, Rowland JM et al. Antibody to capsular polysaccharides of Streptococcus pneumoniae: prevalence, persistence, and response to revaccination. Clin Infect Dis 1993;17(1):66-73.

153 Goldblatt D, Hussain M, Andrews N et al. Antibody responses to nasopharyngeal carriage of Streptococcus pneumoniae in adults: a longitudinal household study. J Infect Dis 2005;192(3):387-93.

154 Sleeman KL, Daniels L, Gardiner M et al. Acquisition of Streptococcus pneumoniae and nonspecific morbidity in infants and their families: a cohort study. Pediatr Infect Dis $J$ 2005;24(2):121-7.

155 Malley R. Antibody and cell-mediated immunity to Streptococcus pneumoniae: implications for vaccine development. J Mol Med (Berl) 2010;88(2):135-42.

156 Perlman DM, Ampel NM, Schifman RB et al. Persistent Campylobacter jejuni infections in patients infected with the human immunodeficiency virus (HIV). Ann Intern Med 1988;108(4):540-6.

157 Fischl AS, Homann MJ, Poole MA et al. Phosphatidylinositol synthase from Saccharomyces cerevisiae. Reconstitution, characterization, and regulation of activity. J Biol Chem 1986;261(7):3178-83.

158 French MA. Disorders of immune reconstitution in patients with HIV infection responding to antiretroviral therapy. Curr HIV /AIDS Rep 2007;4(1):16-21.

159 Nuorti JP, Butler JC, Gelling L et al. Epidemiologic relation between HIV and invasive pneumococcal disease in San Francisco County, California. Ann Intern Med 2000;132(3):182-90.

160 McEllistrem MC, Mendelsohn AB, Pass MA et al. Recurrent invasive pneumococcal disease in individuals with human immunodeficiency virus infection. $J$ Infect Dis 2002;185(9):13648.

161 Wallace JM, Rao AV, Glassroth J et al. Respiratory illness in persons with human immunodeficiency virus infection. The Pulmonary Complications of HIV Infection Study Group. Am Rev Respir Dis 1993;148(6 Pt 1):1523-9.

162 Grau I, Pallares R, Tubau F et al. Epidemiologic changes in bacteremic pneumococcal disease in patients with human immunodeficiency virus in the era of highly active antiretroviral therapy. Arch Intern Med 2005;165(13):1533-40.

163 Everett DB, Mukaka M, Denis B et al. Ten years of surveillance for invasive Streptococcus pneumoniae during the era of antiretroviral scale-up and cotrimoxazole prophylaxis in Malawi. PLoS ONE 2011;6(3):e17765. 
164 Barry PM, Zetola N, Keruly JC et al. Invasive pneumococcal disease in a cohort of HIVinfected adults: incidence and risk factors, 1990-2003. Aids 2006;20(3):437-44.

165 Nunes MC, von GA, de GL et al. Persistent high burden of invasive pneumococcal disease in South African HIV-infected adults in the era of an antiretroviral treatment program. PLoS ONE 2011;6(11):e27929.

166 Lopez-Palomo C, Martin-Zamorano M, Benitez E et al. Pneumonia in HIV-infected patients in the HAART era: incidence, risk, and impact of the pneumococcal vaccination. $J$ Med Virol 2004;72(4):517-24.

167 Tacconelli E, Tumbarello M, de GK et al. Highly active antiretroviral therapy decreases the incidence of bacteremia in human immunodeficiency virus-infected individuals. Clin Infect Dis 1998;27(4):901-2.

168 Flannery B, Heffernan RT, Harrison LH et al. Changes in invasive Pneumococcal disease among HIV-infected adults living in the era of childhood pneumococcal immunization. Ann Intern Med 2006;144(1):1-9.

169 Cohen AL, Harrison LH, Farley MM et al. Prevention of invasive pneumococcal disease among HIV-infected adults in the era of childhood pneumococcal immunization. Aids 2010;24(14):2253-62.

170 Malaspina A, Moir S, Orsega SM et al. Compromised B cell responses to influenza vaccination in HIV-infected individuals. J Infect Dis 2005;191(9):1442-50.

171 Miedema F, Petit AJ, Terpstra FG et al. Immunological abnormalities in human immunodeficiency virus (HIV)-infected asymptomatic homosexual men. HIV affects the immune system before CD4+ T helper cell depletion occurs. J Clin Invest 1988;82(6):190814.

172 Ballet JJ, Sulcebe G, Couderc LJ et al. Impaired Anti-Pneumococcal Antibody-Response in Patients with Aids-Related Persistent Generalized Lymphadenopathy. Clinical and Experimental Immunology 1987;68(3):479-87.

173 Titanji K, De Milito A, Cagigi A et al. Loss of memory B cells impairs maintenance of longterm serologic memory during HIV-1 infection. Blood 2006;108(5):1580-7.

174 Pedersen R, Lohse N, Ostergaard L et al. The effectiveness of pneumococcal polysaccharide vaccination in HIV-infected adults: a systematic review. HIV Med 2010.

175 Subramaniam K, Metzger B, Hanau LH et al. IgM(+) memory B cell expression predicts HIV-associated cryptococcosis status. J Infect Dis 2009;200(2):244-51.

176 Iwajomo OH, Finn A, Moons P et al. Deteriorating pneumococcal-specific B-cell memory in minimally symptomatic African children with HIV infection. J Infect Dis 2011;204(4):53443.

177 Pensieroso S, Cagigi A, Palma P et al. Timing of HAART defines the integrity of memory B cells and the longevity of humoral responses in HIV-1 vertically-infected children. Proc Natl Acad Sci U S A 2009;106(19):7939-44.

178 Laursen AL, Andersen PL. Low levels of IgG antibodies against pneumocystis carinii among HIV-infected patients. Scand J Infect Dis 1998;30(5):495-9.

179 Pitzurra L, Perito S, Baldelli F et al. Humoral response against Cryptococcus neoformans mannoprotein antigens in HIV-infected patients. Clin Exp Immunol 2003;133(1):91-6. 
180 Bekker V, Scherpbier H, Pajkrt D et al. Persistent humoral immune defect in highly active antiretroviral therapy-treated children with HIV-1 infection: Loss of specific antibodies against attenuated vaccine strains and natural viral infection. Pediatrics 2006;118(2):E315E322.

181 Kroon FP, van Dissel JT, Ravensbergen E et al. Impaired antibody response after immunization of HIV-infected individuals with the polysaccharide vaccine against Salmonella typhi (Typhim-Vi (R)). Vaccine 1999;17(23-24):2941-5.

182 Carne CA, Weller IVD, Waite J et al. Impaired Responsiveness of Homosexual Men with Hiv Antibodies to Plasma Derived Hepatitis-B Vaccine. British Medical Journal 1987;294(6576):866-8.

183 Opravil M, Fierz W, Matter L et al. Poor Antibody-Response After Tetanus and Pneumococcal Vaccination in Immunocompromised, Hiv-Infected Patients. Clinical and Experimental Immunology 1991;84(2):185-9.

184 Ahmed F, Steinhoff MC, Rodriguez-Barradas MC et al. Effect of human immunodeficiency virus type 1 infection on the antibody response to a glycoprotein conjugate pneumococcal vaccine: results from a randomized trial. J Infect Dis 1996;173(1):83-90.

185 Crum-Cianflone NF, Huppler HK, Roediger M et al. A randomized clinical trial comparing revaccination with pneumococcal conjugate vaccine to polysaccharide vaccine among HIVinfected adults. $J$ Infect Dis 2010;202(7):1114-25.

186 French N, Gordon SB, Mwalukomo T et al. A trial of a 7-valent pneumococcal conjugate vaccine in HIV-infected adults. N Engl J Med 2010;362(9):812-22.

187 Chang Q, Abadi J, Alpert P et al. A pneumococcal capsular polysaccharide vaccine induces a repertoire shift with increased $\mathrm{V}(\mathrm{H}) 3$ expression in peripheral B cells from human immunodeficiency virus (HIV)-uninfected but not HIV-infected persons. Journal of Infectious Diseases 2000;181(4):1313-21.

188 Madhi SA, Kuwanda L, Cutland C et al. The impact of a 9-valent pneumococcal conjugate vaccine on the public health burden of pneumonia in HIV-infected and -uninfected children. Clin Infect Dis 2005;40(10):1511-8.

189 Peset Llopis MJ, Harms G, Hardonk MJ et al. Human immune response to pneumococcal polysaccharides: complement-mediated localization preferentially on CD21-positive splenic marginal zone B cells and follicular dendritic cells. J Allergy Clin Immunol 1996;97(4):1015-24.

190 Boes M, Esau C, Fischer MB et al. Enhanced B-1 cell development, but impaired IgG antibody responses in mice deficient in secreted IgM. J Immunol 1998;160(10):4776-87.

191 Ehrenstein MR, O'Keefe TL, Davies SL et al. Targeted gene disruption reveals a role for natural secretory IgM in the maturation of the primary immune response. Proc Natl Acad Sci U S A 1998;95(17):10089-93.

192 Morris L, Binley JM, Clas BA et al. HIV-1 antigen-specific and -nonspecific B cell responses are sensitive to combination antiretroviral therapy. J Exp Med 1998;188(2):23345.

193 Moir S, Buckner CM, Ho J et al. B cells in early and chronic HIV infection: evidence for preservation of immune function associated with early initiation of antiretroviral therapy. Blood 2010 
194 Kroon FP, Rimmelzwaan GF, Roos MTL et al. Restored humoral immune response to influenza vaccination in HIV-infected adults treated with highly active antiretroviral therapy. Aids 1998;12(17):F217-F223.

195 Deayton JR, Sabin CA, Britt WB et al. Rapid reconstitution of humoral immunity against cytomegalovirus but not HIV following highly active antiretroviral therapy. Aids 2002;16(16):2129-35.

196 Melvin AJ, Mohan KM. Response to immunization with measles, tetanus, and Haemophilus influenzae type $b$ vaccines in children who have human immunodeficiency virus type 1 infection and are treated with highly active antiretroviral therapy. Pediatrics 2003;111(6 Pt 1):e641-e644.

197 Jacobson MA, Khayam-Bashi H, Martin JN et al. Effect of long-term highly active antiretroviral therapy in restoring HIV-induced abnormal B-lymphocyte function. $J$ Acquir Immune Defic Syndr 2002;31(5):472-7.

198 Combined antiretroviral therapy reduces hyperimmunoglobulinemia in HIV-1 infected children. Aids 2004;18(10):1423-8.

199 Ghosh S, Feyen O, Jebran AF et al. Memory B cell function in HIV-infected childrendecreased memory B cells despite ART. Pediatr Res 2009;66(2):185-90.

200 Ibegbu C, Spira TJ, Nesheim S et al. Subpopulations of T and B cells in perinatally HIVinfected and noninfected age-matched children compared with those in adults. Clin Immunol Immunopathol 1994;71(1):27-32.

201 Ananworanich J, Apornpong T, Kosalaraksa P et al. Characteristics of lymphocyte subsets in HIV-infected, long-term nonprogressor, and healthy Asian children through 12 years of age. J Allergy Clin Immunol 2010;126(6):1294-301.

202 Jacobsen MC, Thiebaut R, Fisher $\mathrm{C}$ et al. Pediatric Human Immunodeficiency Virus Infection and Circulating $\operatorname{IgD}(+)$ Memory B Cells. J Infect Dis 2008.

203 Bliss SJ, O'Brien KL, Janoff EN et al. The evidence for using conjugate vaccines to protect HIV-infected children against pneumococcal disease. Lancet Infect Dis 2008;8(1):67-80.

204 Dankner WM, Lindsey JC, Levin MJ. Correlates of opportunistic infections in children infected with the human immunodeficiency virus managed before highly active antiretroviral therapy. Pediatr Infect Dis J 2001;20(1):40-8.

205 Hatherill M. Sepsis predisposition in children with human immunodeficiency virus. Pediatr Crit Care Med 2005;6(3 Suppl):S92-S98.

206 Obaro SK, Pugatch D, Luzuriaga K. Immunogenicity and efficacy of childhood vaccines in HIV-1-infected children. Lancet Infect Dis 2004;4(8):510-8.

207 Pessoa SD, Miyamoto M, Ono E et al. Persistence of vaccine immunity against hepatitis B virus and response to revaccination in vertically HIV-infected adolescents on HAART. Vaccine 2010;28(6):1606-12.

208 Sutcliffe CG, Moss WJ. Do children infected with HIV receiving HAART need to be revaccinated? Lancet Infect Dis 2010;10(9):630-42.

209 Nair N, Moss WJ, Scott S et al. HIV-1 infection in Zambian children impairs the development and avidity maturation of measles virus-specific immunoglobulin $\mathrm{G}$ after vaccination and infection. J Infect Dis 2009;200(7):1031-8. 
210 von GA, Cohen C, de GL et al. Epidemiology of invasive pneumococcal disease in the preconjugate vaccine era: South Africa, 2003-2008. Vaccine 2013;31(38):4200-8.

211 Bhattacharya SD, Niyogi SK, Bhattacharyya S et al. High rates of colonization with drug resistant hemophilus influenzae type B and Streptococccus Pneumoniae in unvaccinated HIV infected children from West Bengal. Indian J Pediatr 2011;78(4):423-9.

212 Chang Q, Abadi J, Rosenberg M et al. VH3 gene expression in children with HIV infection. J Infect 2004;49(4):274-82.

213 Rainwater-Lovett K, Nkamba H, Mubiana-Mbewe M et al. Antiretroviral therapy restores age-dependent loss of resting memory B cells in young HIV-infected Zambian children. $J$ Acquir Immune Defic Syndr 2013.

214 Farquhar C, Wamalwa D, Selig S et al. Immune responses to measles and tetanus vaccines among Kenyan human immunodeficiency virus type 1 (HIV-1)-infected children pre- and post-highly active antiretroviral therapy and revaccination. Pediatr Infect Dis J 2009;28(4):295-9.

215 Cagigi A., Rinaldi S., Cotugno N. et al. Early Highly-Active Antiretroviral Therapy Enhances B-Cell Longevity: A 5 Year Follow-Up. Pediatr Infect Dis J 2013;Epub ahead of print.

216 Castro H, Judd A, Gibb DM et al. Risk of triple-class virological failure in children with HIV: a retrospective cohort study. Lancet 2011;377(9777):1580-7.

217 Comans-Bitter WM, de GR, van den Beemd R et al. Immunophenotyping of blood lymphocytes in childhood. Reference values for lymphocyte subpopulations. J Pediatr 1997;130(3):388-93.

218 Andersson B, Skoglund AC, Ronnholm M et al. Functional aspects of IgM and IgG Fc receptors on murine T lymphocytes. Immunol Rev 1981;56:5-50.

219 Madore DV, Johnson CL, Phipps DC et al. Safety and immunologic response to Haemophilus influenzae type b oligosaccharide-CRM197 conjugate vaccine in 1- to 6month-old infants. Pediatrics 1990;85(3):331-7.

220 Einhorn MS, Weinberg GA, Anderson EL et al. Immunogenicity in infants of Haemophilus influenzae type B polysaccharide in a conjugate vaccine with Neisseria meningitidis outermembrane protein. Lancet 1986;2(8502):299-302.

221 Gans HA, Arvin AM, Galinus J et al. Deficiency of the humoral immune response to measles vaccine in infants immunized at age 6 months. JAMA 1998;280(6):527-32.

222 Barzanji AJ, Emery JL. Germinal centers in the spleens of neonates and stillbirths. Early Hum Dev 1978;1(4):363-9.

223 Asano S, Akaike Y, Muramatsu T et al. Immunohistologic detection of the primary follicle (PF) in human fetal and newborn lymph node anlages. Pathol Res Pract 1993;189(8):921-7.

224 Timens W, Rozeboom T, Poppema S. Fetal and neonatal development of human spleen: an immunohistological study. Immunology 1987;60(4):603-9.

225 Sanchez M, Lindroth K, Sverremark E et al. The response in old mice: positive and negative immune memory after priming in early age. Int Immunol 2001;13(10):1213-21.

226 Gibson KL, Wu YC, Barnett Y et al. B cell diversity decreases in old age and is correlated with poor health status. Aging Cell 2008. 
227 Gibb DM, Newberry A, Klein N et al. Immune repopulation after HAART in previously untreated HIV-1-infected children. Lancet 2000;355(9212):1331-2.

228 De RA, Walker AS, Klein N et al. Increased thymic output after initiation of antiretroviral therapy in human immunodeficiency virus type 1-infected children in the Paediatric European Network for Treatment of AIDS (PENTA) 5 Trial. J Infect Dis 2002;186(3):31220.

229 Resino S, Seoane E, Perez A et al. Different profiles of immune reconstitution in children and adults with HIV-infection after highly active antiretroviral therapy. BMC Infect Dis 2006;6:112.

230 Sandgaard KS, Lewis J, Adams S et al. Antiretroviral therapy increases thymic output in children with HIV. Aids 2013.

231 Haynes BF, Markert ML, Sempowski GD et al. The role of the thymus in immune reconstitution in aging, bone marrow transplantation, and HIV-1 infection. Annu Rev Immunol 2000;18:529-60.

232 Resino S, Correa R, Bellon JM et al. Preserved immune system in long-term asymptomatic vertically HIV-1 infected children. Clin Exp Immunol 2003;132(1):105-12.

233 Dollfus C, Le CJ, Faye A et al. Long-term outcomes in adolescents perinatally infected with HIV-1 and followed up since birth in the French perinatal cohort (EPF/ANRS CO10). Clin Infect Dis 2010;51(2):214-24.

234 Welch S, Sharland M, Lyall EG et al. PENTA 2009 guidelines for the use of antiretroviral therapy in paediatric HIV-1 infection. HIV Med 2009;10(10):591-613.

235 World Health Organization. Consolidated Guidelines on the use of antiretroviral drugs for treating and preventing HIV infection. 2013.

236 Nadler LM, Anderson KC, Marti G et al. B4, a human B lymphocyte-associated antigen expressed on normal, mitogen-activated, and malignant B lymphocytes. J Immunol 1983;131(1):244-50.

237 Wehr C, Kivioja T, Schmitt C et al. The EUROclass trial: defining subgroups in common variable immunodeficiency. Blood 2008;111(1):77-85.

238 Piatosa B, Wolska-Kusnierz B, Pac M et al. B cell subsets in healthy children: reference values for evaluation of B cell maturation process in peripheral blood. Cytometry B Clin Cytom 2010;78(6):372-81.

239 Herzenberg LA, Tung J, Moore WA et al. Interpreting flow cytometry data: a guide for the perplexed. Nat Immunol 2006;7(7):681-5.

240 Autissier P, Soulas C, Burdo TH et al. Evaluation of a 12-color flow cytometry panel to study lymphocyte, monocyte, and dendritic cell subsets in humans. Cytometry $A$ 2010;77(5):410-9.

241 Baumgarth N, Roederer M. A practical approach to multicolor flow cytometry for immunophenotyping. J Immunol Methods 2000;243(1-2):77-97.

242 Maecker HT, Frey T, Nomura LE et al. Selecting fluorochrome conjugates for maximum sensitivity. Cytometry A 2004;62(2):169-73. 
243 Perfetto SP, Chattopadhyay PK, Lamoreaux L et al. Amine reactive dyes: an effective tool to discriminate live and dead cells in polychromatic flow cytometry. J Immunol Methods 2006;313(1-2):199-208.

244 Roederer M. Spectral compensation for flow cytometry: visualization artifacts, limitations, and caveats. Cytometry 2001;45(3):194-205.

245 Hughes OR, Stewart R, Dimmick I et al. A critical appraisal of factors affecting the accuracy of results obtained when using flow cytometry in stem cell investigations: where do you put your gates? Cytometry A 2009;75(9):803-10.

246 Lal G, Balmer P, Stanford E et al. Development and validation of a nonaplex assay for the simultaneous quantitation of antibodies to nine Streptococcus pneumoniae serotypes. $J$ Immunol Methods 2005;296(1-2):135-47.

247 Musher DM, Watson DA, Baughn RE. Does naturally acquired IgG antibody to cell wall polysaccharide protect human subjects against pneumococcal infection? J Infect Dis 1990;161(4):736-40.

248 Concepcion NF, Frasch CE. Pneumococcal type $22 \mathrm{f}$ polysaccharide absorption improves the specificity of a pneumococcal-polysaccharide enzyme-linked immunosorbent assay. Clin Diagn Lab Immunol 2001;8(2):266-72.

249 Soriano-Sarabia N, Leal M, Delgado C et al. Effect of hepatitis C virus coinfection on humoral immune alterations in naive HIV-infected adults on HAART: a three year follow-up study. J Clin Immunol 2005;25(3):296-302.

250 Redgrave BE, Stone SF, French MA et al. The effect of combination antiretroviral therapy on C. HIV Med 2005;6(5):307-12.

251 Agematsu K, Hokibara S, Nagumo H et al. CD27: a memory B-cell marker. Immunol Today 2000;21(5):204-6.

252 Wilkins BS, Davis Z, Lucas SB et al. Splenic marginal zone atrophy and progressive CD8+ T-cell lymphocytosis in HIV infection: a study of adult post-mortem spleens from Cote d'Ivoire. Histopathology 2003;42(2):173-85.

253 Caraux A, Klein B, Paiva B et al. Circulating human B and plasma cells. Age-associated changes in counts and detailed characterization of circulating normal C. Haematologica 2010;95(6):1016-20.

254 Mei HE, Yoshida T, Sime W et al. Blood-borne human plasma cells in steady state are derived from mucosal immune responses. Blood 2009;113(11):2461-9.

255 Odendahl M, Mei H, Hoyer BF et al. Generation of migratory antigen-specific plasma blasts and mobilization of resident plasma cells in a secondary immune response. Blood 2005;105(4):1614-21.

256 Potter KN, Mockridge CI, Rahman A et al. Disturbances in peripheral blood B cell subpopulations in autoimmune patients. Lupus 2002;11(12):872-7.

257 Odendahl M, Jacobi A, Hansen A et al. Disturbed peripheral B lymphocyte homeostasis in systemic lupus erythematosus. J Immunol 2000;165(10):5970-9.

258 Buckner CM, Moir S, Ho J et al. Characterization of plasmablasts in the blood of HIVinfected viremic individuals: evidence for nonspecific immune activation. $J$ Virol 2013;87(10):5800-11. 
259 Moir S, Fauci AS. Insights into B cells and HIV-specific B-cell responses in HIV-infected individuals. Immunol Rev 2013;254(1):207-24.

260 Sims GP, Ettinger R, Shirota Y et al. Identification and characterization of circulating human transitional B cells. Blood 2005;105(11):4390-8.

261 Cuss AK, Avery DT, Cannons JL et al. Expansion of functionally immature transitional B cells is associated with human-immunodeficient states characterized by impaired humoral immunity. J Immunol 2006;176(3):1506-16.

262 Johannesson TG, Sogaard OS, Tolstrup M et al. The impact of B-cell perturbations on pneumococcal conjugate vaccine response in HIV-infected adults. PLOS ONE 2012;7(7):e42307.

263 Malaspina A, Moir S, Chaitt DG et al. Idiopathic CD4+ T lymphocytopenia is associated with increases in immature/transitional B cells and serum levels of IL-7. Blood 2007;109(5):2086-8.

264 Napolitano LA, Grant RM, Deeks SG et al. Increased production of IL-7 accompanies HIV1-mediated T-cell depletion: implications for T-cell homeostasis. Nat Med 2001;7(1):73-9.

265 LeBien TW, Tedder TF. B lymphocytes: how they develop and function. Blood 2008;112(5):1570-80.

266 Bugault F, Benati D, Mouthon L et al. Altered responses to homeostatic cytokines in patients with idiopathic CD4 lymphocytopenia. PLoS ONE 2013;8(1):e55570.

267 Ehrhardt GR, Hijikata A, Kitamura $\mathrm{H}$ et al. Discriminating gene expression profiles of memory B cell subpopulations. J Exp Med 2008;205(8):1807-17.

268 Ehrhardt GR, Hsu JT, Gartland L et al. Expression of the immunoregulatory molecule FcRH4 defines a distinctive tissue-based population of memory B cells. J Exp Med 2005;202(6):783-91.

269 Isnardi I, Ng YS, Menard L et al. Complement receptor 2/. Blood 2010;115(24):5026-36.

270 Rakhmanov M, Keller B, Gutenberger S et al. Circulating CD21low B cells in common variable immunodeficiency resemble tissue homing, innate-like B cells. Proc Natl Acad Sci U S A 2009;106(32):13451-6.

271 Warnatz K, Wehr C, Drager R et al. Expansion of CD19(hi)CD21(lo/neg) B cells in common variable immunodeficiency (CVID) patients with autoimmune cytopenia. Immunobiology 2002;206(5):502-13.

272 Wehr C, Eibel H, Masilamani M et al. A new CD21low B cell population in the peripheral blood of patients with SLE. Clin Immunol 2004;113(2):161-71.

273 Culton DA, Nicholas MW, Bunch DO et al. Similar CD19 dysregulation in two autoantibody-associated autoimmune diseases suggests a shared mechanism of B-cell tolerance loss. J Clin Immunol 2007;27(1):53-68.

274 Nicholas MW, Dooley MA, Hogan SL et al. A novel subset of memory B cells is enriched in autoreactivity and correlates with adverse outcomes in SLE. Clin Immunol 2008;126(2):189201.

275 Charles ED, Brunetti C, Marukian S et al. Clonal B cells in patients with hepatitis C virusassociated mixed cryoglobulinemia contain an expanded anergic CD21low B-cell subset. Blood 2011;117(20):5425-37. 
276 Moir S, Fauci AS. Pathogenic mechanisms of B-lymphocyte dysfunction in HIV disease. $J$ Allergy Clin Immunol 2008;122(1):12-9.

277 Kardava L, Moir S, Wang W et al. Attenuation of HIV-associated human B cell exhaustion by siRNA downregulation of inhibitory receptors. J Clin Invest 2011;121(7):2614-24.

278 Fogli M, Torti C, Malacarne F et al. Emergence of exhausted B cells in asymptomatic HIV1 -infected patients naive for HAART is related to reduced immune surveillance. Clin Dev Immunol 2012;2012:829584.

279 Koncz G, Hueber AO. The Fas/CD95 Receptor Regulates the Death of Autoreactive B Cells and the Selection of Antigen-Specific B Cells. Front Immunol 2012;3:207.

280 Muller G, Hopken UE, Lipp M. The impact of CCR7 and CXCR5 on lymphoid organ development and systemic immunity. Immunol Rev 2003;195:117-35.

281 Henneken M, Dorner T, Burmester GR et al. Differential expression of chemokine receptors on peripheral blood B cells from patients with rheumatoid arthritis and systemic lupus erythematosus. Arthritis Res Ther 2005;7(5):R1001-R1013.

282 Avery DT, Ellyard JI, Mackay F et al. Increased expression of CD27 on activated human memory B cells correlates with their commitment to the plasma cell lineage. J Immunol 2005;174(7):4034-42.

283 Shearer WT, Rosenblatt HM, Gelman RS et al. Lymphocyte subsets in healthy children from birth through 18 years of age: the Pediatric AIDS Clinical Trials Group P1009 study. $J$ Allergy Clin Immunol 2003;112(5):973-80.

284 van GJ, Cubas RA, Noto A et al. Loss of memory B cells during chronic HIV infection is driven by Foxo3a- and TRAIL-mediated apoptosis. J Clin Invest 2011;121(10):3877-88.

285 Fecteau JF, Cote G, Neron S. A new memory CD27-IgG+ B cell population in peripheral blood expressing VH genes with low frequency of somatic mutation. $J$ Immunol 2006;177(6):3728-36.

286 Wei C, Anolik J, Cappione A et al. A new population of cells lacking expression of CD27 represents a notable component of the B cell memory compartment in systemic lupus erythematosus. J Immunol 2007;178(10):6624-33.

287 Anderson SM, Tomayko MM, Shlomchik MJ. Intrinsic properties of human and murine memory B cells. Immunol Rev 2006;211:280-94.

288 Madhi SA, Madhi A, Petersen K et al. Impact of human immunodeficiency virus type 1 infection on the epidemiology and outcome of bacterial meningitis in South African children. Int J Infect Dis 2001;5(3):119-25.

289 Jones N, Huebner R, Khoosal M et al. The impact of HIV on Streptococcus pneumoniae bacteraemia in a South African population. Aids 1998;12(16):2177-84.

290 Nunes MC, von GA, de GL et al. The impact of antiretroviral treatment on the burden of invasive pneumococcal disease in South African children: a time series analysis. Aids 2011;25(4):453-62.

291 Madhi SA, Petersen K, Madhi A et al. Impact of human immunodeficiency virus type 1 on the disease spectrum of Streptococcus pneumoniae in South African children. Pediatr Infect Dis J 2000;19(12):1141-7. 
292 Baxendale HE, Davis Z, White HN et al. Immunogenetic analysis of the immune response to pneumococcal polysaccharide. European Journal of Immunology 2000;30(4):1214-23.

293 Moberley SA, Holden J, Tatham DP et al. Vaccines for preventing pneumococcal infection in adults. Cochrane Database Syst Rev 2008;(1):CD000422.

294 Stein KE. Thymus-independent and thymus-dependent responses to polysaccharide antigens. J Infect Dis 1992;165 Suppl 1:S49-S52.

295 Musher DM, Manof SB, Liss C et al. Safety and antibody response, including antibody persistence for 5 years, after primary vaccination or revaccination with pneumococcal polysaccharide vaccine in middle-aged and older adults. J Infect Dis 2010;201(4):516-24.

296 Douglas RM, Paton JC, Duncan SJ et al. Antibody response to pneumococcal vaccination in children younger than five years of age. J Infect Dis 1983;148(1):131-7.

297 O'Brien KL, Hochman M, Goldblatt D. Combined schedules of pneumococcal conjugate and polysaccharide vaccines: is hyporesponsiveness an issue? Lancet Infect Dis 2007;7(9):597606.

298 Bjarnarson SP, Benonisson H, Del GG et al. Pneumococcal polysaccharide abrogates conjugate-induced germinal center reaction and depletes antibody secreting cell pool, causing hyporesponsiveness. PLoS ONE 2013;8(9):e72588.

299 Kovacs JA, Masur H. Prophylaxis against opportunistic infections in patients with human immunodeficiency virus infection. N Engl J Med 2000;342(19):1416-29.

300 Janoff EN, Douglas JM, Jr., Gabriel M et al. Class-specific antibody response to pneumococcal capsular polysaccharides in men infected with human immunodeficiency virus type 1. J Infect Dis 1988;158(5):983-90.

301 Ambrosino DM, Siber GR, Chilmonczyk BA et al. An immunodeficiency characterized by impaired antibody responses to polysaccharides. N Engl J Med 1987;316(13):790-3.

302 Rodriguez-Barradas MC, Alexandraki I, Nazir T et al. Response of human immunodeficiency virus-infected patients receiving highly active antiretroviral therapy to vaccination with 23-valent pneumococcal polysaccharide vaccine. Clin Infect Dis 2003;37(3):438-47.

303 Nielsen H, Kvinesdal B, Benfield TL et al. Rapid loss of specific antibodies after pneumococcal vaccination in patients with human immunodeficiency virus-1 infection. Scand J Infect Dis 1998;30(6):597-601.

304 Dworkin MS, Ward JW, Hanson DL et al. Pneumococcal disease among human immunodeficiency virus-infected persons: incidence, risk factors, and impact of vaccination. Clin Infect Dis 2001;32(5):794-800.

305 French N, Gilks CF, Mujugira A et al. Pneumococcal vaccination in HIV-1-infected adults in Uganda: humoral response and two vaccine failures. Aids 1998;12(13):1683-9.

306 French N, Nakiyingi J, Carpenter LM et al. 23-valent pneumococcal polysaccharide vaccine in HIV-1-infected Ugandan adults: double-blind, randomised and placebo controlled trial. Lancet 2000;355(9221):2106-11.

307 Watera C, Nakiyingi J, Miiro G et al. 23-Valent pneumococcal polysaccharide vaccine in HIV-infected Ugandan adults: 6-year follow-up of a clinical trial cohort. Aids 2004;18(8):1210-3. 
308 Falco V, Jordano Q, Cruz MJ et al. Serological response to pneumococcal vaccination in HAART-treated HIV-infected patients: one year follow-up study. Vaccine 2006;24(14):2567-74.

309 Robbins JB, Schneerson R, Szu SC. Hypothesis: how licensed vaccines confer protective immunity. Adv Exp Med Biol 1996;397:169-82.

310 Pollard AJ, Perrett KP, Beverley PC. Maintaining protection against invasive bacteria with protein-polysaccharide conjugate vaccines. Nat Rev Immunol 2009;9(3):213-20.

311 Wuorimaa T, Kayhty H. Current state of pneumococcal vaccines. Scand J Immunol 2002;56(2):111-29.

312 Black S, Shinefield H, Fireman B et al. Efficacy, safety and immunogenicity of heptavalent pneumococcal conjugate vaccine in children. Northern California Kaiser Permanente Vaccine Study Center Group. Pediatr Infect Dis J 2000;19(3):187-95.

313 Black S, Shinefield H, Cohen R et al. [Clinical effectiveness of seven-valent pneumococcal conjugate vaccine (Prevenar) against invasive pneumococcal diseases: prospects for children in France]. Arch Pediatr 2004;11(7):843-53.

314 Madhi SA, Kuwanda L, Cutland C et al. Quantitative and qualitative antibody response to pneumococcal conjugate vaccine among African human immunodeficiency virus-infected and uninfected children. Pediatr Infect Dis J 2005;24(5):410-6.

315 Madhi SA, Adrian P, Cotton MF et al. Effect of HIV infection status and anti-retroviral treatment on quantitative and qualitative antibody responses to pneumococcal conjugate vaccine in infants. $J$ Infect Dis 2010;202(3):355-61.

316 Nachman S, Kim S, King J et al. Safety and immunogenicity of a heptavalent pneumococcal conjugate vaccine in infants with human immunodeficiency virus type 1 infection. Pediatrics 2003;112(1 Pt 1):66-73.

317 King JC, Jr., Vink PE, Farley JJ et al. Safety and immunogenicity of three doses of a fivevalent pneumococcal conjugate vaccine in children younger than two years with and without human immunodeficiency virus infection. Pediatrics 1997;99(4):575-80.

318 Spoulou VI, Tsoumas DL, Papaevangelou VG et al. Immunogenicity and immunological memory induced by a 7-valent pneumococcal CRM197 conjugate vaccine in symptomatic HIV-1 infected children. Vaccine 2005;23(46-47):5289-93.

319 Klugman KP, Madhi SA, Huebner RE et al. A trial of a 9-valent pneumococcal conjugate vaccine in children with and those without HIV infection. N Engl J Med 2003;349(14):13418.

320 Madhi SA, Adrian P, Kuwanda L et al. Long-term immunogenicity and efficacy of a 9valent conjugate pneumococcal vaccine in human immunodeficient virus infected and noninfected children in the absence of a booster dose of vaccine. Vaccine 2007;25(13):2451-7.

321 Ho YL, Brandao AP, de Cunto Brandileone MC et al. Immunogenicity and safety of pneumococcal conjugate polysaccharide and free polysaccharide vaccines alone or combined in HIV-infected adults in Brazil. Vaccine 2013;31(37):4047-53.

322 King JC, Jr., Vink PE, Farley JJ et al. Comparison of the safety and immunogenicity of a pneumococcal conjugate with a licensed polysaccharide vaccine in human immunodeficiency virus and non-human immunodeficiency virus-infected children. Pediatr Infect Dis J 1996;15(3):192-6. 
323 Kroon FP, van Dissel JT, Ravensbergen E et al. Enhanced antibody response to pneumococcal polysaccharide vaccine after prior immunization with conjugate pneumococcal vaccine in HIV-infected adults. Vaccine 2000;19(7-8):886-94.

324 Baxendale HE, Johnson M, Stephens RC et al. Natural human antibodies to pneumococcus have distinctive molecular characteristics and protect against pneumococcal disease. Clin Exp Immunol 2008;151(1):51-60.

325 Ehrenstein MR, Notley CA. The importance of natural IgM: scavenger, protector and regulator. Nat Rev Immunol 2010;10(11):778-86.

326 Rajewsky K. Clonal selection and learning in the antibody system. Nature 1996;381(6585):751-8.

327 World Health Organization. Recommendations for the production and control of pneumococcal conjugate vaccines. WHO Tech Rep Ser 2005;927((Annex 2)):64-98.

328 Landesman SH, Schiffman G. Assessment of the antibody response to pneumococcal vaccine in high-risk populations. Rev Infect Dis 1981;3 Suppl:S184-S197.

329 Lawrence EM, Edwards KM, Schiffman G et al. Pneumococcal vaccine in normal children. Primary and secondary vaccination. Am J Dis Child 1983;137(9):846-50.

330 Kamchaisatian W, Wanwatsuntikul W, Sleasman JW et al. Validation of current joint American Academy of Allergy, Asthma \& Immunology and American College of Allergy, Asthma and Immunology guidelines for antibody response to the 23-valent pneumococcal vaccine using a population of HIV-infected children. J Allergy Clin Immunol 2006;118(6):1336-41.

331 Orange JS, Ballow M, Stiehm ER et al. Use and interpretation of diagnostic vaccination in primary immunodeficiency: a working group report of the Basic and Clinical Immunology Interest Section of the American Academy of Allergy, Asthma \& Immunology. J Allergy Clin Immunol 2012;130(3 Suppl):S1-24.

332 Tangsinmankong N, Kamchaisatian W, Day NK et al. Immunogenicity of 23-valent pneumococcal polysaccharide vaccine in children with human immunodeficiency virus undergoing highly active antiretroviral therapy. Ann Allergy Asthma Immunol 2004;92(5):558-64.

333 Teshale EH, Hanson D, Flannery B et al. Effectiveness of 23-valent polysaccharide pneumococcal vaccine on pneumonia in HIV-infected adults in the United States, 1998-2003. Vaccine 2008;26(46):5830-4.

334 Breiman RF, Keller DW, Phelan MA et al. Evaluation of effectiveness of the 23-valent pneumococcal capsular polysaccharide vaccine for HIV-infected patients. Arch Intern Med 2000;160(17):2633-8.

335 Crum-Cianflone NF, Roediger M, Huppler HK et al. The association of ethnicity with antibody responses to pneumococcal vaccination among adults with HIV infection. Vaccine 2010;28(48):7583-8.

336 Baxendale HE, Johnson M, Keating SM et al. Circulating pneumococcal specific plasma and memory B cells in the elderly two years after pneumococcal conjugate versus polysaccharide vaccination. Vaccine 2010;28(42):6915-22.

337 Ehrenstein MR, O'Keefe TL, Davies SL et al. Targeted gene disruption reveals a role for natural secretory IgM in the maturation of the primary immune response. Proc Natl Acad Sci U S A 1998;95(17):10089-93. 
338 Rinaldi S, Zangari P, Cotugno $\mathrm{N}$ et al. Antibody but not memory B-cell responses are tuneddown in vertically HIV-1 infected children and young individuals being vaccinated yearly against influenza. Vaccine 2013. 